UCRL-ID-131491

\title{
Single-Heater Test Final Report
}

\author{
Stephen C. Blair \\ Thomas A. Buscheck \\ Laura D. DeLoach \\ Wunan Lin \\ Abelardo L. Ramirez
}

December 1998

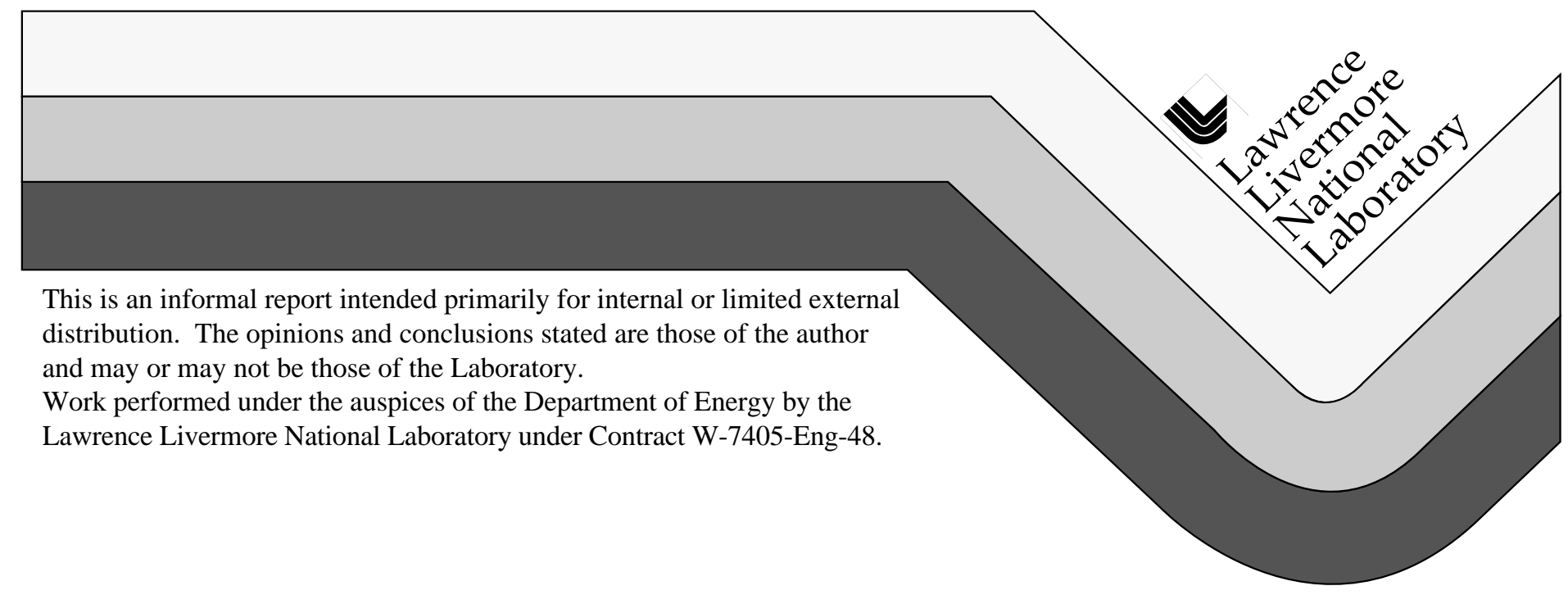




\section{DISCLAIMER}

This document was prepared as an account of work sponsored by an agency of the United States Government. Neither the United States Government nor the University of California nor any of their employees, makes any warranty, express or implied, or assumes any legal liability or responsibility for the accuracy, completeness, or usefulness of any information, apparatus, product, or process disclosed, or represents that its use would not infringe privately owned rights. Reference herein to any specific commercial product, process, or service by trade name, trademark, manufacturer, or otherwise, does not necessarily constitute or imply its endorsement, recommendation, or favoring by the United States Government or the University of California. The views and opinions of authors expressed herein do not necessarily state or reflect those of the United States Government or the University of California, and shall not be used for advertising or product endorsement purposes.

This report has been reproduced directly from the best available copy.

Available to DOE and DOE contractors from the Office of Scientific and Technical Information

$$
\text { P.O. Box 62, Oak Ridge, TN } 37831
$$

Prices available from (615) 576-8401, FTS 626-8401

Available to the public from the National Technical Information Service

U.S. Department of Commerce

5285 Port Royal Rd.

Springfield, VA 2216 


\section{Contents}

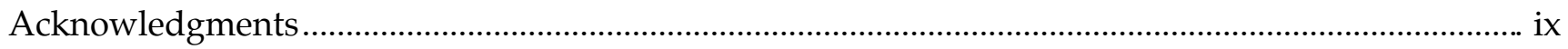

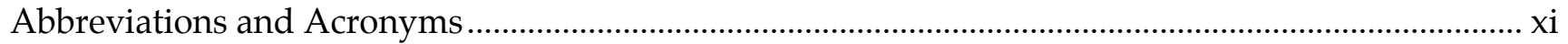

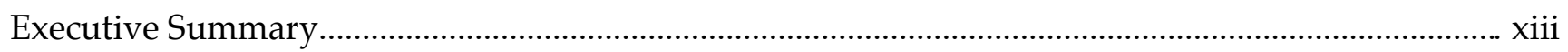

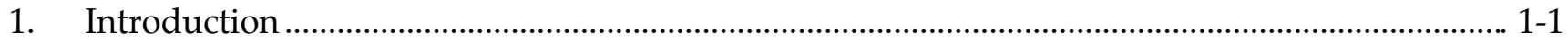

1.1 Description of the Single-Heater Test ..................................................................... 1-1

1.1.1 Post-Test Evaluation of Instrumentation............................................................... 1-2

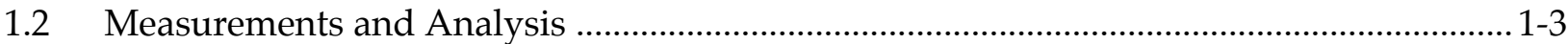

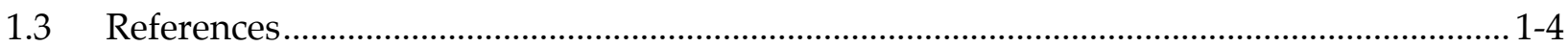

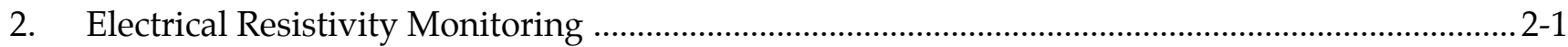

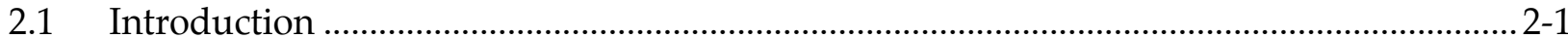

2.2 Electrical Resistance Tomography .................................................................................. 2-1

2.2.1 Changes in Resistivity .......................................................................................... 2-2

2.2.2 Inferences of Moisture Changes................................................................................ 2-4

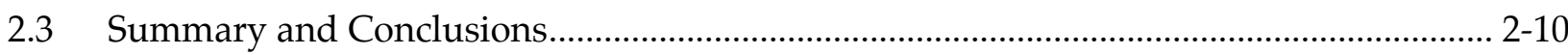

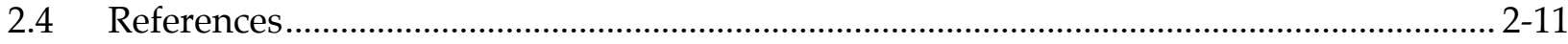

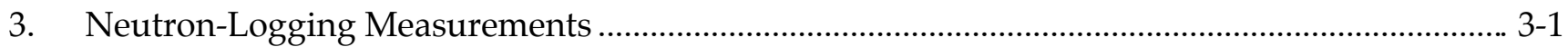

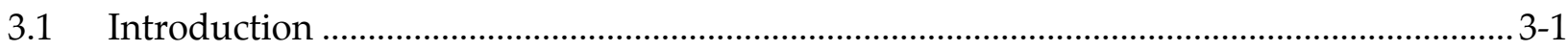

3.2 Measurement Procedures .............................................................................................. $3-1$

3.3 Calibration of the Neutron Tool......................................................................................... 3-2

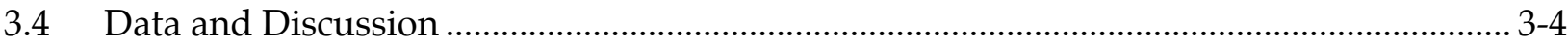

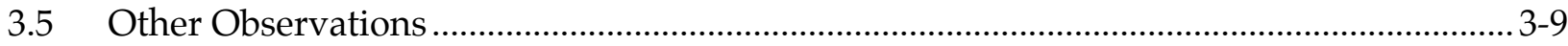

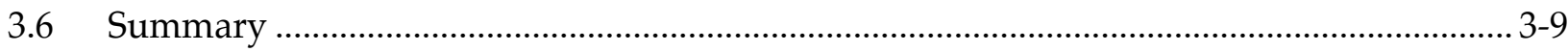

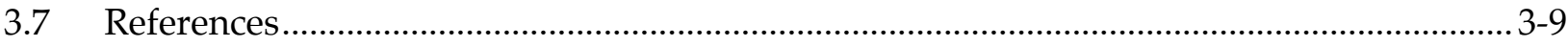

4. Geochemical and Mineralogical Studies ................................................................................... $4-3$

4.1 Geochemical Studies in the Single-Heater Test ............................................................. 4-3

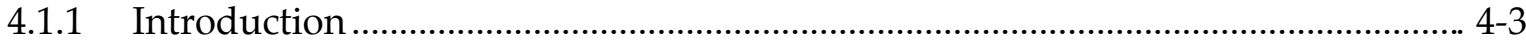

4.1.2 Water Collection During the SHT.......................................................................... 4-3

4.1.3 SHT Water Analytical Tests .................................................................................. 4-4

4.1.4 Analytical Results....................................................................................................... 4-5 


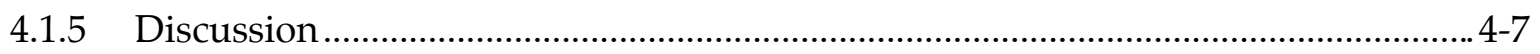

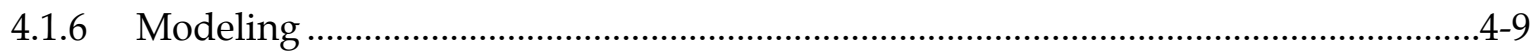

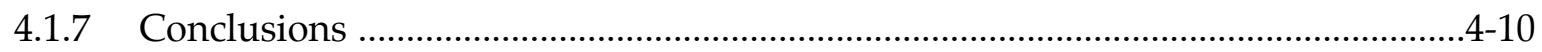

4.2 Mineral Abundances in Exploratory Studies Facility Core Samples ................................4-11

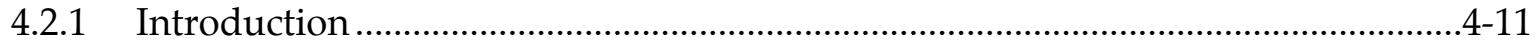

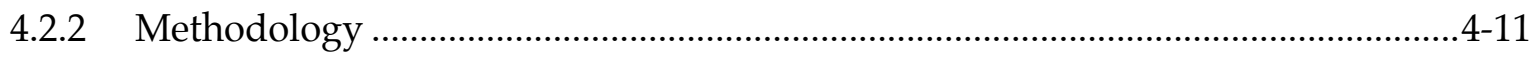

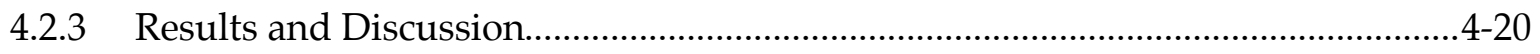

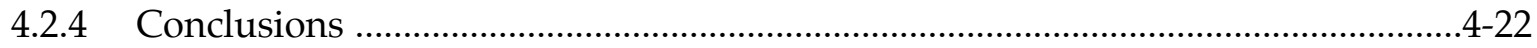

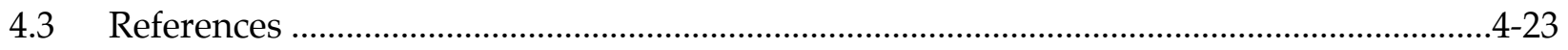

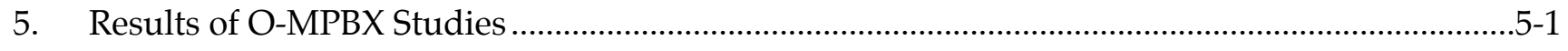

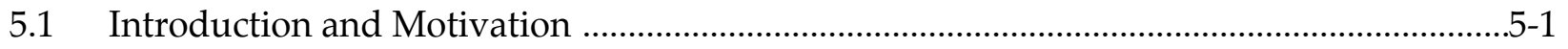

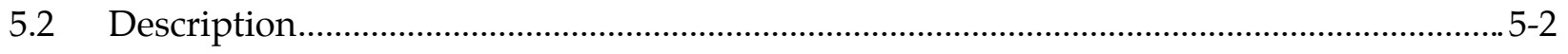

5.3 Results for the Single-Heater Test ...................................................................................

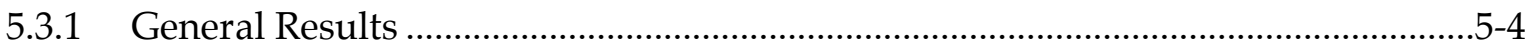

5.3.2 Results for Borehole 6 ..................................................................................... $5-5$

5.3.3 Results for Borehole 7 ...........................................................................................

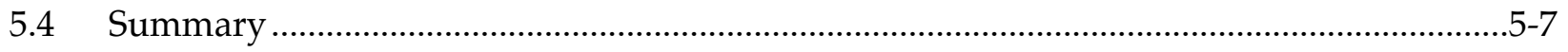

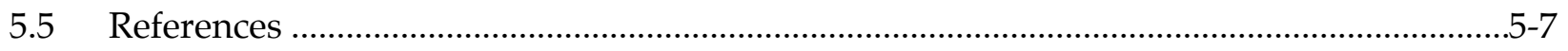

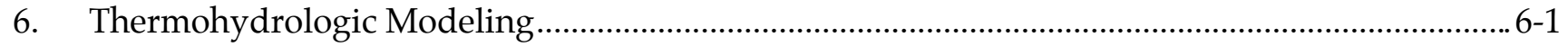

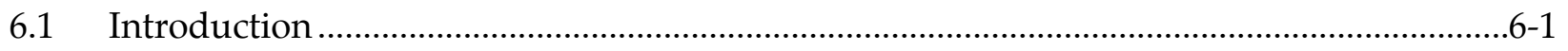

6.2 Numerical Models and Assumptions ..................................................................................6-2

6.2.1 NUFT Numerical Simulation Code ......................................................................6-2

6.2.2 Representing Fracture-Matrix Interaction.............................................................6-2

6.2.3 Model Geometry, Boundary Conditions, and Numerical Mesh ...........................6-4

6.2.4 Thermal/Hydrologic Properties and Percolation-Flux Assumptions..................... 6-5

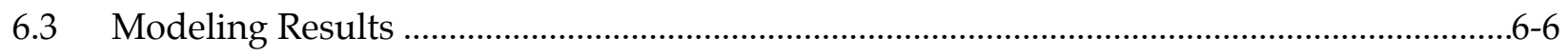

6.3.1 Simulated Temperature and Liquid-Phase Saturation ...........................................6-6

6.3.2 Comparison of Simulated and Measured Temperatures .....................................6-10

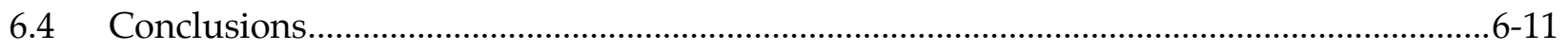

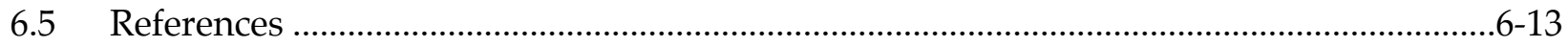

7. Thermomechanical Analysis and Estimates of Permeability Changes.........................................7-1 


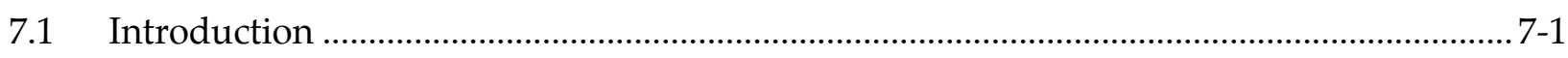

7.2 2-D FLAC Model of the Single-Heater Test ……………………………………………..... 7-1

7.3 Shear Slip Model ....................................................................................................... 7-4

7.4 Discussion .......................................................................................................... 7-5

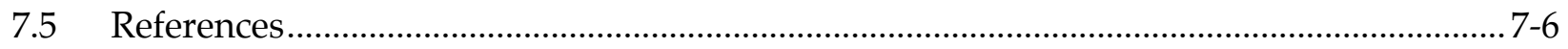

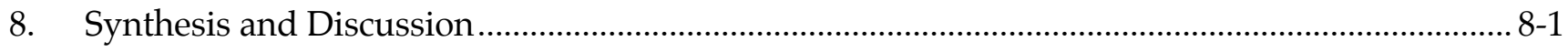

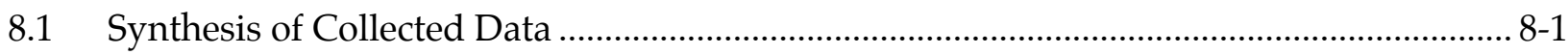

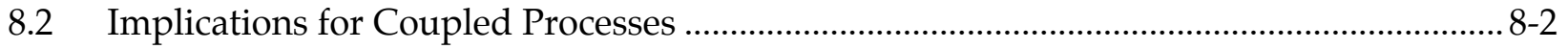

8.3 Simulation and Analysis ....................................................................................... 8-2

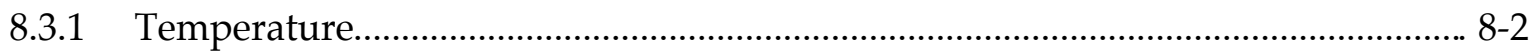

8.3.2 Hydrologic Processes …………………………………………………………. 8-3

8.3.3 Wetting/Drying Asymmetry …………………………………………………. 8-3

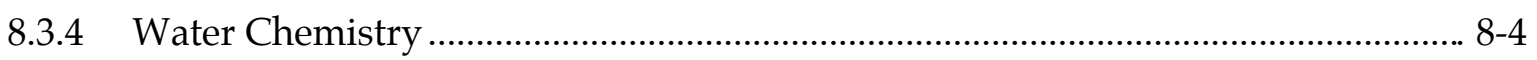

\section{Tables}

Table 1-1. Results of post-test calibration for RTD \#234 .............................................................. 1-2

Table 1-2. Results of post-test calibration for RTD \#244 ………................................................. 1-2

Table 3-1. Probe-Calibration Data .............................................................................................. 3-3

Table 4-1. Water chemistry summary of SHT Borehole 16-4 waters, Yucca Mountain unsaturated-zone perched water, YM saturated-zone groundwaters, and Rainier Mesa fracture water............................................................................................ 4-5

Table 4-2. Normalized mineral abundances (weight-\%) for samples from the SHT................... 4-12

Table 4-3. Normalized mineral abundances (weight-\%) for samples from the ESF)................... 4-13

Table 4-4. Normalized mineral abundances (weight-\%) for samples from the ESF ..................... 4-15

Table 4-5. Composition of cavity and fracture-fill samples from ESF drill-core samples........... 4-19

Table 5-1. Summary of available technologies for underground deformation measurements.... 5-2

Table 5-2. Locations of anchors in Boreholes 6 and 7 of the SHT ................................................ 5-4

Table 5-3. Summary data for separation of anchors 2 and 3 in Borehole 7 of the SHT................ 5-6

Table 6-1. Summary of the four cases considered in this study...................................................... 6-2

Table 6-2. Thermal and hydrologic properties summarized for the host rock for the

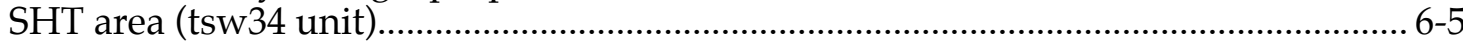

Table 7-1 FLAC properties and sources …………………....................................................... 


\section{Figures}

Figure 1-1. (a) Vertical cross section of the borehole layout of the SHT

(b) plan view of the borehole layout of the SHT

Figure 2-1. The borehole layout relative to the drifts and the RTD boreholes ................................2-1

Figure 2-2. Resistivity-ratio tomographs during the heating phase .............................................2-2

Figure 2-3. Resistivity-ratio tomographs during the cooling phase) ............................................2-3

Figure 2-4. Resistivity ratios as a function of saturation and temperature for models 1 and $2 \ldots . . .2-7$

Figure 2-5. Interpretation of where the rock lost or gained moisture during the heating phase ...2-8

Figure 2-6. Interpretation of where the rock lost or gained moisture during the cooling phase ...2-8

Figure 2-7. Conceptual model of TH behavior during the SHT, which is

consistent with the saturation estimates presented in Figure 2-2 and

Figure 2-3

Figure 3-1. Smoothed difference fraction volume water content in Borehole 15 as a

function of depth from collar on September 6, 1996, and September 19, 1996

Figure 3-2. Smoothed difference fraction volume water content in Borehole 15 as a

function of depth from collar on October 24, 1996, and November 26, 1996

Figure 3-3. Smoothed difference fraction volume water content in Borehole 15 as a function of depth from collar on January 16, 1997, and January 30, 1997......................

Figure 3-4. Smoothed difference fraction volume water content in Borehole 15 as a function of depth from collar on February 27, 1997, and March 26, 1997.

Figure 3-5. Smoothed difference fraction volume water content in Borehole 15 as a function of depth from collar on April 30, 1997, and May 21, 1997.......

Figure 3-6. Smoothed difference fraction volume water content in Borehole 15 as a function of depth from collar on June 10, and June 24, 1997

Figure 3-7. Smoothed difference fraction volume water content in Borehole 15 as a

function of depth from collar on July 23, and August 26, 1997

Figure 3-8. Smoothed difference fraction volume water content in Borehole 15 as a function of depth from collar on September 25, 1997, and October 29, 1997

Figure 3-9. Smoothed difference fraction volume water content in Borehole 15 as a function of depth from collar on November 24, 1997, and December 17, 1997

Figure 3-10. Smoothed difference fraction volume content at various depths in Borehole 15 as a function of time

Figure 3-11. Smoothed difference fraction volume water content in Borehole 17 as a function of depth from collar on September 6, 1996, and September 19, 1996

Figure 3-12. Smoothed difference fraction volume water content in Borehole 17 as a function of depth from collar on October 24, 1996, and November 26, 1996 .3-6

Figure 3-13. Smoothed difference fraction volume water content in Borehole 17 as a function of depth from collar on January 16, 1997, and January 30, 1997. .3-6

Figure 3-14. Smoothed difference fraction volume water content in Borehole 17 as a function of depth from collar on February 27, 1997, and March 26, 1997. .3-6 
Figure 3-15. Smoothed difference fraction volume water content in Borehole 17 as a function of depth from collar on April 30, 1997, and May 21, 1997

Figure 3-16. Smoothed difference fraction volume water content in Borehole 17 as a function of depth from collar on June 10, 1997, and June 24, 1997.

Figure 3-17. Smoothed difference fraction volume water content in Borehole 17 as a function of depth from collar on July 23, 1997, and August 26, 1997 3-6

Figure 3-18. Smoothed difference fraction volume water content in Borehole 17 as a function of depth from collar on September 25, 1997, and October 29, 1997 3-6

Figure 3-19. Smoothed difference fraction volume water content in Borehole 17 as a function of depth from collar on November 24, 1997, and December 17, 1997............ 3-6

Figure 3-20. Smoothed difference fraction volume water content at various depths in Borehole 17 as a function of time

Figure 3-21. Smoothed difference fraction volume water content in Borehole 22 as a function of depth from collar on September 6, 1996, and September 19, 1996

Figure 3-22. Smoothed difference fraction volume water content in Borehole 22 as a function of depth from collar on October 24, 1996, and November 26, 1996.

Figure 3-23. Smoothed difference fraction volume water content in Borehole 22 as a function of depth from collar on January 16, 1997, and January 30, 1997

Figure 3-24. Smoothed difference fraction volume water content in Borehole 22 as a function of depth from collar on February 27, 1997, and March 26, 1997

Figure 3-25. Smoothed difference fraction volume water content in Borehole 22 as a function of depth from collar on April 30, 1997, and May 21, 1997

Figure 3-26. Smoothed difference fraction volume water content in Borehole 22 as a function of depth from collar on June 10, 1997, and June 24, 1997.

Figure 3-27. Smoothed difference fraction volume water content in Borehole 22 as a function of depth from collar on July 23, 1997, and August 26, 1997

Figure 3-28. Smoothed difference fraction volume water content in Borehole 22 as a function of depth from collar on September 25, 1997, and October 29, 1997

Figure 3-29. Smoothed difference fraction volume water content in Borehole 22 as a function of depth from collar on November 24, 1997, and December 17, 1997.

Figure 3-30 Smoothed difference fraction volume water content at various depths in Borehole 22 as a function of time

Figure 3-31. Smoothed difference fraction volume water content in Borehole 23 as a function of depth from collar on September 6, 1996, and September 19, 1996

Figure 3-32. Smoothed difference fraction volume water content in Borehole 23 as a function of depth from collar on October 24, 1996, and November 26, 1996. 3-8

Figure 3-33. Smoothed difference fraction volume water content in Borehole 23 as a function of depth from collar on January 16, 1997, and January 30, 1997 3-8

Figure 3-34. Smoothed difference fraction volume water content in Borehole 23 as a function of depth from collar on February 27, 1997, and March 26, 1997

Figure 3-35. Smoothed difference fraction volume water content in Borehole 23 as a function of depth from collar on April 30, 1997, and May 21, 1997 
Figure 3-36. Smoothed difference fraction volume water content in Borehole 23 as a function of depth from collar on June 10, 1997, and June 24, 1997

Figure 3-37. Smoothed difference fraction volume water content in Borehole 23 as a function of depth from collar on July 23, 1997, and August 26, 1997

Figure 3-38. Smoothed difference fraction volume water content in Borehole 23 as a function of depth from collar on September 25, 1997, and October 29, 1997

Figure 3-39. Smoothed difference fraction volume water content in Borehole 23 as a function of depth from collar on November 24, 1997, and December 17, 1997

Figure 3-40. Smoothed difference fraction volume water content at various depths in Borehole 23 as a function of time

Figure 4-1. SHT Borehole 16-4 water composition as a function of time .......................................4-7

Figure 4-2. Composition of SHT waters compared for Suites 1-4

Figure 4-3. Stable isotope data for SHT waters (Suite 1-4), saturated-zone waters G-4 and J-13, UZ-14 perched water, and ESF pore water

Figure 4-4. Comparison of SHT water, pore water, perched water, saturated-zone water, and fracture water (Rainier Mesa).

Figure 4-5. Concentration ratios of SHT water to perched water ...................................................4-8

Figure 4-6. Comparison of normalized abundances of quartz and cristobalite............................4-20

Figure 4-7. Variation in cristobalite abundance vs. quartz plus tridymite abundance for SHT and ESF thermal test samples

Figure 4-8. Variation in cristobalite abundance vs. quartz plus tridymite abundance for ESF core samples of different matrix color collected from the same core

Figure 5-1. Illustration of how a modulated signal can be used to measure distance......

Figure 5-2. Schematic of distance measuring module ..... $.5-3$

Figure 5-3. Schematic of ROX borehole extensometer system .

Figure 5-4. Schematic of optical head and downhole reflectors used for ROX system ...................5-3

Figure 5-5. Borehole anchor and installation tool prior to installation in the SHT ........................5-4

Figure 5-6. Deformation data from SHT, Borehole 7 over period July 1996 through December 1997

Figure 5-7. Deformation data from SHT, Borehole 7 over period November 11, 1997, to December 31, 1997

Figure 6-1. SHT layout, including dimensions and SHT-model coordinate system, in plan view and vertical Section A-A'.

Figure 6-2. (a) Temperature $\mathrm{T}$ distribution and (b) liquid-phase saturation $S_{\text {liq }}$ distribution at the end of the SHT heating phase ( $t=275$ days) plotted in a vertical $(x-z)$ plane transverse to the midpoint of the heater for Case 1, which uses the ECM ......... 6-6

Figure 6-3. (a) Temperature $T$ distribution and (b) liquid-phase saturation $S_{\text {liq }}$ distribution at the end of the SHT heating phase $(t=275$ days) plotted in a vertical $(y-z)$ plane along the axis of the heater for Case 1, which uses the ECM. 
Figure 6-4. (a) Temperature $T$ distribution and (b) liquid-phase saturation $S_{\text {liq }}$ distribution in the matrix continuum at the end of the SHT heating phase $(t=275$ days) plotted in a vertical $(x-z)$ plane transverse to the midpoint of the heater for Case 3, which uses the DKM.

Figure 6-5. (a) Temperature $T$ distribution and (b) liquid-phase saturation $S_{\text {liq }}$ distribution in the fracture continuum at the end of the SHT heating phase ( $t=275$ days) plotted in a vertical $(x-z)$ plane transverse to the midpoint of the heater for Case 3, which uses the DKM.

Figure 6-6. (a) Temperature $T$ distribution and (b) liquid-phase saturation $S_{\text {liq }}$ distribution in the matrix continuum at the end of the SHT heating phase $(t=275$ days) plotted in a vertical $(y-z)$ plane along the axis of the heater for Case 3, which uses the DKM

Figure 6-7. (a) Temperature $T$ distribution and (b) liquid-phase saturation $S_{\text {liq }}$ distribution in the fracture continuum at the end of the SHT heating phase $(t=275$ days) plotted in a vertical $(y-z)$ plane along the axis of the heater for Case 3, which uses the DKM

Figure 6-8. (a) Simulated and measured temperature histories compared at thermocouple TMA-TC-1A-9, located at $x=-0.221, y=2.978$, and $z=0.331$; simulated and measured temperature distributions compared along borehole TMA-TC-5 at (b) the end of the SHT heating period ( $t=275$ days) and (c) 213 days after the end of heading ( $t=487$ days) 6-9

Figure 7-1. Layout of Single-Heater Test in plan and cross section ............................................... 7-1

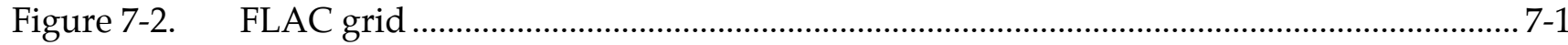

Figure 7-3. Temperature field near the single heater at 100 days ................................................ 7-3

Figure 7-4. Temperature field near the single heater at 200 days .................................................... 7-3

Figure 7-5. Principal stresses near the single heater before heating ............................................. 7-3

Figure 7-6. Principal stresses near the single heater at 100 days ................................................... 7-3

Figure 7-7. Principal stresses near the single heater at 200 days ................................................ 7-3

Figure 7-8. Ratio of shear stress to frictional resistance for vertical planes at 100 days..................7-4

Figure 7-9. Ratio of shear stress to frictional resistance for vertical planes at 200 days ................ 7-4

Figure 7-10. Ratio of shear stress to frictional resistance for horizontal planes at 100 days............. 7-5

Figure 7-11. Ratio of shear stress to frictional resistance for horizontal planes at 200 days............ 7-5

Figure 7-12. Electrical resistance tomography showing drying and wetting regions in a cross section through the single heater as a function of time $7-5$

Figure 8-1. Synthesis of ERT and neutron measurements for SHT near the end of the heating phase

Figure 8-2. Synthesis of ERT measurements and predicted temperatures near the end of the heating phase

Figure 8-3. Regions of shear slip predicted for vertical fractures, oriented perpendicular to the page 



\section{Acknowledgments}

The authors gratefully acknowledge the assistance of Karen L. Lew in editing and preparing the manuscript and of Paul Harding for creation and preparation of the graphics. The technical reviews by Dale Wilder, Jesse Yow, and Wunan Lin are also acknowledged with appreciation. 



\section{Abbreviations and Acronyms}

2-D

3-D

AOD

CPN

DFM

DKM

DTN

ECM

ERT

ESF

FMX

JCPDS-PDF

LANL

LBNL

LDTH

LLNL

MPBX

NF/AZ

NFE

NIST

NUFT

ROX

RTD

SEAMIST ${ }^{\mathrm{TM}}$

SHT

SZ

$\mathrm{TC}$

$\mathrm{TH}$

THCM

TM

TMAE

TSPA-VA

USGS

UZ

WP

XRD

YM

YMP two-dimensional

three-dimensional

access / observation drift

Campbell Pacific Nuclear

discrete-fracture method

dual-permeability method

data-tracking number

equivalent-continuum method

electrical-resistance tomography

Exploratory Studies Facility

fracture-matrix interaction

Joint Committee on Powder Diffraction Standards Powder Diffraction File Los Alamos National Laboratory

Lawrence Berkeley National Laboratory

line-averaged-heat-source, drift-scale thermohydrologic

Lawrence Livermore National Laboratory

multiple-point borehole extensometer

near field and altered zone

near-field environment

National Institute of Standards

Nonisothermal Unsaturated-Saturated Flow and Transport

reflective optical extensometer

resistance-temperature device

Science Engineering Associates Membrane Insitu Sampling Technology

Single-Heater Test

saturated zone

thermochemical

thermohydrologic

thermal-hydrologic-chemical-mechanical

thermomechanical

thermomechanical alcove extension

Total System Performance Assessment-Viability Assessment

U.S. Geological Survey

unsaturated zone

waste package

X-ray diffraction

Yucca Mountain

Yucca Mountain Site Characterization Project 



\section{Executive Summary}

The Single-Heater Test (SHT) was one phase of the field-scale thermal testing program of the Yucca Mountain Site Characterization Project. The primary purpose of the SHT was to study the thermomechanical (TM) behavior of the densely welded, non-lithophysal Topopah Spring tuff at the Exploratory Studies Facility. The SHT was also used as a shake-down for testing thermal-hydrologic-chemical-mechanical processes in situ, testing that will be conducted in the Drift-Scale Test.

In the SHT, a line-heat source 5-m long was emplaced in a pillar and used to heat the pillar for approximately nine months. The thermal field was relatively cylindrical about the line-heat source. The heater was turned off after nine months of heating, and the rock mass was monitored during the cool-down for another nine months, until May 28, 1997, when the test was terminated.

Electrical resistance tomography (ERT) was used during the SHT to monitor the rock's water saturation, with a special interest in the movement of steam condensate out of the system. This report presents images of resistivity change calculated using data collected before, during, and after the heating episode. These images were used to calculate changes in water saturation (after accounting for temperature effects) during or after heating. The saturation estimates suggested that, during the heating phase, a region of drying forms around the heater. The estimates also suggested that rock on either side of the heater and below the heater elevation showed the highest saturation increases. This is consistent with results of a similar test conducted at the G-tunnel (Ramirez et al. 1991). During the cooling phase, the dry region remained relatively stable. Wetter rock regions, which developed below the heater during the heating phase, became relatively smaller in size during the cooling phase, particularly below and to the north of the heater.

Thermal neutron-logging was used to monitor moisture content in four boreholes during the SHT. Neutron-logging data and analysis presented here indicated drying of the rock mass during the heating phase of the test. Neutron-logging results were in good agreement with ERT results. The degree of drying seemed in good correlation with the temperatures in the rock. ERT and neutron-logging data indicated drying in regions of rock that reached $60^{\circ} \mathrm{C}$ and more.

On November 25, 1996, February 4, 1997, February 27, 1997, and May 22, 1997, water samples were collected from one of the boreholes in the SHT. Analysis of water composition and associated modeling showed that the waters collected were slowly evolving while still maintaining consistent compositional characteristics. These characteristics were that $\mathrm{Na}$ and $\mathrm{Si}$ were the dominant cations in solution, followed by $\mathrm{Ca}, \mathrm{K}$, and $\mathrm{Mg}$. Values of $\mathrm{pH}$ of the water, which ranged from 6.2 to 6.9 , reflected slightly acidic waters. The low $\mathrm{pH}$ was indicative of higher $\mathrm{CO}_{2}$ partial pressures (approximately two orders of magnitude, relative to ambient).

The evolution can be explained by a simple model in which condensate interacted with fracture-lining minerals only. Preliminary modeling suggested that the flow distance was 3 to $6 \mathrm{~m}$ from the heater and also that the concentration of Ca followed precisely that expected if calcium concentration reflected the interaction of calcite and a water in which $\mathrm{pH}$ is externally controlled, that the solution concentration remained saturated with respect to quartz, and that the concentrations of $\mathrm{K}$ were consistent with $\mathrm{K}$-feldspar dissolution. 
These conclusions were also consistent with the primary characteristics of the solution chemistry developing within a few meters of the heater, at temperatures and flow conditions expected in the actively convecting portion of the heated region.

X-ray analysis of samples taken from the ESF has shown the uniformity of the total $\mathrm{SiO}_{2}$ polymorph and feldspar abundances in the repository horizon (Topopah Spring tuff). Within this horizon and adjacent zones, the relative abundance of quartz plus tridymite is positively correlated with gray, altered zones adjacent to lithophysae and fractures. Work presented here indicates that the relative abundance of cristobalite relative to quartz plus tridymite could potentially be used to assess the number and distribution of paleo fluid pathways. A strong negative correlation between cristobalite and quartz plus tridymite abundances was observed and may reflect post-devitrification alteration by aqueous fluids.

An optical extensometer was also installed in two boreholes in the SHT. This prototype instrument was developed for use in the high-temperature environment that is expected in a geologic repository for nuclear waste. The system has many advantages over conventional rod extensometers because there are no moving parts in the borehole, and a system correction for temperature is incorporated in the design. Precision of data gathered during the SHT with this system was not adequate to monitor small deformations. However, valuable field experience with this system was gained, and, because the system is still under development, it is hoped that the system performance and data quality will be improved in future realizations of this instrument.

The thermohydrologic (TH) behavior during the heating and cooling stages of the SHT was modeled with the NUFT code. Two different conceptual models for fracture-matrix interaction were considered: the ECM, which assumes equilibrium between the fracture and matrix continua, and the DKM that accounts for disequilibrium processes between the fracture and matrix continua. All of the models in this study included the influence of vapor and heat flow along the heater borehole.

The DKM model predicted temperatures that were in outstanding agreement with the observed temperatures throughout the heating stage of the SHT. The ECM model did not have as good an agreement; it predicted lower temperatures, but a more extensive dry-out region, than did the DKM model. Both the ECM and DKM models predicted a pronounced cold-trap effect in the heater borehole. Vapor and latent-heat flowed from the heated interval of the heater borehole to the cool end of the heater borehole adjacent to its collar, where the vapor condensed, resulting in focused condensate drainage and a local increase in $S_{\text {liq }}$ in the matrix. The cold-trap effect efficiently transferred heat along the heater borehole toward the TM alcove. The cold-trap effect is a potentially important mechanism influencing TH behavior in emplacement drifts.

This work also showed that the SHT was ineffective for distinguishing between alternative conceptual models of the fracture-matrix interaction (FMX) factor. Both approaches resulted in the same outstanding agreement with observed temperatures, and both approaches predicted the same distribution of $S_{\text {liq }}$ in the matrix continua. This analysis also showed that the SHT was not a useful test for diagnosing the magnitude of percolation flux $q_{\text {perc }}$. The lack of sensitivity of the SHT to $q_{\text {perc }}$ arose from the heat-driven condensate fluxes being much greater than any of the values of $q_{\text {perc }}$ that were considered.

A simple TM analysis of the SHT is also presented. This analysis was designed to assess the potential for TM stresses developed in the SHT to cause shear slip on fracture sets occurring in the rock mass heated during the SHT. Shear slip has been shown to increase rock-mass permeability. This analysis showed that thermal gradients and associated thermal 
stresses induced by heating and cooling of the SHT were relatively low. However, some zones of predicted shear correlated directly with zones in which increased rock saturation was observed.

\section{References}

Ramirez, A.L., Buscheck, T.A., Carlson, R., Daily, W.D., Lee, K., Lin, W., Mao, N., Ueng, T., Wang, H., and Watwood, D. 1991. Prototype Engineered Barrier System Field Test (PEBSFT) Final Report. UCRL-ID-106159. Livermore, California: Lawrence Livermore National Laboratory. NNA.910711.0047. 



\section{Introduction}

The Single-Heater Test (SHT) was one phase of the field-scale thermal testing program of the Yucca Mountain Site Characterization Project. It was conducted to obtain data on thermal, mechanical, hydrologic, and chemical processes in situ. The resulting data would allow testing and refinement of model assumptions and evaluation of simulation capabilities. A detailed description, which reflects the as-built conditions of the SHT, is provided in Figure 1-1. This figure shows the test configuration and borehole layout of the SHT.

Figure 1-1. (a) Vertical cross section of the borehole layout of the SHT (b) plan view of the borehole layout of the SHT (not to scale)

The boreholes are identified by the numbers. See Chapter 3 of CRWMS M\&O (1997) for description of the boreholes.

\subsection{Description of the Single-Heater Test}

Details of the purpose of the SHT, the design of the test, and the borehole layout are included in the Single-Heater Test Interim Report of the Office of Civilian Radioactive Waste Management and Operating Contractor (CRWMS M\&O 1997). Briefly, the main purpose of the SHT was to study the thermomechanical (TM) behavior of the densely welded, nonlithophysal Topopah Spring tuff at the Exploratory Studies Facility (ESF). The SHT was also used as a shake-down for the Drift-Scale Test, which was designed to study the coupled thermal-hydrologic-chemical-mechanical processes.

The SHT comprised 41 boreholes having a cumulative length of approximately $230 \mathrm{~m}$. To heat the rock, a 4-kW, 5-m-long, electrical-resistance heater was emplaced in a 9.6-cmdiameter, horizontal borehole slightly inclined upward in the west face of the test block. The nominal electrical power supplied to the heater was $3.86 \mathrm{~kW}$. The remaining boreholes housed 520 sensors that measured the thermal, mechanical, hydrologic, and chemical responses from heat generated by the emplaced heater.

The test configuration included the heater in roughly the center (Figure 1-1b) of the test block, with instrumentation access from all three free surfaces bounded by excavations. The heated block was bounded to the north by the access / observation drift, to the south by the TM alcove extension, and to the west by the TM alcove. The horizontal heater borehole was collared $6.59 \mathrm{~m}$ from the access/observation drift and $1.52 \mathrm{~m}$ above the floor of the TM alcove and was drilled parallel to the access / observation drift. The heater was installed with its front (i.e., closest) end $1.99 \mathrm{~m}$ from the borehole collar. The walls of the access / observation drift and alcoves facing the block were covered by a 15-cm-thick layer of fiberglass insulation with a thermal conductivity of $0.044 \mathrm{~W} / \mathrm{m}-\mathrm{K}$.

The SHT was initiated on August 26, 1996, with activation of the heater. The SHT continued heating for nine months; the heater was turned off on May 28, 1997. The cooling phase then lasted for approximately another nine months, until the end of February 1998.

Ambient site characterization information was obtained primarily from data gathered in situ at the SHT block and from cores taken from selected boreholes (CRWMS M\&O 1996). The characterization information included bulk permeability from air-injection tests; water saturation from laboratory testing; rock-mass-quality assessment from scanline mapping; 
intact rock modulus and Poisson's ratio from laboratory testing, and intact thermal conductivity from laboratory testing (CRWMS M\&O 1997, pp. 3-1). This characterization information was used in pre-test analyses of the SHT.

Temperature data collected during the SHT are presented in a previous report (CRWMS M\&O 1997, Chapter 5) and discussed throughout this report.

\subsubsection{Post-Test Evaluation of Instrumentation}

To evaluate the performance of the temperature-measuring instrumentation, two resistance-temperature devices (RTDs) were removed from the test after cool-down and recalibrated by Bechtel Nevada Standards and Calibration Laboratory on August 25, 1998. Results of the calibration tests are shown in Table 1-1 and Table 1-2.

Table 1-1. Results of post-test calibration for RTD \#234 (Model RF1016019 1000-Ohm RTD; $a=0.00385 ; 150 ")$ (DTN LL980810904244.068)

Insulation Test: Failed: $<12 \mathrm{M}$ Ohm Loop to Shield at 100 Volts Spec: >200 M Ohms Loop to Shield at 100 Volts

\begin{tabular}{|c|c|r|r|r|c|}
\hline \multicolumn{2}{|c|}{ Temperature $\left({ }^{\circ} \mathbf{C}\right)$} & \multicolumn{4}{c|}{ Calculated Equivalent Temperature $\left({ }^{\circ} \mathbf{C}\right)$} \\
\hline \hline Nominal & Actual & Minimum & Temp. & Maximum & Pass/Fail \\
\hline 0 & -0.01 & -0.16 & -0.12 & 0.14 & Pass \\
\hline 25 & 24.71 & 24.36 & 24.95 & 25.06 & Pass \\
\hline 100 & 100.02 & 99.67 & 100.06 & 100.37 & Pass \\
\hline 200 & 199.67 & 199.12 & 204.31 & 200.22 & Fail \\
\hline
\end{tabular}

Note: Failed temperature test at $200^{\circ} \mathrm{C}$ allowed $\pm 0.35^{\circ} \mathrm{C}$, error $+4.64^{\circ} \mathrm{C}$

Table 1-2. Results of post-test calibration for RTD \#244 (Model RF1016023 1000-Ohm RTD; $a=0.00385 ; 174 ")$ (DTN LL980810904244.068)

Insulation Test: Passed: $260 \mathrm{M}$ Ohm Loop to Shield at 100 Volts Spec: $\quad>200$ M Ohms at 100 Volts Loop to Shield

\begin{tabular}{|c|c|c|c|c|c|}
\hline \multicolumn{2}{|c|}{ Temperature $\left({ }^{\circ} \mathbf{C}\right)$} & \multicolumn{4}{c|}{ Calculated Equivalent Temperature $\left({ }^{\circ} \mathbf{C}\right)$} \\
\hline \hline Nominal & \multicolumn{1}{|c|}{ Actual } & Minimum & Temp. & Maximum & Pass/Fail \\
\hline 0 & -0.01 & -0.16 & -0.11 & 0.14 & Pass \\
\hline 25 & 24.72 & 24.37 & 25.01 & 25.07 & Pass \\
\hline 100 & 99.59 & 99.24 & 99.68 & 99.94 & Pass \\
\hline 200 & 199.48 & 198.93 & 199.41 & 200.03 & Pass \\
\hline
\end{tabular}

As shown in the table, both RTDs performed within specification over the temperature range $0^{\circ}$ to $100^{\circ} \mathrm{C}$. Moreover, RTD \#244 also performed within specifications at $200^{\circ} \mathrm{C}$; RTD $\# 234$, however, was out of specification at this temperature and showed an error of $4.64^{\circ} \mathrm{C}$. Results presented in this and other SHT reports show that temperatures in the rock mass did not reach $200^{\circ} \mathrm{C}$; for most of the rock mass heated in the SHT, temperatures were $100^{\circ} \mathrm{C}$ or less. Thus, confidence is high in temperature measurements made with RTDs. Because the 
RTDs remained within specification, no comparison of pre- and post-test calibrations was performed. All the other RTDs were set in grout and therefore could not be removed for recalibration.

The Humicaps ${ }^{\mathrm{TM}}$ and pressure transducers in Boreholes 16 and 18 were also recovered and sent to be recalibrated. The calibration results were not available at the time of this report.

\subsection{Measurements and Analysis}

Thermal effects from proposed high-level nuclear waste emplacement are expected to dominate the movement and chemical evolution of in situ pore water and fracture water in the unsaturated zone surrounding the repository. At sufficiently high temperatures, the water may evaporate or boil, migrating as vapor into cooler regions of the rock and condensing. The movement and composition of the water are of particular importance in and around the waste packages (WP), where contact with the potentially chemically reactive, introduced materials would be an issue relevant to the lifetime of the WPs and to subsequent radionuclide transport. The ability to model and predict conditions surrounding the WPs depends in large part on the availability of data sets from thermal field tests such as the SHT.

Rock-mass heating creates temperature and liquid saturation changes that result in readily measured electrical resistivity changes. Electrical resistance tomography (ERT) is a geophysical imaging technique that can be used to map subsurface resistivity. Chapter 2 of this report describes ERT surveys made during the SHT to map the changes in moisture content caused by heating. These saturation estimates are used to construct a conceptual model for the thermohydrologic (TH) behavior of the SHT.

This report also presents results from thermal neutron-logging of four boreholes in the SHT. This technique is used to determine moisture content in rocks and soils and was used to monitor moisture content in Boreholes 15, 17, 22, and 23 (see Figure 1-1) during the SHT. The neutron probe contains a source of high-energy neutrons and a detector for slow (thermal) neutrons. Water present (more specifically, the hydrogen in water) in rocks slows down the neutrons, making them detectable. Thus, higher counts (or a positive difference in counts relative to background or pre-heat levels) indicate higher water content (or increased water content over background). Neutron-logging measurements are reported in Chapter 3.

A few water samples were collected during the SHT, and chemical analysis of these samples is presented in Chapter 4. That chapter also presents data on mineral abundances determined for core samples taken from the SHT.

Chapter 5 describes the development of an optical extensometer to measure deformation in a geologic repository for high-level nuclear waste. A prototype of this instrument was fielded in the SHT, and results from its use are presented.

TH model calculations are described in Chapter 6. The purpose of this modeling is to compare the simulated temperatures with the temperatures measured in the field during the heat-up and cool-down periods of the SHT. Comparison of simulated and measured temperatures is a useful means of assessing the applicability of the models and also of the December 1997 base-case hydrologic parameter set used in the Total System Performance Assessment-Viability Assessment to predict TH behavior in one of the three major host-rock units. Another purpose of the TH-model calculations is to investigate differences in predicted $\mathrm{TH}$ behavior between two different approaches to representing fracture-matrix interaction: the equivalent-continuum method and the dual-permeability method. 
Chapter 7 presents results of a simple thermomechanical analysis of the SHT to assess the potential for TM stresses developed in the SHT to cause shear slip on fracture sets in the rock mass heated during the SHT. Shear slip is of interest because slip on fractures can change (increase) fracture permeability and thus influence the hydrologic behavior of the test.

Finally, Chapter 8 presents a brief synthesis of the results detailed in the report.

\subsection{References}

CRWMS M\&O 1996. Characterization of the ESF Thermal Test Area. B00000000-01717-5705-00047 REV 1. Las Vegas, Nevada: Civilian Radioactive Waste Management System Management and Operating Contractor: TRW Environmental Safety Systems, Inc. MOL.19970116.0187.

CRWMS M\&O 1997. Single Heater Test Interim Report. Yucca Mountain Site Characterization Project Milestone Report. BABEAF000-01717-69000001 REV 00. Las Vegas, Nevada: Civilian Radioactive Waste Management System, Management and Operating Contractor: TRW Environmental Safety Systems, Inc. 
Chapter 1 Figure 


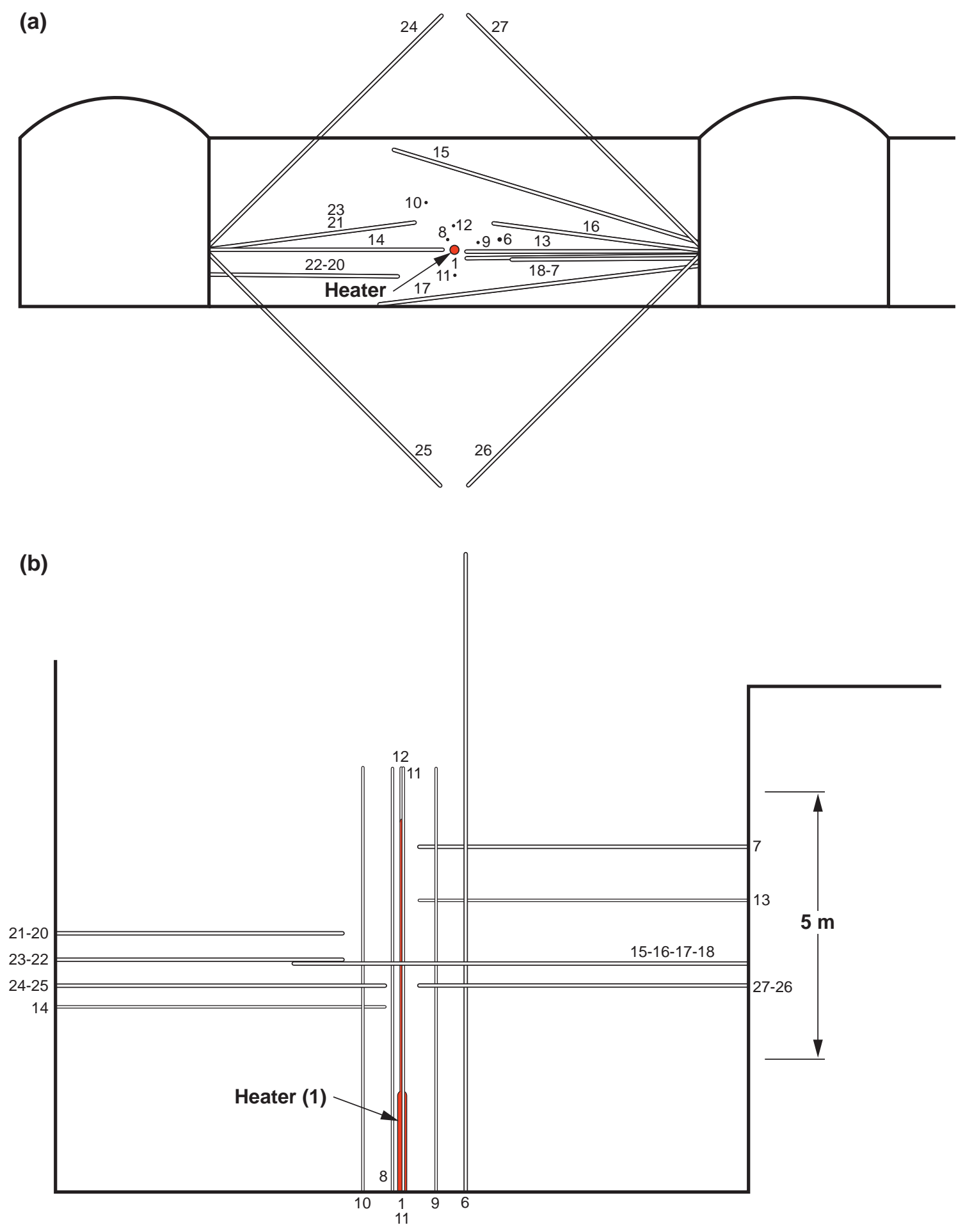

Figure 1-1. (a) Vertical cross section of the borehole layout of the SHT (b) plan view of the borehole layout of the SHT (not to scale; boreholes are identified by the numbers) 



\title{
2. Electrical Resistivity Monitoring
}

\author{
by Abelardo L. Ramirez and William Daily
}

\subsection{Introduction}

This chapter describes electrical resistance tomography (ERT) surveys made during the Single-Heater Test (SHT) to map the changes in moisture content caused by heating. Of particular interest is the formation and movement of condensate within the fractured rock mass. Figure 2-1 shows the relative position of the ERT boreholes in the SHT. Four inclined boreholes, forming a plane perpendicular to the heater axis, were used to position electrodes around the region of interest; this plane intercepts the heater near its midpoint. Twenty-eight electrodes, equally spaced within the four boreholes, were used to conduct ERT surveys around the heater.

Figure 2-1. The borehole layout relative to the drifts and the RTD boreholes

Twenty-eight electrodes distributed among the four holes were used to conduct ERT surveys around the heater.

\subsection{Electrical Resistance Tomography}

ERT is a geophysical imaging technique that can be used to map subsurface resistivity. Rock-mass heating creates temperature and liquid saturation changes that result in readily measured electrical resistivity changes. The ERT measurements are made with an automated data collection system and consist of a series of voltage and current measurements from buried electrodes. The data are then processed to produce electrical resistivity tomographs using state-of-the-art data-inversion algorithms. These measurements are used to calculate tomographs that show changes in electrical resistivity as a function of space and time.

Following are brief descriptions of some of the important features of the two-dimensional (2-D) algorithm. For additional details, the reader is referred to Morelli and LaBrecque (1996, pp. 629-631). The algorithm solves both the forward and inverse problems. The forward problem is solved using a finite element technique in two dimensions. The inverse problem implements a regularized solution that minimizes an objective function. The goal of the inverse routine is to minimize the misfit between the forward modeling data and the field data. The resistivity model's roughness is used as a function to stabilize the solution. This means that the inverse procedure tries to find the smoothest resistivity model that fits the field data to a prescribed tolerance. Resistivity values assigned in this way to the finite element mesh constitute the ERT image. Although the mesh is of a large region around the electrode arrays, only the region inside the ERT electrode array is shown in the results because the region outside the array is poorly constrained by the data.

To calculate the changes in the rock's electrical resistivity, a data set obtained after heating started was compared to a corresponding data set obtained prior to heating. One may consider subtracting, pixel by pixel, images from two different conditions. However, this approach could not be used because the resistivity structure was three-dimensional (3-D) (i.e., several boreholes containing metallic instruments were located orthogonal and parallel to the plane of interest; see Figure 2-1). These metallic instruments caused large conductive 
anomalies and made the resistivity structure 3-D. The finite-element forward solver cannot generate a model that will fit the data; thus, the code chooses a solution with a poor fit. Experience shows that these effects can be reduced by inverting the quantity:

$$
\frac{R_{a}}{R_{b}} \times R_{h}
$$

where $R_{\mathrm{a}}$ is the measured transfer resistance after heating started, $R_{\mathrm{b}}$ is the transfer resistance before heating and $R_{\mathrm{h}}$ is the calculated transfer resistance for a model of uniform resistivity. This approach tends to reduce the effects of anomalies that do not match the 2-D assumptions of the resistivity model because the 3-D effects cancel in the ratio (because they are contained in both terms $R_{\mathrm{a}}$ and $R_{\mathrm{b}}$ ).

The data used for the tomographs in this chapter were the average of three consecutive data sets (the time intervals between data sets was approximately 40 minutes). That is, each reading used for the tomographs was the average value of the reading measured in three consecutive field surveys. This was done to improve the signal-to-noise ratio of the measurements made at low voltages.

\subsubsection{Changes in Resistivity}

To get an estimate of the effects of measurement noise on the tomographs, data sets collected a few hours apart on August 22, 1996, were used to calculate resistivity-change tomographs. No changes were expected at this time because the heater was off (heating started on August 26, 1996). Therefore, any changes observed in this image would be indicative of the effects of measurement error on the inversion process; thus, this image can be used to determine the significance of resistivity changes shown in subsequent images. On average, these "noise" images showed the resistivity ratio to deviate from 1.0 (i.e., perfect result when no changes occur) by \pm 0.05 , so changes of about $5 \%$ can be expected on the basis of measurement error. Therefore, to be considered reliable, the changes observed during heating need to be substantially larger than $5 \%$.

Figure 2-2 shows tomographs of electrical resistivity change during the course of the heating phase; these tomographs are shown in the left hand column of the figure. The images labeled 9/3/96 in Figure 2-2 show changes 8 days after heating started on 8/26/96. After just 8 days there is a weak conductive anomaly showing significant changes (i.e., changes significantly larger that those expected to be caused by measurement error; up to $20 \%$ change) with a circular region of enhanced conductivity forming, not centered on the heater, but shifted about $1 \mathrm{~m}$ upward.

The rest of the images in Figure 2-2 show a clear trend of overall increase in electrical conductivity in the rock mass (i.e., decreasing resistivity or a ratio less than 1.0). However, the first 59 days of heating show a pattern that is different from the pattern observed in subsequent images. Prior to the December data the conductive anomaly is mostly circular in section (although not centered on the heater). However, after a 41-day data gap between October and December, 1996, the pattern is much more irregular, and there is no clear pattern or symmetry from which one could locate the heater. We believe that this is due to the fact that rock heterogeneities such as fractures are influencing the changes in saturation and temperature, which in turn drive the resistivity changes observed; the relationships among saturation, temperature, and resistivity ratio are discussed in detail in Section 2.2.2 of this report. 
Figure 2-2. Resistivity-ratio tomographs during the heating phase (left column of images) (DTN LL980105204244.049)
Also shown are corresponding temperature maps ( second column from the left). The results of the saturation calculations are shown by the images in the third and fourth columns. The estimates of saturation assume that the initial saturation is $92 \%$ and are based on two models (described in the text) relating moisture content to resistivity.

The complex and irregular pattern in the images (after day 59) is interpreted as changes in moisture content due to drying and wetting along fracture systems having a complex, 3-D geometry. As the temperature increases above ambient, the vapor pressure in the pores increases. Fractures connected pneumatically to the drift will provide a pressure gradient so that moisture will leave the rock through fracture openings and move along the fractures in response to buoyancy or thermally driven pressure gradients. The result will be dryer zones along fractures near the heater but wetter zones along fractures further away, where temperature and pressure allow condensation below the local dew point.

Between heating days 100 and 270 (middle to late portions of the heating phase), the rock zones showing the largest conductivity increases (i.e., zones showing the smallest resistivity ratios) appear to gradually migrate downward below the heater borehole. The image collected on May 23, 1997, (heating day 270) shows the resistivity changes observed near the end of the heating phase (the heater was turned off on May 28, 1997). Note that an invertedL-shaped resistivity decrease region (indicated by resistivity ratios less than 1.0) is located near the heater location.

Figure 2-3 shows tomographs of electrical resistivity change during the course of the cooling phase; these tomographs are shown in the left-hand column of the figure. Twelve days into the cooling phase, the upper tip of the inverted-L-shaped resistivity decrease region had disappeared; a region of resistivity increase (ratios greater than 1.0) began to develop near the heater. After 29 days of cooling, the zone of resistivity increases near the heater grew in size and continued growing, as seen in subsequent images. Note that this resistive anomaly was not centered on the heater, possibly because of heterogeneities in the rock mass (notably fractures). Also, the regions of decreased resistivity observed below the heater became smaller in size as cooling progressed.

Figure 2-3. Resistivity-ratio tomographs during the cooling phase (left column of images) (DTN (DTN LL980105204244.049; LL971002904244.044)
Also shown are corresponding temperature maps (second column from the left). The results of the saturation calculations are shown by the images in the third and fourth columns. The estimates of saturation assume that the initial saturation is $92 \%$ and are based on two models (described in the text) relating moisture content to resistivity.

During heating, there were competing effects at work (i.e., temperature increases caused resistivity decreases while drying caused resistivity increases). Just before the end of the heating phase, the dominant effect was the resistivity decrease due to temperature. This changed by June 26, 1997 (cooling phase day 29) when the local region at the nine-o'clock position from the heater was more resistive than initial conditions. Note that the temperatures at this time had already dropped to near $50^{\circ} \mathrm{C}$ at the heater borehole. As the temperature decreased to near $40^{\circ} \mathrm{C}$ (cooling phase day 57), the water resistivity returned to 
higher values. The effects of drying on the resistivity (which made the resistivity increase) were now beginning to dominate over the effects of temperature (which made the resistivity decrease); as result, the resistivity was increasing. The net effect was that, up to day 57 during cooling, the resistivity increased. However, once the pattern on day 57 was established, it remained fairly stable until the last survey (taken cooling day 270); there were minor changes, but the basic pattern was the same.

Interpretation of moisture content based on resistivity changes is complicated by several factors. One of these is related to the dependency of the resistivity on temperature and saturation. Fortunately, a measure of temperature exists so that it is possible, in principle, to separate the two effects; an attempt to do this will be made in Section 2.3.2.

\subsubsection{Inferences of Moisture Changes}

The resistivity changes in Figure 2-2 and Figure 2-3 are influenced by changes in moisture content and temperature (e.g., an increase in temperature or moisture causes a resistivity decrease, while drying will cause the resistivity to increase). Near the heater, there are regions where the resistivity decrease caused by increasing temperatures is counterbalanced by the effect of drying, which increases the resistivity; the resistivity ratio may be higher than 1.0 (resistivity is higher than the preheat case) or lower than 1.0 depending on the temperature. Farther away from the heater, where steam condenses and temperatures are above ambient, the resistivity will go down because of the increasing saturation and temperature. The goal is to use the images of resistivity change, along with the measured temperature field (shown in the second column of Figure 2-2 and Figure 2-3) and what is known of initial conditions in the rock mass, to estimate moisture during the test (shown in the third and fourth columns of Figure 2-2 and Figure 2-3).

To estimate moisture content changes, one needs to make use of temperature, measured at many points by temperature sensors, and resistivity changes, measured by ERT. The saturation estimates can be made by using empirically derived relations based on laboratory data or by using a suitable model of electrical conduction in porous media. Roberts and Lin (1997, pp. 579-580) published data on the resistivity of Topopah Spring tuff as a function of moisture content and temperature. There is, however, only limited data on temperature dependence (up to $95^{\circ} \mathrm{C}$ ), and the samples were not from the SHT alcove, so direct use of this data is not straightforward.

A second approach is to use an electrical conduction model. Waxman and Thomas (1974a, pp. 213-214) describe the Waxman-Smits model (intended for oil field data) for electrical conduction in partially saturated shale sands that accounts for conduction through the bulk pore water as well as conduction through the electrical double layer near the pore surface. This model can predict temperature dependence of the resistivity (Waxman and Thomas 1974b, pp. 218-220), but several of the model parameters are empirically determined and not available for tuff. Roberts and Lin (1997, p. 585) suggest that the Waxman-Smits conceptual model provides reasonably good estimates of resistivity for saturations greater than $20 \%$. For saturations less than $20 \%$, their data show that the Waxman-Smits conceptual model substantially underpredicts the resistivity. The capacity of this model to account for the temperature-dependent behavior of welded tuff was not investigated by Lin and Roberts. This model will be used to account for the temperature effects on the resistivity because, as far as is known, it is the only approach that provides the means to cover the temperature range of interest and that has been used successfully in other field applications. 
Waxman and Thomas (1974a, p. 213) begin with a parallel circuit model for conductance for saturated rock:

$$
C=\frac{1}{F^{*}}\left(C_{w}+B Q_{v}\right)
$$

where

$C$ is the conductivity or $1 / R$ where $R$ is the resistivity,

$F^{*}$ is the formation factor or $\phi^{-\mathrm{m}}$ where $\phi$ is the porosity and $\mathrm{m}$ the porosity exponent,

$C_{w}$ is the pore-water conductivity,

$B$ is the equivalent conductance of counter-ions on the double layer, and

$Q_{v}$ is the effective concentration of exchange cations.

The first term within parentheses represents conductance through the bulk pore water; the second term is the conductance along the double layer. This expression can be modified for partially saturated media by realizing that the first term is just Archie's equation and Q/S $=Q_{v}$ where $S$ is the fractional saturation, and $Q$ is the cation-exchange capacity of the rock. In terms of resistivity, Equation 2-2 can be rewritten as

$$
R=\frac{R_{w} \phi^{-m} S^{1-n}}{S+R_{w} B Q}
$$

where the exponent $n$ is approximately 2, the saturation index in Archie's modified equation, and $R_{w}$ is the water resistivity. Waxman and Thomas (1974a, p. 217) reported results that suggest that $m$ is approximately equal to $n$. When $R_{w} B Q>S$, the electrical double layer is the primary conduction pathway. When $R_{w} B Q<<S$, the primary conduction pathway is through the pore space. For rocks and soils having low cation-exchange capacities (e.g., clean sands and granite), the primary conduction pathway is through the pore space. For rocks and soils with high cation-exchange capacities (e.g., clays and rocks with zeolite minerals), the primary conduction pathway is the electrical double layer.

Equation 2-3 can be used in ratio form to calculate resistivity changes in the form of resistivity ratios. The analysis that follows assumes that the porosity and cation-exchange capacity remain constant during the test; thus, these terms will cancel when Equation 2-3 is used to calculate resistivity ratios. When the primary conduction pathway is through water in the open pore space, one can assume that the term $\left(S+R_{w} B Q\right)$ in the denominator of Equation 2-3 is approximately equal to $S$. In this case, the resistivity ratio can be calculated as

$$
\frac{R_{a}}{R_{b}}=\frac{R_{w, a}}{R_{w, b}}\left(\frac{S_{b}}{S_{a}}\right)^{2},
$$

where $R_{b}$ and $R_{a}$ are the resistivities before and after heating started, $R_{w, b}$ and $R_{w, a}$ are the water resistivities before and after heating. $S_{b}$ and $S_{a}$ are the saturations before and after heating started; this case will be referred to as model 1 . This equation implies that the temperature dependence of the resistivity change is proportional to the change in water resistivity caused by temperature increases. 
When the primary conduction pathway is through the electrical double layer, one can assume that the term $\left(S+R_{w} B Q\right)$ in the denominator of Equation 2-3 is approximately equal to $R_{w} B Q$. In this case, the ratio form of Equation 2-3 simplifies to

$$
\frac{R_{a}}{R_{b}}=\frac{S_{b}}{S_{a}} \frac{B_{b}}{B_{a}},
$$

where $B_{b}$ and $B_{a}$ are the equivalent conductances of counter-ions in the electrical double layer; this case will be referred to as model 2 . This equation implies that the temperature dependence of the resistivity ratio is caused by changes in counter-ion conductance due to temperature changes. Also note that this model is independent of $R_{w}$. Comparing Equations 2-4 and 2-5, one can see that the resistivity changes caused by saturation changes are largest for model 1, where the primary conduction pathway is through the pore space. One notes that neither of these models accounts for changes in water resistivity caused by rock-water chemical interactions. If chemical reactions cause large changes in the concentration or types of ions in the water, the estimated saturation changes will be in error.

The dependence of resistivity ratios on temperature and saturation for models 1 and 2 is illustrated in Figure 2-4. Both models show qualitatively similar behavior. The resistivity ratio curves assume that the starting conditions are $25^{\circ} \mathrm{C}$ and a saturation of $92 \%$. The following observations are based on model 2. Note that the $25^{\circ} \mathrm{C}$ curve indicates a resistivity ratio of 1.0 (no change condition) for a $92 \%$ saturation. If temperature remains constant at $25^{\circ} \mathrm{C}$ and saturation decreases, the resistivity ratio reaches values greater than 1.0 (i.e., the resistivity is higher than the preheat case, and drying makes the resistivity increase). On the other hand, if the saturation remains constant at $92 \%$ and the temperature increases to $150^{\circ} \mathrm{C}$, the resistivity ratio becomes approximately 0.3 (this means that the resistivity during heating is 0.3 times as high as the preheat resistivity and that heating makes the resistivity go down).

The bottom set of curves in Figure 2-4 shows the trajectory that the resistivity ratio would follow for two different regions near the heater. The trajectory curves assume that the initial conditions were $25^{\circ} \mathrm{C}$ and $92 \%$ initial saturation. The trajectories shown are approximate. For rock very near the heater, temperatures increased to approximately $300^{\circ} \mathrm{C}$, and saturations decreased to $10 \%$ or less. In this case, the temperature and saturation changes have opposing effects: the temperature increases would make the resistivity ratio decrease to less than 1.0, while the saturation decrease tends to increase the resistivity ratio more than 1.0. The approximate trajectory for this case is shown by the red curve near the bottom of Figure 2-4. Note that the resistivity ratio drops below 1.0 as the temperature increases and saturation decreases.

During the early stages of heating, the rock heated up, but relatively little drying had occurred; this causes the temperature effect to dominate over the drying effect. and the resistivity ratio drops to less than 1.0. As heating progresses, the resistivity ratio reaches a minimum near saturation of $40 \%$ and then begins to increase as the temperatures continue to increase and saturation continues to decrease. The resistivity ratio reaches a maximum of about 1.3 when the temperatures have reached approximately $300^{\circ} \mathrm{C}$ and the saturation is $10 \%$. Note that there is a rapid increase in resistivity ratio when the saturation drops to less than 25\%; at low saturation the film of water along which conduction occurs becomes discontinuous, thereby forcing the resistivity to increases rapidly. Thus, when the saturation gets low enough, the effect of drying (which makes the resistivity increase) dominates over the effect of heating (which make the resistivity decrease). 
A second trajectory curve is shown in blue to illustrate the behavior for rock that reaches a maximum temperature of $100^{\circ} \mathrm{C}$ while its saturation increases to $100 \%$. In this case, the increasing temperature and saturation both make the resistivity decrease. Thus, in this case, the resistivity decreases faster than for the previous case.

In the SHT, saturation and temperature were both changing at the same time. For the case of rock near the heater borehole during the heating phase (large increase in temperature and large decrease in saturation), the model 2 curves show that, for temperatures greater than $150^{\circ} \mathrm{C}$, the resistivity ratio will be less than 1.0 if the saturation remains at $20 \%$ or more. This means that the effect of temperature tends to dominate over the effect of saturation because the net effect is one of decreasing resistivity. In other words, the drying effects near the heater make the resistivity decreases created by the rising temperatures less pronounced (closer to a ratio of 1.0). For saturations less than $20 \%$, the drying effect on the resistivity more than makes up for the heating effect, and the net effect is for the resistivity to increase. For the case of rock farther from the heater (smaller increases in temperature and increases in saturation due to condensate imbibition), model 2 indicates that the resistivity ratio will be less than 1.0 in all cases. In other words, saturation increases coupled with rising temperatures make the resistivity decreases more pronounced (the resistivity ratio is smaller than it would be if only one if the effects were present).

Figure 2-4. Resistivity ratios as a function of saturation and temperature for models 1 and 2 (DTN LL980105204244.049)

Curves representing the temperature range of 25 to $300^{\circ} \mathrm{C}$ are shown to illustrate the temperature and saturation dependence of the resistivity ratios. The bottom part of the figure shows resistivity-ratio trajectories for two different rock environments.

The available temperature data were used to construct temperature maps along the ERT image plane. It is necessary to have a reliable temperature measurement for each area (each tomograph pixel) if one wishes to calculate the saturation change. At the SHT, there are many temperatures sensors located along roughly horizontal boreholes. However, the temperature coverage in the vertical direction is sparse, extending only $\pm 1.7 \mathrm{~m}$ from the heater. To construct temperature maps, it was necessary to extrapolate vertically out to $\pm 6.3 \mathrm{~m}$ from the heater. It was also necessary to assume that the vertical temperature gradient equaled the horizontal gradient to obtain physically reasonable temperature values for regions beyond $1.7 \mathrm{~m}$ vertically. Thus, the accuracy of the temperature maps is expected to be good along the horizontal direction but may be in error along the vertical direction for regions farther than 1.7 meters from the heater.

The ERT images provide a measure of change in $\mathrm{R}$ from baseline (through the resistivity ratio). Equations 2-4 and 2-5 can be used to relate electrical resistivity changes to changes in saturation when the temperatures are known and the temperature dependence of $R_{w}$ and $B$ can be calculated. Because the magnitude of $R_{w} B Q$ is changing in space and time, it was decided to estimate the changes in saturation by using both model 1 and model 2 . This approach should provide bounds to the domain of possible saturations that may be present. Available data suggests that the welded tuff at the SHT should show behavior closer to model 2 than to model 1. Assuming average values of cation-exchange capacity for welded tuff of about $3 \mathrm{meq} / 100 \mathrm{~g}$, porosity of 0.10 (porosity is used to calculate Q), and $R_{w}=39$ ohm-m at $25^{\circ} \mathrm{C}$ (resistivity of J-13 water), it can be shown that $R_{w} B Q$ is about 23 at $25^{\circ} \mathrm{C}$ and that it increases as the temperature increases. Given that $S$ ranges from 0.0 to 1.0, 
this result suggests that $R_{w} B Q$ is $>>S$ and thus that the primary pathway for conduction at the SHT is the electrical double layer. Therefore, it is believed that the results of model 2 are probably closer to reality. However, if the cation-exchange capacity, porosity, or water resistivity varied significantly across the ERT image plane, it is possible that model 1 results may be closer to reality.

Figure 2-2 and Figure 2-3 show estimates of saturation (third and fourth columns) based on the resistivity ratios and interpolated/extrapolated maps of temperature. The temperature maps were used to calculate the temperature-dependent properties on models 1 and $2\left(R_{w}, B\right)$. It was assumed that initial saturation $\left(S_{b}\right)$ of the rock unit was $92 \%$; this is the average saturation from grab samples collected along the observation drift and reported in DiBernardo and Wagner (1997, pp. 5-8). Both models indicate that the saturation around the heater decreased as heating time increased. Model 2 generally predicts substantially drier saturations near the heater than does model 1; model 2 saturations near the heater are closer to a priori expectations than those from model 1 . The discussions that follow will be based on the model 2 results.

The saturation estimates produced by model 2 have been used to produce cartoons that highlight the drying and wetting zones interpreted from the moisture estimates. It is hoped that these cartoons facilitate the interpretation of the saturation estimates previously shown in Figure 2-2 and Figure 2-3. The cartoons can be found in Figure 2-5 (heating phase) and Figure 2-6 (cooling phase). The outline of the drying and wetting regions roughly coincide with saturations equal to $70 \%$ or less for the drying zone and $98 \%$ or more for the wetting zone.

Figure 2-5. Interpretation of where the rock lost or gained moisture during the heating phase

The drying and wetting regions in this figure are based on hand tracings made over the model 2 saturation estimates shown in Figure 2-2.

Figure 2-6. Interpretation of where the rock lost or gained moisture during the cooling phase

The drying and wetting regions in this figure are based on hand tracings made over the model 2 saturation estimates shown in Figure 2-3.

A significant region of drying is present around the heater. The dry zone is not centered on the heater and certainly is not symmetric about the heater. The pattern suggests a distribution of moisture that is strongly controlled by fractures. As time increased, the drying zone appeared to propagate upward, especially after 219 days of heating; also, the minimum saturation estimate was near 10\% (model 2). During the cooling phase, the dry zone around the heater appeared to remain relatively stable; an exception to this observation is the result from September 25, 1997, which showed a change in the dry zone near the heater's location.

Drying appears strongest in regions at the heater elevation and above. The lowest imaged moisture content is on May 23, 1997, the last ERT data before the heater was turned off; the saturation estimates indicated that the driest rock had a saturation of about $10 \%$. As the 
temperature field collapsed during the first 29 days of cool down, that extremely dry region remains relatively stable. The rest of the dry zone also appeared stable except for minor changes that imply water is still moving in the rock mass.

Moisture accumulation appears prevalent in regions below and to the sides of the heater, where some rock zones show saturations near or greater than $100 \%$. (In some regions, the saturation is calculated to be greater than $100 \%$-clearly a nonphysical condition because the rock can be no more than fully saturated. It is possible that those regions began as dryer than the $92 \%$ saturation level assumed to be the initial condition for the calculation or that the water resistivity changed because of changes in the concentration or types of ions.) The largest zones near full saturation are mostly located below the heater at the four- and fiveo'clock positions and the seven- and eight-o' clock positions. Smaller zones are visible above the heater elevation at the ten-o'clock and two-o'clock positions. On April 2, 1997 (late heating phase), these regions cover a significant portion of the area below the heater.

The results of June 26, 1997, show the moisture content estimates after 29 days of cooling. The fully saturated regions below the heater appear somewhat smaller, suggesting that some of the water was leaving this area. Between the June 26, 1997, and August 27, 1997, images, the wet regions below and above the heater appeared to be stable. The data from September 25, 1997, indicate a change from the trend above the heater (i.e., above the heater, at the twoo'clock position, a couple of small regions show increased moisture content). It is interesting that wet regions at the two- and eight-o' clock positions on the September 25 data are aligned with a region near the heater that did not dry as much during the course of the heating phase. This pattern suggests the possibility that a fracture or fracture zone was bringing moisture to dry regions near the heater. The final cool-down phase result shown in Figure 2-6 (December $17,1997)$ still shows a clear dry zone around the heater and significant wetting regions on the lower, left flank of the heater. The wetting regions on the lower, right flank of the heater are substantially diminished in size relative to the sequence observed during heating.

The behavior of the wetting zones on the right flank of the heater borehole is different from that of those on the left flank. Note that the wetting zones on the left flank remain relatively large and stable during the course of the cool-down phase. Those on the right flank of the heater appear to break into smaller zones during the cool-down phase. This behavioral difference may indicate differences in rock hydraulic conductivity between the left and right flanks. This may be associated with fractures (see Chapter 7).

The saturation estimates presented here are considered approximate because their accuracy is limited by one or more of the following factors:

- The accuracy of the temperature maps in the vertical direction is limited by the sparse vertical coverage of the temperature sensors. Errors in the interpolated/extrapolated temperature maps will result in erroneous saturation estimates.

- The effects of rock-water chemical interactions on electrical resistivity are not accounted for by the Waxman-Smits conceptual model. This means that, if significant changes develop in the number or types of ions in solution, such changes will cause resistivity changes that the model would treat as saturation changes.

- Laboratory measurements of the electrical resistivity of welded tuff (Roberts and Lin 1997, p. 585) indicate that the Waxman-Smits conceptual model underpredicts resistivity for saturations less than $20 \%$. The estimates of saturation less than $20 \%$ in Figure 2-2 and Figure 2-3 are affected by this limitation. 
- The inversion algorithm used to reconstruct the tomographs finds the smoothed model that fits the data. This means that the structures observed are "smeared" versions of the true target. Thus, the size of the anomalies is larger than that of the true target.

- Work by Llera et al. (1990, p. 576) suggests that growth of microcracks at high temperature can affect electrical resistivity of welded tuff; this effect, if present at the SHT, is not accounted for by the Waxman-Smits conceptual model.

- The resistivity ratios were calculated using a 2-D algorithm; natural heterogeneities such as fractures are likely 3-D. Changes in resistivity occurring along fractures may be distorted by use of the 2-D algorithm.

- Several boreholes containing metallic instruments are located near the plane of interest. These metallic instruments caused large conductive anomalies that may reduce sensitivity to resistivity changes occurring in the rock, thereby resulting in resistivity-change tomographs that show smaller change than those changes present in the rock.

- The Waxman-Smits conceptual model was developed for the case of shale sands. The validity of this model for welded tuff has been only partially investigated by the laboratory work of Roberts and Lin; the temperature dependence implied by the Waxman-Smits conceptual model has not been tested in the laboratory with welded tuff samples.

- The thermal expansion of the water and the bulk rock is assumed to have negligible effects on the saturation.

\subsection{Summary and Conclusions}

To calculate the changes in the rock's electrical resistivity, a data set obtained after heating started was compared to a corresponding data set obtained prior to heating. Resistivity-change tomographs were calculated based on these data. Saturation estimates have been presented. These estimates were calculated using two models derived from the Waxman-Smits equation, the resistivity ratio tomographs, and maps of interpolated temperatures. It is believed that, of the two models considered, the model that assumes dominant surface conductance (model 2) may provide the most accurate estimates.

During the heating phase, the resistivity-change tomographs show a region of decreasing resistivity approximately centered around the heater. The size of this region grew with time, and the resistivity decreases became stronger. The resistivity decreases migrated downward as heating progressed. The resistivity-ratio tomographs show that heterogeneities in the rock (e.g., fractures) are probably affecting drying and wetting in the rock mass. The complex and irregular pattern in the images was interpreted as changes in moisture content due to drying and wetting along fracture systems having a complex 3-D geometry. As the temperature increased above ambient, the vapor pressure in the pores increased. Fractures connected pneumatically to the drift will provide a pressure gradient so that moisture will leave the rock through fracture openings and move along the fractures in response to buoyancy or thermally driven pressure gradients. The result will be dryer zones along fractures near the heater, but wetter zones along fractures further away, where temperature and pressure allow condensation below the local dew point.

During the cooling phase, the resistivity around the heater increased relative to the preheat case, and the saturation estimates showed a region of drying around the heater. The dry region shape appeared to be controlled by heterogeneities in the formation (fractures). 
The dry region appeared to remain stable throughout most of this time; by September 25, 1997, small increases in moisture content could be seen for regions above the heater at the two-o' clock position. These increases disappeared by the time of the December 27, 1997, tomographs. Wetter rock regions observed below the heater slowly became smaller early in the cooling phase, up to the September 25, 1997, results. The wetting zones on the lower left flank appeared to grow in size, as shown on the December 17, 1997, tomographs. The reasons for the apparent enlargement are unknown; perhaps they are due to activities, unrelated to the test, that may have spilled water along the access/observation drift.

The saturation estimates presented can be used as the basis for a conceptual model of thermohydrologic (TH) behavior (shown in Figure 2-7). The model shows a hot boiling zone in which a large fraction of the steam produced during heating moves away from the hot boiling region and condenses. Some of this condensate slowly imbibes into the cooler surrounding rock and causes the saturation to increase. The rest of the condensate drains along fractures to lower-elevation regions. The zones of saturation increase located above the heater elevation are smaller in size than those below the heater because condensate drains quickly from the zones above the heater elevation. Zones below the heater elevation receive condensate generated locally as well as condensate draining from regions above; this allows larger amounts of water to be imbibed below the heater.

Figure 2-7. Conceptual model of TH behavior during the SHT, which is consistent with the saturation estimates presented in Figure 2-2 and Figure 2-3

\subsection{References}

DiBernardo, M., and Wagner, R. 1997. Ambient Characterization of the Drift-Scale Test Block. BADD00000-01717-5705-00001 REV 00. Las Vegas, Nevada: TRW, Inc., Yucca Mountain Site Characterization Project.

Llera, F., Sato, M., Nakasuka, K., and Yokohama, H. 1990. “Temperature dependence of the electrical resistivity of water-saturated rocks." Geophysics 55(5):576-585.

Morelli, G., and LaBrecque, D. 1996. "Robust scheme for ERT inverse modeling." In proceedings from Symposium on the Application of Geophysics to Engineering and Environmental Problems. Keystone, Colorado: April 28-May 2, 1996.

Roberts, J.J., and Lin, W. 1997. "Electrical properties of partially saturated Topopah Spring tuff: Water distribution as a function of saturation." Water Resources Res. 33(4):577-587. LLNL report under MOL.19961014.0060. (Also UCRL-JC-123763, Lawrence Livermore National Laboratory, Livermore, California)

Waxman, M.H., and Thomas, E.C. 1974a. "Electrical conductivities in shaly sands: I. The relation between hydrocarbon saturation and resistivity index." J. Petrol. Tech. Feb:213-218. NNA.19000703.0124. (Transactions AIME, 257)

Waxman, M.H., and Thomas, E.C. 1974b. “Electrical conductivities in shaly sands: II. The temperature coefficient of electrical conductivity." J. Petrol. Tech. Feb:218-225. (Transactions AIME, 257) 

Chapter 2 Figures 



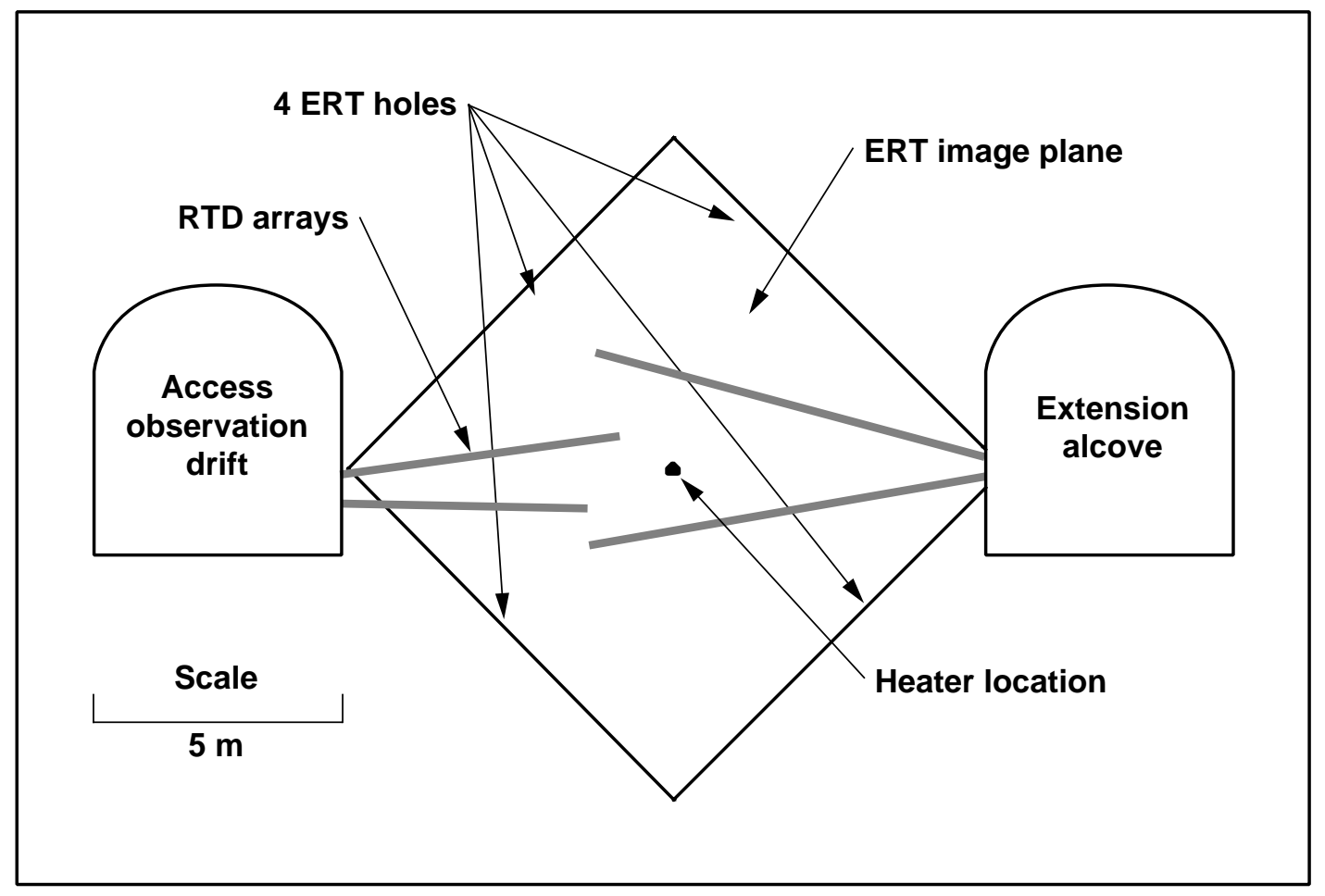

Figure 2-1. The borehole layout relative to the drifts and the RTD boreholes. Twenty-eight electrodes distributed among the four holes were used to conduct ERT surveys around the heater. 
Resistivity ratio
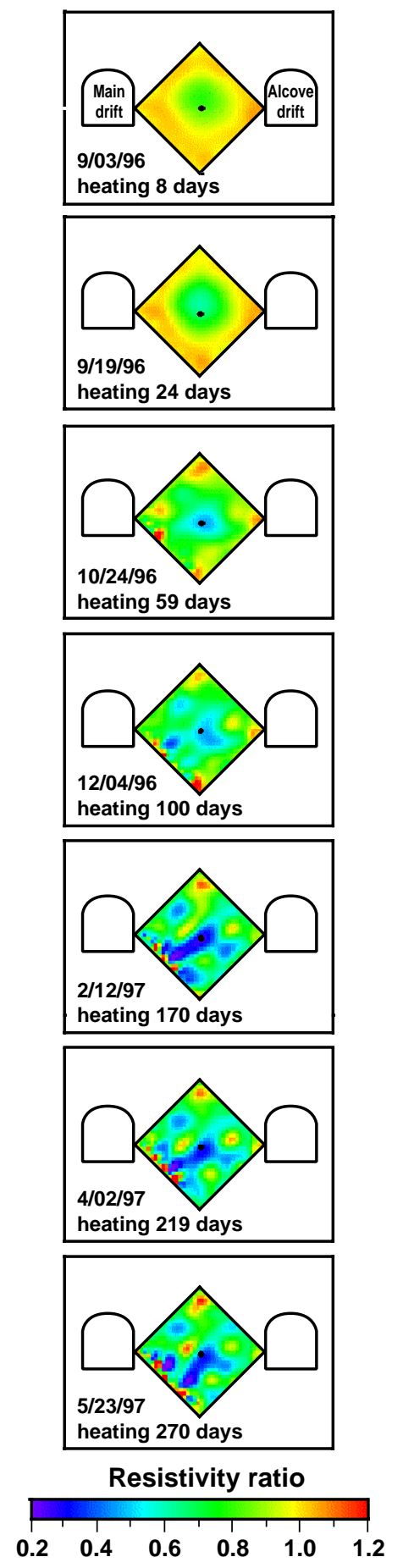

Interpolated temperatures along ERT plane
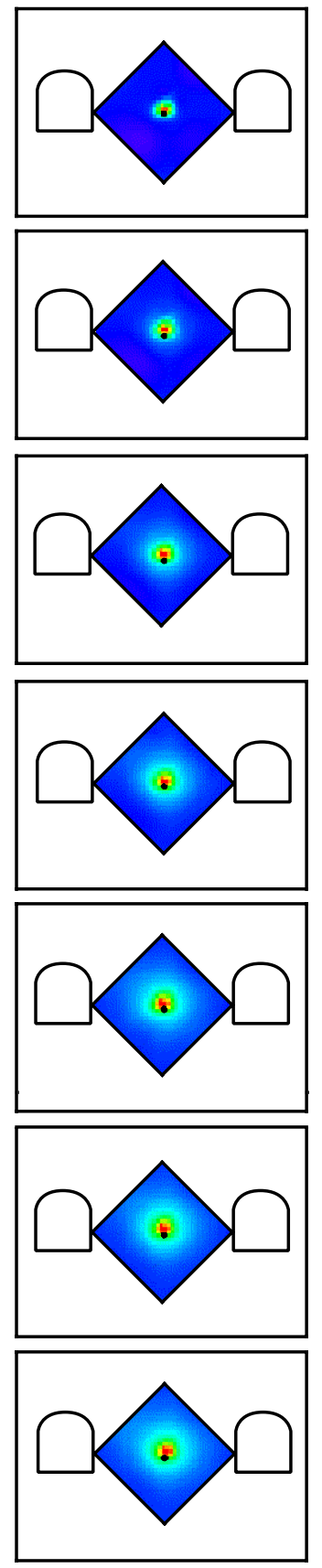

Temperature $\left({ }^{\circ} \mathrm{C}\right)$

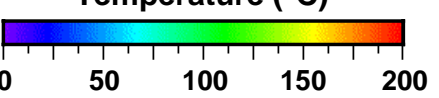

Saturation estimate
from model 1 assuming
0.92 initial saturation
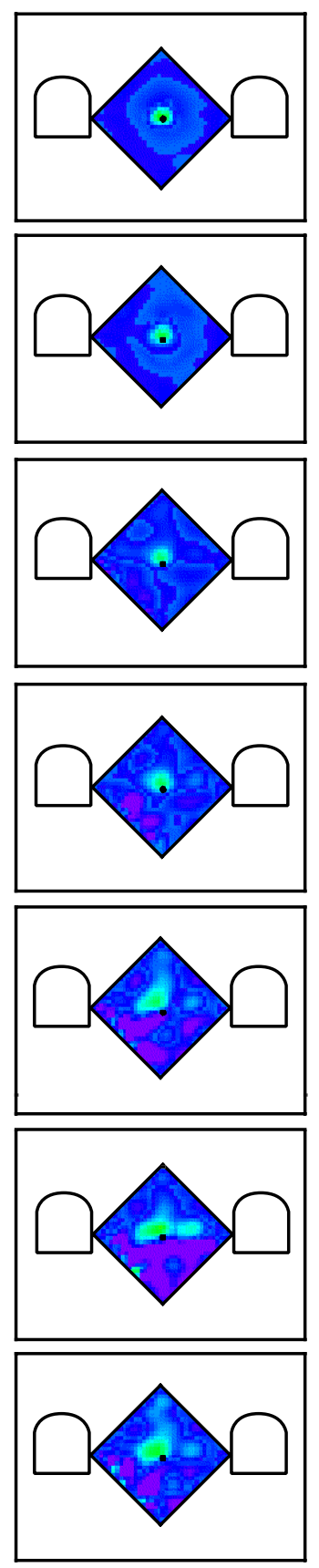

Saturation estimate

from model 2 assuming

0.92 initial saturation
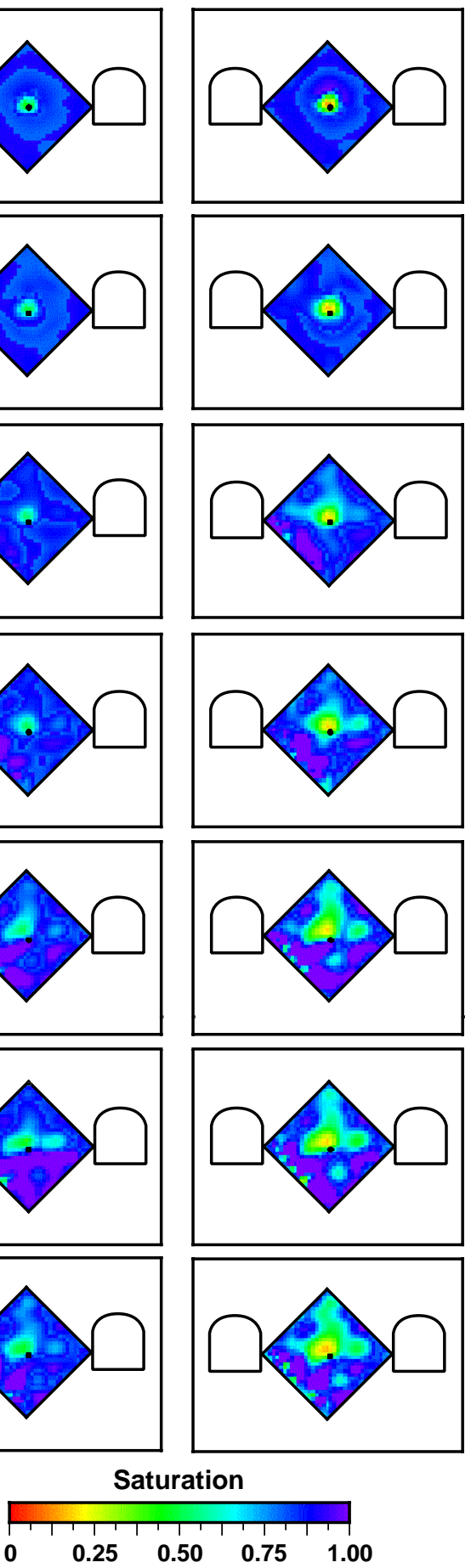

Figure 2-2. Resistivity-ratio tomographs during the heating phase (left column of images). Also shown are corresponding temperature maps ( second column from the left). The results of the saturation calculations are shown by the images in the third and fourth columns. The estimates of saturation assume that the initial saturation is $92 \%$ and are based on two models (described in the text) relating moisture content to resistivity. 
Resistivity ratio
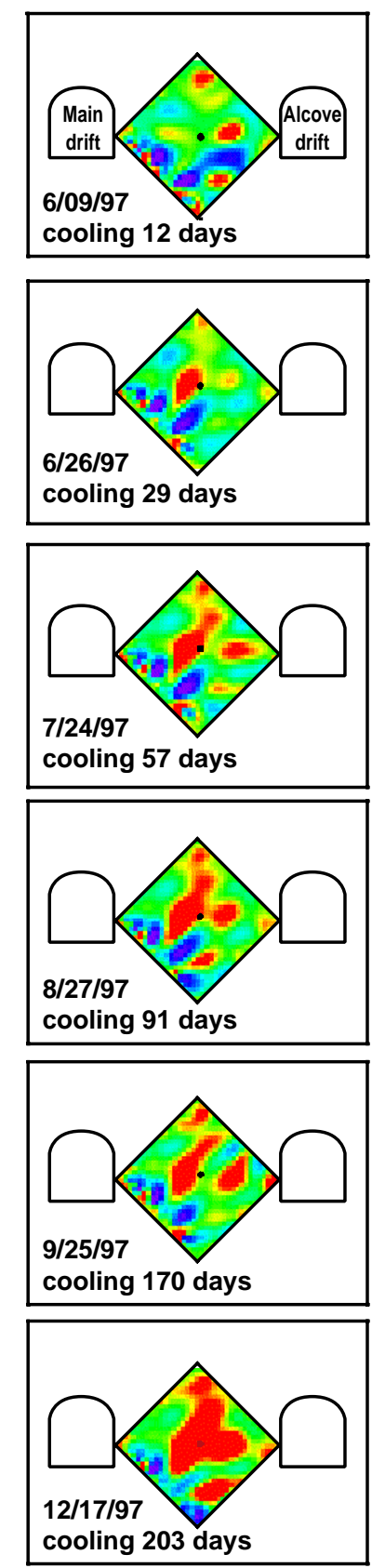

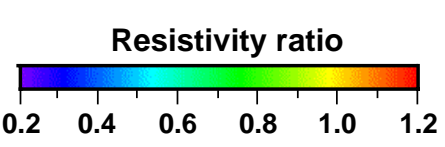

Interpolated

temperatures along ERT plane
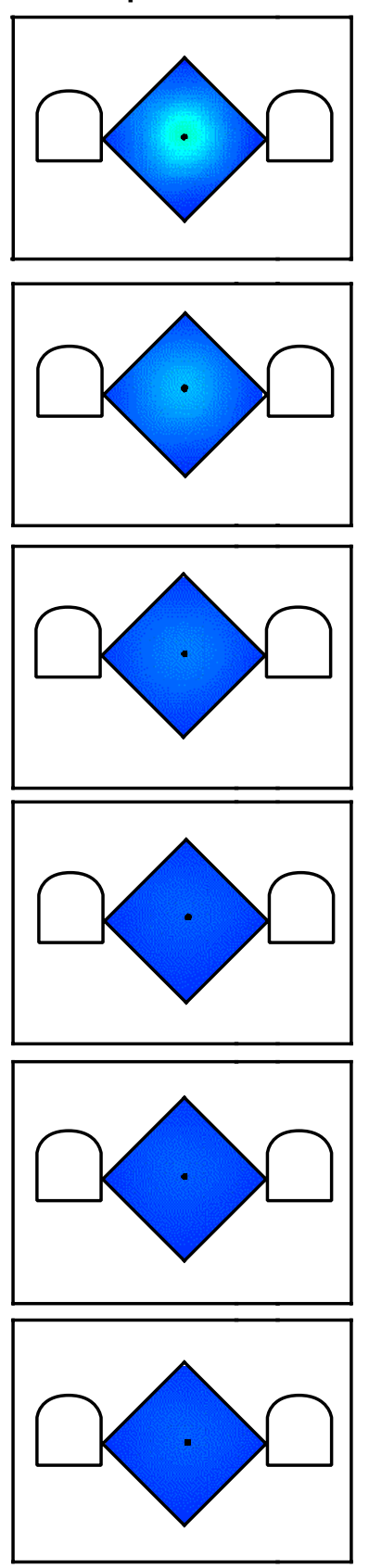

Temperature $\left({ }^{\circ} \mathrm{C}\right)$

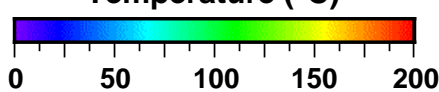
Saturation estimate
from model 1 assuming
0.92 initial saturation
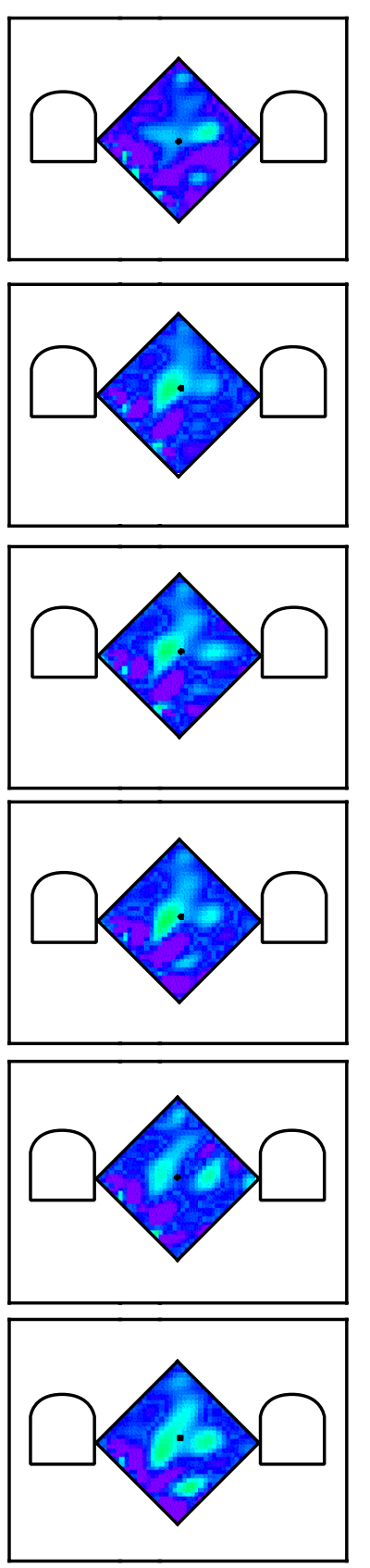

Saturation

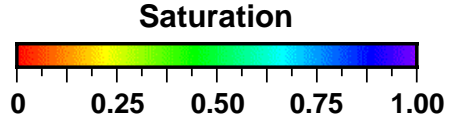

Saturation estimate from model 2 assuming 0.92 initial saturation
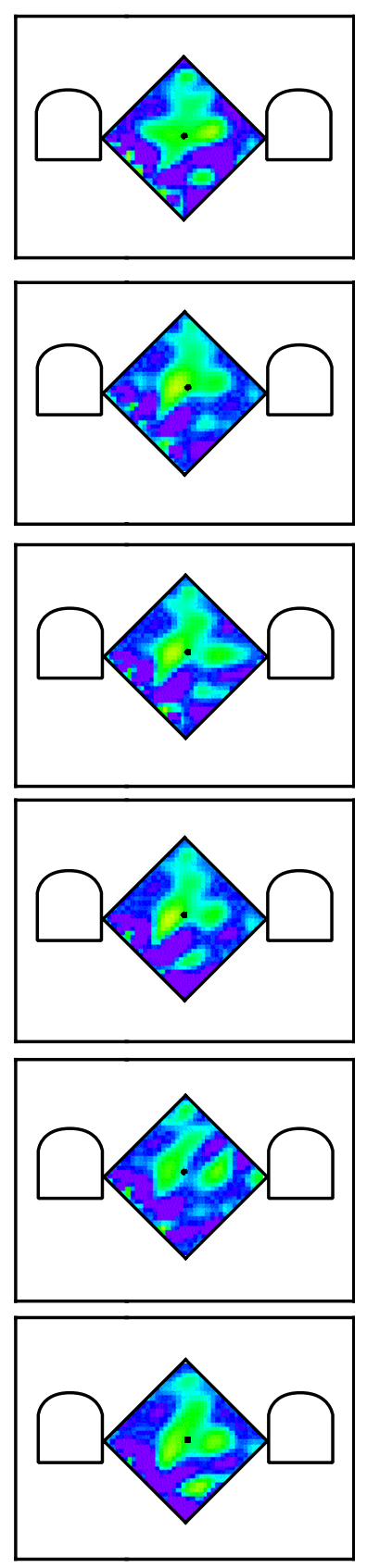

Figure 2-3. Resistivity-ratio tomographs during the cooling phase (left column of images). Also shown are
corresponding temperature maps (second column from the left). The results of the saturation calculations are shown by the images in the third and fourth columns. The estimates of saturation assume that the initial saturation is $92 \%$ and are based on two models (described in the text) relating moisture content to resistivity. 

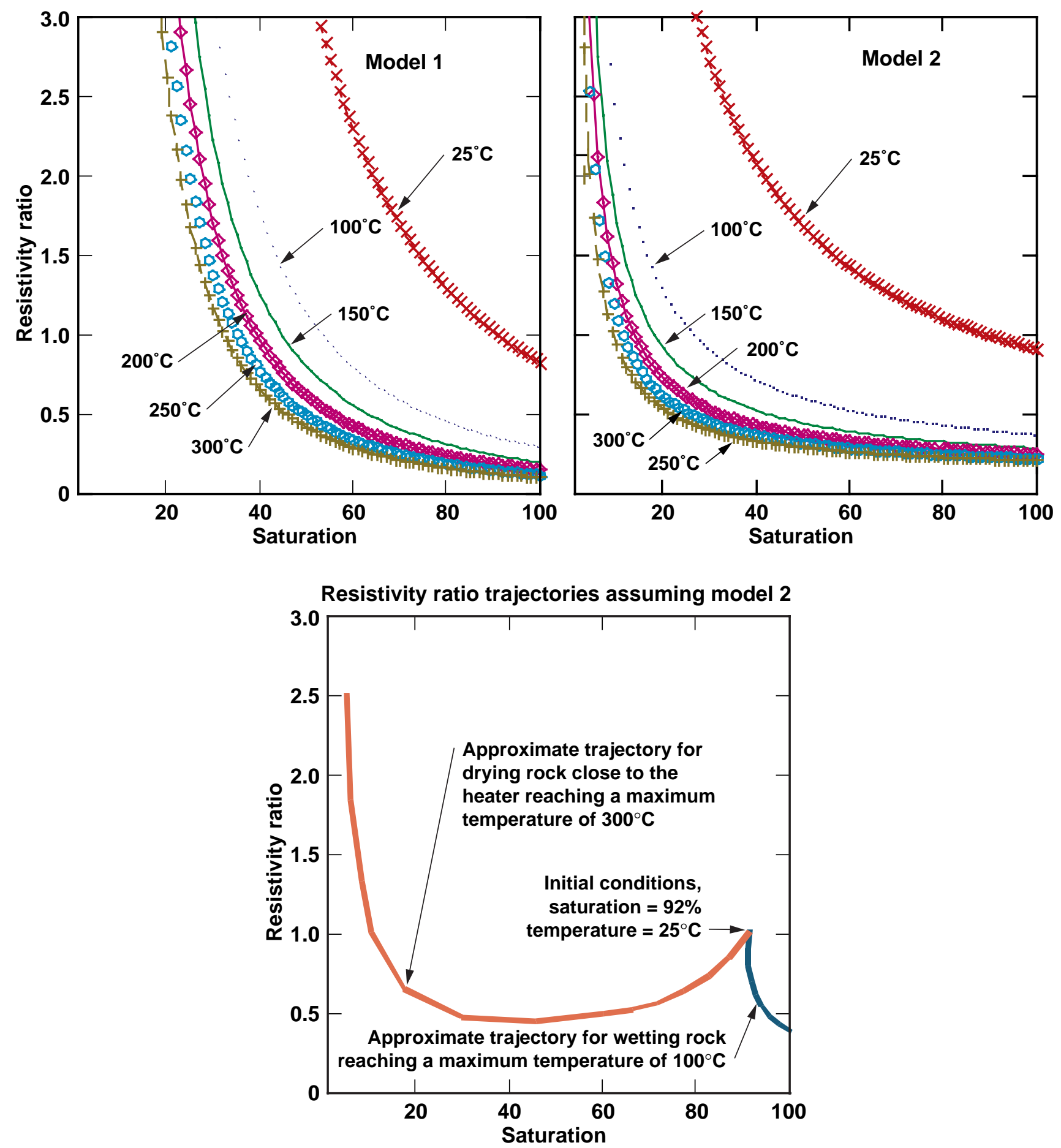

Figure 2-4. Resistivity ratios as a function of saturation and temperature for models 1 and 2. Curves representing the temperature range of 25 to $300^{\circ} \mathrm{C}$ are shown to illustrate the temperature and saturation dependence of the resistivity ratios. The bottom part of the figure shows resistivity-ratio trajectories for two different rock environments. 

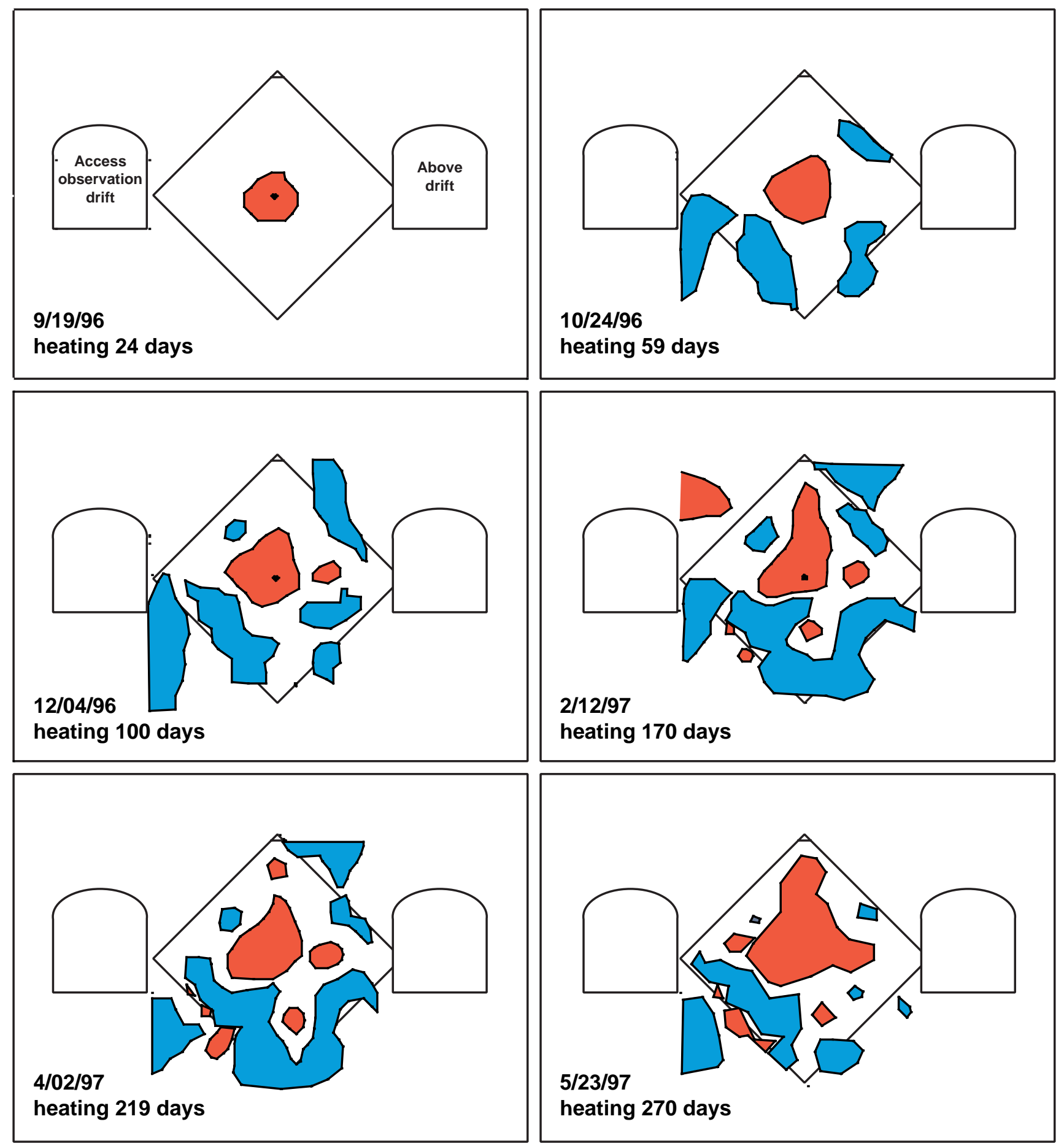

Wetting regions

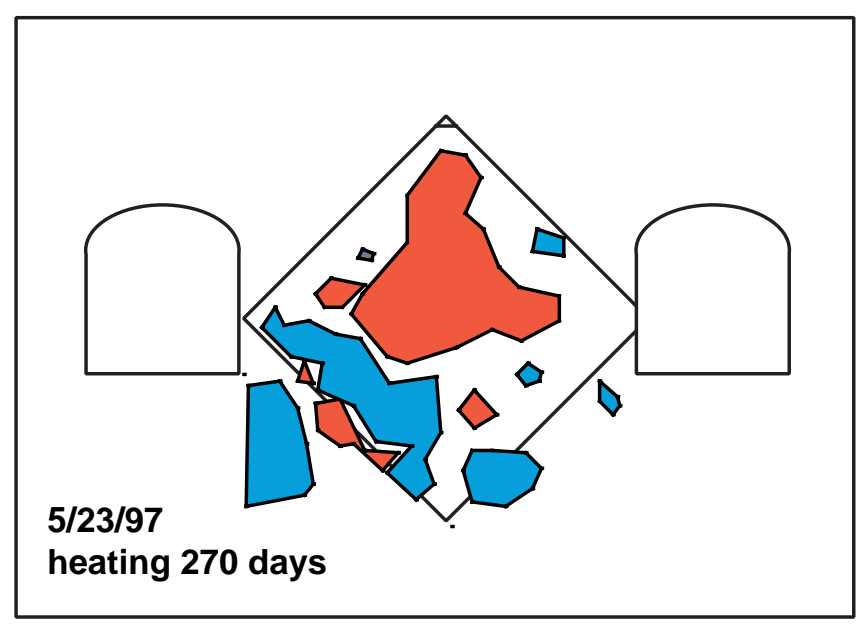

$5 / 23 / 97$

heating 270 days

Drying regions

Figure 2-5. Interpretation of where the rock lost or gained moisture during the heating phase. The drying and wetting regions in this figure are based on hand tracings made over the model 2 saturation estimates shown in Figure 2-2. 

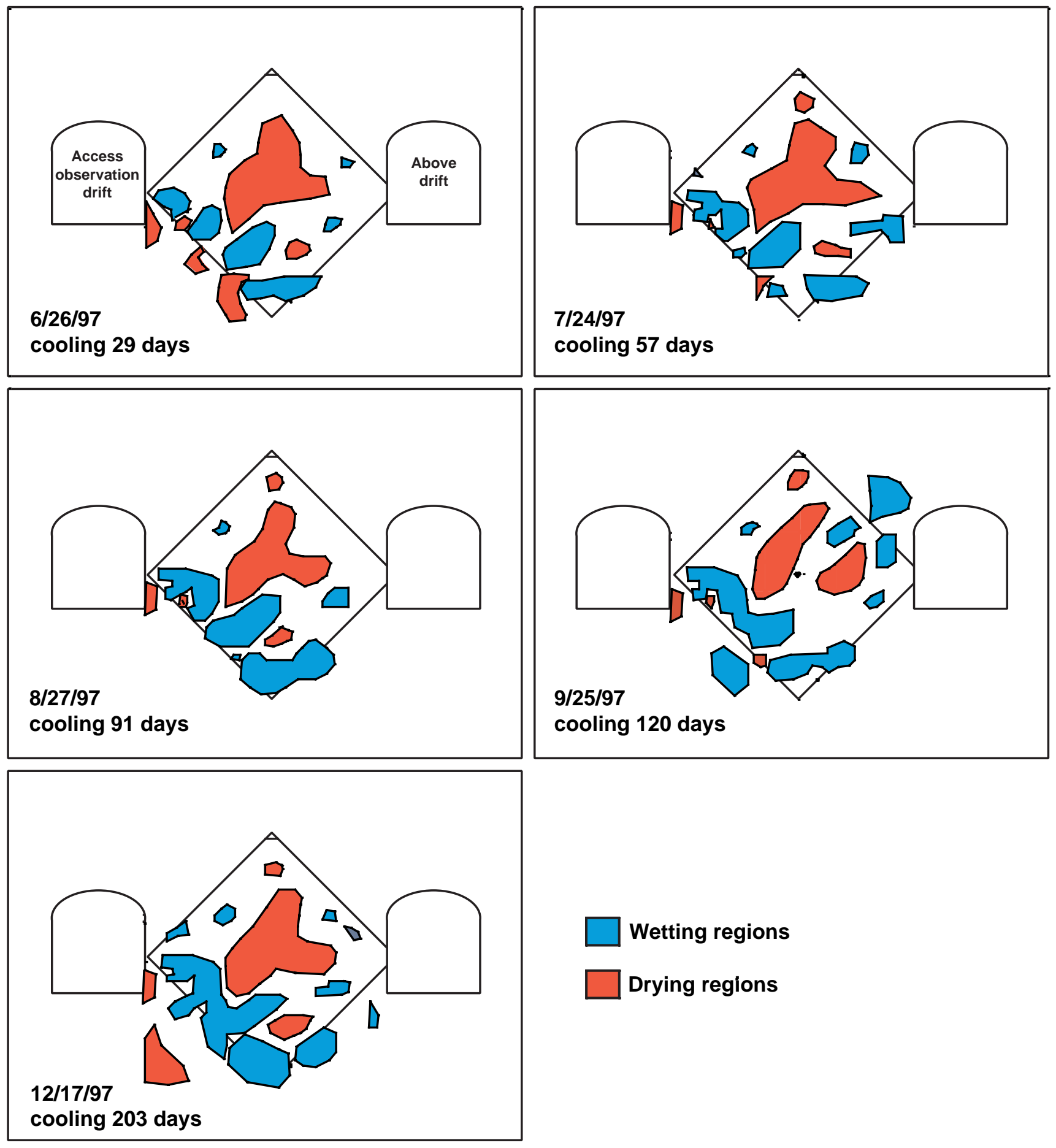

Wetting regions

Drying regions

Figure 2-6. Interpretation of where the rock lost or gained moisture during the cooling phase. The drying and wetting regions in this figure are based on hand tracings made over the model 2 saturation estimates shown in Figure 2-3. 


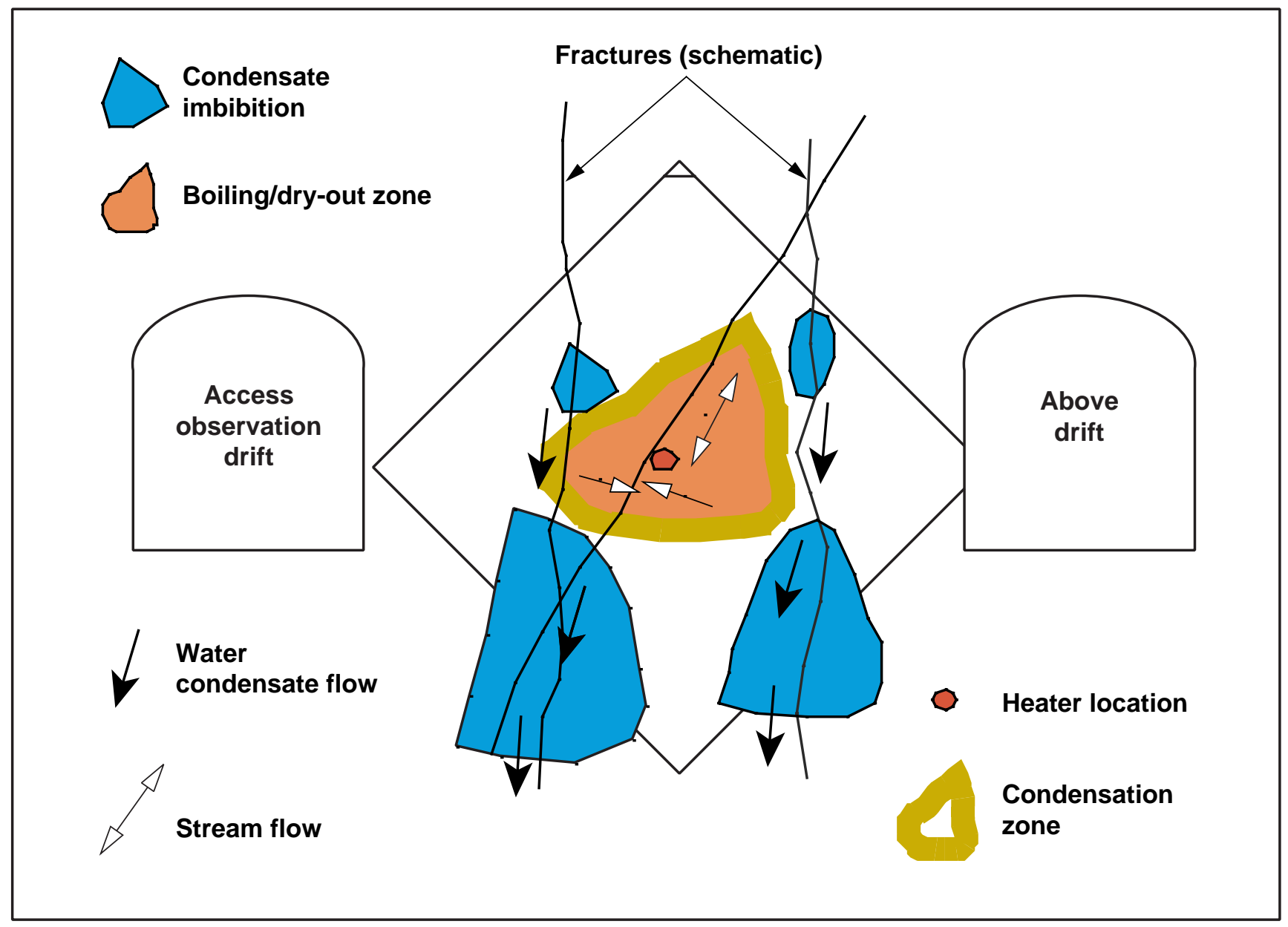

Figure 2-7. Conceptual model of TH behavior during the SHT, which is consistent with the saturation estimates presented in Figure 2-2 and Figure 2-3 



\title{
3. Neutron-Logging Measurements
}

\author{
by Wunan Lin, Richard Carlson, and Don Watwood
}

\subsection{Introduction}

Thermal neutron-logging is used to determine moisture content in rocks and soils and was used to monitor moisture content in Boreholes 15, 17, 22, and 23 (see Figure 1-1) during the Single-Heater Test (SHT). The neutron probe contains a source of high-energy neutrons and a detector for slow (thermal) neutrons. Because of the presence of hydrogen in it, water present in rocks slows down the neutrons, making them detectable. Thus, higher counts (or a positive difference in counts relative to background or pre-heat levels) indicate higher water content (or increased water content over background).

The probe used in this test is a Campbell Pacific Nuclear (CPN) model 503DR. A 3.81-cm (1.5-in.) diameter probe (serial number H37067677) was used for the SHT. Under ambient conditions, the sampling volume surrounding the probe has a diameter of approximately $15 \mathrm{~cm}$; this volume diameter increases as moisture content decreases. Measurements are sensitive to the presence of elements, such as chlorine and boron, that have large neutroncapture cross sections. The uncertainty of the neutron logging is about 3 to $5 \%$ in water content.

For the SHT, a Teflon ${ }^{\mathrm{TM}}$ tube, with a resistance temperature device (RTD) bundle mounted on its outside, was inserted into the boreholes and grouted into place. The Teflon ${ }^{\mathrm{TM}}$ tube permits easy insertion, placement, and removal of the tool. Calibrations of the neutron tool in a liner-RTD-grout assembly identical to that used in the holes were conducted by Richard Carlson and Dan Neubauer, as described subsequently in this chapter. Relative change in water content is calculated from the neutron counts using the calibration results.

As mentioned previously, the heating phase of the SHT was from August 23, 1996, to May 28, 1997; the cooling phase was from May 28, 1997, to January 15, 1998.

\subsection{Measurement Procedures}

The following procedure describes the method of collecting neutron data during the SHT. The 3.81-cm diameter probe and a counting time of $16 \mathrm{sec}$ were used. Standard counts, which are the neutron counts when the tool is in the tool holder away from any influence of the rock mass to be measured, were measured and recorded immediately prior to and subsequent to performing measurements. The neutron probe was placed in a borehole at a specific location, and the neutron count was recorded in a scientific notebook as well as electronically in the device memory. Upon completion of the test, data were downloaded to a computer, and the data values were checked against the hand-recorded values. Data were recorded at depth intervals of $10 \mathrm{~cm}$ in each borehole.

Eighteen neutron loggings were conducted during the heating and cooling phases of the SHT. The data were smoothed in both the space and time domains using a three-point smoothing algorithm, which weights the middle point by 0.6 and the two side points by 0.2 each. The smoothing made the data look smoother but did not significantly change the amplitude of the differences in the fraction volume water. All of the in-heat and cool-down data up to December 17, 1997, are presented in this chapter. 
The test of the coupled thermal-hydrologic-chemical-mechanical (THCM) processes focuses on the change in effect of heat on the behavior of the rock mass. Therefore, presented is the difference of the water content in the rock mass between the pre-heat background (measured on August 21, 1996) and that on the dates of measurement listed on the figures. The heaters were turned on at 1:30 p.m. on August 26, 1996. The heater was turned off on May 28, 1997, which was 275 days after the heater was energized. Two neutron logs were conducted during the first month of the in-heat and cool-down phases.

\subsection{Calibration of the Neutron Tool}

The neutron measurement boreholes at the SHT are lined with Teflon ${ }^{\mathrm{TM}}$ tubing, and the annulus is sealed with grout. The liner inside diameter is $4.04 \mathrm{~cm}$ to just past the $3.81 \mathrm{~cm}$ tool, and the liner has a $0.381-\mathrm{cm}$ thick wall. The holes were drilled at $7.62 \mathrm{~cm}$ to provide space for RTD wires to measure temperature in the same borehole. The $1.41-\mathrm{cm}$ annulus of water-rich grout was expected to affect the response of the probe, thus a special calibration for this geometry was required.

To calibrate the CPN moisture probe in terms of volume fraction of water, a $7.62-\mathrm{cm}$ walled aluminum tubing was installed along the centerline of each of five 55-gal. drums; each annular space was filled with a mix of sandlike material to achieve a known density and hydrogen content (water content equivalent). Grout was then poured around a piece of the Teflon ${ }^{\mathrm{TM}}$ liner inside a slightly undersized piece of the aluminum tubing, so the grout/liner assembly would slide snugly inside the tubes in the drums. Counts were then taken with both the probe and the grout/liner assembly at various heights in each drum to check for homogeneity and edge effects in the vertical direction; long counts were taken in the central regions to improve statistics on the values actually used for calibration. Because RTDs were installed in the annular space between the Teflon ${ }^{\mathrm{TM}}$ liner and the borehole wall, the calibration procedures were also repeated in a grout-liner-RTD assembly. To check for neutron loss from the finite-sized drums, additional counts were taken with a 100-lb bag of tabular alumina, one of the mix constituents, placed against the side of the drum; that increased the radius by $15 \mathrm{~cm}$. The raw counts were then adjusted for the loss as described subsequently.

It is clear that the density of the rock will change over the course of the SHT. However, it is not expected that the solid parts of the rock will change appreciably; only the amount of water in the pores will change. Thus, if the calibration is constructed in terms of water and dry density, the density effects can be absorbed into constants. Initial information indicated the porosity at the SHT was approximately $13 \%$, and the density was about $2.2 \mathrm{gm} / \mathrm{cc}$. It was decided to build 3 drums with dry density $2.2 \mathrm{gm} / \mathrm{cc}$ and with 0,5 , and $10 \mathrm{vol} \%$ water (drums a, b, and c in Table 3-1). To control for density variations, two additional drums were built; they had dry density $1.8 \mathrm{gm} / \mathrm{cc}$ and 0 and 10 vol\% water (drums d and e in Table 3-1). The weight fraction water was precisely controlled by digital scales. Density, however, was determined (after the mix was vibrated in place) by how high a given weight of mix increased the fill height in the drum. The recipe for the mix was determined by trial and error on small samples, and the entire drum was filled in approximately $12.7 \mathrm{~cm}$ lifts of that recipe. For each lift, the mix was vibrated, leveled, and packed, and the fill height was measured to within $0.16 \mathrm{~cm}$. The total fill height was about $81.28 \mathrm{~cm}$; thus, density and volume fraction water are known to about $2 \%$ of value in each lift and to about $1 \%$ of value overall. 
The five drums are represented as $a, b, c, d$, and e in Table 3-1. The first four rows of the table show the raw counts ("raw count"), the total density ("density") in gm/cc, the vol\% water (" $\mathrm{H}_{2} \mathrm{O}$ "), and the dry density ("dry dens") in gm/ cc obtained for the drums. The fifth row ("100lb TA") is the count obtained with the extra $100 \mathrm{lb}$ of material against the side of the drum, and the sixth row ("dcnt/dTA") gives the change in count between row 1 and row 5. The seventh row ("dw/ d6"“) is the weight of that drum's mix needed to add 6 in. $(15 \mathrm{~cm})$ to the drum radius (about the thickness of the 100-lb bag), and the eighth row, labeled "loss," gives the expected count change if that were done; this equals dcnt/dTA times $\mathrm{dw} / \mathrm{d} 6$ " divided by 100. The "loss" is shown in term of the fraction of the total count in the ninth row ("fr loss"). The values in row 9 multiplied by the densities in row 2 are shown in row 10 ("fr loss*den"). The values in row 10 are nearly equal, except for drum $b$ which is very different. Eliminating the drum $b$ value and averaging the rest gives a value of 0.1424 , which is used to calculate the count on row 11 ("count"): Count (row 11) = raw count (row $1)^{*}[1+0.1424 /$ density (row 2)]. The count in row 11 is the expected count for an infinite drum of that density and water content. To make plots, one needs dry densities that do not change with water content. Appropriate density values are shown on row 12 ("adj den"); these are calculated using a dry density of $2.1464 \mathrm{gm} / \mathrm{cc}$ and the associated water content. The counts in row 13 ("adj count") were then calculated by taking into account the effect of density. The effect of density on the count was determined from the raw count (row 1) and density (row 2) data in columns a and d. The "adj count" (row 13) are used to calculate volume water content from measured counts.

There are a number of ways to fit equations to these calibration data. Water values given in this chapter are generated from count data using the equation for the line through the upper two water-content points for dry density $2.1464 \mathrm{gm} / \mathrm{cc}$. These are the values closest to SHT conditions. Further calibration work is planned to better define the linearity of the probe response, especially in the region above $10 \%$ water where one currently must extrapolate.

Table 3-1. Probe-Calibration Data (DTN LL971004604244.045)

\begin{tabular}{|c|l|c|c|c|c|c|}
\cline { 2 - 7 } \multicolumn{1}{c|}{} & \multicolumn{1}{c|}{ Drum } & a & b & c & d & e \\
\hline \hline $\mathbf{1 .}$ & raw count & 3358 & 6453 & 9078 & 2512 & 7774 \\
\hline $\mathbf{2 .}$ & density $(\mathrm{gm} / \mathrm{cc})$ & 2.155 & 2.195 & 2.201 & 1.789 & 1.839 \\
\hline $\mathbf{3 .}$ & $\mathrm{H}_{2} \mathrm{O}$ & 0 & 0.0486 & 0.096 & 0 & 0.0967 \\
\hline $\mathbf{4 .}$ & dry dens $(\mathrm{gm} / \mathrm{cc})$ & 2.155 & 2.1464 & 2.105 & 1.789 & 1.7423 \\
\hline $\mathbf{5 .}$ & $100 \mathrm{lb}$ TA & 3414 & 6622 & 9227 & 2575 & 7955 \\
\hline $\mathbf{6 .}$ & dcnt/dTA & 56 & 169 & 149 & 63 & 181 \\
\hline $\mathbf{7 .}$ & dw/d6" & 418.7 & 426.4 & 427.6 & 347.5 & 357.3 \\
\hline $\mathbf{8 .}$ & loss & 234.4 & 720.7 & 637.1 & 219.0 & 646.6 \\
\hline $\mathbf{9 .}$ & fr loss & 0.06526 & 0.10046 & 0.06558 & 0.08018 & 0.07679 \\
\hline $\mathbf{1 0 .}$ & fr loss*den & 0.14064 & 0.22051 & 0.14434 & 0.14343 & 0.14122 \\
\hline $\mathbf{1 1 .}$ & count & 3580 & 6872 & 9665 & 2712 & 8376 \\
\hline $\mathbf{1 2 .}$ & adj den $(\mathrm{gm} / \mathrm{cc})$ & 2.146 & 2.195 & 2.242 & 1.789 & 1.886 \\
\hline $\mathbf{1 3 .}$ & adj count & 3560 & 6872 & 9813 & 2712 & 8542 \\
\hline
\end{tabular}




\subsection{Data and Discussion}

All the moisture content data determined by neutron logging is included in this chapter. The fraction volume water calculated from the neutron counts at every $10 \mathrm{~cm}$ in each borehole is presented in this chapter. The fraction volume water content as a function of time at some locations in each borehole is also presented. The neutron results are presented as the difference in water content between the in-heat measurements, which were conducted after the heater was energized on August 26, 1996, and the pre-heat background data, which were obtained on August 21, 1996. Therefore, in the following figures, the positive difference fraction volume water means gaining moisture content, and negative difference fraction volume water means drying. The fraction volume water results depicted in the following figures are presented on the same scale so that comparisons can be easily made. Saturation level in the rock mass can be calculated by dividing the fraction volume water by the fraction porosity of the rock mass. For example, if the porosity of the rock is 0.1 , a difference fraction volume water of 0.01 equals a change of $10 \%$ in saturation level.

Figure 3-1 through Figure 3-9 show the difference fraction volume water in Borehole 15 as a function of depth from the collar on various dates of in-heat and cool-down phase measurements. Figure 3-10 shows the water content in this borehole at various depths from collar as a function of time. The 0 day in Figure 3-10 is the date the heater was turned on. Borehole 15 is above the heater and has an inclination of about 17 degrees (CRWMS M\&O 1997b, Table 3-1). The shortest distance between the hole and the heater is about $2.07 \mathrm{~m}$, at approximately $5.75 \mathrm{~m}$ from the collar of the hole. The peak temperature in this borehole before the heater was de-energized was approximately $62^{\circ} \mathrm{C}$. A slight decrease in fraction volume water content began to develop at the closest point between the heater and the borehole in October 1996. This decrease in the water content reached approximately 0.004 on May 21, 1997. If one assumes a porosity of 0.13 (CRWMS M\&O 1997a, Table 5-3), the maximum saturation level decrease was about 3\%. A similar decrease in the moisture content was also observed at about $1.5 \mathrm{~m}$ from the collar of the borehole. During the cooling phase, the neutron results show a slight rewetting, especially at the closest point between the heater and the borehole, as shown by Figure 3-6 through Figure 3-10.

Figure 3-1. Smoothed difference fraction volume water content in Borehole 15 as a function of depth from collar on September 6, 1996, and September 19, 1996 (DTN LL971004604244.045)

Figure 3-2. Smoothed difference fraction volume water content in Borehole 15 as a function of depth from collar on October 24, 1996, and November 26, 1996 (DTN LL971004604244.045)

Figure 3-3. Smoothed difference fraction volume water content in Borehole 15 as a function of depth from collar on January 16, 1997, and January 30, 1997 (DTN LL971004604244.045)

Figure 3-4. Smoothed difference fraction volume water content in Borehole 15 as a function of depth from collar on February 27, 1997, and March 26, 1997 (DTN LL971004604244.045) 
Figure 3-5. Smoothed difference fraction volume water content in Borehole 15 as a function of depth from collar on April 30, 1997, and May 21, 1997 (DTN LL971004604244.045)

Figure 3-6. Smoothed difference fraction volume water content in Borehole 15 as a function of depth from collar on June 10, and June 24, 1997 (DTN LL971004604244.045)

Figure 3-7. Smoothed difference fraction volume water content in Borehole 15 as a function of depth from collar on July 23, and August 26, 1997 (DTN LL971004604244.045)

Figure 3-8. Smoothed difference fraction volume water content in Borehole 15 as a function of depth from collar on September 25, 1997, and October 29, 1997 (DTN LL980196904244.051)

Figure 3-9. Smoothed difference fraction volume water content in Borehole 15 as a function of depth from collar on November 24, 1997, and December 17, 1997 (DTN LL980196904244.051)

Figure 3-10. Smoothed difference fraction volume content at various depths in Borehole 15 as a function of time (DTN LL980196904244.051)

The neutron logging results in Borehole 17 as a function of depth from the collar on various dates of the in-heat and cool-down phase measurements are shown in Figure 3-11 through Figure 3-19. Figure 3-20 shows the water content in this hole at various depths from collar as a function of time. The 0 day in Figure 3-20 is the day the heater was turned on. Borehole 17 is below the heater and has a decline angle of about 7 degrees (CRWMS M\&O 1997b, Table 3-1). The shortest distance between the heater and this borehole is about $1.2 \mathrm{~m}$, at approximately $6.48 \mathrm{~m}$ from the collar of the hole. The peak temperature in this borehole before the heater was turned off was approximately $90^{\circ} \mathrm{C}$. A well-defined trend of drying was observed on November 26, 1996, at just below the closest point to the heater. The maximum decrease in the fraction volume water content in this borehole was approximately 0.010 , which equals a decrease in saturation level of about $8 \%$, again assuming a porosity of 0.13 . This region of decrease in the water content later extended to the bottom of the borehole. The width of the drying region in this borehole is greater than that in other boreholes. An increase in the water content was also observed near the collar of the borehole. The amplitude of that increase in the water content was approximately 0.01 . The abnormally low fraction volume water on January 16, 1997, at about $5.5 \mathrm{~m}$ from the collar (Figure 3-13) is probably due to a measurement error, not to the water content in the rock. Figure 3-16 to Figure 3-20 show that no change in the moisture content was observed during the cool-down phase, except at $4.46 \mathrm{~m}$ from the collar, where the decrease in the water content was slightly recovered after the cool-down phase started (Figure 3-20).

Figure 3-11. Smoothed difference fraction volume water content in Borehole 17 as a function of depth from collar on September 6, 1996, and September 19, 1996 (DTN LL980196904244.051) 
Figure 3-12. Smoothed difference fraction volume water content in Borehole 17 as a function of depth from collar on October 24, 1996, and November 26, 1996 (DTN LL980196904244.051)

Figure 3-13. Smoothed difference fraction volume water content in Borehole 17 as a function of depth from collar on January 16, 1997, and January 30, 1997 (DTN LL980196904244.051)

Figure 3-14. Smoothed difference fraction volume water content in Borehole 17 as a function of depth from collar on February 27, 1997, and March 26, 1997 (DTN LL980196904244.051)

Figure 3-15. Smoothed difference fraction volume water content in Borehole 17 as a function of depth from collar on April 30, 1997, and May 21, 1997 (DTN LL980196904244.051)

Figure 3-16. Smoothed difference fraction volume water content in Borehole 17 as a function of depth from collar on June 10, 1997, and June 24, 1997 (DTN LL980196904244.051)

Figure 3-17. Smoothed difference fraction volume water content in Borehole 17 as a function of depth from collar on July 23, 1997, and August 26, 1997 (DTN LL980196904244.051)

Figure 3-18. Smoothed difference fraction volume water content in Borehole 17 as a function of depth from collar on September 25, 1997, and October 29, 1997 (DTN LL980196904244.051)

Figure 3-19. Smoothed difference fraction volume water content in Borehole 17 as a function of depth from collar on November 24, 1997, and December 17, 1997 (DTN LL980196904244.051)

Figure 3-20. Smoothed difference fraction volume water content at various depths in Borehole 17 as a function of time (DTN LL980196904244.051)

Figure 3-21 through Figure 3-29 show the difference fraction volume water content in Borehole 22 as a function of depth from the collar on various dates of the in-heat and cooldown phase measurements. Figure 3-30 shows the water content in this borehole at various depths from collar as a function of time. The 0 day in Figure 3-30 is the day the heater was turned on. Borehole 22 is almost horizontal and is approximately $0.65 \mathrm{~m}$ below the heater horizon. The end of this borehole is about $1.56 \mathrm{~m}$ from the heater (CRWMS M\&O 1997b, Table 3-1). The peak temperature in this borehole before the heater was turned off was approximately $74^{\circ} \mathrm{C}$. A slight drying region near the bottom of the borehole was observed near the end of the heating phase (Figure 3-25). The decrease in the fraction volume water content in that region was approximately 0.006 , slightly greater than that in Borehole 15 . The 
cause of the two single-point anomalies on September 6, 1996, (Figure 3-21) was not clear, but they seemed to be isolated events and, therefore, not related to the thermohydrologic (TH) conditions in the rock.

Figure 3-21. Smoothed difference fraction volume water content in Borehole 22 as a function of depth from collar on September 6, 1996, and September 19, 1996 (DTN LL980196904244.051)

Figure 3-22. Smoothed difference fraction volume water content in Borehole 22 as a function of depth from collar on October 24, 1996, and November 26, 1996 (DTN LL971004604244.045)

Figure 3-23. Smoothed difference fraction volume water content in Borehole 22 as a function of depth from collar on January 16, 1997, and January 30, 1997 (DTN LL971004604244.045)

Figure 3-24. Smoothed difference fraction volume water content in Borehole 22 as a function of depth from collar on February 27, 1997, and March 26, 1997 (DTN LL971004604244.045)

Figure 3-25. Smoothed difference fraction volume water content in Borehole 22 as a function of depth from collar on April 30, 1997, and May 21, 1997 (DTN LL971004604244.045)

Figure 3-26. Smoothed difference fraction volume water content in Borehole 22 as a function of depth from collar on June 10, 1997, and June 24, 1997 (DTN LL971004604244.045)

Figure 3-27. Smoothed difference fraction volume water content in Borehole 22 as a function of depth from collar on July 23, 1997, and August 26, 1997 (DTN LL971004604244.045)

Figure 3-28. Smoothed difference fraction volume water content in Borehole 22 as a function of depth from collar on September 25, 1997, and October 29, 1997 (DTN LL980196904244.051)

Figure 3-29. Smoothed difference fraction volume water content in Borehole 22 as a function of depth from collar on November 24, 1997, and December 17, 1997 (DTN LL980196904244.051)

Figure 3-30. Smoothed difference fraction volume water content at various depths in Borehole 22 as a function of time (DTN LL980196904244.051)

Again, Figure 3-28 through 3-30 show some changes in the moisture content during the cool-down phase. The cause of the spike at about $1.2 \mathrm{~m}$ depth from the collar on June 24, 1997, and July 23, 1997, (Figure 3-26 and Figure 3-27) is not clear. Because it is a localized 
phenomenon, it probably has no significant implication on the moisture distribution in the rock mass. Figure 3-29 and Figure 3-30 show that, during the last three measurements, the outer half (portion closest to the collar) of the borehole showed rewetting, but the inner half showed further drying. The cause for these changes is still not clear; because the SHT was terminated shortly after the December 1997 measurements, it is difficult to determine its cause.

The difference fraction volume water content in Borehole 23 as a function of depth from the collar on various dates during the heating and cool-down phases are shown in Figure 3-31 through Figure 3-39. Figure 3-40 shows the water content in this borehole at various depths from the collar as a function of time. The 0 day in Figure 3-40 is the day the heater was turned on. Borehole 23 reaches the upper left side of the heater with an incline angle of about 7.5 degrees. The end of this borehole is approximately $1.31 \mathrm{~m}$ from the heater (CRWMS M\&O 1997b, Table 3-1). The peak temperature in this borehole was approximately $88^{\circ} \mathrm{C}$. A drying region near the bottom of this borehole began to develop about two months into the heating phase. The maximum decrease in the fraction volume water content in this borehole was approximately 0.016 , which equals about $13 \%$ in saturation level for a porosity of 0.13 . The spike at $1.2 \mathrm{~m}$ from the collar on May 21, 1997, (Figure 3-35) is an isolated occurrence and probably has no significant implication on the moisture distribution in the rock mass. However, the region near the collar (at about $2 \mathrm{~m}$ from the collar) showed a slight increase in water content during the heating phase. Figure 3-36 through Figure 3-40 show no significant changes in the water content during the cool-down phase (May 28, 1997, through February 28, 1998), except in the region deeper than $4.7 \mathrm{~m}$, where rewetting has been observed (Figure 3-40).

Figure 3-31. Smoothed difference fraction volume water content in Borehole 23 as a function of depth from collar on September 6, 1996, and September 19, 1996 (DTN LL980196904244.051)

Figure 3-32. Smoothed difference fraction volume water content in Borehole 23 as a function of depth from collar on October 24, 1996, and November 26, 1996 (DTN LL980196904244.051)

Figure 3-33. Smoothed difference fraction volume water content in Borehole 23 as a function of depth from collar on January 16, 1997, and January 30, 1997 (DTN LL980196904244.051)

Figure 3-34. Smoothed difference fraction volume water content in Borehole 23 as a function of depth from collar on February 27, 1997, and March 26, 1997 (DTN LL980196904244.051)

Figure 3-35. Smoothed difference fraction volume water content in Borehole 23 as a function of depth from collar on April 30, 1997, and May 21, 1997 (DTN LL980196904244.051)

Figure 3-36. Smoothed difference fraction volume water content in Borehole 23 as a function of depth from collar on June 10, 1997, and June 24, 1997 (DTN LL980196904244.051) 
Figure 3-37. Smoothed difference fraction volume water content in Borehole 23 as a function of depth from collar on July 23, 1997, and August 26, 1997 (DTN LL980196904244.051)

Figure 3-38. Smoothed difference fraction volume water content in Borehole 23 as a function of depth from collar on September 25, 1997, and October 29, 1997 (DTN LL980196904244.051)

Figure 3-39. Smoothed difference fraction volume water content in Borehole 23 as a function of depth from collar on November 24, 1997, and December 17, 1997 (DTN LL980196904244.051)

Figure 3-40. Smoothed difference fraction volume water content at various depths in Borehole 23 as a function of time (DTN LL980196904244.051)

\subsection{Other Observations}

Vapor condensation was observed in Boreholes 22 and 23 during the later part of the heating phase (April and May 1997). The inner surfaces of the liners in those boreholes were wiped dry before each logging. Some condensed water was collected from the liner of Borehole 23. Chemical analyses on the water samples are being conducted. During the first month of the cool-down phase, vapor condensation was still observed in Boreholes 22 and 23, but no condensed water was in Borehole 23 to be collected. Later, after the third month of the cooling phase, no condensation was observed in Boreholes 22 and 23. During both the heating and cool-down phases, no vapor condensation was observed in Boreholes 15 and 17.

\subsection{Summary}

Neutron logging in the SHT region observed changes in the moisture content in the heated rock mass. The degree of drying seemed in good correlation with the temperatures in the rock. The decreases of the water content in the drying regions were small because the neutron logging holes are not close to the heater. The results indicate that the drying seems to be more widespread in the region below the heater than in other regions. Rewetting was observed at a few localized regions during the cooling phase. The amplitude of the rewetting was small.

\subsection{References}

CRWMS M\&O 1997a. Ambient Characterization of the Drift-Scale Test Block. B00000000-07175705-00001 REV 00. Las Vegas, Nevada: Civilian Radioactive Waste Management System, Management and Operating Contractor: TRW Environmental Safety Systems, Inc.

CRWMS M\&O 1997b. Single Heater Test Status Report. B00000000-01717-5700-00002 REV 1.

Las Vegas, Nevada: Civilian Radioactive Waste Management System, Management and Operating Contractor: TRW Environmental Safety Systems, Inc. 

Chapter 3 Figures 



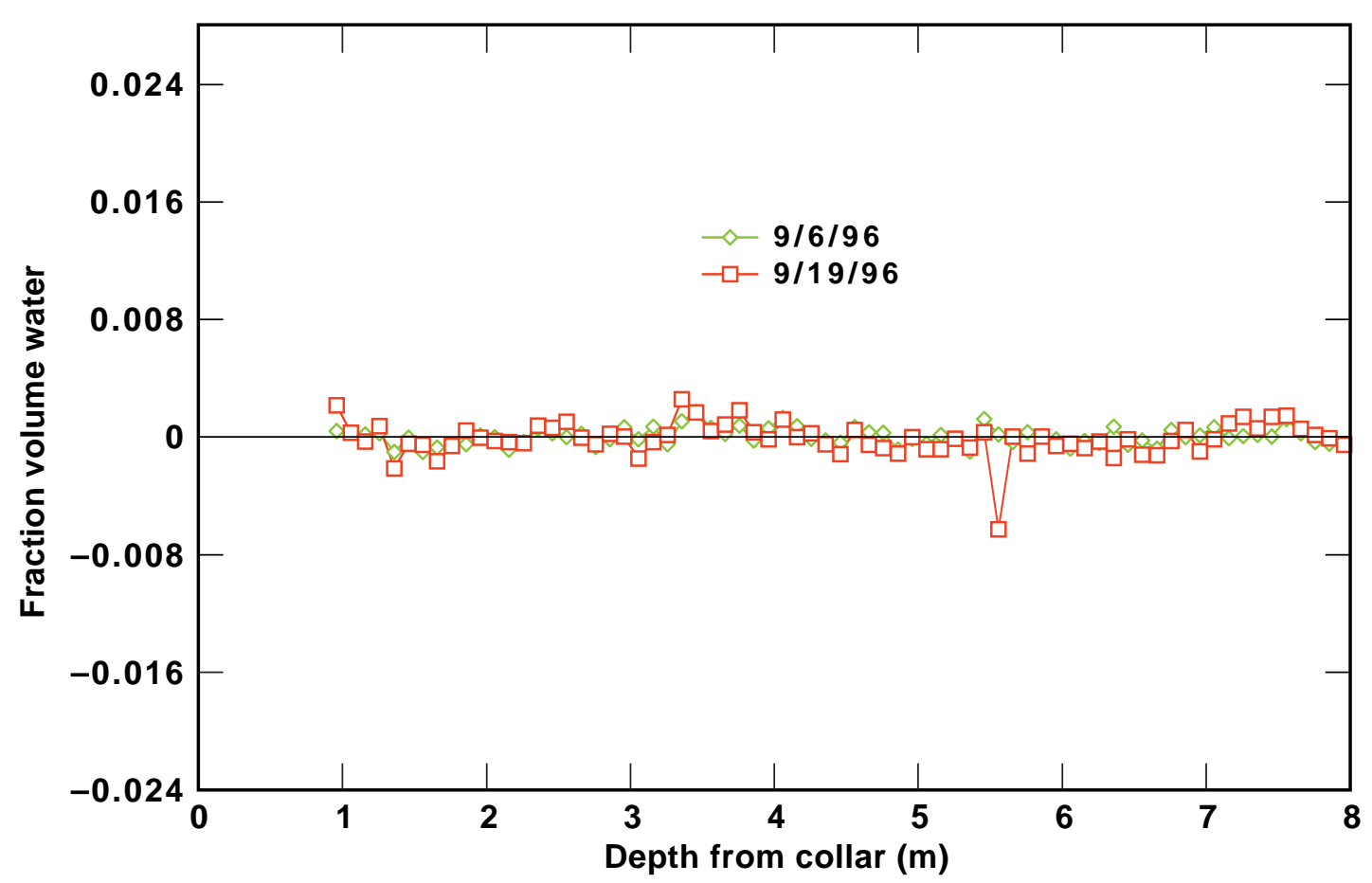

Figure 3-1. Smoothed difference fraction volume water content in Borehole 15 as a function of depth from collar on September 6, 1996, and September 19, 1996

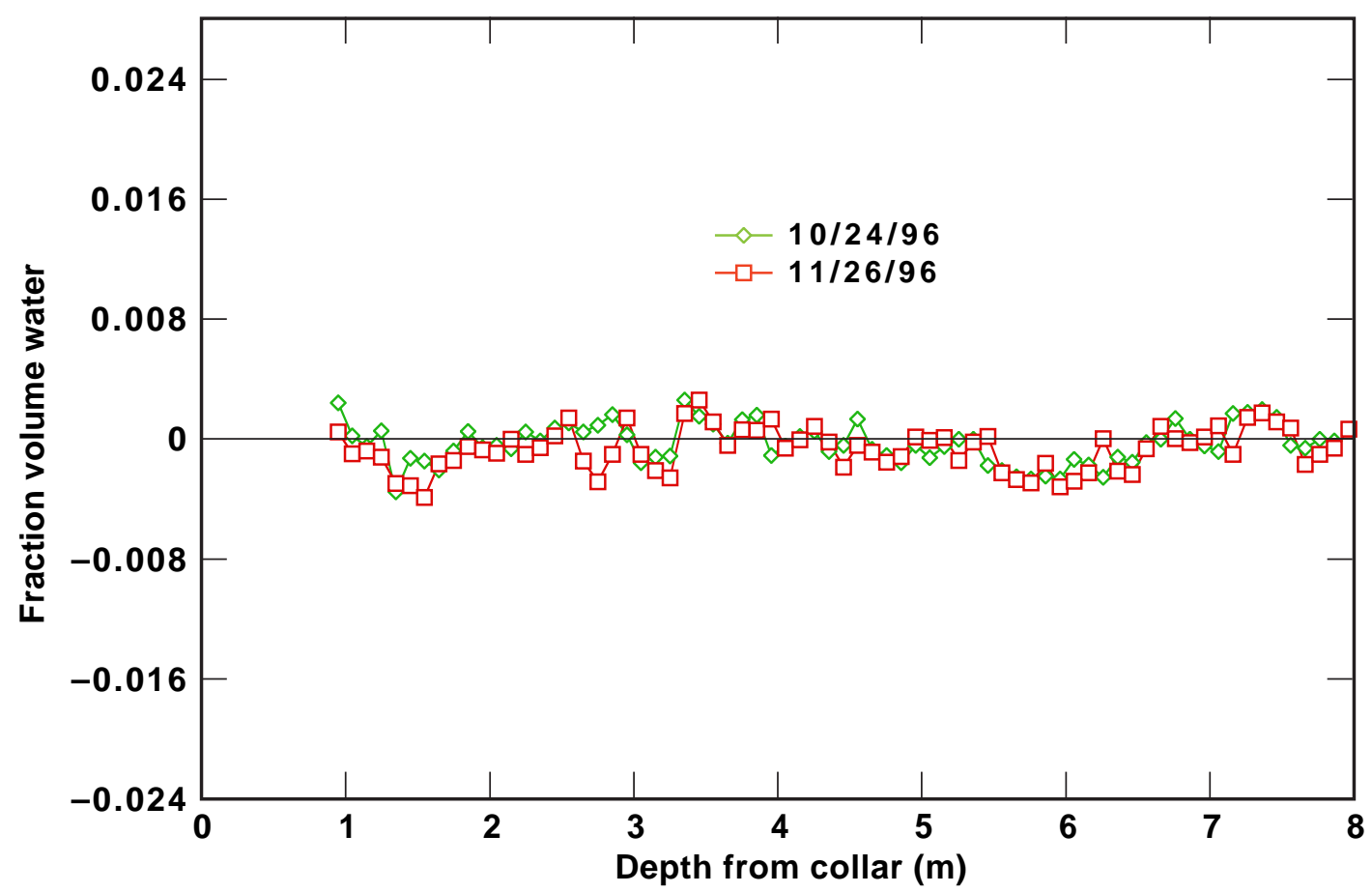

Figure 3-2. Smoothed difference fraction volume water content in Borehole 15 as a function of depth from collar on October 24, 1996, and November 26, 1996 


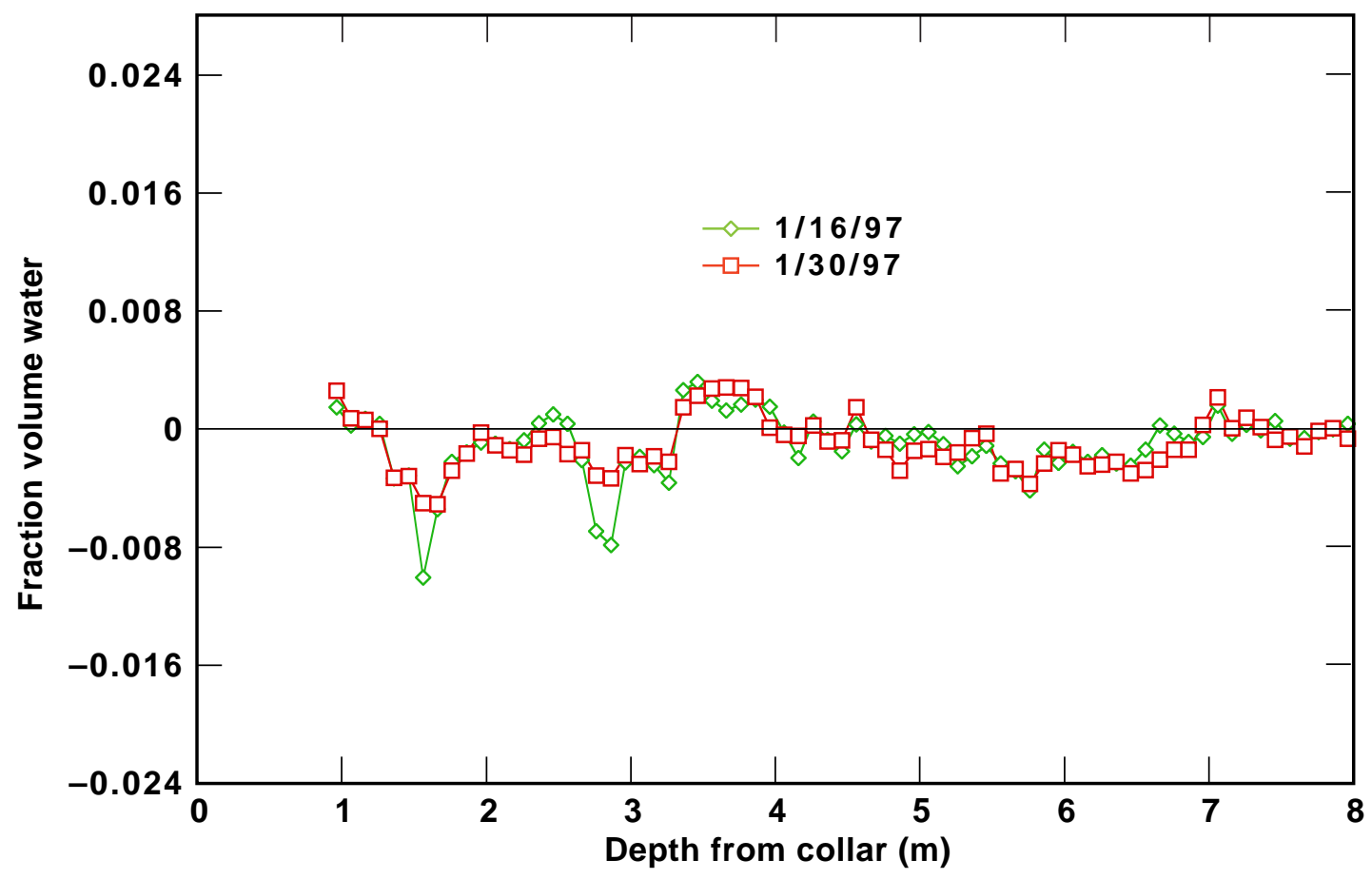

Figure 3-3. Smoothed difference fraction volume water content in Borehole 15 as a function of depth from collar on January 16, 1997, and January 30, 1997

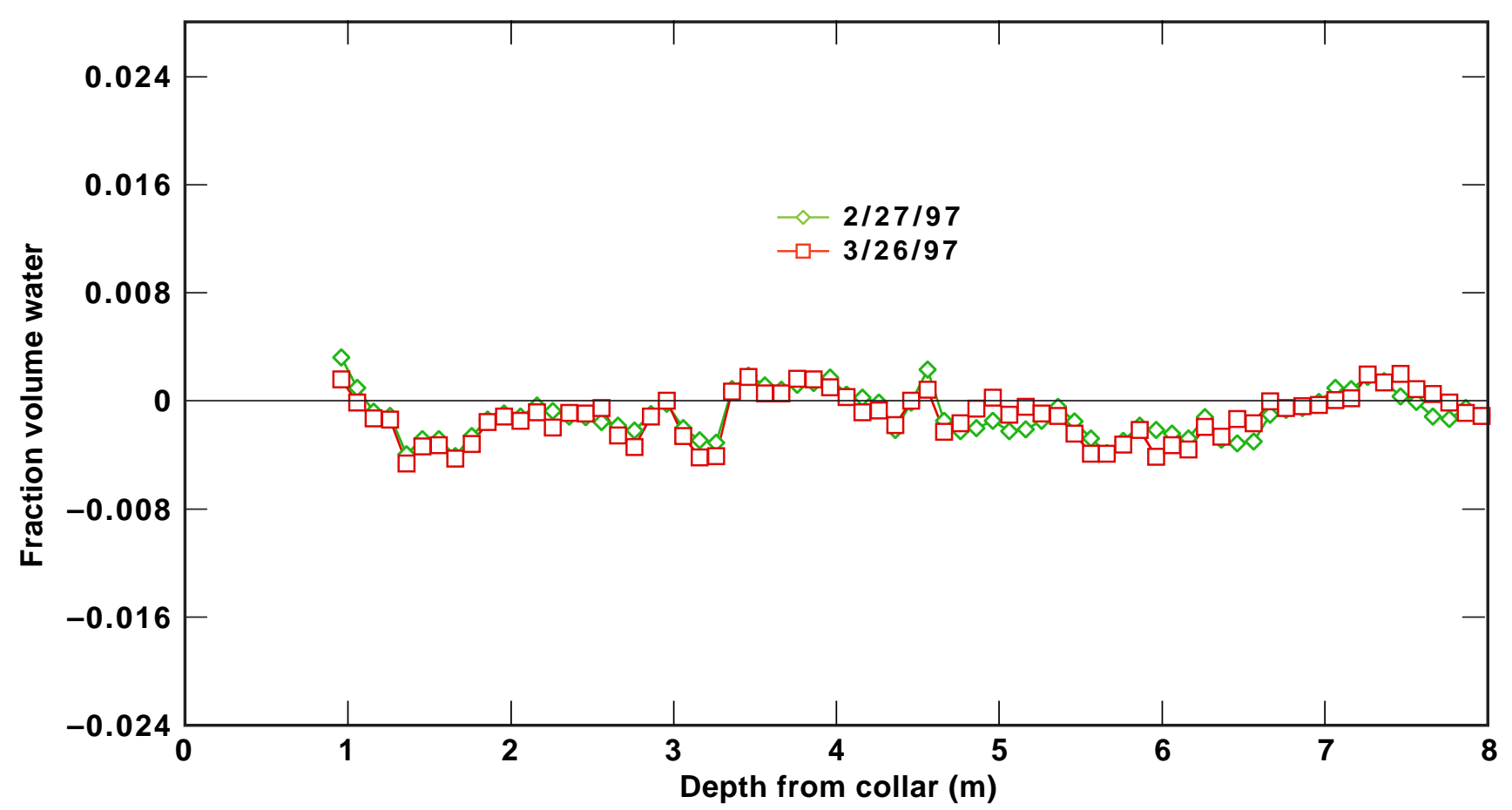

Figure 3-4. Smoothed difference fraction volume water content in Borehole 15 as a function of depth from collar on February 27, 1997, and March 26, 1997 


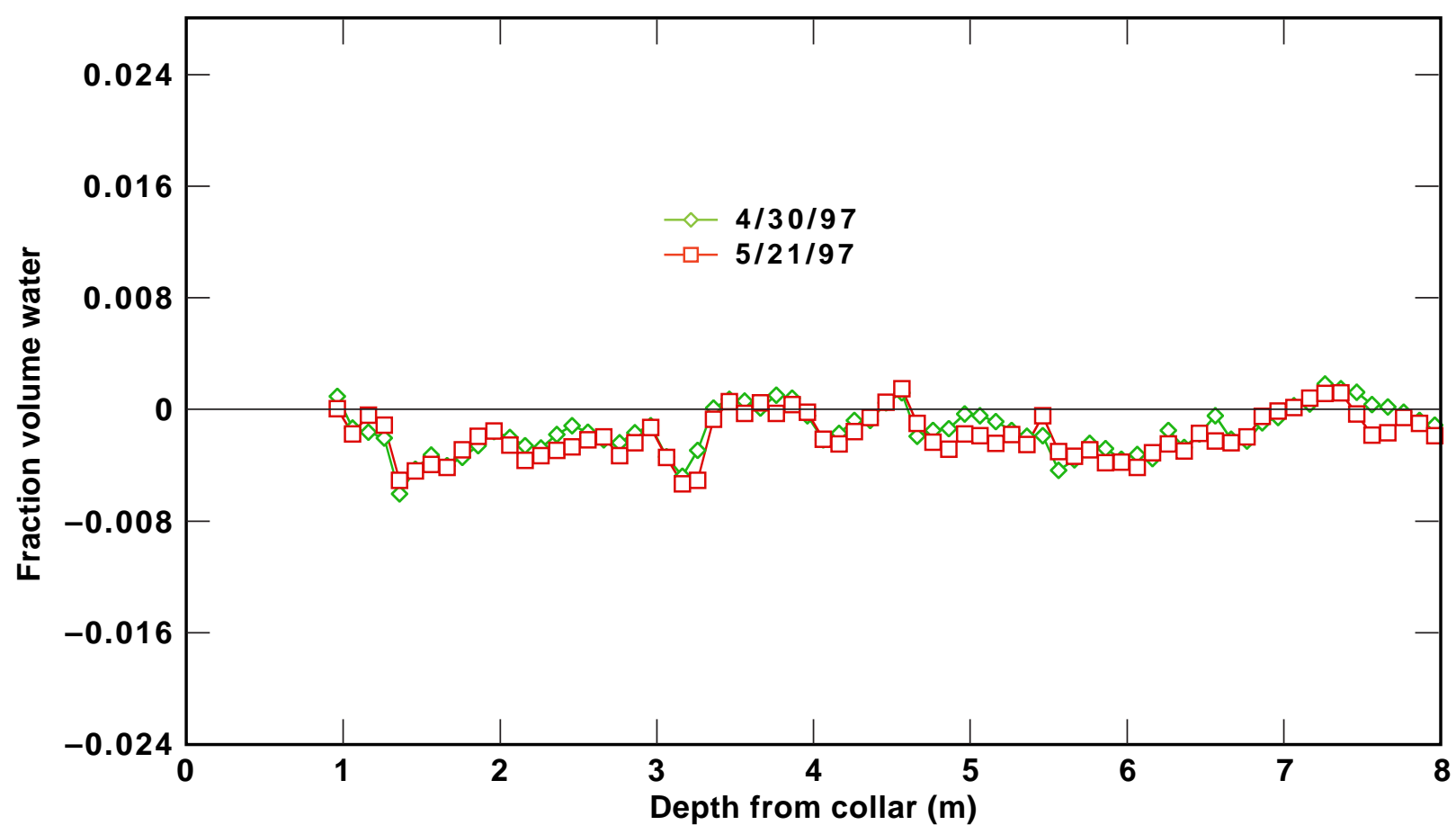

Figure 3-5. Smoothed difference fraction volume water content in Borehole 15 as a function of depth from collar on April 30, 1997, and May 21, 1997

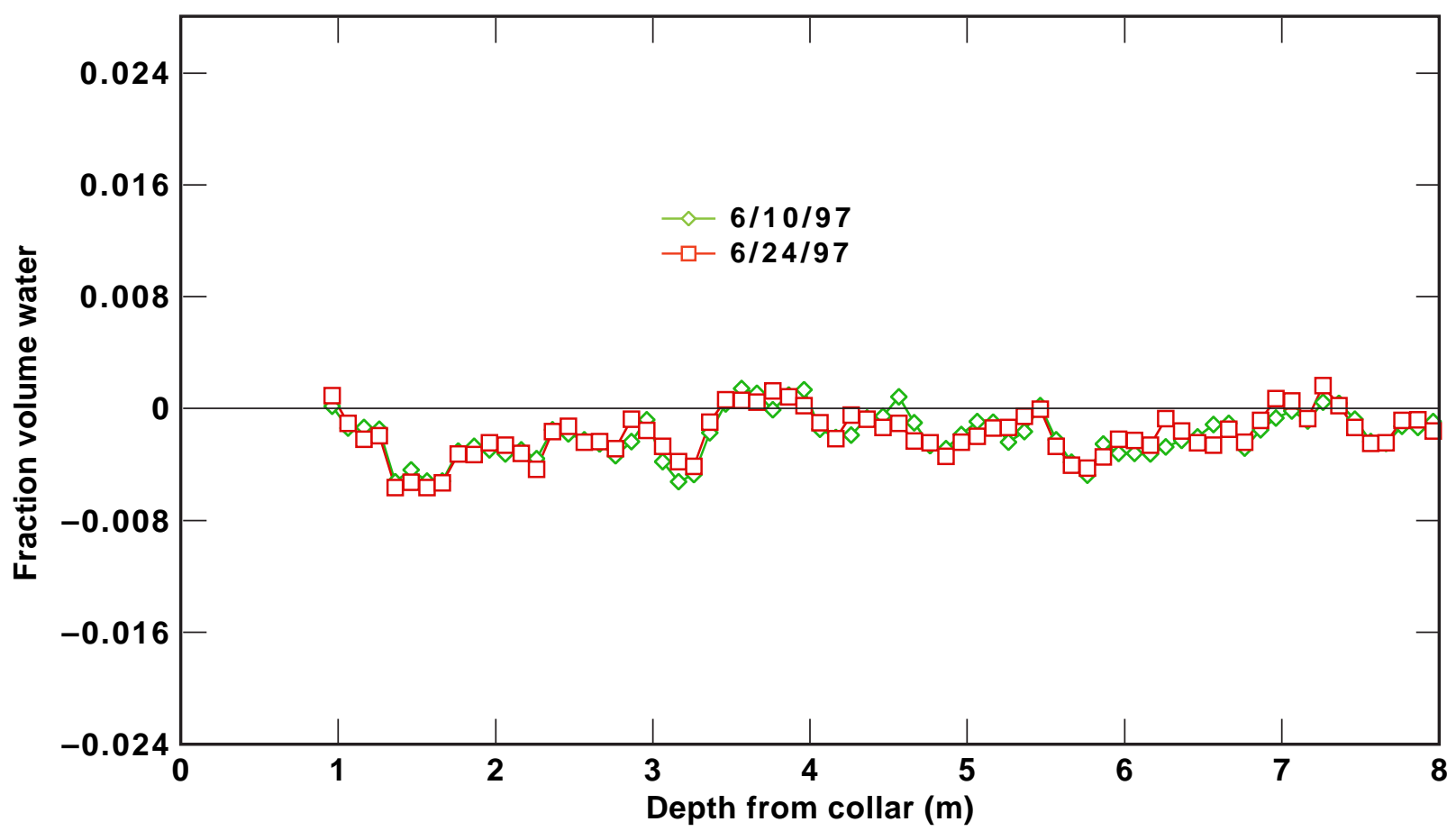

Figure 3-6. Smoothed difference fraction volume water content in Borehole 15 as a function of depth from collar on June 10, and June 24, 1997 


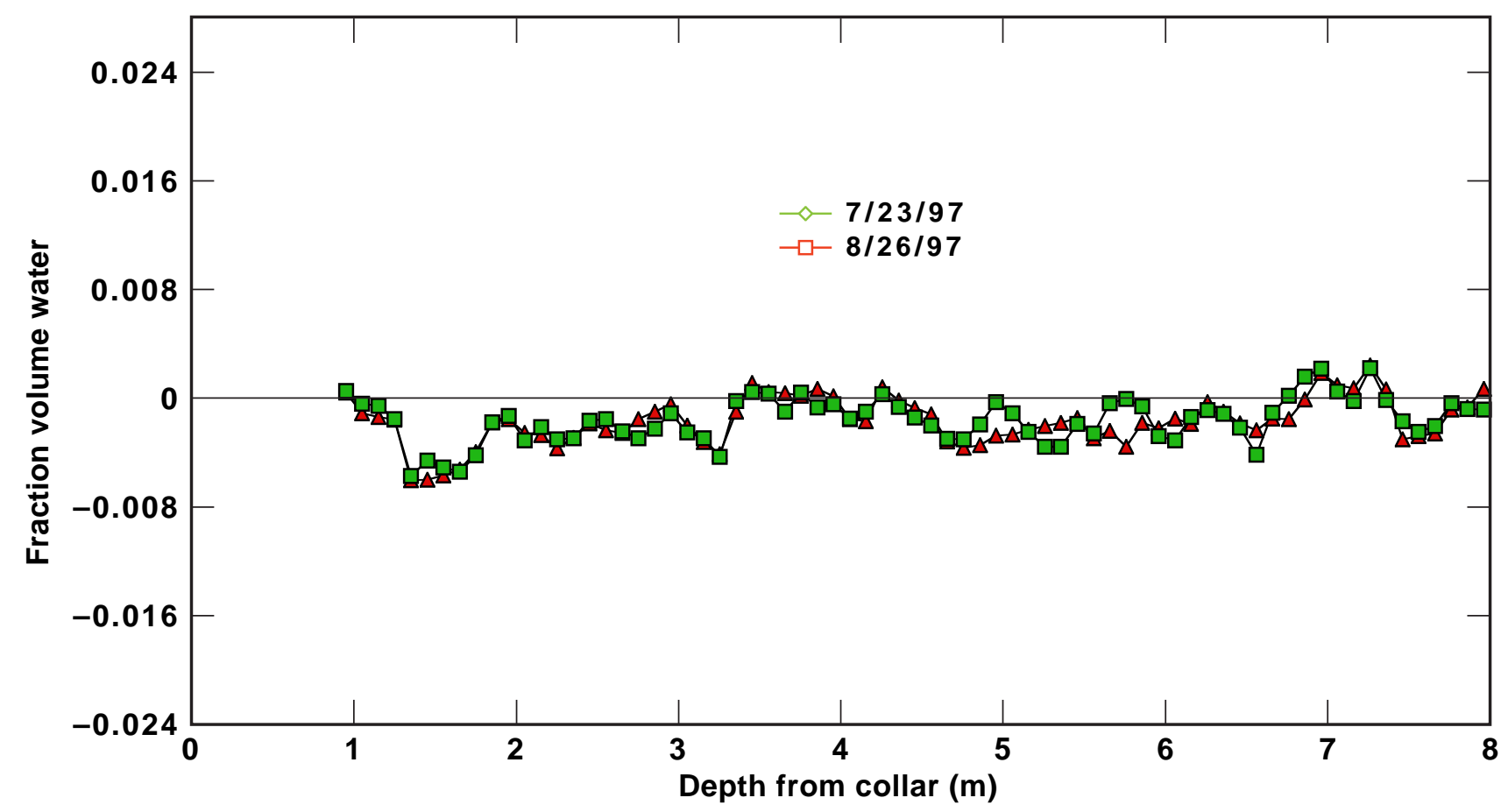

Figure 3-7. Smoothed difference fraction volume water content in Borehole 15 as a function of depth from collar on July 23, and August 26, 1997

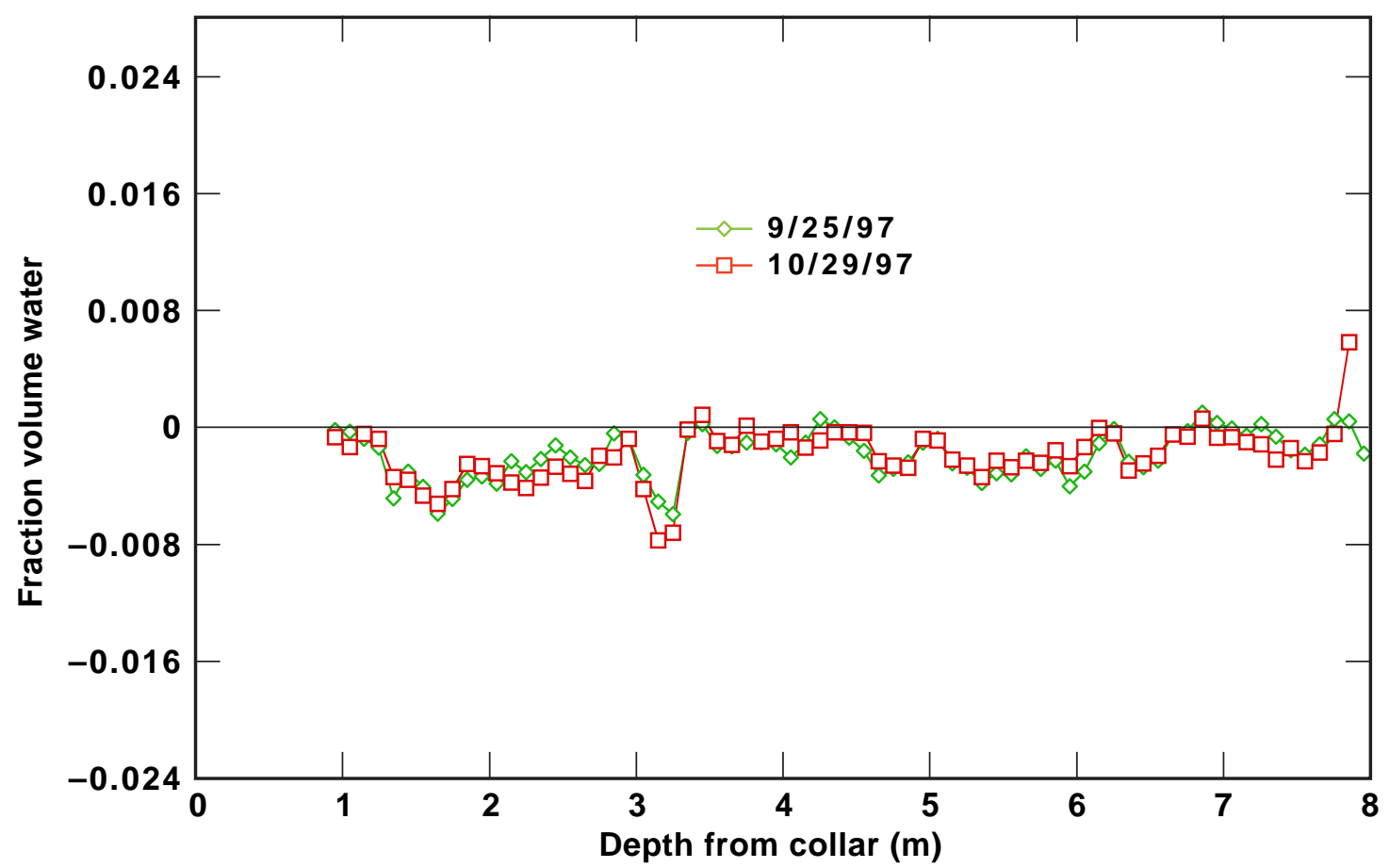

Figure 3-8. Smoothed difference fraction volume water content in Borehole 15 as a function of depth from collar on September 25, 1997, and October 29, 1997 


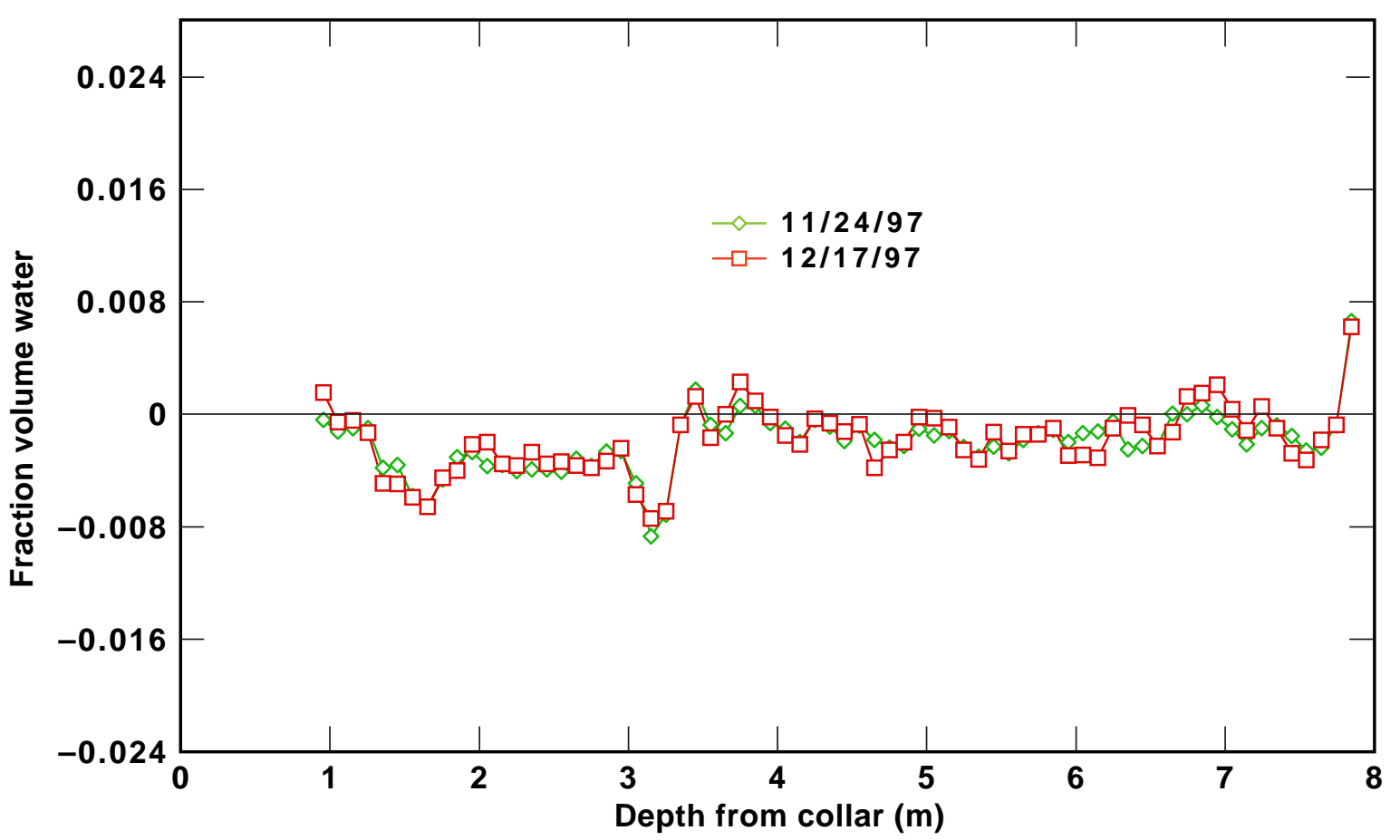

Figure 3-9. Smoothed difference fraction volume water content in Borehole 15 as a function of depth from collar on November 24, 1997, and December 17, 1997

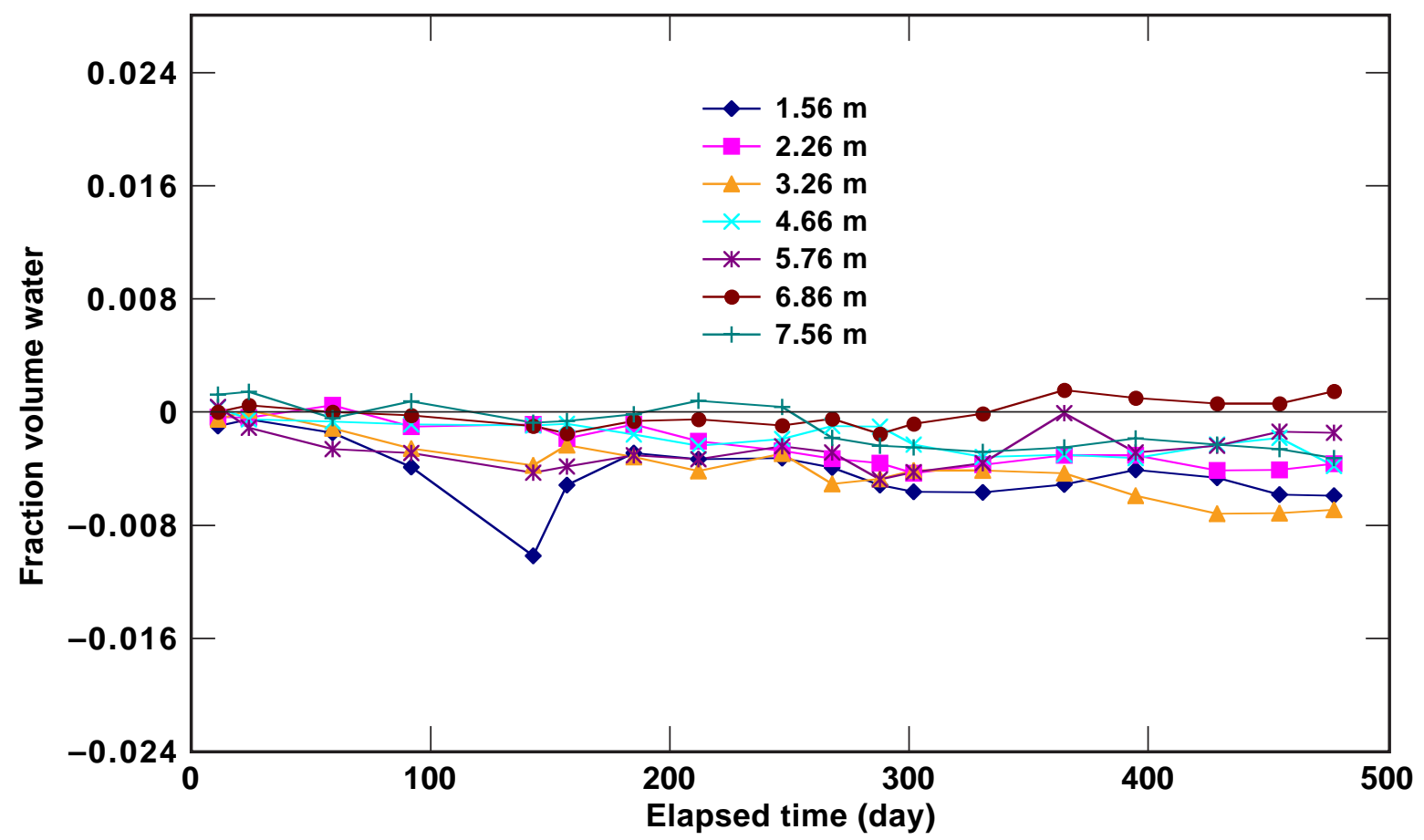

Figure 3-10. Smoothed difference fraction volume content at various depths in Borehole 15 as a function of time 


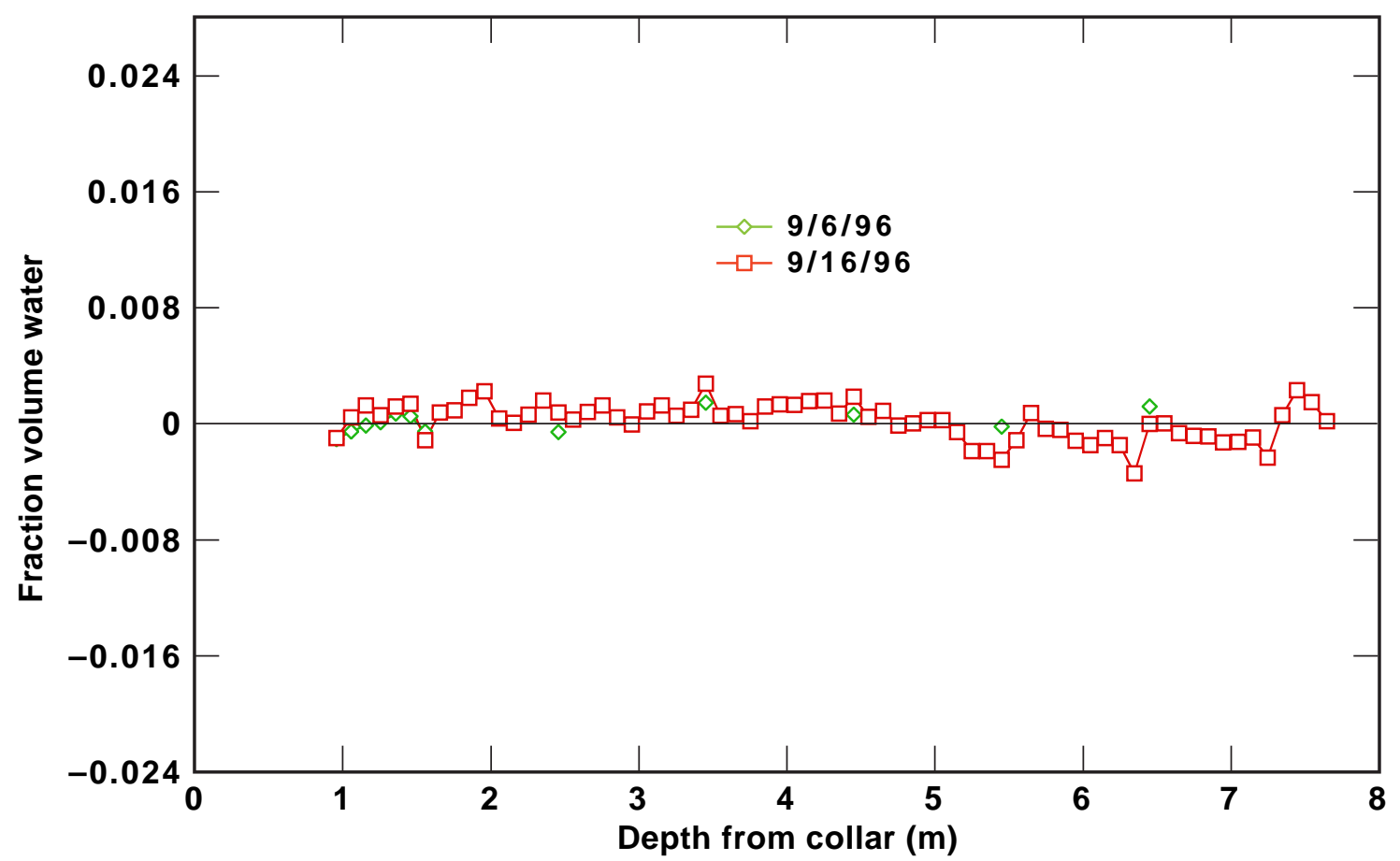

Figure 3-11. Smoothed difference fraction volume water content in Borehole 17 as a function of depth from collar on September 6, 1996, and September 19, 1996

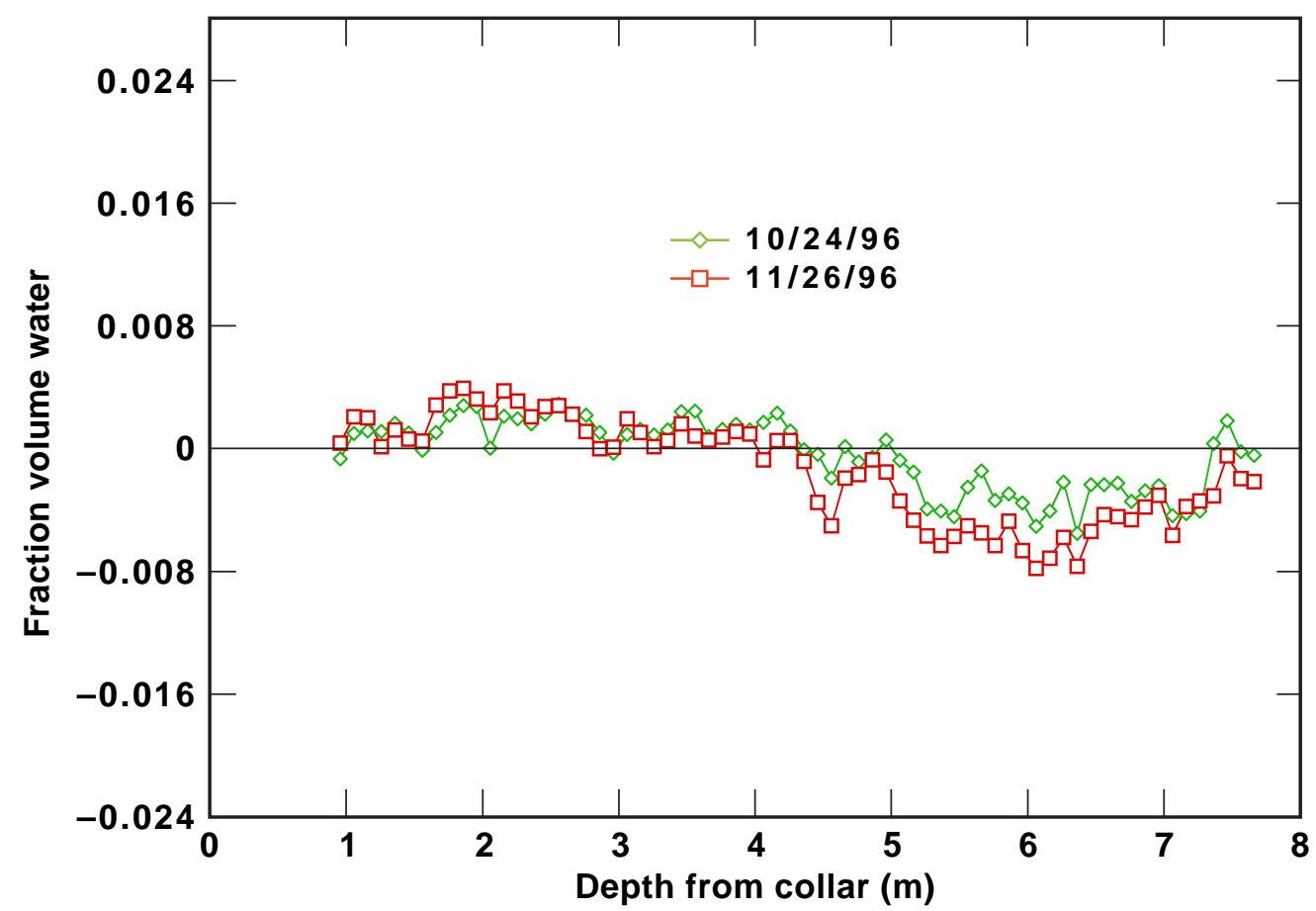

Figure 3-12. Smoothed difference fraction volume water content in Borehole 17 as a function of depth from collar on October 24, 1996, and November 26, 1996 


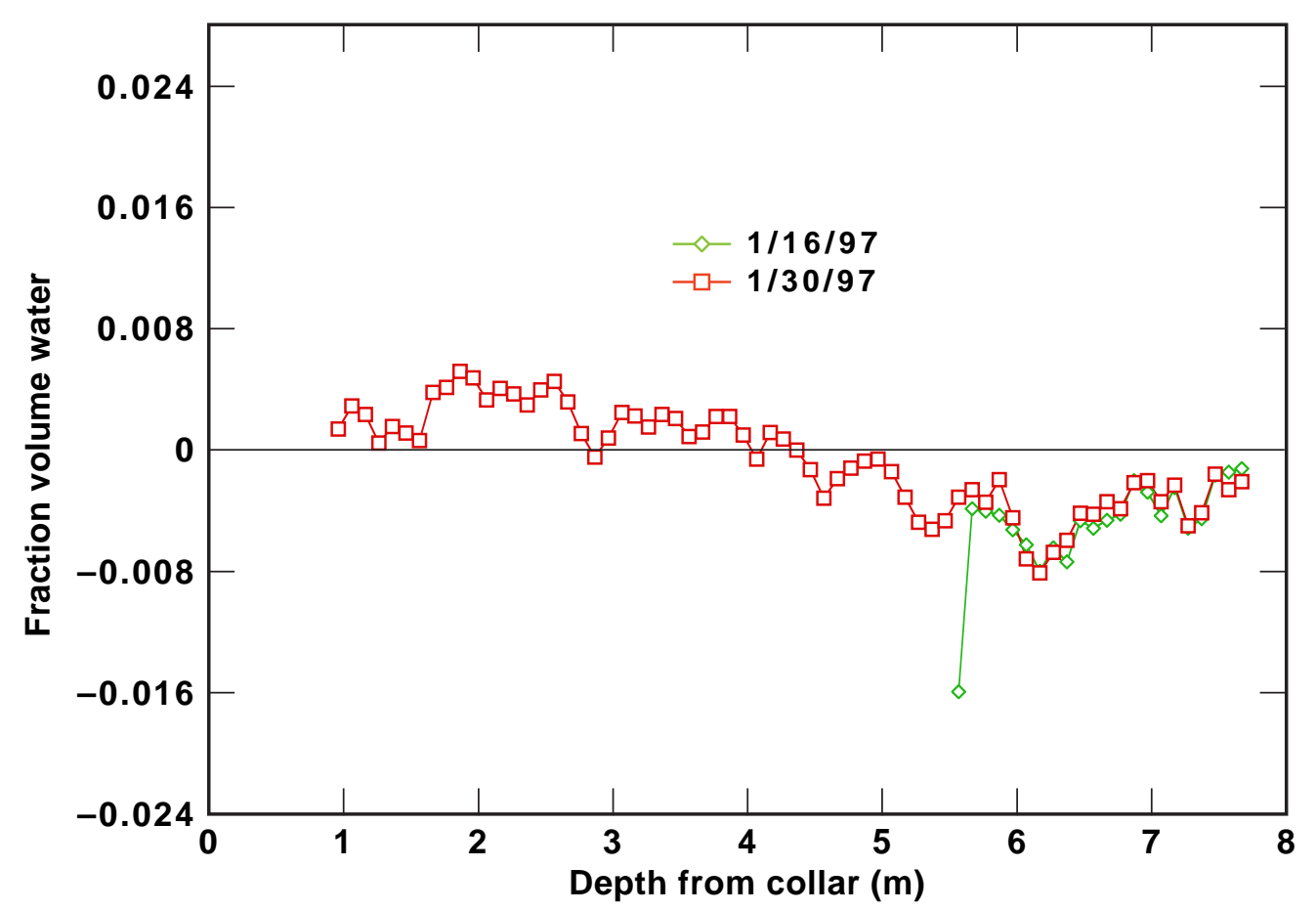

Figure 3-13. Smoothed difference fraction volume water content in Borehole 17 as a function of depth from collar on January 16, 1997, and January 30, 1997

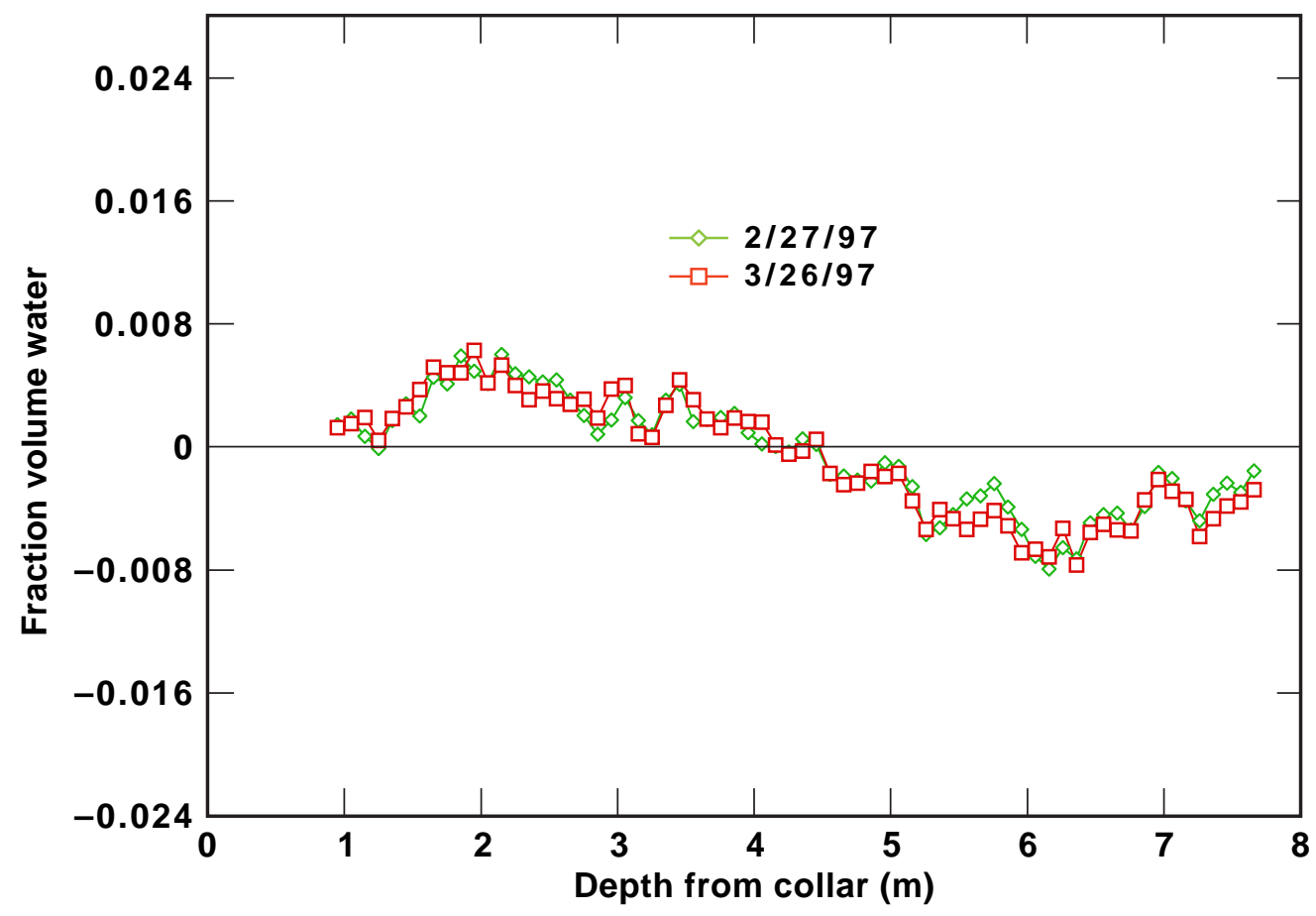

Figure 3-14. Smoothed difference fraction volume water content in Borehole 17 as a function of depth from collar on February 27, 1997, and March 26, 1997 


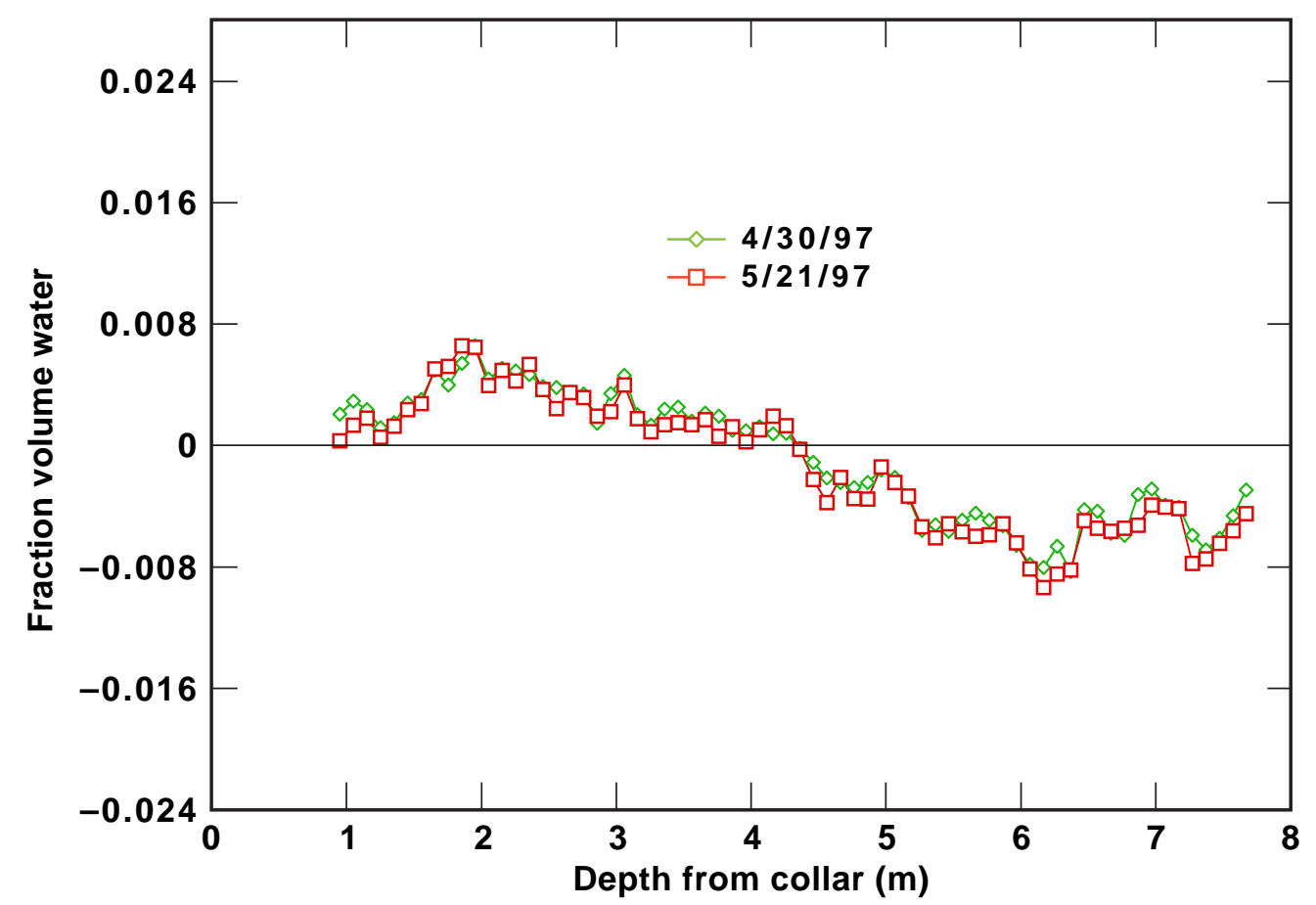

Figure 3-15. Smoothed difference fraction volume water content in Borehole 17 as a function of depth from collar on April 30, 1997, and May 21, 1997

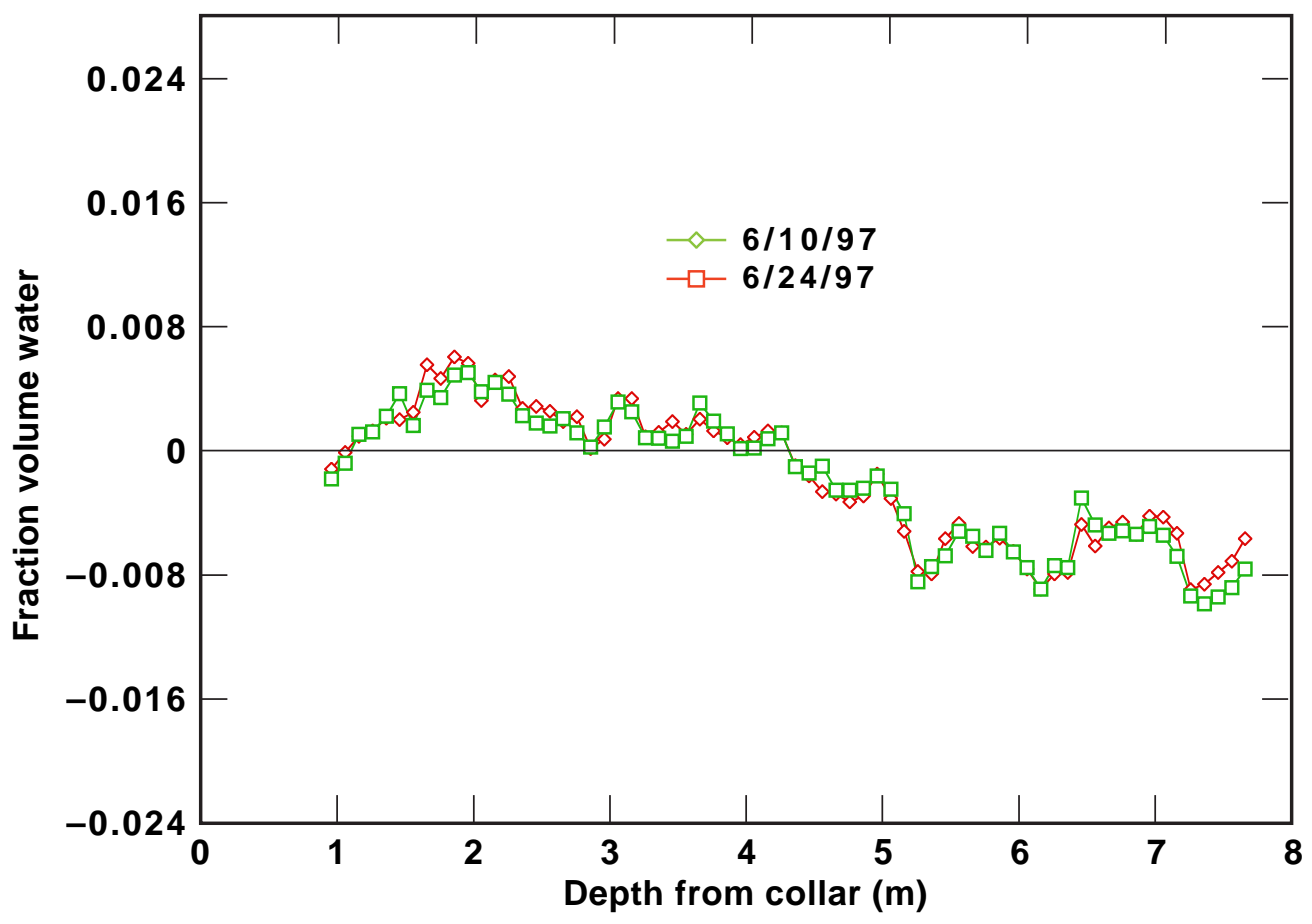

Figure 3-16. Smoothed difference fraction volume water content in Borehole 17 as a function of depth from collar on June 10, 1997, and June 24, 1997 


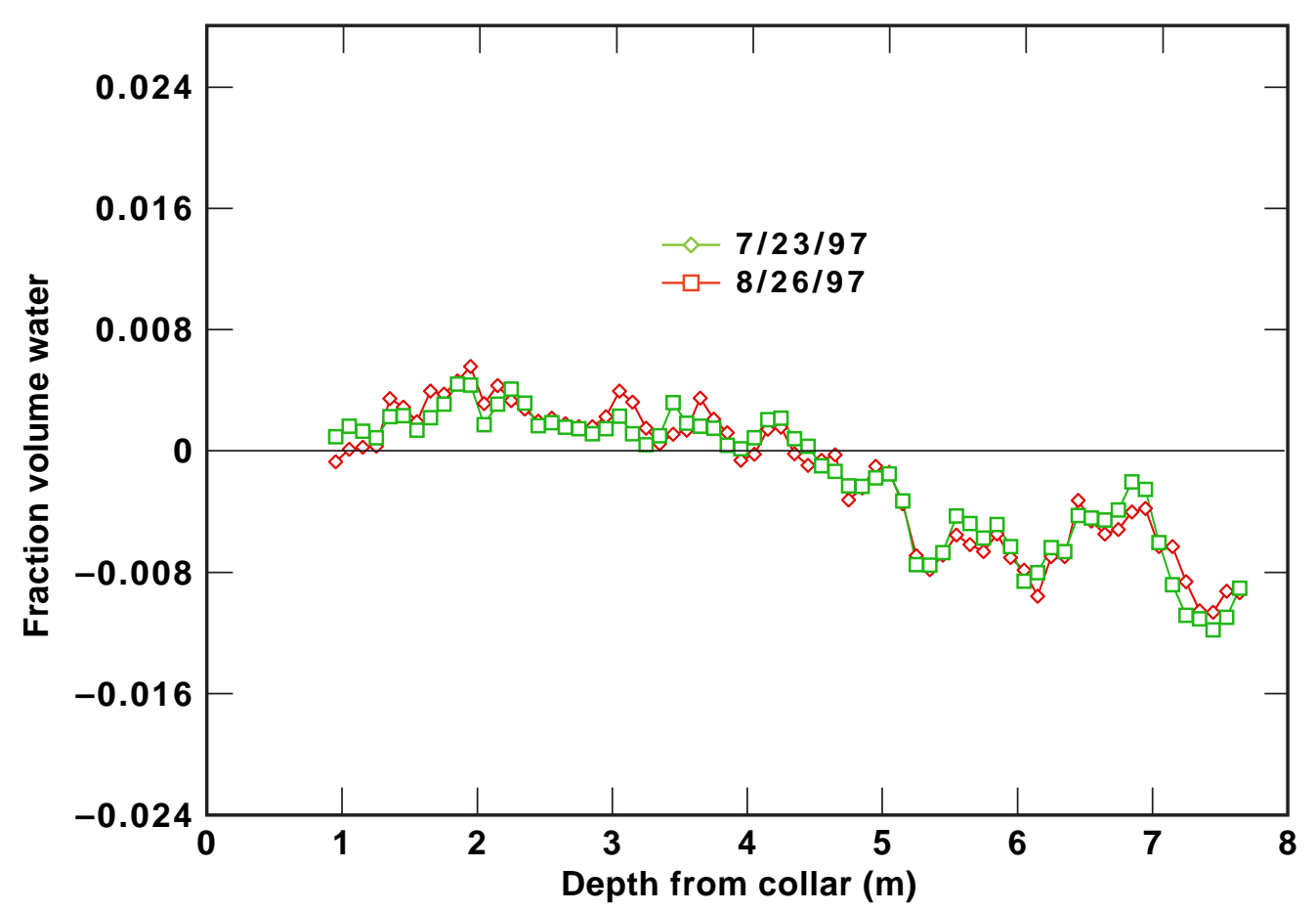

Figure 3-17. Smoothed difference fraction volume water content in Borehole 17 as a function of depth from collar on July 23, 1997, and August 26, 1997

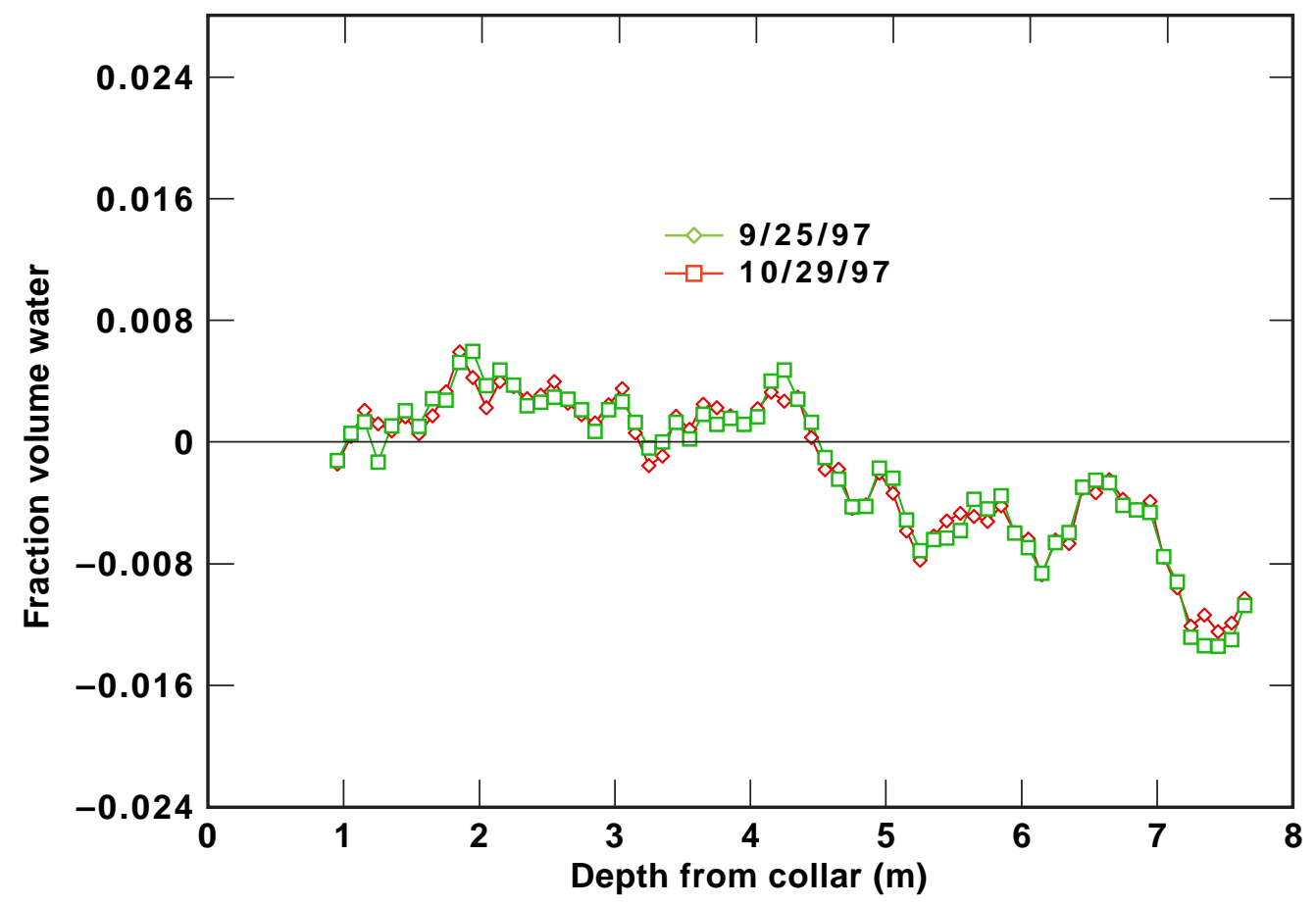

Figure 3-18. Smoothed difference fraction volume water content in Borehole 17 as a function of depth from collar on September 25, 1997, and October 29, 1997 


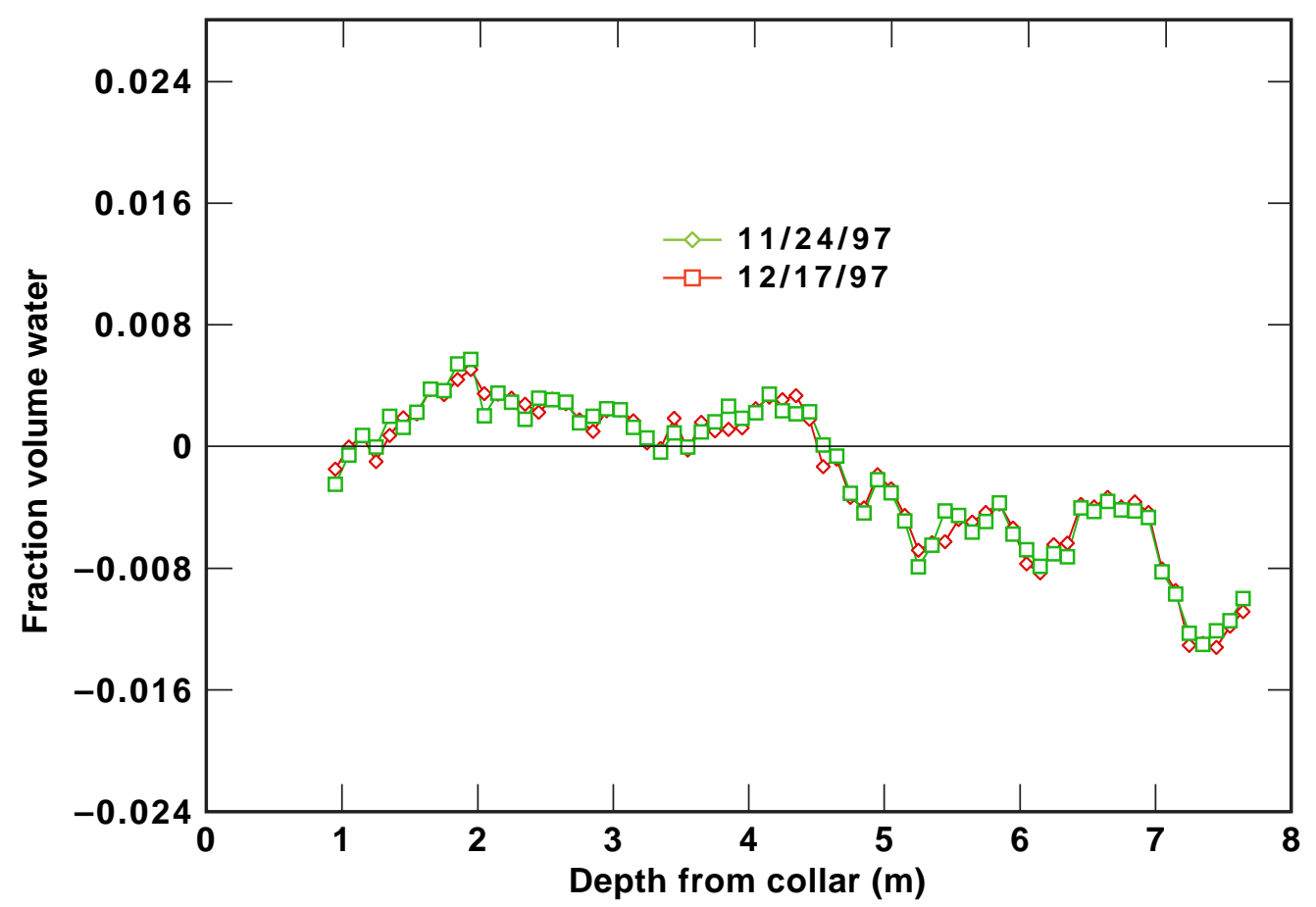

Figure 3-19. Smoothed difference fraction volume water content in Borehole 17 as a function of depth from collar on November 24, 1997, and December 17, 1997

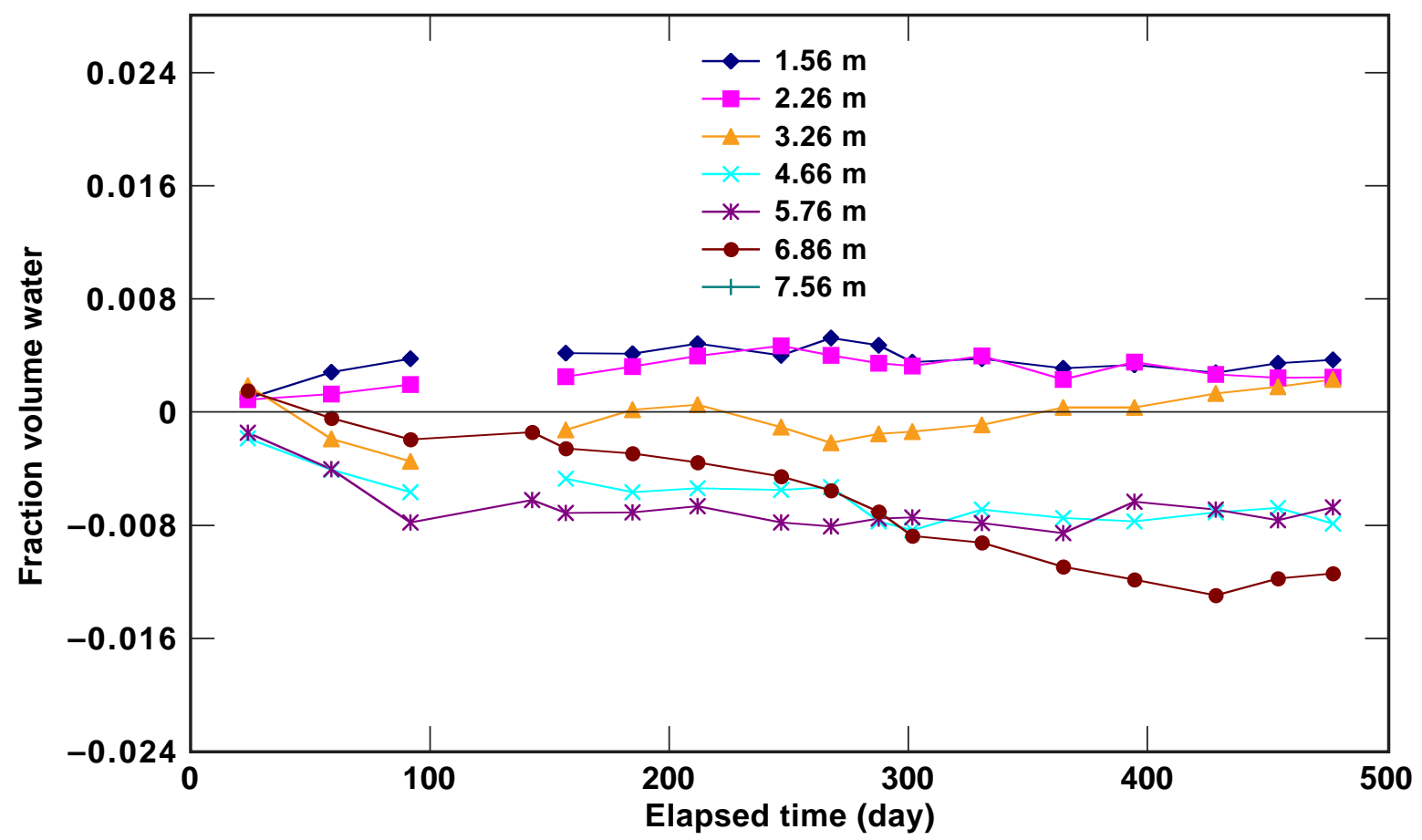

Figure 3-20. Smoothed difference fraction volume water content at various depths in Borehole 17 as a function of time 


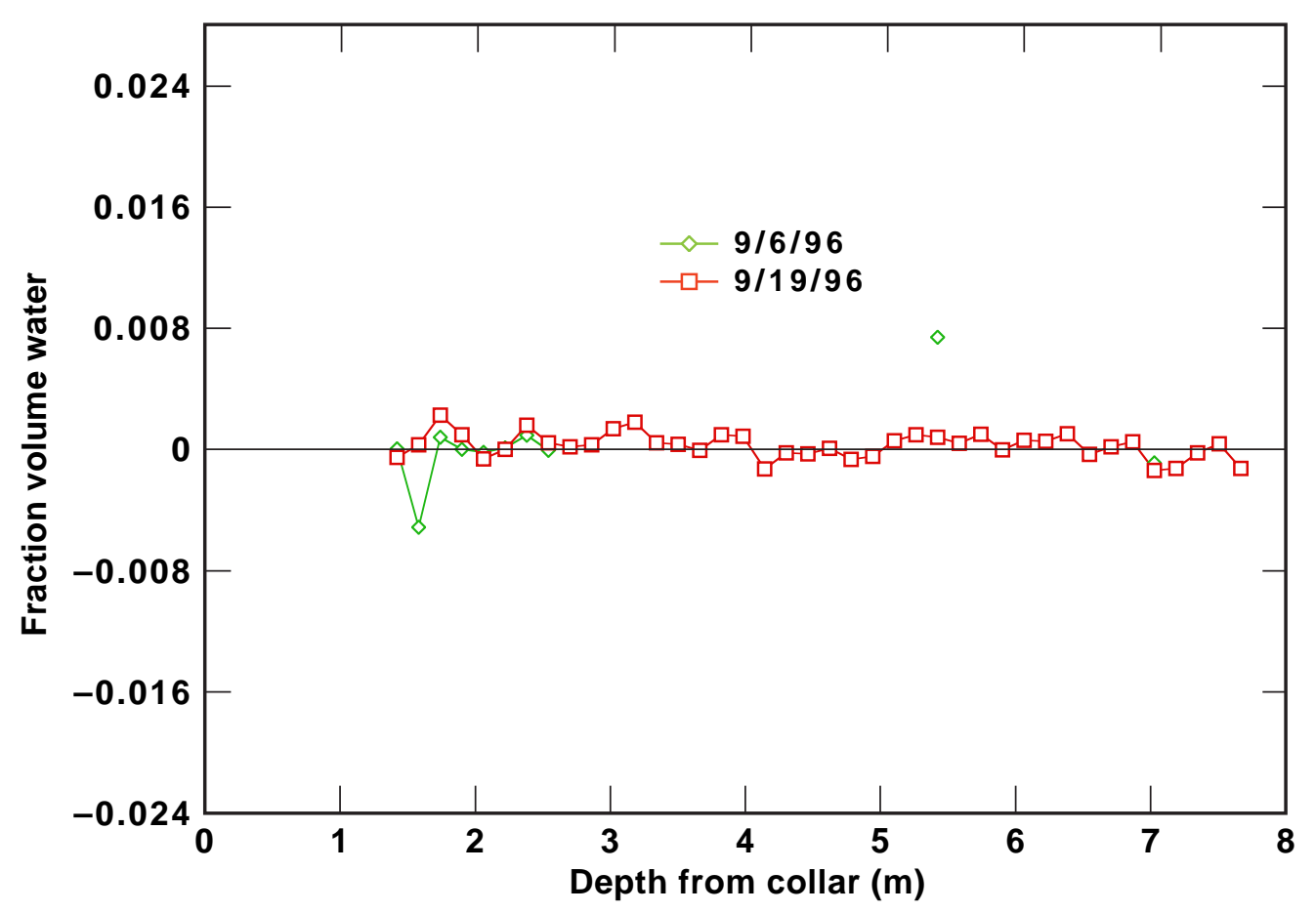

Figure 3-21. Smoothed difference fraction volume water content in Borehole 22 as a function of depth from collar on September 6, 1996, and September 19, 1996

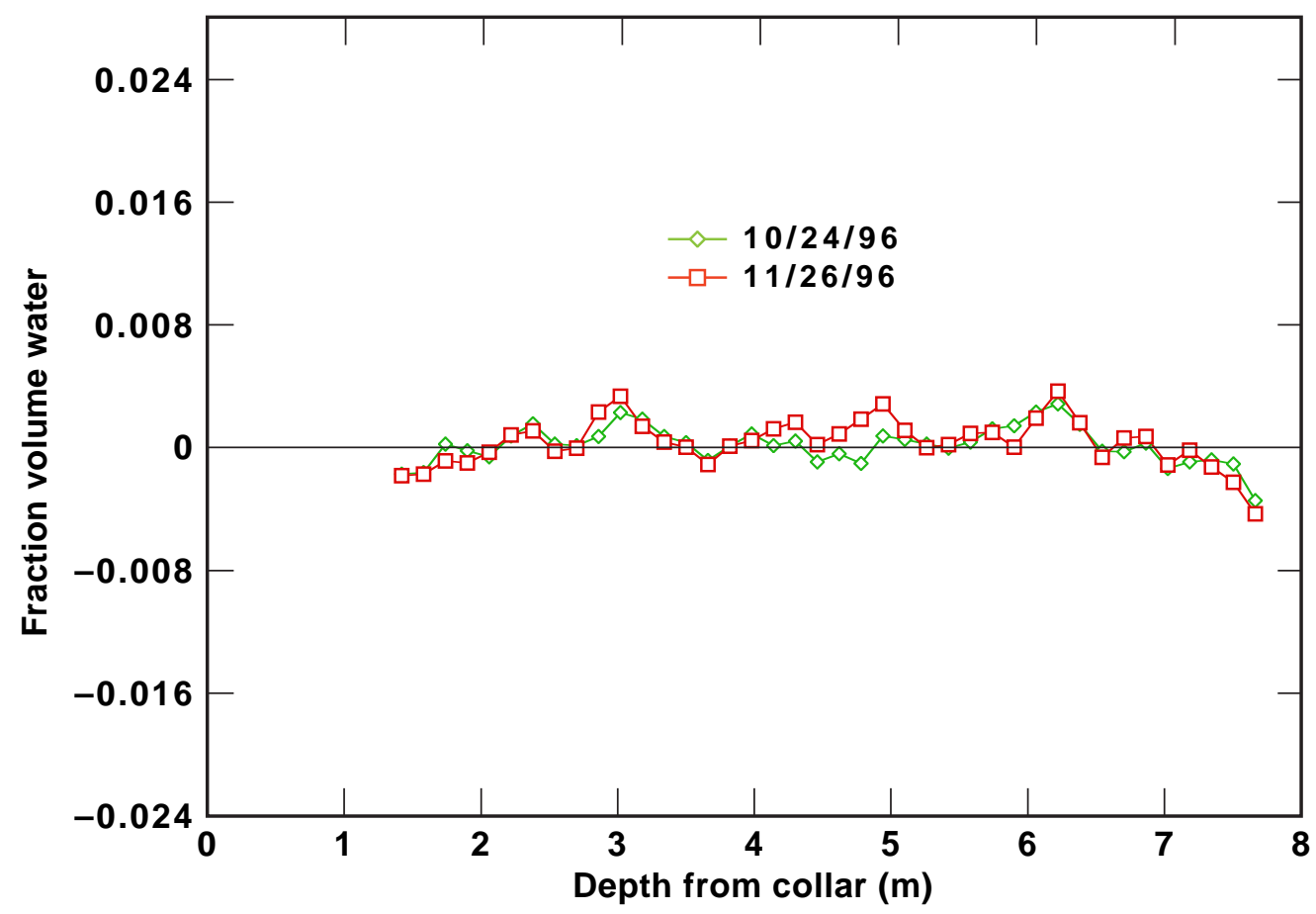

Figure 3-22. Smoothed difference fraction volume water content in Borehole 22 as a function of depth from collar on October 24, 1996, and November 26, 1996 


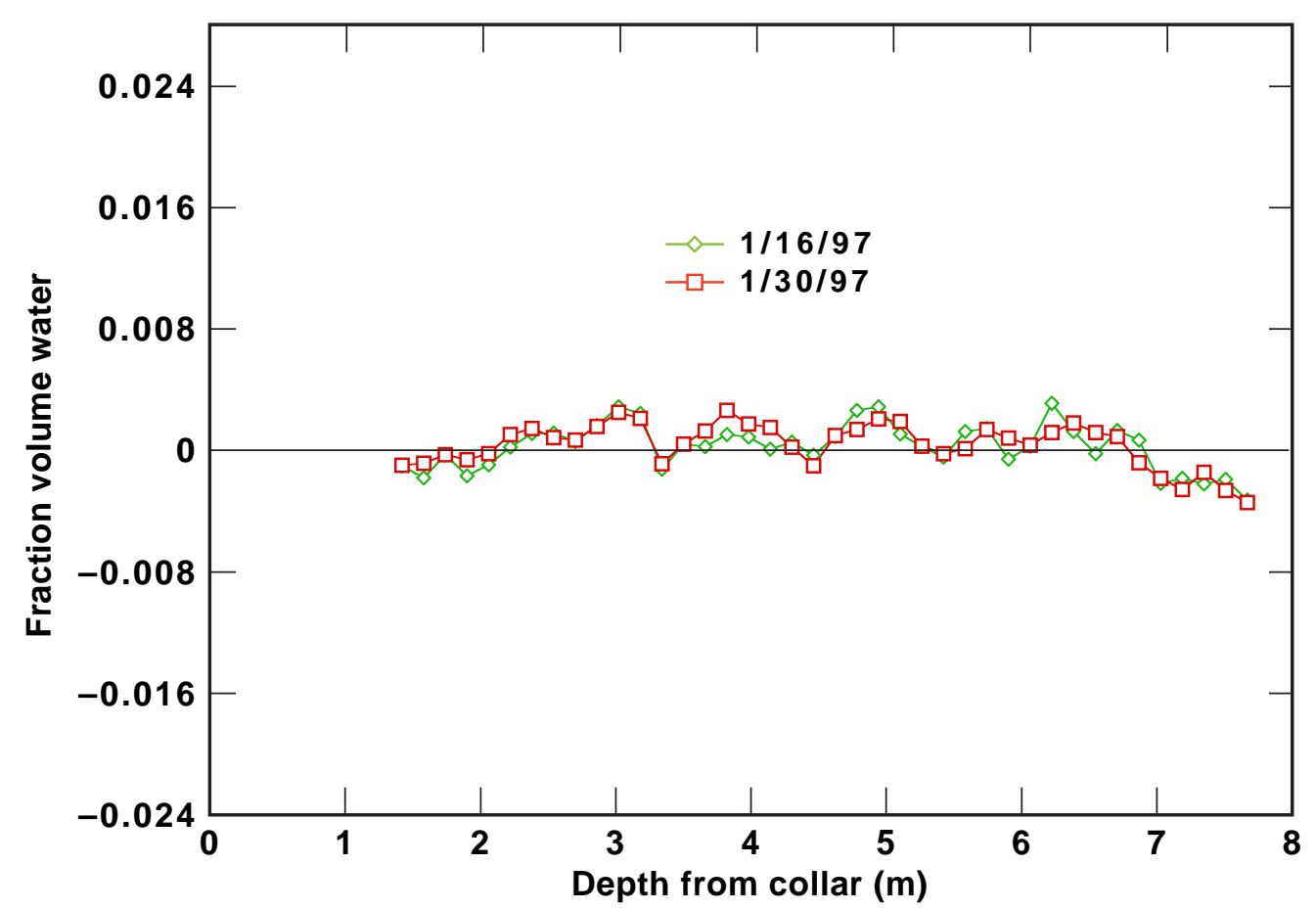

Figure 3-23. Smoothed difference fraction volume water content in Borehole 22 as a function of depth from collar on January 16, 1997, and January 30, 1997

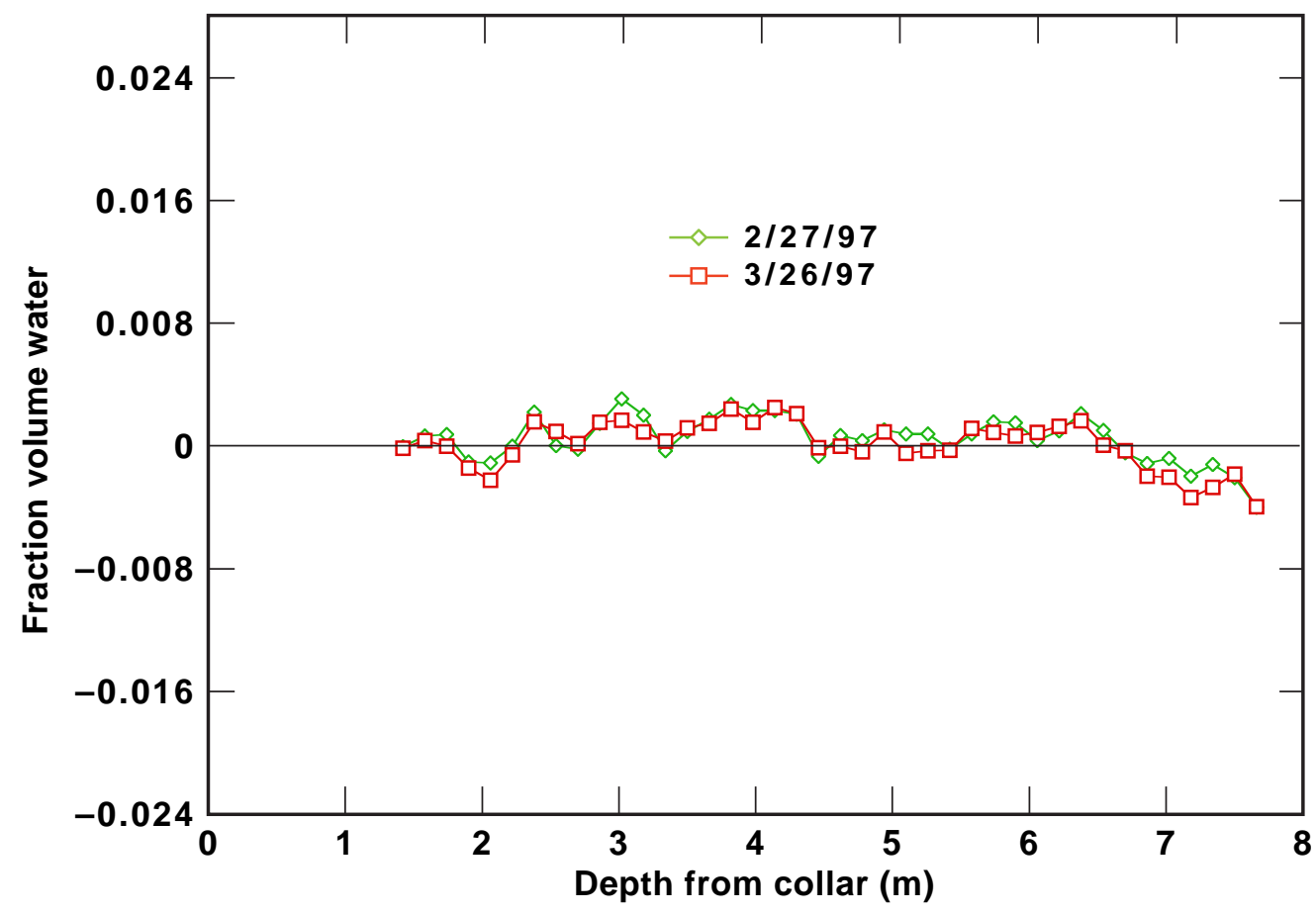

Figure 3-24. Smoothed difference fraction volume water content in Borehole 22 as a function of depth from collar on February 27, 1997, and March 26, 1997 


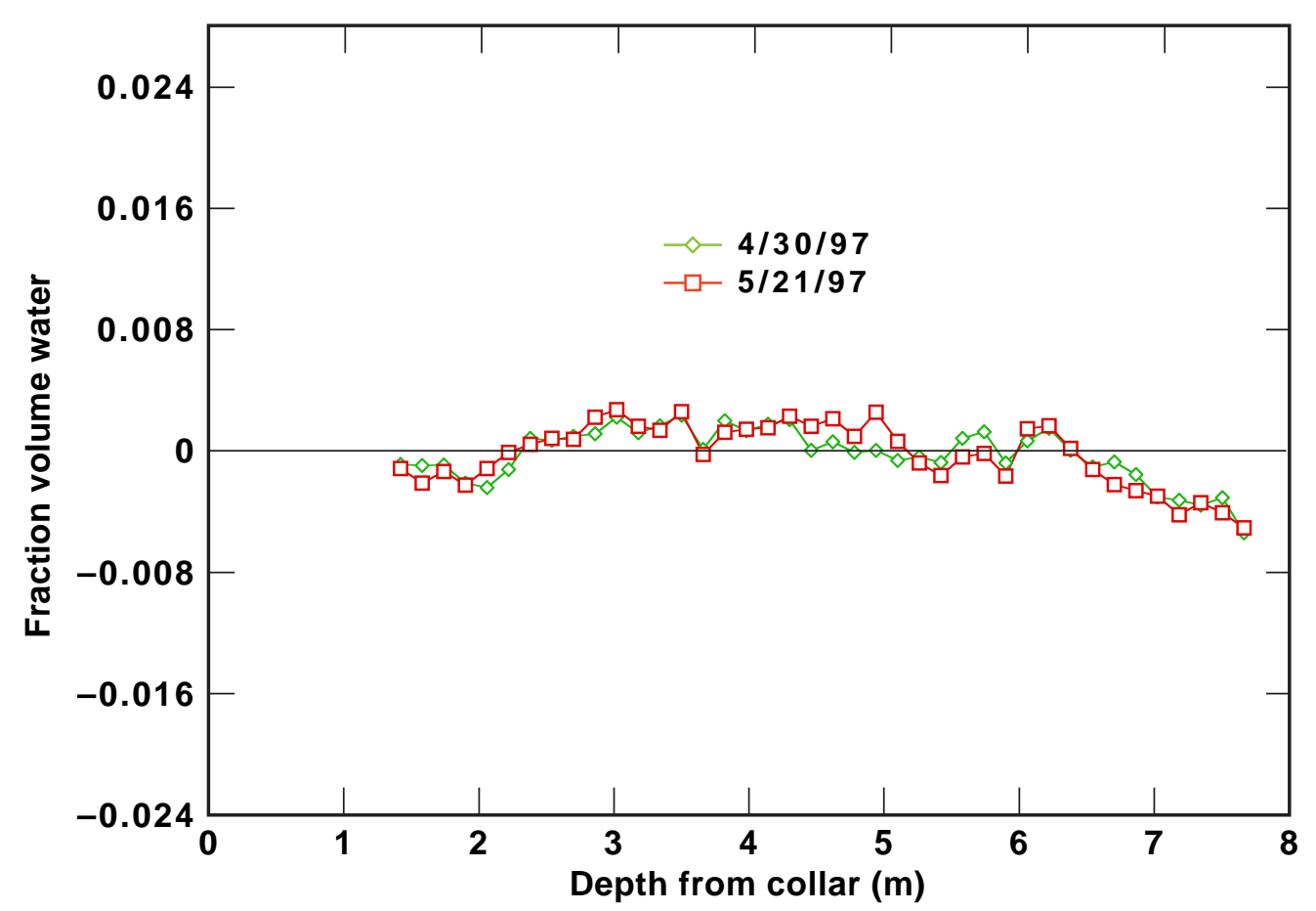

Figure 3-25. Smoothed difference fraction volume water content in Borehole 22 as a function of depth from collar on April 30, 1997, and May 21, 1997

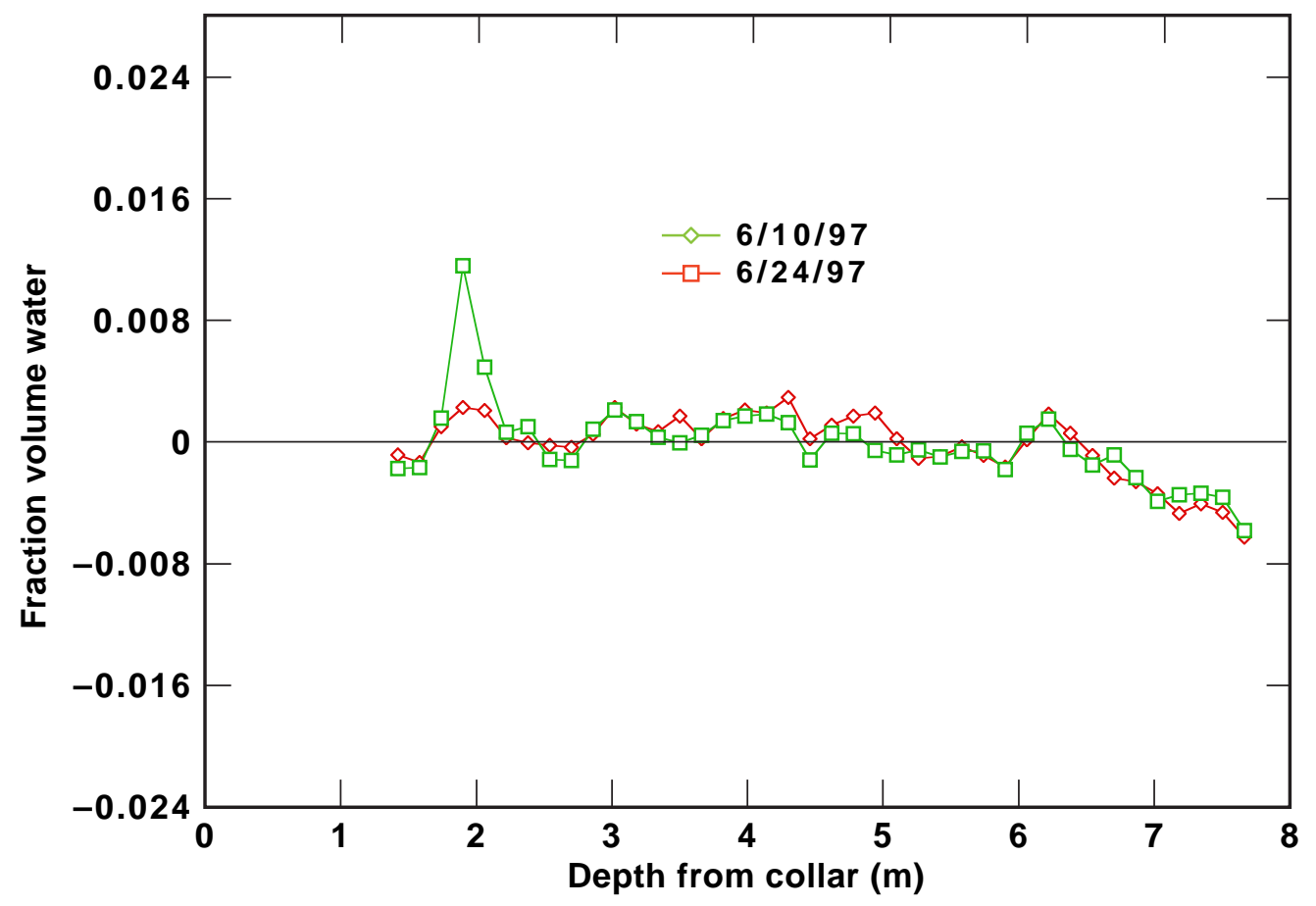

Figure 3-26. Smoothed difference fraction volume water content in Borehole 22 as a function of depth from collar on June 10, 1997, and June 24, 1997 


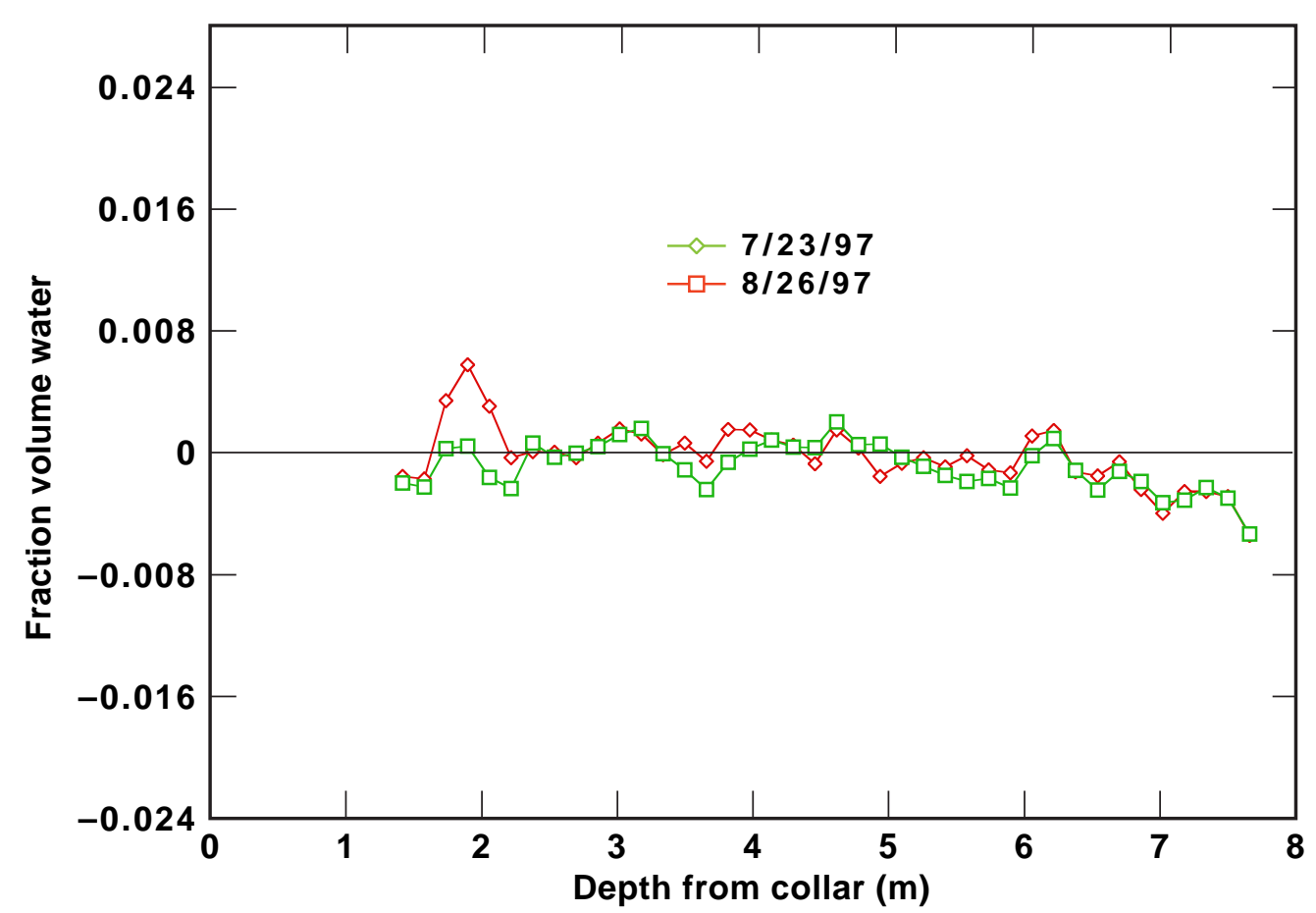

Figure 3-27. Smoothed difference fraction volume water content in Borehole 22 as a function of depth from collar on July 23, 1997, and August 26, 1997

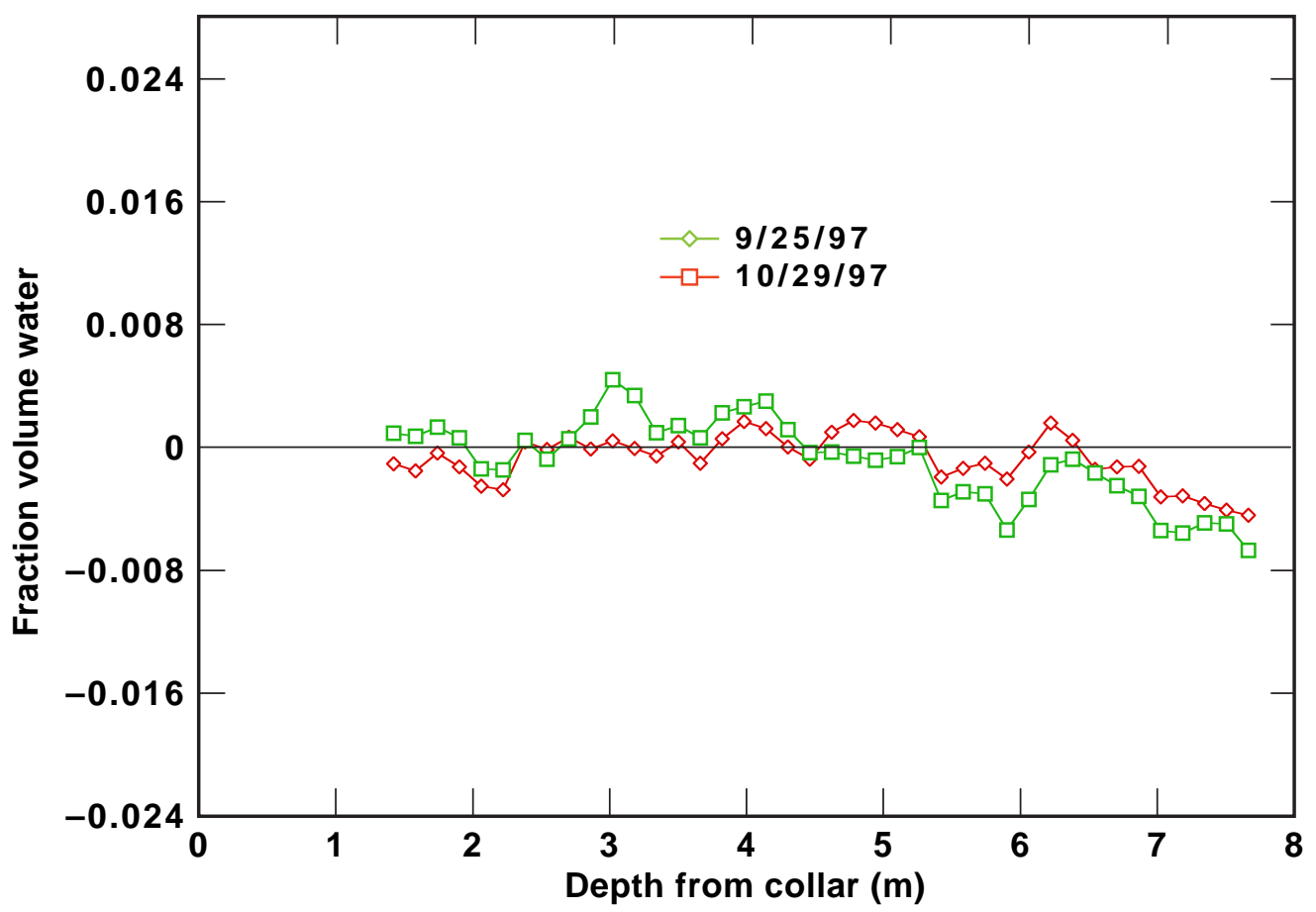

Figure 3-28. Smoothed difference fraction volume water content in Borehole 22 as a function of depth from collar on September 25, 1997, and October 29, 1997 


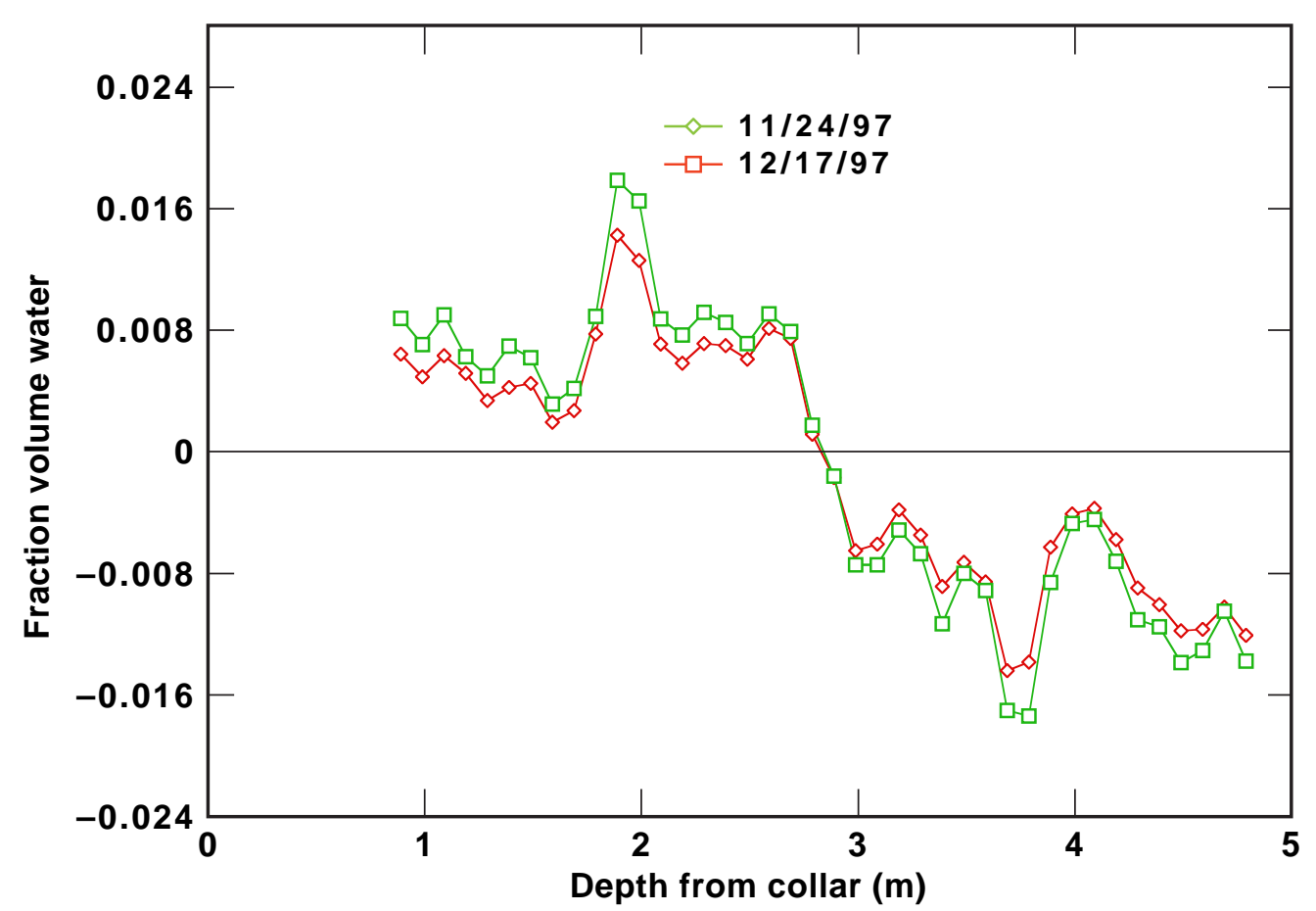

Figure 3-29. Smoothed difference fraction volume water content in Borehole 22 as a function of depth from collar on November 24, 1997, and December 17, 1997

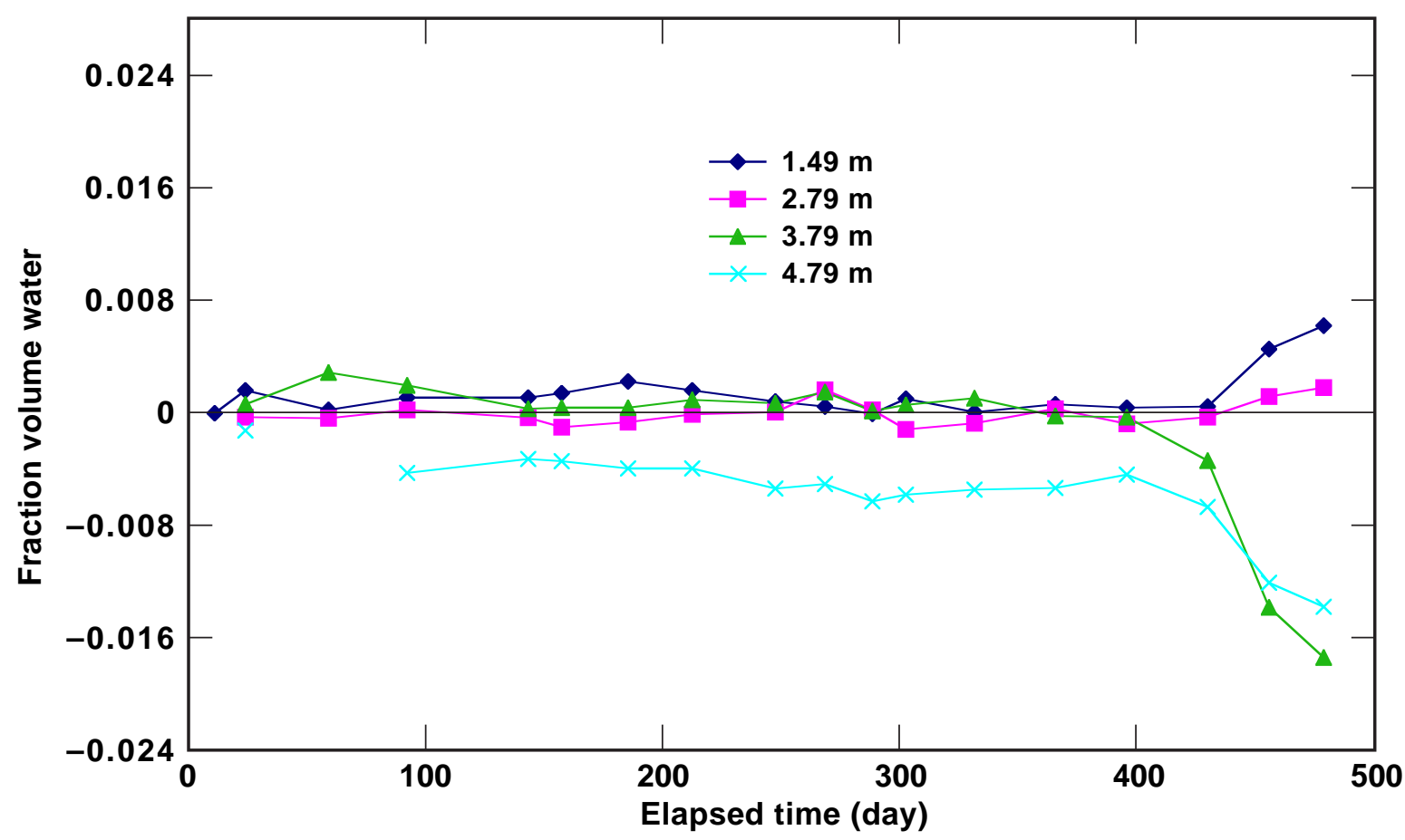

Figure 3-30. Smoothed difference fraction volume water content at various depths in Borehole 22 as a function of time 


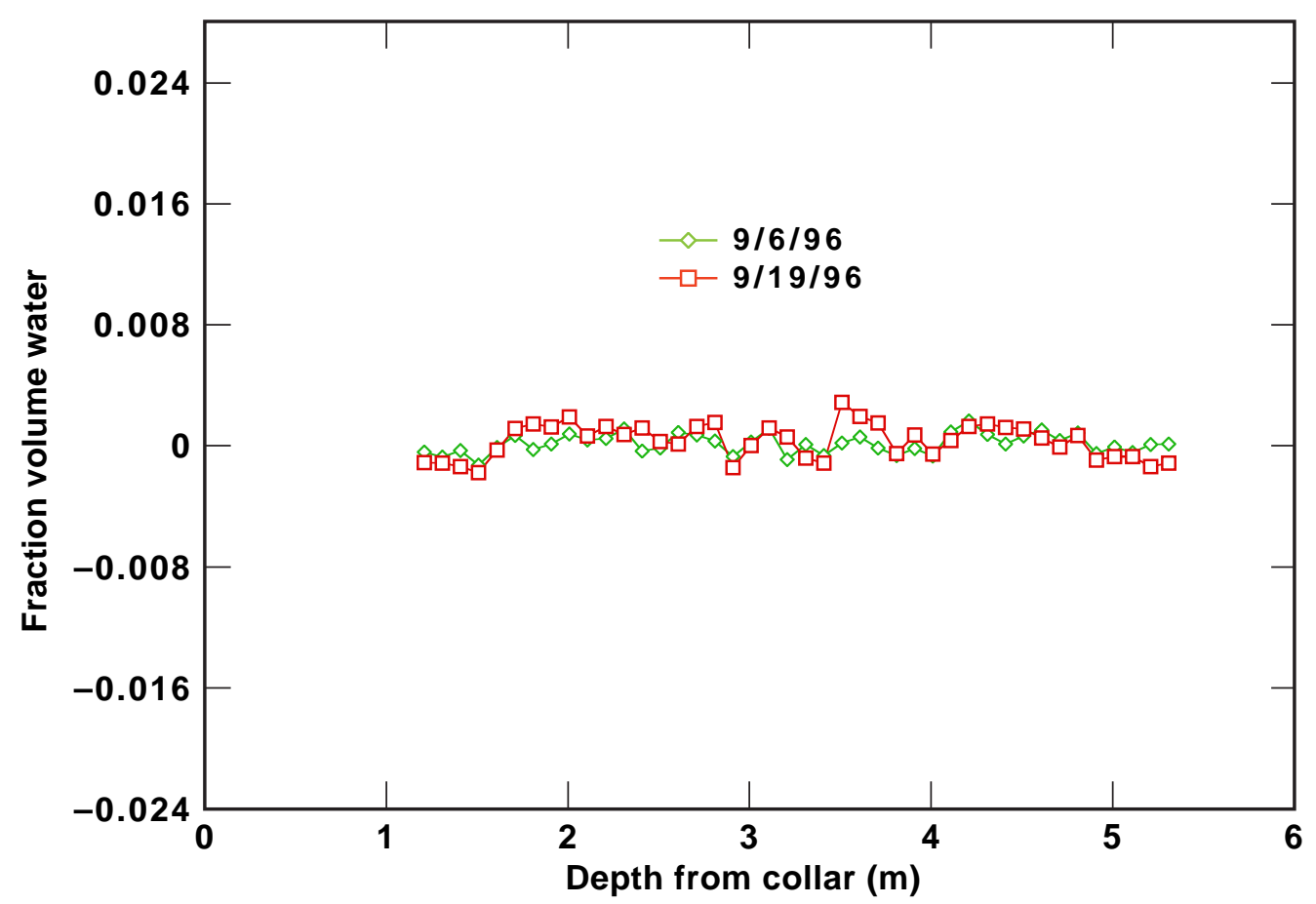

Figure 3-31. Smoothed difference fraction volume water content in Borehole 23 as a function of depth from collar on September 6, 1996, and September 19, 199

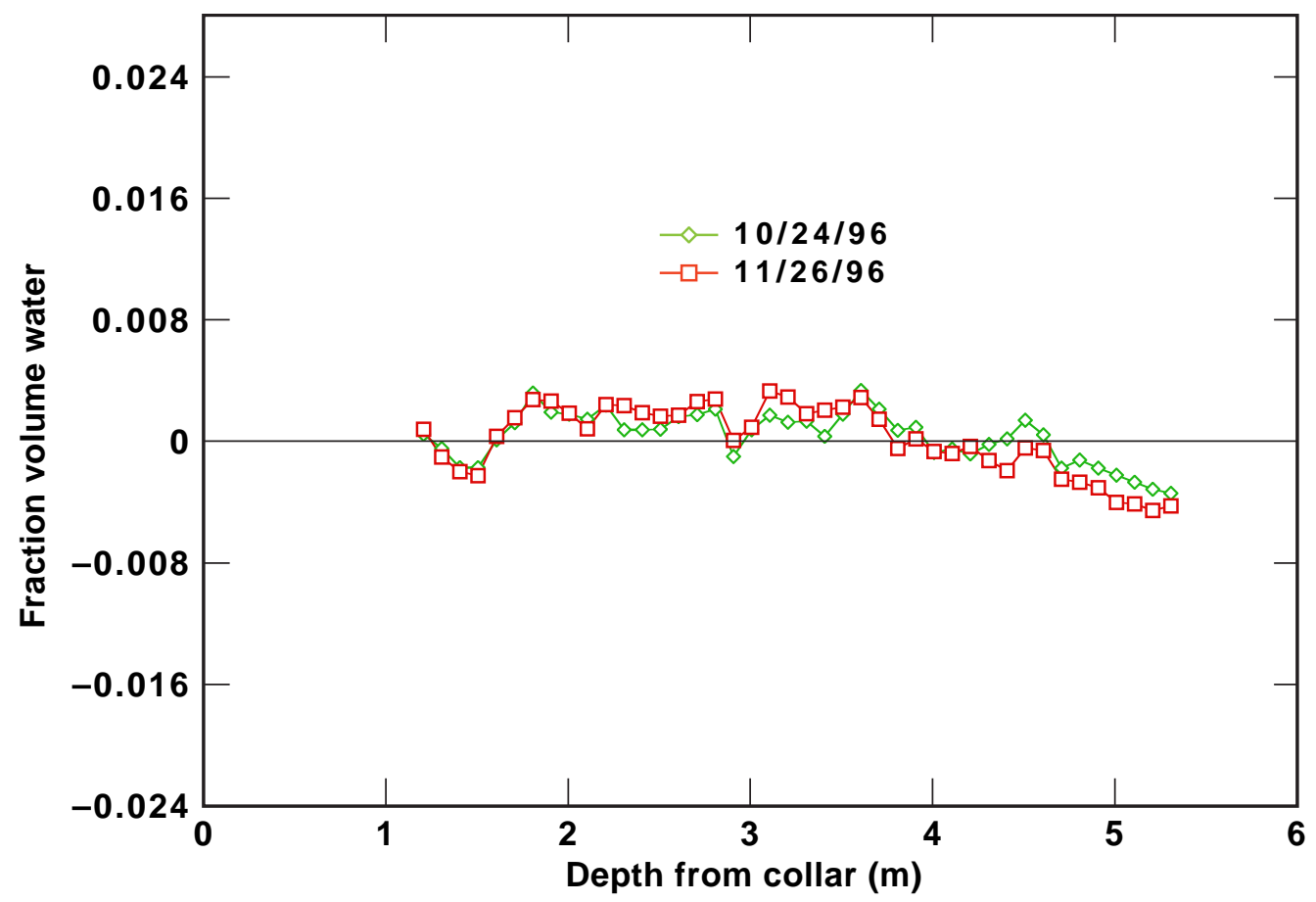

Figure 3-32. Smoothed difference fraction volume water content in Borehole 23 as a function of depth from collar on October 24, 1996, and November 26, 1996 


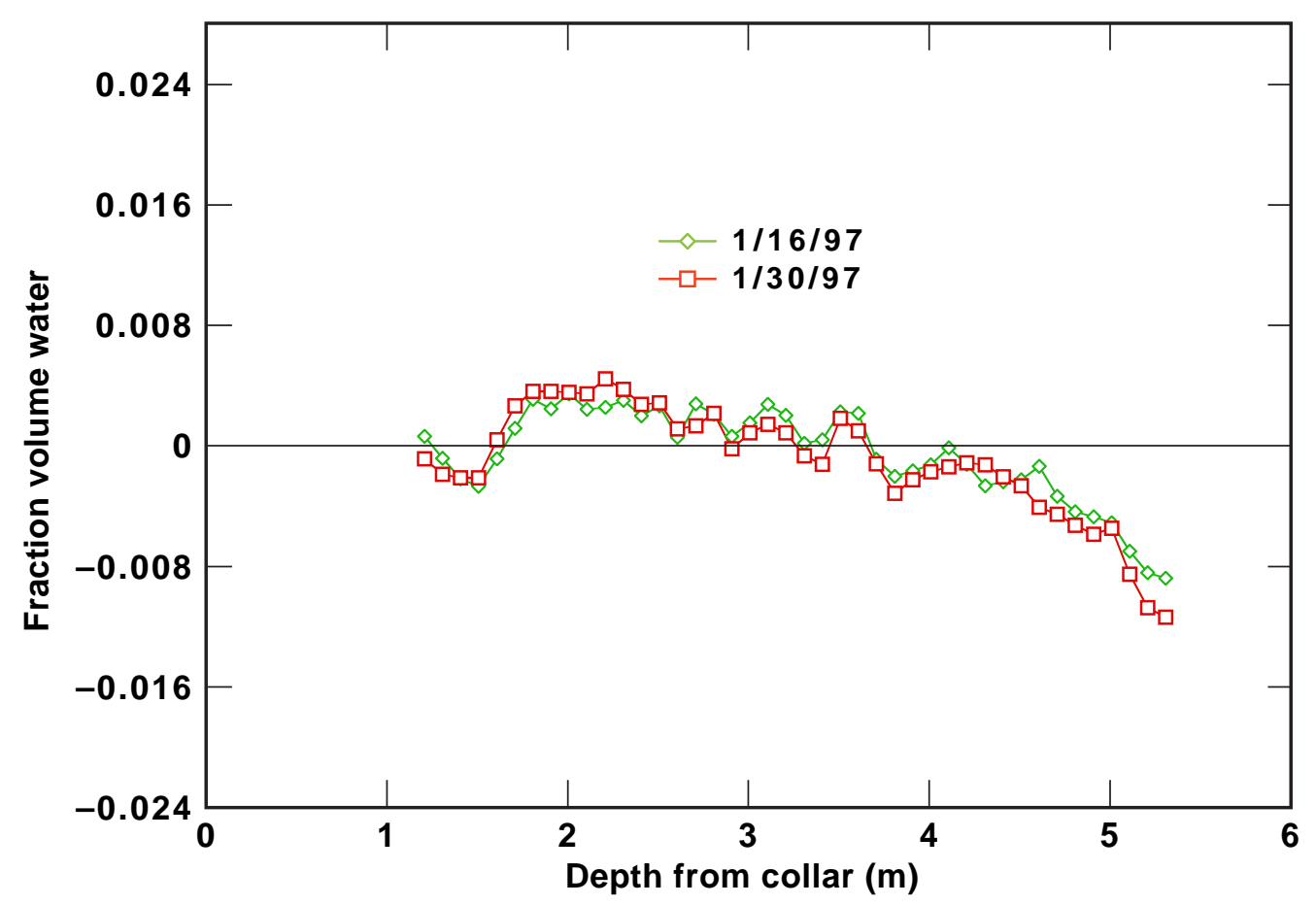

Figure 3-33. Smoothed difference fraction volume water content in Borehole 23 as a function of depth from collar on January 16, 1997, and January 30, 1997

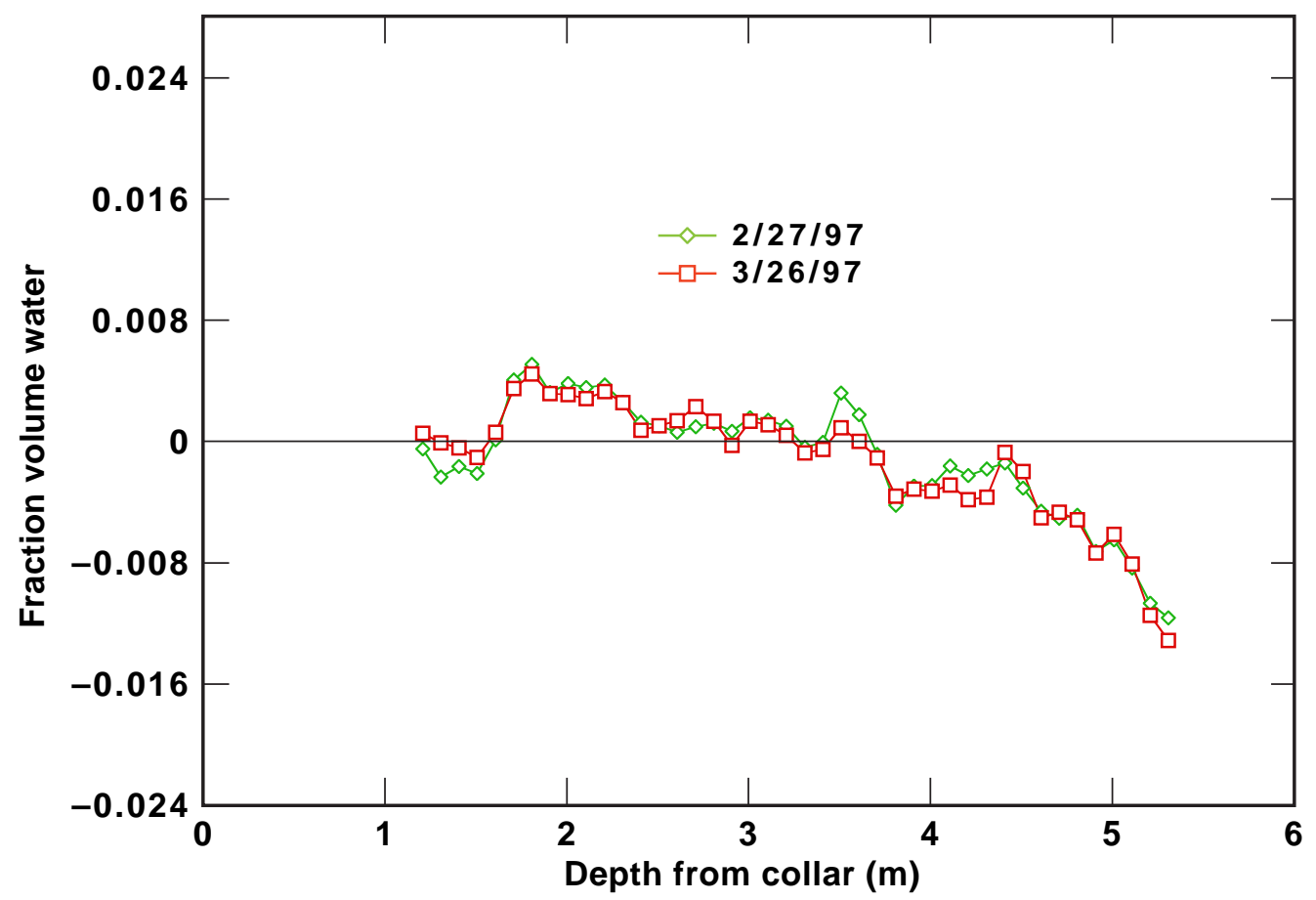

Figure 3-34. Smoothed difference fraction volume water content in Borehole 23 as a function of depth from collar on February 27, 1997, and March 26, 1997 


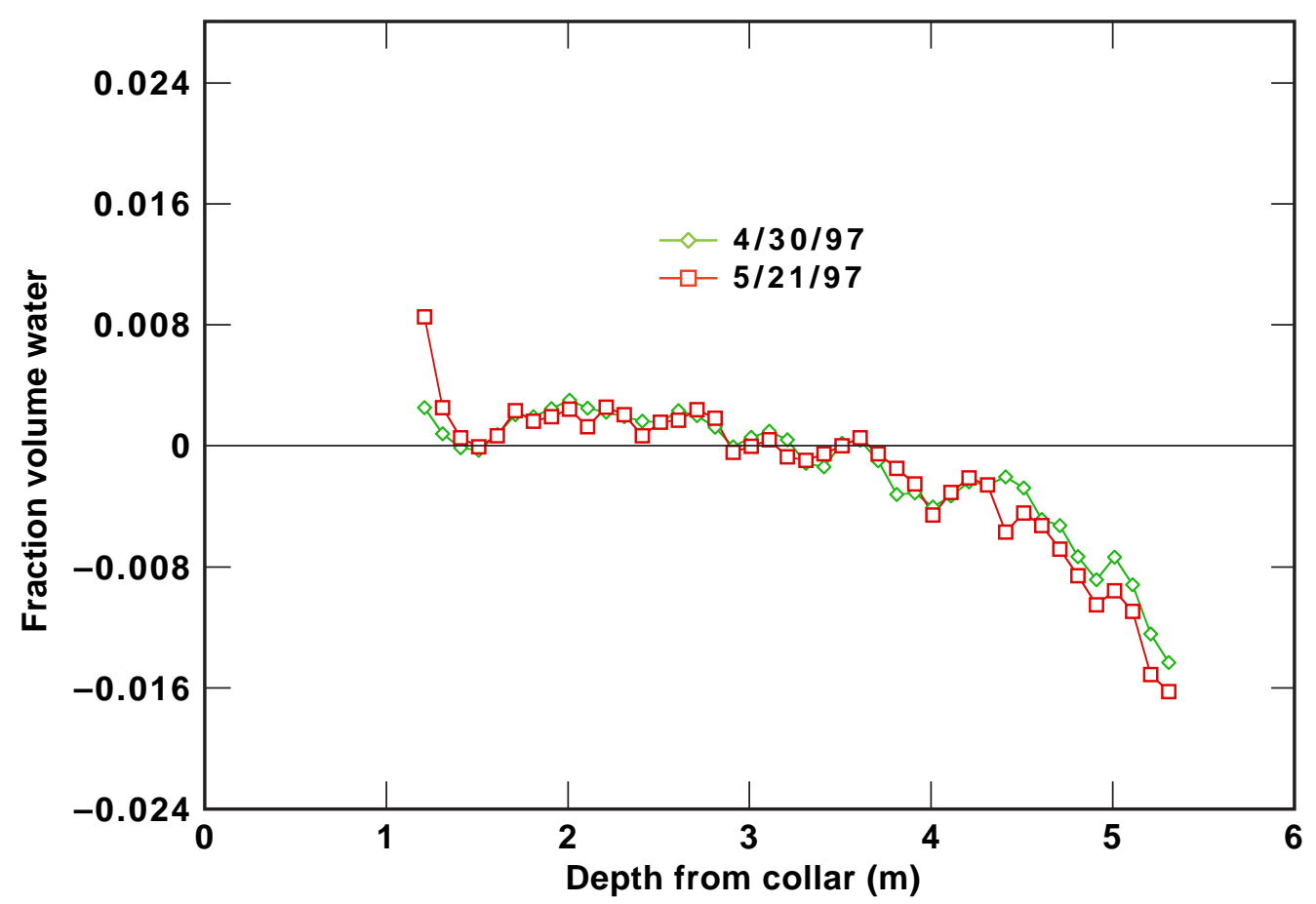

Figure 3-35. Smoothed difference fraction volume water content in Borehole 23 as a function of depth from collar on April 30, 1997, and May 21, 1997

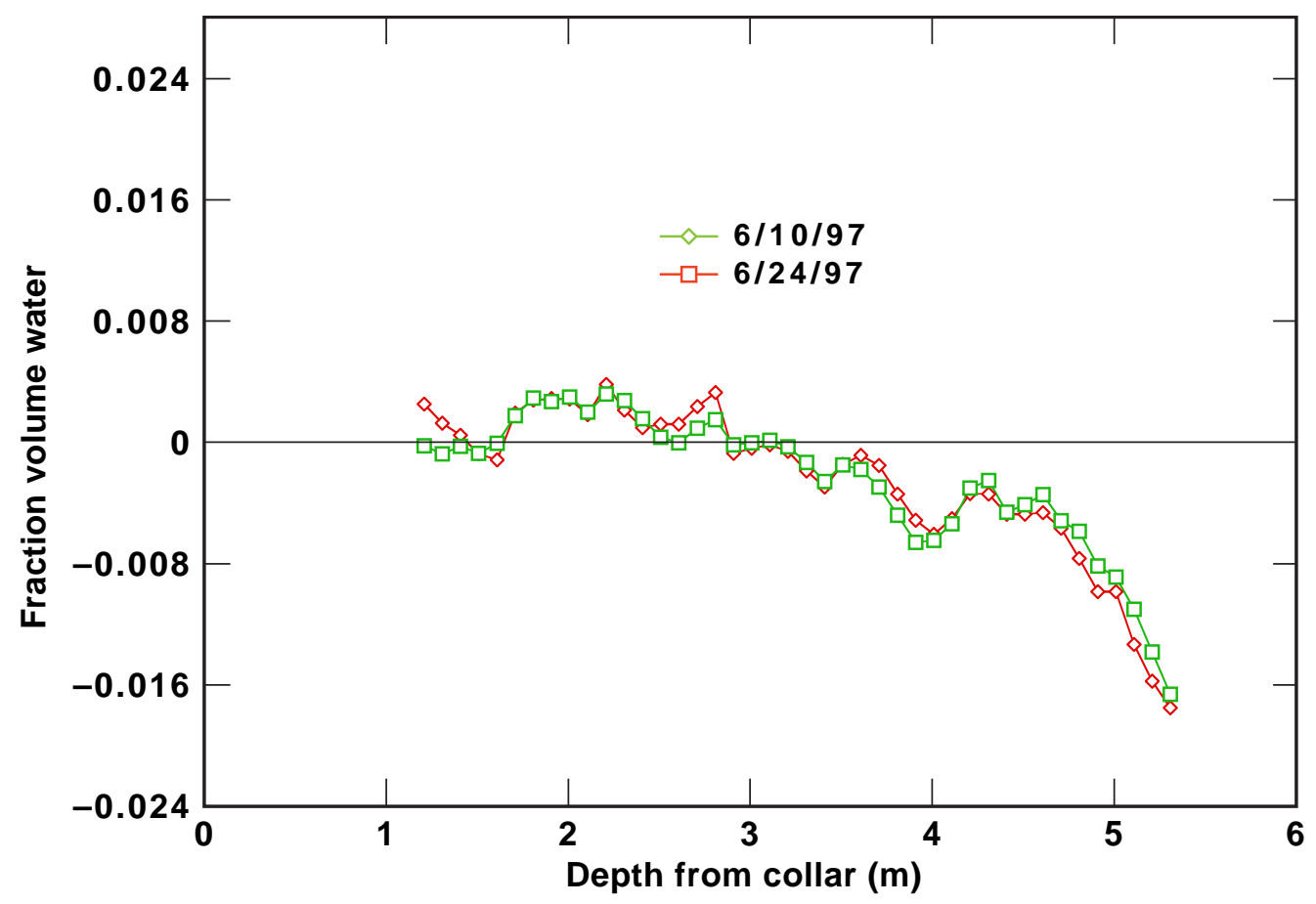

Figure 3-36. Smoothed difference fraction volume water content in Borehole 23 as a function of depth from collar on June 10, 1997, and June 24, 1997 


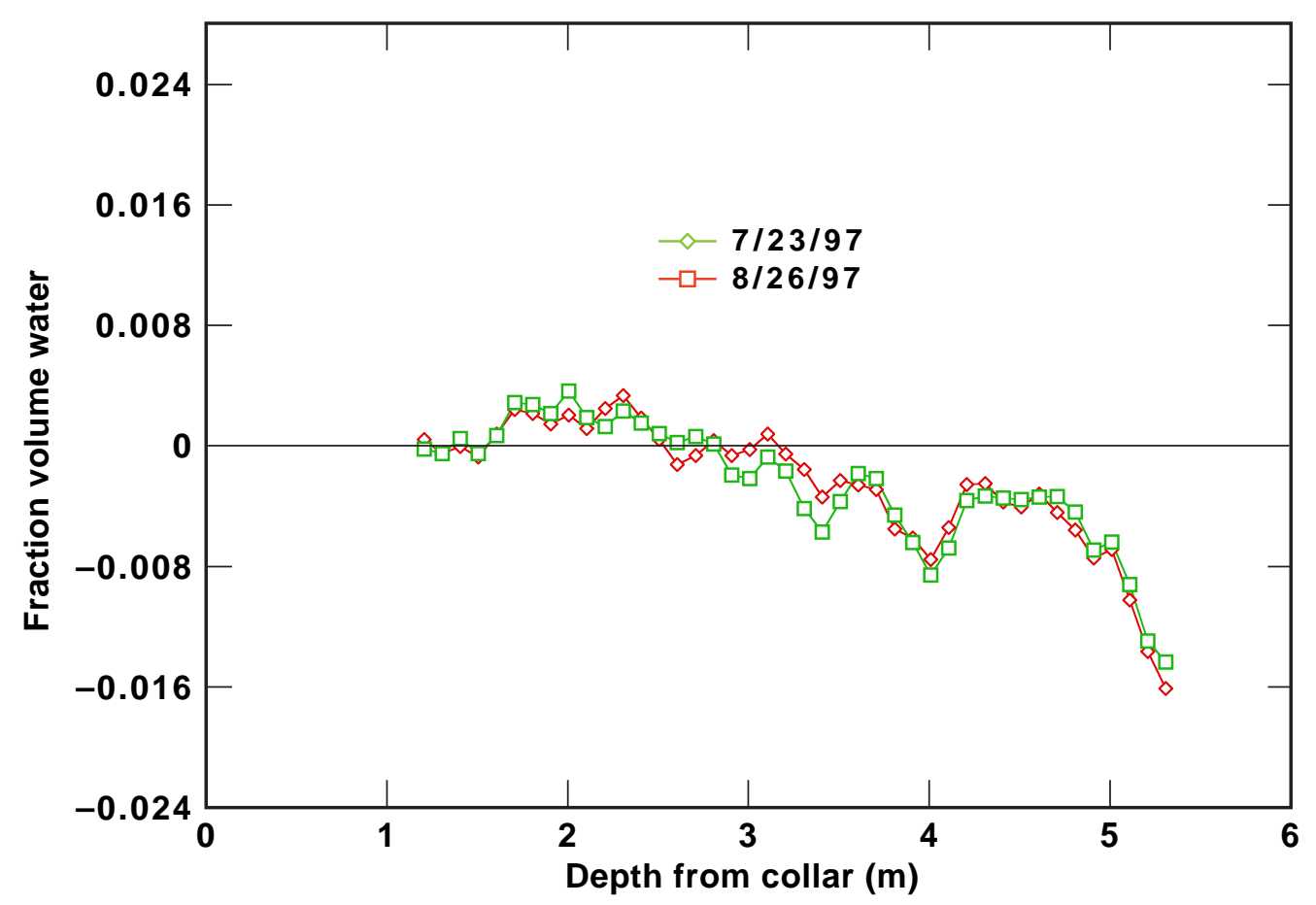

Figure 3-37. Smoothed difference fraction volume water content in Borehole 23 as a function of depth from collar on July 23, 1997, and August 26, 1997

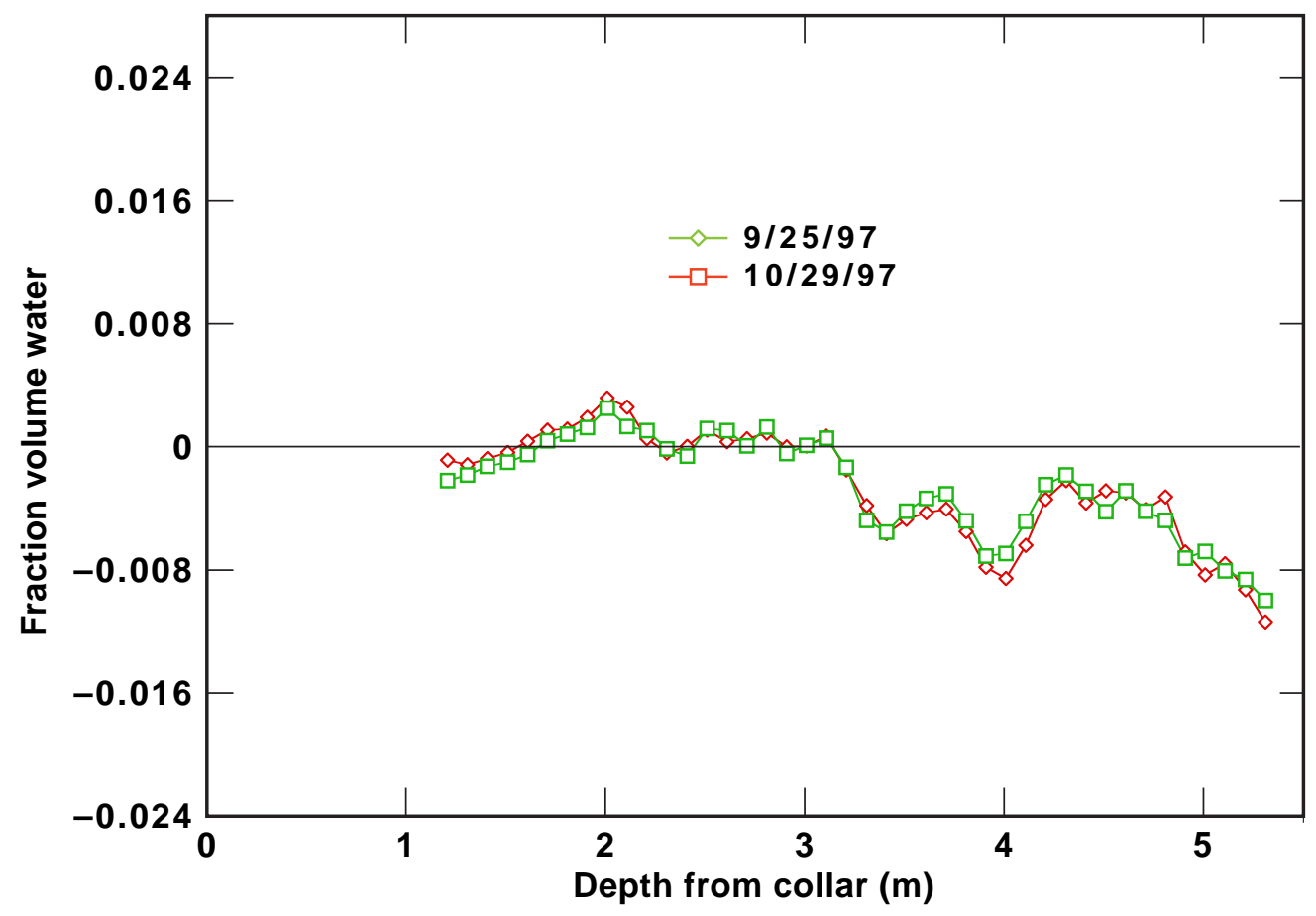

Figure 3-38. Smoothed difference fraction volume water content in Borehole 23 as a function of depth from collar on September 25, 1997, and October 29, 1997 


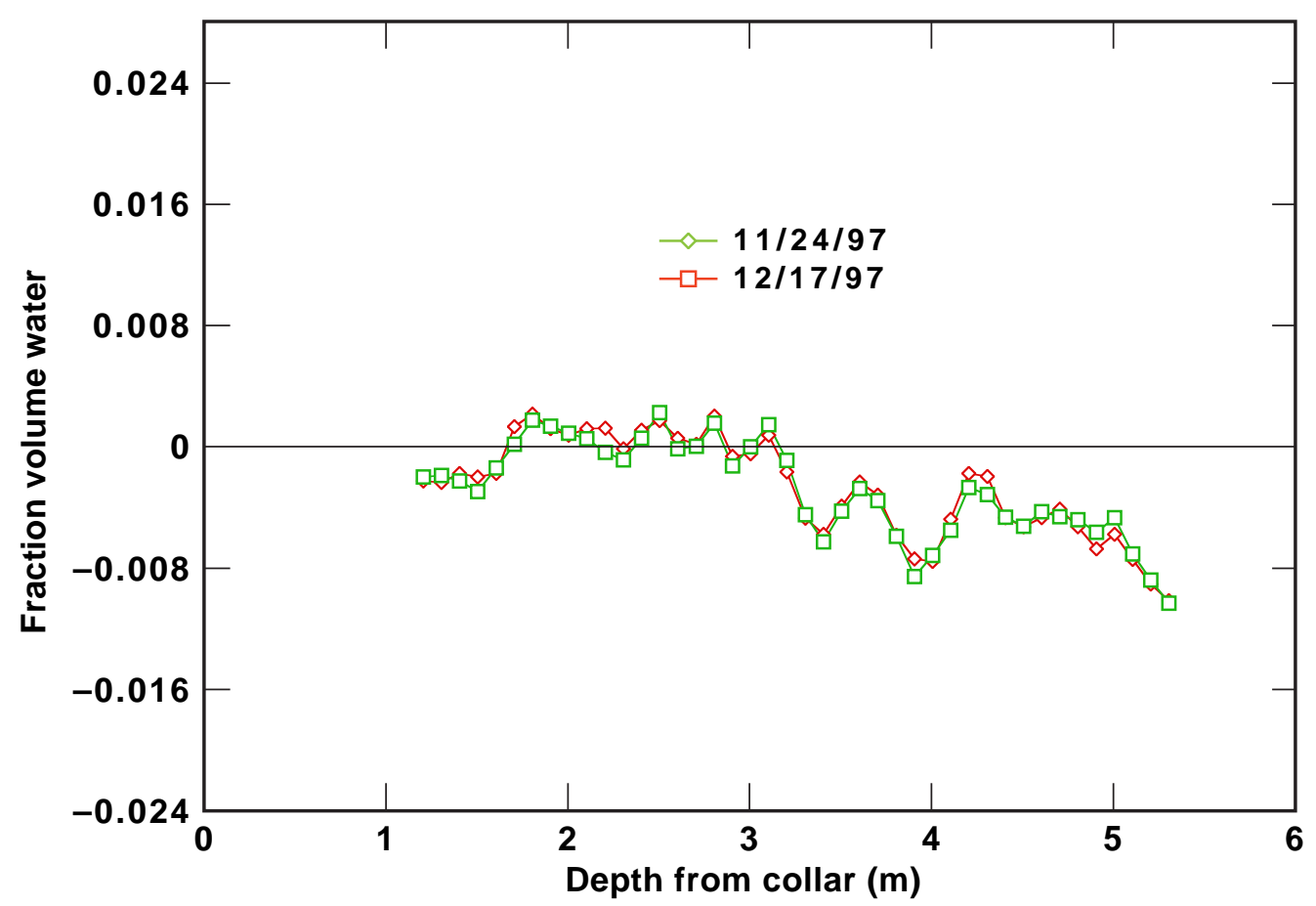

Figure 3-39. Smoothed difference fraction volume water content in Borehole 23 as a function of depth from collar on November 24, 1997, and December 17, 1997

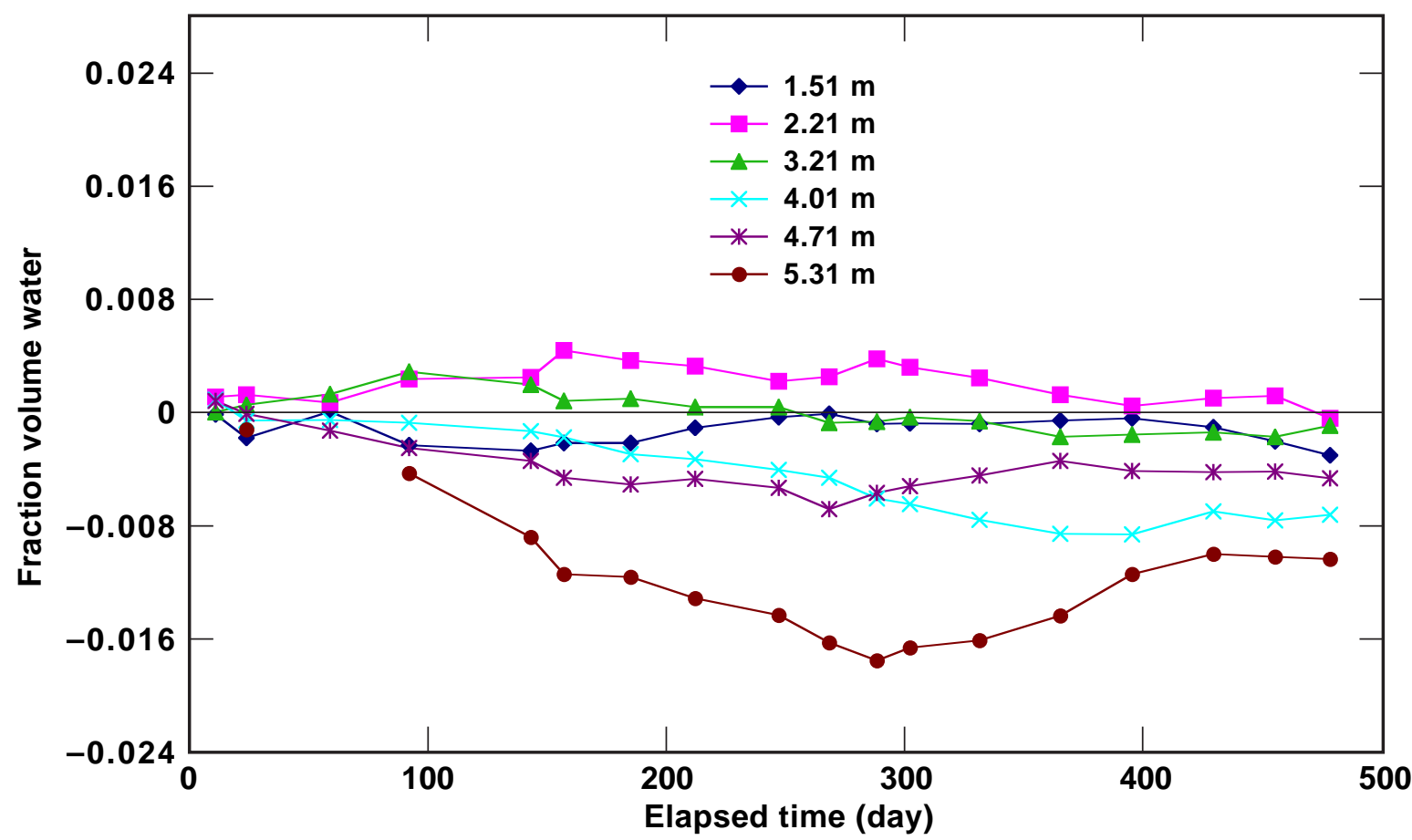

Figure 3-40. Smoothed difference fraction volume water content at various depths in Borehole 23 as a function of time 


\title{
4. Geochemical and Mineralogical Studies
}

This chapter presents results of geochemical studies of water collected during the SingleHeater Test (SHT) (Section 4.1) and mineralogical studies done on core collected from the Exploratory Studies Facility (ESF) (Section 4.2). The study of the geochemical composition of the water collected during the test provides insight into the geochemical processes active during the test. The mineralogical studies present information on the rock, providing a necessary starting point for the study of rock and water evolution with temperature and time.

\subsection{Geochemical Studies in the Single-Heater Test}

\author{
by Laura D. DeLoach and William E. Glassley
}

\subsubsection{Introduction}

Thermal effects from proposed high-level nuclear waste emplacement in a geologic repository are expected to dominate the movement and chemical evolution of in situ pore water and fracture water in the unsaturated zone (UZ) surrounding the repository. At sufficiently high temperatures, the water may evaporate or boil, migrating as vapor into cooler regions of the rock and then condensing; the movement and composition of the water are of particular importance in and around the waste packages (WP), where contact with the potentially chemically reactive, introduced materials would be relevant to the lifetime of the WPs and to subsequent radionuclide transport. The ability to model and predict conditions surrounding the WPs depends in large part on experimentally derived data. Thus, field-scale and laboratory experiments, including the Single-Heater Test, have been initiated to study relevant processes within the proposed "repository-equivalent" rock at Yucca Mountain, Nevada. The results of water chemistry studies during the SHT are presented in this chapter together with the models developed based on the analytical results.

\subsubsection{Borehole Performance and Water Collection During the SHT}

Boreholes drilled into the rock surrounding the heating element of the SHT were instrumented with various sensors and monitoring systems for spatial and temporal resolution of the physical properties. Among these boreholes, two chemistry boreholes were drilled to a depth of approximately $5 \mathrm{~m}$ from the access/observation drift of the ESF into rock surrounding the heating element. These boreholes-ESF-TMA-CHE-1 (\#20) and ESF-TMACHE-2 (\#21) - occupied a plane normal to the single heater and were oriented at very low angles above (up $0.5^{\circ}$ ) and below (down $7.5^{\circ}$ ) the heater plane (see Figure 1-1 for reference). The holes were instrumented with SEAMIST ${ }^{\mathrm{TM}}$ (Science Engineering Associates Membrane Insitu Sampling Technology) inflatable liners for the express purpose of evaluating the contacting water chemistry. Another borehole, ESF-TMA-NEU-2 (\#16), was drilled from the thermomechanical alcove extension (TMAE), just opposite of the chemistry boreholes, and turned out to be critical to collecting SHT water. This borehole, also depicted in Figure 1-1, was instrumented by Lawrence Berkeley National Laboratory (LBNL) for hydrology studies. Borehole \#16 was oriented in a plane normal to the heater axis at an upward angle of $7.5^{\circ}$ and to a depth of $5.5 \mathrm{~m}$ into the rock. 
Two methods of water-chemistry evaluation were employed in the chemical boreholes of the SHT:

1. One of the SEAMIST liners was fitted with a suite of solid-state chemical sensors for in situ, real-time chemical evaluation of waters entering the boreholes.

2. Absorbent pads were installed on a liner to be retrieved for more precise, laboratory chemical testing.

Early tests on the solid state sensors conducted at the SHT facility were inconsistent with the manufacturer's specified performance parameters. Subsequently, the sensors were subjected to laboratory tests; these demonstrated significant compositional dependencies, the sensors inappropriate for deployment in the field thermal-testing program. Instead, absorber pads were used in conjunction with SEAMIST liners and were periodically retrieved for characterization. In general, the pads exhibited only slight moisture content, thus making extraction of water by "wringing" unrealistic. An extraction process was developed in which pads were immersed and soaked in deionized water (dilution). This process was followed by sampling and filtration of the resulting solution. Simultaneously, a clean-pad blank was run to provide baseline corrections (per gram weight of fabric) for the actual samples. During the course of sampling, the blanks used for the baseline corrections were found to produce a high degree of scatter in the chemical analyses with respect to some important metal ions. The chemical data, consequently, could not be assumed to be reliable without a blank from the original manufacturing lot, and these were not available.

The LBNL hydrology holes, on the other hand, were instrumented for the monitoring of temperature, pressure, and relative humidity. The system employed was a string of hightemperature, inflatable packers, which isolated four open zones of a particular borehole. Fortuitously, the inflated packers, which straddled fractured regions, also provided a means of containing ambient or mobilized water entering the open region of the borehole. One borehole and zone in particular-Borehole \#16, zone 4 (at a depth of $3 \mathrm{~m}$ )-yielded a significant and steady supply of water for chemical analyses starting in November 1996 and continuing throughout the heating phase of the SHT.

Four samples of water were collected from Borehole 16, zone 4 (hereafter referred to as Borehole 16-4) during the course of the SHT and were distributed for analyses. A pH value was determined in the field when the water sample or suite was collected. Samples were filtered, using a $0.45-\mu \mathrm{m}$ pore filter, and then split for distribution and chemical analyses. In the case of samples designated for cation analysis, the sample preparation included acidifying the water with $\mathrm{HNO}_{3}$ to stabilize the metals in solution. Handling and storage of samples were maintained under refrigeration. In general, samples were refrigerated to prevent evaporation (although thermally controlled conditions were not completely maintained during shipment and receiving). Samples designated for major ion-analyses were stored in polyethylene bottles, and samples for stable isotope analyses were stored in glass bottles. All bottles were filled to minimize headspace and capped to reduce evaporation.

An important distinction should be noted for Suite 1, the first sample collected on November 25, 1996. This initial water sampling opportunity was unexpected; as a consequence, the sample was collected without obtaining a $\mathrm{pH}$ measurement in the field, and neither the filtration nor the acidification procedure was performed. 


\subsubsection{SHT Water Analytical Tests}

The cation analyses were performed at Lawrence Livermore National Laboratory (LLNL) and were obtained by inductively coupled plasma and atomic emission spectroscopy. Total metal concentrations of $\mathrm{Al}, \mathrm{B}, \mathrm{Ca}, \mathrm{Fe}, \mathrm{Mg}, \mathrm{Li}, \mathrm{Na}, \mathrm{K}, \mathrm{S}, \mathrm{Si}$, and $\mathrm{Sr}$ were measured. Anions were measured by liquid chromatography at LLNL; anions measured included $\mathrm{F}^{-}, \mathrm{Cl}^{-}, \mathrm{Br}^{-}, \mathrm{NO}_{2}^{-}$, $\mathrm{NO}_{3}{ }^{-}, \mathrm{PO}_{4}{ }^{3-}$, and $\mathrm{SO}_{4}{ }^{2-}$. $\mathrm{HCO}_{3}$ was computed by charge balance, assuming the measured $\mathrm{pH}$ corresponded to the actual hydrogen activity at the time of sampling. In addition, stable isotopes of oxygen and hydrogen were analyzed by mass spectrometry by LLNL, LBNL, and the U. S. Geological Survey (USGS) at Denver, Colorado. Measurements of uranium and strontium isotopes have been made by other investigators for these same suites of waters.

\subsubsection{Analytical Results}

The results of chemical analyses for the four suites of SHT water are presented in Table 4-1. For comparative purposes, data from several relevant water sources have been included, and their respective sources are cited among the footnotes. Row 1 of the tabulated information gives the date of collection. Row 2 reports the temperature of the borehole interval as downloaded from the data-acquisition system for the corresponding date and time of collection. Concentrations for the listed analytes are given along with the field-recorded $\mathrm{pH}$ values; as previously stated, Suite 1 (obtained November 25, 1996) was collected without the benefit of a $\mathrm{pH}$ meter on hand. The value reported was for a sample measured about 30 days after collection and should, therefore, be considered approximate.

It is noteworthy that several anion concentrations measured among the SHT waters appeared to have different levels of detection depending on the sample being analyzed. Those reported for $\mathrm{NO}_{3}{ }^{-}$, for example, showed lower detectable limits of $0.4 \mathrm{mg} / 1$ (Suite 2) and $2.0 \mathrm{mg} / 1$ (Suites 3 and 4). This was a consequence of the instrument's response to significant concentrations of some ions, such as $\mathrm{F}^{-}$or $\mathrm{Cl}^{-}$, masking adjacent peaks of other ions of interest.

Table 4-1. Water chemistry summary of SHT Borehole 16-4 waters, Yucca Mountain (YM) unsaturated-zone (UZ) perched water, YM saturated-zone (SZ) groundwaters, and Rainier Mesa fracture water (DTN LL971006604244.046)

\begin{tabular}{|c|c|c|c|c|c|c|c|c|c|}
\hline & Suite $1^{a}$ & Suite $2^{b}$ & Suite $3^{c}$ & Suite $4^{d}$ & & & & & \\
\hline Collected & $11 / 25 / 96$ & $02 / 04 / 97$ & $02 / 27 / 97$ & 05/22/97 & & & & & \\
\hline \multirow[t]{2}{*}{ Temp $\left({ }^{\circ} \mathrm{C}\right)$} & & 46.9 & 47.60 & 51.20 & & & & & \\
\hline & $\begin{array}{c}\text { Borehole } \\
16-4 \\
\text { LLNL Data }\end{array}$ & $\begin{array}{c}\text { Borehole } \\
16-4 \\
\text { LLNL } \\
\text { Data }\end{array}$ & $\begin{array}{c}\text { Borehole } \\
16-4 \\
\text { LLNL } \\
\text { Data }\end{array}$ & $\begin{array}{c}\text { Borehole } \\
16-4 \\
\text { LLNL } \\
\text { Data }\end{array}$ & $\begin{array}{c}\text { Perched } \\
\text { Water } \\
\text { UZ-14 } \\
\text { PT-4' }\end{array}$ & $\begin{array}{c}\mathrm{SZ} \\
\text { Ground- } \\
\text { water } \\
\mathrm{J}-13^{\mathrm{j}}\end{array}$ & $\begin{array}{l}\text { Pore } \\
\text { Water } \\
\text { UZ-5- } \\
\text { TP-4 }\end{array}$ & $\begin{array}{c}\text { Rainier } \\
\text { Mesa } \\
\text { Fracture } \\
\text { Water }\end{array}$ & $\begin{array}{c}\text { SZ } \\
\text { Ground- } \\
\text { water } \\
\text { G-4 }\end{array}$ \\
\hline $\mathrm{Na}(\mathrm{mg} / \mathrm{l})$ & 16 & 13.9 & 12.20 & 11.00 & 34.0 & 45.8 & 33 & 35 & 57 \\
\hline Si $(\mathrm{mg} / \mathrm{l})$ & 16.8 & 17.4 & 14.50 & 15.20 & 32.1 & 28.5 & 99 & 25 & 21 \\
\hline $\mathrm{Ca}(\mathrm{mg} / \mathrm{l})$ & 13. & 9.76 & 8.65 & 7.70 & 27.0 & 13 & 58 & 8.4 & 13 \\
\hline K (mg/l) & $\begin{array}{l}2.5 \\
2.69^{\mathrm{e}}\end{array}$ & 2.5 & 3.30 & 2.30 & 1.8 & 5 & 9 & 4.7 & 2.1 \\
\hline $\mathrm{Mg}(\mathrm{mg} / \mathrm{l})$ & 1.63 & 1.16 & 1.01 & 0.92 & 2.1 & 2.01 & 12 & 1.5 & 0.20 \\
\hline $\mathrm{pH}$ & $6.2^{\mathrm{k}}$ & 6.9 & 6.80 & 6.55 & & 7.4 & & 7.5 & \\
\hline
\end{tabular}




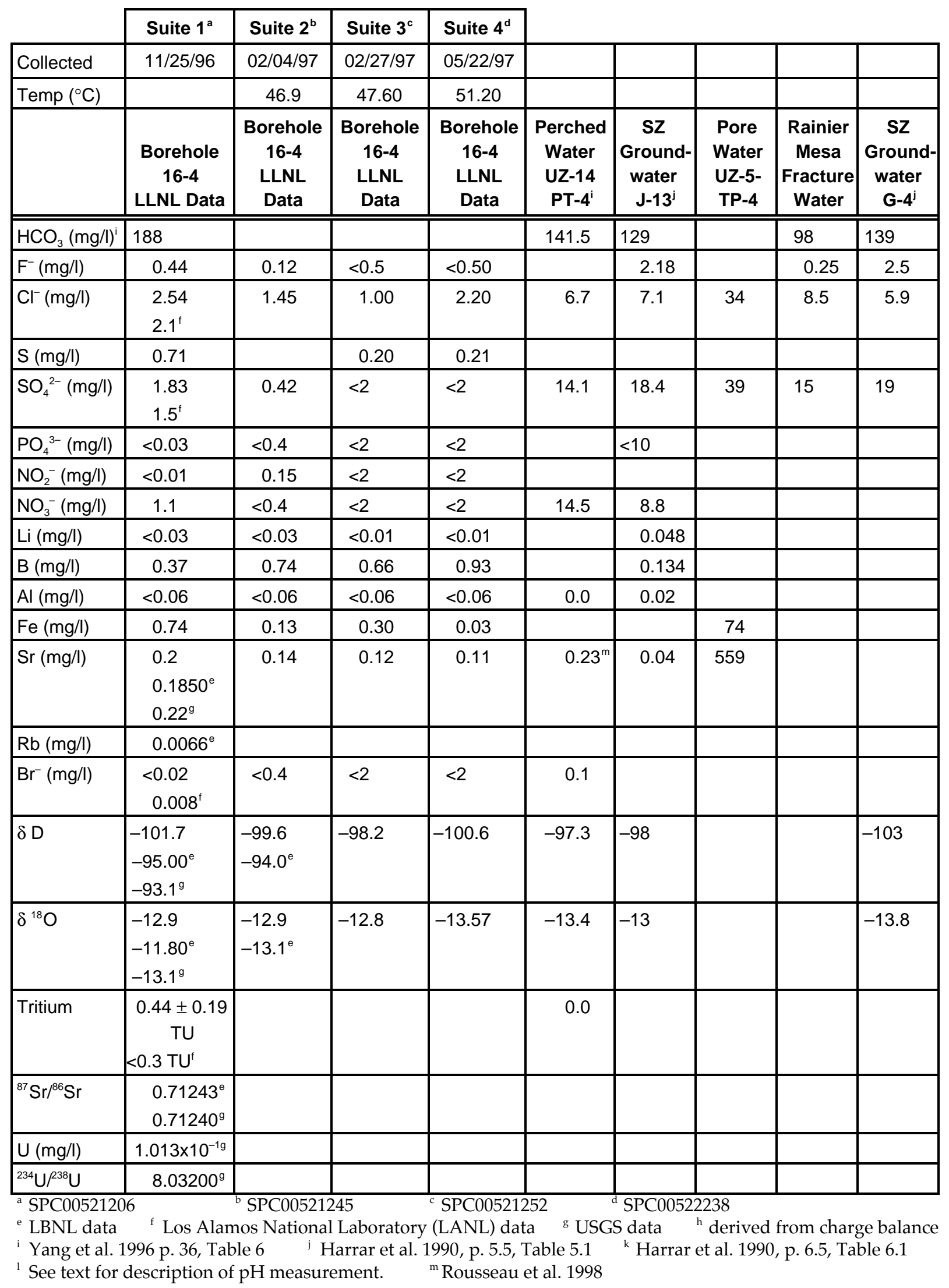


Table 4-1 clearly shows that the SHT water is more dilute than are the other in situ waters. Clearly revealed among the chemical trends for the waters sampled from the SHT was relatively high $\mathrm{Na}$ and $\mathrm{Si}$ content with significant $\mathrm{Ca}$ concentrations, but low abundances of other cations and anions; these trends were similar to those of all in situ waters in the vicinity, as shown in Table 4-1. Values of $\mathrm{pH}$ were slightly acidic and between 6.2 and 6.9. These measured $\mathrm{pH}$ readings may have indicated elevated $\mathrm{CO}_{2}$ partial pressures in equilibrium with the water in the packed-off interval.

The water samples were collected over a 6-month period-from November 25, 1996, through May 22, 1997-with the first sample collected approximately 90 days after start of heating. A plot of the data for the main cation species in water $(\mathrm{mg} / \mathrm{l})$ as a function of time (days lapsed since heater turn-on) is given in Figure 4-1. Here, concentrations were observed to generally become more dilute with time. Temperatures of the borehole interval were also increasing with time, although the change between Suite 2 and Suite 4 waters was on the order of only $5^{\circ} \mathrm{C}$.

Figure 4-1. SHT Borehole 16-4 water composition as a function of time (DTN LL971006604244.046)

In all cases, $\mathrm{Na}, \mathrm{Ca}, \mathrm{Mg}$, and $\mathrm{Sr}$ systematically decreased, whereas all other elements exhibited nonsystematic variation. Generally, the four suites of water were characteristically rich in $\mathrm{Na}$ and $\mathrm{Si}$, with significant concentrations of $\mathrm{Ca}$. Figure 4-2 is a plot of analyte concentrations for Suites 1-4. The $\mathrm{x}$-axis is the measured components, and the concentrations in $\mathrm{mg} / \mathrm{l}$ are plotted on the $\mathrm{y}$-axis. It is evident from Figure $4-2$ that the relative concentrations of elements tended to follow a similar pattern for all of the samples.

\section{Figure 4-2. Composition of SHT waters compared for Suites 1-4} (DTN LL971006604244.046)

Stable isotopic data $\left({ }^{18} \mathrm{O}\right.$ and deuterium) are plotted as $\delta^{18} \mathrm{O}$ relative to $\delta \mathrm{D}$ in Figure 4-3. The meteoric water line is plotted for reference. The scatter in the data for Suite 1 may reflect the fact that the first samples were collected during an unanticipated "window of opportunity" in which water appeared in a borehole not necessarily designed for chemical sampling, and, consequently, standard collection procedures were not employed. Generally, data for Suites 2-4 were more tightly grouped and were broadly consistent with the other analyzed waters. There does not appear to be a clear distinction in the isotopic data among the various water sources represented here.

Figure 4-3. Stable isotope data for SHT waters (Suite 1-4), saturated-zone waters G-4 and J-13, UZ-14 perched water, and ESF pore water (USGS memorandum: Albert Yang et al. to Robert Craig, YMSCP, "Submission of Milestone SPH37DM4, due June 13, 1997," June 10, 1997, DTN GS970608312272.004)

\subsubsection{Discussion}

The origin of the water in Borehole 16-4 may potentially be derived from any one of several sources or some combination. Therefore, chemical data have been included in Table 4-1 for relevant waters sampled in and around Yucca Mountain. The compositions of pore water (from the nonwelded Paintbrush tuff at Yucca Mountain) and perched waters (from UZ-14) are reproduced in Table 4-1 from the work reported by Yang (1996; 1988). Water 
samples collected from fractures at Rainier Mesa and waters from the saturated zone J-13 well water and G-4 well water are included (Harrar et al. 1990, Vol. 1). Of course, condensate produced during the heating process and with little to no rock-water interaction would be readily identifiable as essentially distilled water. Drilling water also could potentially pool in the area, but it has a distinctive $\mathrm{Br} / \mathrm{Cl}$ signature not consistent with any of these sample suites.

To compare the compositional makeup of SHT waters to the sources just mentioned, Figure 4-4 was plotted with pore water (Yang et al. 1988), fracture water (Rainier Mesa), saturated zone water (G-4 and J-13), and perched water (UZ-14) with Suite 2 SHT water. (Suites 1, 3, and 4 would plot very close to Suite 2 waters [see Figure 4-2] and are therefore omitted for clarity.)

Figure 4-4. Comparison of SHT water, pore water, perched water, saturated-zone water (Harrar et al. 1990, Vol. 1), and fracture water (Rainier Mesa) (DTN LL971006604244.046)

Waters that are genetically related by simple addition of condensate (which is the most likely and simplest mechanism whereby Borehole 16-4 waters could be related to other waters) would exhibit trends that approximately parallel Suite 2 SHT. The pore water exhibited sharply contrasting trends and, thus, could not be related to the Borehole 16-4 waters. In the case of fracture and saturated zone waters, the most abundant elements in those waters ( $\mathrm{Na}$ and $\mathrm{Si}$ ) exhibited inverse relative concentrations to those seen in Borehole 16-4 waters. Only perched water from UZ-14 exhibited the same general trend. The major ions in solution $(\mathrm{Na}, \mathrm{Si}$, and $\mathrm{Ca}$ ) seemed to have similar relative proportions.

Detailed comparison of the perched water compositions, however, demonstrated that simple dilution of perched water by condensate to generate SHT water is not possible. Figure 4-5 compares ratios of elements between the Borehole 16-4 waters and the perched water. Figure 4-5 shows that most elements depleted in SHT waters with respect to perched water, with ratios of $\sim 0.3$ to 0.5 . However, these ratios were not entirely consistent; in fact, $\mathrm{K}$ was enriched in SHT water, and Sr had a slightly greater relative concentration than did most other ions.

\section{Figure 4-5. Concentration ratios of SHT water to perched water (DTN LL971006604244.046) \\ Perched water concentrations plot on the $y=1$ line. Above this line, SHT water is enriched in the represented ions; below the line, SHT waters are depleted in the represented ions.}

This suggests that both Borehole 16-4 waters and the perched waters followed reaction paths that were similar, but were individually affected by processes unique to the specific environments in which they occurred. If, for example, perched waters originated from rain water, and the Borehole 16-4 waters originated from condensate, it may be that the perched waters, which have a residence time in the mountain that is much greater than that of the condensate waters, had exchanged $\mathrm{K}$ and Sr with slowly evolving alteration products in the regions in which they resided; this resulted in relative depletion of these elements in the waters. In this scenario, one would predict that K- and Sr-rich clays would be much more abundant in the perched water zones than in the Borehole 16-4 environments. 
The predominant mechanism for water movement is expected to be fracture flow; the rate at which water apparently entered the borehole is consistent with fracture flow rather than with matrix flow. Thus, the overall composition of the fracture water in Borehole 16-4 will likely be a result of interaction between condensate and fracture-lining minerals. Fracture-lining minerals have principally been described as calcite $\left(\mathrm{CaCO}_{3}\right)$ and a silica $\left(\mathrm{SiO}_{2}\right)$ polymorph (opal-CT, quartz, or trydimite) accompanied by minor amounts of zeolites, oxides, clays, and potassium feldspar (Vaniman et al. 1997, Vol. 1, Section 2, Table 2.1; Roberts and Viani 1996, p. 14, Table 4). Compositional characteristics of SHT waters from Borehole 16-4 were consistent with dissolution of such fracture mineralogy.

\subsubsection{Modeling}

\subsubsection{Assumptions}

Geochemical modeling can be used to gain insight into the origin and evolution of the water sampled in Borehole 16-4. A simulation matrix was constructed to evaluate the combination of variables that provided the best match to the observed water composition.

The mechanism by which water enters Borehole 16-4 is presumed to be fracture flow. The low, measured $\mathrm{pH}$ is inconsistent with water-air equilibrium. Thus, two assumptions in the simulations were that SHT water composition is derived from the interaction of condensate and fracture-lining mineralogy and that gas composition must be allowed to vary.

The fracture mineralogy was assumed to be $90 \%$ calcite and 5\% opal (modeled as amorphous $\mathrm{SiO}_{2}$ ) with a minor alkali feldspar component. These proportions are also consistent with previously published reports of fracture mineralogy (see, for example, Roberts and Viani 1996, p. 14, Table 4; Vaniman et al. 1997, Vol. 1, Section 2, Table 2.1; and observations from the Large-Block Test [Glassley and Boyd 1995, pp. 1-20]). These mineral phases were considered because they represent the primary sources and sinks for the principal cations and anions in solution.

The dominant gas components were assumed to be $\mathrm{H}_{2} \mathrm{O}$ and $\mathrm{CO}_{2}$. Previous work has suggested that $\mathrm{CO}_{2}$ may play an important role in the evolution of the gas phase during boiling (see Arthur and Murphy 1989, pp. 313-327, and Criscenti and Arthur 1991, pp. 513-517). The low $\mathrm{pH}$ observed for the SHT waters is consistent with this observation, therefore $\mathrm{CO}_{2}$ evolution was considered in the simulations.

Because the time between initiation of the heater test and sampling was about 90 days, it was assumed that the time duration of the simulation covered a period as long as two months. Presumably, until at least a week of heating had elapsed, not enough water would be heated to result in significant condensate shedding.

\subsubsection{Strategy}

The simulations were conducted using EQ3 / 6 reaction path models (version 7.2a of the EQ3 / 6 code package (Wolery 1992a, pp. 1-65; Wolery 1992b, pp. 1-246, the R22a "com" database) and GIMRT (Steefel and Yabusaki 1995). The primary variables for the simulations were reaction rate constants for the solids of concern and the partial pressure of $\mathrm{CO}_{2}$. The rate constants were varied within the uncertainty envelope of the values that generated the best simulations for laboratory plug-flow experiments (a description of the experiment and results can be found in (Johnson et al. 1998, pp. 1-3 and p. 27, Table 3). 
The modeling suggests that the reaction-rate kinetics previously reported (Johnson et al. 1998 , p. 27) apply to the solid phase mineral assemblage here-although, as previously noted, the rates for albite are problematic (Glassley 1997, p. 3). The results also suggest that the previously assumed surface areas underestimate those actually relevant for the models.

\subsubsection{Results}

The evaluation of simulations done on the SHT waters established the following points:

- The concentration of Ca followed precisely that expected if calcium concentration reflected the interaction of calcite and water in which $\mathrm{pH}$ was externally controlled. This confirmed the conceptual model in which the dominant Ca phase participating in the reaction was calcite.

- The solution concentration of Si remained supersaturated with respect to quartz. (This is consistent with the post-mortem, secondary mineral findings reported for Borehole 16-4 as including a pure silica phase.) (Attachment, "Mineralogic Projects of the ESF Single-Heater Test: Input to Draft Single-Heater Test Final Report SPY147M4," to interagency memorandum from S.S. Levy, LANL, to L.D. DeLoach, LLNL, August 24, 1998)

- The concentrations of $\mathrm{K}$ were consistent with K-feldspar dissolution.

- The Na concentration was too high for a plagioclase feldspar interaction in aqueous solution model; this was anticipated because, as previously noted (Johnson et al. 1998, p. 27), solid solution dissolution kinetics remain poorly characterized.

- $\mathrm{CO}_{2}$ partial pressure must have been elevated, relative to ambient atmospheric values. The low $\mathrm{pH}$, relative abundances of major ions, and the time period over which that low $\mathrm{pH}$ formed require that the coexisting $\mathrm{CO}_{2}$ partial pressure be approximately two orders of magnitude greater than ambient. Additional and ongoing field studies in the ESF would support this observation.

- It is suggested that the primary characteristics of the solution chemistry were developed within a flow distance of 3 to $6 \mathrm{~m}$ of the heater at temperatures and flow conditions within the actively convecting portion of the heated region.

- Along the flow path, the effective surface area of the primary fracture minerals would be expected to diminish as secondary minerals precipitate. The solution then would become less concentrated with time. This evolution was also generally consistent with the measured solution chemistries.

\subsubsection{Conclusions}

Comparison of SHT Borehole 16-4 waters over time showed them to be slowly evolving while maintaining certain consistent compositional characteristics. These characteristics were that $\mathrm{Na}$ and $\mathrm{Si}$ were the dominant cations in solution, followed by $\mathrm{Ca}, \mathrm{K}$, and $\mathrm{Mg}$. Values of $\mathrm{pH}$ at about 6.5 all reflect slightly acidic waters. The low $\mathrm{pH}$ was indicative of higher $\mathrm{CO}_{2}$ partial pressures. Increased $\mathrm{CO}_{2}$ partial pressures of approximately two orders of magnitude, relative to ambient atmospheric values, would account for the conditions seen.

The characteristics of these waters were similar to those of perched water obtained from UZ-14 but were distinct from pore waters, saturated-zone waters, and fracture waters previously documented. No simple mechanism exists for generation of Borehole 16-4 waters by condensate dilution of pre-existing waters. This suggests a model in which both perched waters and Borehole 16-4 waters evolve from condensate (or rain water, in the case of the perched water) through interaction of fracture-lining minerals during fracture flow. 
However, the specific histories are uniquely determined by the time and mineralogical interaction in their respective settings. With regard to J-13, this may indicate the need to revisit the selection of the principal reference water chemistry.

The plot of SHT water chemistry as a function of time demonstrates that the composition was slowly evolving. The evolution was consistent with a simple model in which condensate interacted with fracture-lining minerals only. As dissolution and evolution of secondary minerals proceeded, the effective surface areas of reactant phases decreased and those of equilibrium secondary minerals increased. As a result, condensate was closer to equilibrium with the evolved fracture surfaces; this resulted in less dissolution per unit time and distance of flow and led to a lower dissolved load by the time the solution reaches Borehole 16-4.

Preliminary modeling suggests that the flow distance was 3 to $6 \mathrm{~m}$ from the heater and that the concentration of Ca followed precisely the concentration expected if calcium concentration reflected the interaction of calcite and a water in which $\mathrm{pH}$ is externally controlled, that the solution concentration remained saturated with respect to quartz, and that the concentrations of $\mathrm{K}$ were consistent with $\mathrm{K}$-feldspar dissolution.

These conclusions are also consistent with the primary characteristics of the solution chemistry developing within a few meters of the heater, at temperatures and flow conditions expected in the actively convecting portion of the heated region, and later entering the Borehole 16-4 cavity.

\title{
4.2 Mineral Abundances in Exploratory Studies Facility Core Samples
}

\author{
by Sarah Roberts, Brian Viani, and Laura D. DeLoach
}

\subsubsection{Introduction}

Assessing the host-rock mineralogy for the potential high-level nuclear waste repository is important from the point of view of thermal and physical stability requirements. For example, it is important to quantify the presence of minerals that undergo phase transitions, dehydration, and consequent volume variations in response to elevated temperatures. The distribution of major minerals and secondary phases may provide evidence of past fluid flow paths and aid in the modeling of fluid movement in and around the WPs. Further, the mineralogy of fracture surfaces (the expected transport pathways for fluid flow) will principally contribute to the rock-water interaction processes of dissolution and precipitation that alter flow and composition of the mobilized waters.

As part of the ongoing, field-based experiments to study thermal effects on the proposed repository host rock at Yucca Mountain, Nevada, cores from drilled-out boreholes are available for mineralogical, thermomechanical, and other laboratory evaluations. Cores from the ESF, of which the SHT was one study, have been examined, and the results of x-ray diffraction (XRD) studies to quantify mineral abundances and identify fracture lining minerals are summarized here. 


\subsubsection{Methodology}

\subsubsection{Samples}

Boreholes drilled into the potential repository-equivalent rock provided core samples for pretest characterization. The densely welded and highly fractured rock of the devitrified Topopah Springs tuff was carefully picked over for representative samples that reflected various color differences. A suite of fracture-lining minerals and cavity-fill minerals was also selected for XRD.

The postmortem characterization of the SHT-affected rock volume also made possible XRD studies of secondary mineral formation. Samples hand-picked from overcoring of some of the same boreholes allowed direct comparison, especially in regions with documented water movement (as described for Borehole 16-4). The post-mortem analysis fell under the work scope of LANL and will not be addressed here.

\subsubsection{Sample Preparation}

All rock samples were crushed, by means of a hydraulic press, to less than $0.25 \mathrm{in}$. and then processed through a flat-plate pulverizer until the entire sample passed a $250-\mu \mathrm{m}$ sieve. A subsample of each was further ground in a vibratory micro-mill (Fritsch) with a sintered corundum mortar and ball for $60 \mathrm{~min}$ at approximately one-third full power and using an intermittent power cycle. Standard mineral specimens (used for calibration purposes) were crushed by hand, if necessary, and then ground in the micro-mill in the same fashion as were the tuff samples. Accompanying fracture minerals were hand-picked from the cores and ground as just described. The particle sizes and uniformity of the milled samples and standards were checked using an optical microscope. Particle sizes determined by this method were approximately $10 \mu \mathrm{m}$ or less. The ground samples were mixed with a corundum internal standard in a 4:1 ratio and again placed in the micro-mill for $30 \mathrm{~min}$ using the power cycles described previously. (The sample of corundum was Buehler, $1.0 \mu \mathrm{m} \mathrm{Al}_{2} \mathrm{O}_{3}$.) Samples were packed into stainless-steel, side-mount holders having a sample length of 18 $\mathrm{mm}$ and width of $13 \mathrm{~mm}$.

Subsamples from cores drilled for the SHT (Table 4-2 and Table 4-4) were ground and homogenized (i.e., no attempt was made to sample these on the basis of morphology). In contrast, the samples collected from other ESF drill core (Table 4-3) were sampled on the basis of color variation. Three distinct colors were observed: dark purple and brown zones in the matrix and gray zones adjacent to lithophysae and fractures. To determine if mineralogical differences existed among the three matrix types, samples of each of these were selected for x-ray analysis. The sampling protocol consisted of examining each core sample individually and choosing one or two of the matrix types for analysis. 
Table 4-2. Normalized mineral abundances ${ }^{1}$ (weight- $\%$ ) for samples from the SHT (re-analyzed data originally reported in Roberts and Viani (1996, pp. 1-20) (DTN LL980106404244.050)

\begin{tabular}{|l|c|c|c|c|c|c|c|c|}
\hline \multicolumn{1}{|c|}{$\begin{array}{c}\text { Sample \# } \\
\text { (depth in ft) }\end{array}$} & Quartz & Cristobalite & Tridymite & Albite & Sanidine & Clinoptilolite & Smectite & Muscovite \\
\hline \hline BJ-1 (1.0)-B & 10 & 22 & & 26 & 39 & & $\operatorname{tr}^{2}$ & 3 \\
\hline BJ-1 (10.0)-B & 9 & 22 & & 25 & 42 & & $\operatorname{tr}$ & \\
\hline BJ-1 (18.0)-B & 8 & 22 & & 28 & 41 & & $\operatorname{tr}$ & \\
\hline $\begin{array}{l}\text { BJ-1 (18.0)-B } \\
\text { (duplicate sample) }\end{array}$ & 6 & 22 & & 27 & 42 & & 1 & \\
\hline MPBX-2 (8.6)-D & 6 & 25 & & 23 & 41 & & 1 & 3 \\
\hline MPBX-3 (12.5)-B & 9 & 20 & & 24 & 42 & 3 & $\operatorname{tr}$ & \\
\hline $\begin{array}{l}\text { MPBX-3 (12.5)-B } \\
\text { (duplicate sample) }\end{array}$ & 13 & 21 & & 19 & 42 & 4 & $\operatorname{tr}$ & \\
\hline MPBX-4 (5.0)-B & 2 & 28 & & 28 & 41 & & $\operatorname{tr}$ & \\
\hline H1 (0.6)-C & 8 & 20 & & 27 & 42 & 1 & $\operatorname{tr}$ & \\
\hline H1 (11.3)-C & 8 & 24 & & 25 & 42 & & $\operatorname{tr}$ & \\
\hline H1 (11.6)-C & 8 & 22 & & 29 & 39 & & $\operatorname{tr}$ & \\
\hline H1; 22.2-B & 8 & 23 & & 22 & 46 & & $\operatorname{tr}$ & \\
\hline $\begin{array}{l}\text { H1; 22.2-B } \\
\text { (duplicate sample) }\end{array}$ & 7 & 24 & & 25 & 42 & & 1 & \\
\hline
\end{tabular}

* Complete borehole designation:

BJ-1-B = ESF-TMA-BJ-1 (\#9)

MPBX-2]-D = ESF-TMA-MPBX-2 (\#3)

MPBX-3-B = ESF-TMA-MPBX-3 (\#4)

MPBX-4-B = ESF-TMA-MPBX-4 (\#5)

$\mathrm{H} 1=\mathrm{EST}-\mathrm{TMA}-\mathrm{H}-1(\# 1)$

1 Normalized on corundum-free basis (totals may not sum to 100 because of round-off error). Average corundum abundance $21.3 \pm 0.5$. Average normalized abundances: total $\mathrm{SiO}_{2}$ polymorphs $-30.5 \pm 1.7$; total feldspars-66.8 \pm 2.4 ; albite-25.2 \pm 2.8 ; sanidine- $\pm 41.6 \pm 1.7$.

2 tr-The phase was identified in the XRD pattern, but Siroquant Rietveld analysis refined the abundance to zero.

Table 4-3. Normalized mineral abundances ${ }^{1}$ (weight- $\%$ ) for samples from the ESF (re-analyzed data originally reported in Roberts and Viani 1997b) and from new data not previously reported) (DTN LL980106404244.050)

\begin{tabular}{|l|c|c|c|c|c|c|c|c|}
\hline $\begin{array}{c}\text { ESF Borehole \#; } \\
\text { Depth Interval (ft) }\end{array}$ & Quartz & Cristobalite & Tridymite & Albite & Sanidine & Zeolite $^{2}$ & Smectite $^{*}$ & $\begin{array}{c}\text { Sample } \\
\text { Color }\end{array}$ \\
\hline \hline CHE-1*; $32.0-32.8^{*}$ & 2 & 29 & & 27 & 43 & & & purple \\
\hline CHE-1; $53.4-54.2^{11}$ & 23 & & 27 & 40 & & & brown \\
\hline CHE-1; $53.4-54.2$ & 17 & 13 & 7 & 28 & 36 & & & gray \\
\hline CHE-1; $66.6-67.3$ & 10 & 21 & & 28 & 42 & & & gray \\
\hline CHE-1; 76.7-77.6 & 33 & 3 & 7 & 28 & 29 & & & gray \\
\hline
\end{tabular}




\begin{tabular}{|c|c|c|c|c|c|c|c|c|}
\hline $\begin{array}{l}\text { ESF Borehole \#*; } \\
\text { Depth Interval (ft) }\end{array}$ & Quartz & Cristobalite & Tridymite & Albite & Sanidine & Zeolite $^{2}$ & Smectite & $\begin{array}{c}\text { Sample } \\
\text { Color }\end{array}$ \\
\hline CHE-1; 76.7-77.6 & 8 & 24 & & 24 & 44 & & & brown \\
\hline CHE-1; 85.7-86.6 & 16 & 5 & 7 & 33 & 38 & & & gray \\
\hline CHE-1; 85.7-86.6 & 6 & 23 & & 33 & 38 & & & brown \\
\hline CHE-1; 122.6-123.2 & 5 & 26 & & 31 & 38 & & & brown \\
\hline CHE-2*; 18.4-19.1 & 8 & 22 & & 24 & 45 & & $\operatorname{tr}^{3}$ & brown \\
\hline CHE-2; 50.3-51.0 & 16 & 17 & & 28 & 38 & & $\operatorname{tr}$ & brown \\
\hline CHE-2; 65.0-65.7 & 10 & 17 & 10 & 25 & 38 & & & gray \\
\hline CHE-2; 76.7-77.4 & 4 & 25 & & 29 & 43 & & $\operatorname{tr}$ & purple \\
\hline CHE-2; 89.0-89.7 & 3 & 30 & & 27 & 40 & & & purple \\
\hline CHE-2; 97.0-97.7 & 4 & 24 & 10 & 30 & 33 & & & $\begin{array}{c}\text { dark } \\
\text { purple }\end{array}$ \\
\hline CHE-2; 114.0-114.7 & 20 & 13 & & 29 & 37 & & & brown \\
\hline CHE-2; 114.0-114.7 & 23 & 14 & & 29 & 34 & & & gray \\
\hline CHE-2; 128.9-129.6 & 17 & 8 & 13 & 24 & 39 & & & gray \\
\hline CHE-2; 128.9-129.6 & 9 & 17 & 2 & 34 & 38 & & $\operatorname{tr}$ & brown \\
\hline 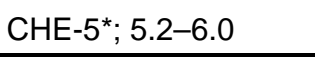 & 14 & 19 & & 31 & 37 & & & brown \\
\hline CHE-5; 5.2-6.0 & 19 & 8 & & 33 & 40 & & & gray \\
\hline CHE-5; 50.0-50.7 & 15 & 6 & 10 & 30 & 40 & & & gray \\
\hline CHE-5; 50.0-50.7 & 6 & 26 & & 26 & 42 & & $\operatorname{tr}$ & brown \\
\hline CHE-5; 74.2-74.9 & 8 & 24 & & 25 & 43 & & & brown \\
\hline CHE-5; 74.2-74.9 & 12 & 12 & 14 & 25 & 38 & & & gray \\
\hline CHE-5; 74.2-74.9 & 11 & 11 & 12 & 26 & 39 & & & gray \\
\hline CHE-5; 74.2-74.9 & 4 & 23 & 8 & 31 & 35 & & & dark \\
\hline CHE-5; 82.8-83.5 & 17 & 13 & 4 & 30 & 36 & & & matrix \\
\hline CHE-5; 99.0-99.6 & 13 & 11 & & 25 & 45 & 5 (st) & & gray \\
\hline CHE-5; 99.0-99.6 & 20 & 10 & 5 & 29 & 36 & & & purple \\
\hline CHE-6*; 29.0-29.7 & 7 & 23 & 4 & 28 & 37 & & & brown \\
\hline CHE-6; 29.0-29.7 & 14 & 9 & 12 & 27 & 37 & & & gray \\
\hline CHE-6; 63.9-64.6 & 5 & 23 & 7 & 32 & 34 & & & matrix \\
\hline CHE-6; 74.8-75.5 & 5 & 27 & & 28 & 40 & & & purple \\
\hline CHE-6; 74.8-75.5 & 15 & 19 & & 27 & 39 & & & brown \\
\hline CHE-6; 74.8-75.5 & 8 & 16 & 9 & 29 & 38 & & & gray \\
\hline CHE-6; 74.8-75.5 & 4 & 18 & 3 & 47 & 28 & & & purple \\
\hline CHE-6; 74.8-75.5 & 7 & 11 & 14 & 26 & 41 & & & gray \\
\hline CHE-6; 91.3-92.0 & 7 & 22 & 5 & 30 & 35 & & & brown \\
\hline CHE-6; 99.7-100.4 & 5 & 25 & 5 & 28 & 37 & & & brown \\
\hline
\end{tabular}


4. Geochemical and Mineralogical Studies

\begin{tabular}{|c|c|c|c|c|c|c|c|c|}
\hline $\begin{array}{l}\text { ESF Borehole \#*; } \\
\text { Depth Interval (ft) }\end{array}$ & Quartz & Cristobalite & Tridymite & Albite & Sanidine & Zeolite $^{2}$ & Smectite & $\begin{array}{l}\text { Sample } \\
\text { Color }\end{array}$ \\
\hline CHE-6; 99.7-100.4 & 5 & 25 & 5 & 28 & 37 & & & brown \\
\hline CHE-6; 99.7-100.4 & 18 & 19 & & 25 & 38 & & & gray \\
\hline CHE-6; 105.0-105.5 & 7 & 26 & & 28 & 39 & & & brown \\
\hline CHE-6; 105.0-105.5 & 10 & 6 & 16 & 35 & 33 & & & gray \\
\hline CHE-6; 118.6-119.3 & 7 & 25 & & 30 & 37 & & & brown \\
\hline CHE-6; 118.6-119.3 & 12 & 9 & 17 & 31 & 31 & & & gray \\
\hline CHE-7*; 80.0-80.7 & 2 & 28 & 5 & 26 & 39 & & & purple \\
\hline CHE-7; 95.6-96.3 & 24 & 11 & 10 & 23 & 32 & & & gray \\
\hline CHE-7; 95.6-96.3 & 3 & 24 & 7 & 32 & 33 & & & dark \\
\hline CHE-7; 101.0-101.7 & 3 & 25 & 8 & 30 & 34 & & & purple \\
\hline CHE-7; 101.0-101.7 & 16 & 11 & 14 & 21 & 35 & $4(\mathrm{cl})$ & $\operatorname{tr}$ & gray \\
\hline CHE-10*; 27.3-28.0 & 16 & 10 & & 28 & 45 & & & $\begin{array}{l}\text { light } \\
\text { brown }\end{array}$ \\
\hline CHE-10; 27.3-28.0 & 10 & 20 & 3 & 22 & 45 & & & brown \\
\hline CHE-10; 75.6-76.3 & 7 & 25 & & 28 & 40 & & & brown \\
\hline CHE-10; 75.6-76.3 & 10 & 7 & 16 & 32 & 35 & & & gray \\
\hline CHE-10; 75.6-76.3 & 8 & 19 & 6 & 30 & 38 & & & matrix \\
\hline CHE-10; 80.7-81.4 & 5 & 12 & 3 & 26 & 43 & 12 (st) & $\operatorname{tr}$ & dark \\
\hline CHE-10; 85.0-85.7 & 17 & 6 & 12 & 30 & 35 & & & gray \\
\hline CHE-10; 85.0-85.7 & 25 & 9 & 2 & 31 & 33 & & & dark \\
\hline CHE-10; 100.1-101.0 & 21 & 6 & 10 & 29 & 35 & & & gray \\
\hline CHE-10; 100.1-101.0 & 24 & 6 & 4 & 34 & 32 & & & dark \\
\hline
\end{tabular}

Complete borehole designation:

CHE-1 = ESF-HD-CHE-1 $(\# 52)$

CHE-2 = ESF-HD-CHE-2 (\#53)

CHE-6 = ESF-HD-CHE-6 (\#69)

CHE-7 = ESF-HD-CHE-7 (\#70)

CHE-5 = ESF-HD-CHE-5 (\#56)

CHE-10 = ESF-HD-CHE-10 (\#73)

1 Normalized on corundum free basis (totals may not sum to 100 due to round-off error). Average corundum abundance 20.6 \pm 1.7. Average normalized abundances: total $\mathrm{SiO}_{2}$ polymorphs-32.7 \pm 4.2 ; total feldspars$67.1 \pm 4.1$; albite $-27.9 \pm 2.9$; sanidine $-39.2 \pm 4.1$

$(\mathrm{cl})=$ clinoptilolite; $(\mathrm{st})=$ stellerite

tr-the phase was identified in the XRD pattern, but Siroquant Rietveld analysis refined the abundance to zero.

Table 4-4. Normalized mineral abundances ${ }^{1}$ (weight-\%) for samples from the ESF (re-analyzed data originally reported in Roberts and Viani 1997a)

(DTN LL980106404244.050)

\begin{tabular}{|c|c|c|c|c|c|c|}
\hline $\begin{array}{c}\text { Sample \# } \\
\text { (depth in ft) }\end{array}$ & Quartz & Cristobalite & Tridymite & Albite & Sanidine & Zeolite $^{2}$ \\
\hline \hline SDM-MPBX1 (1.0-1.2)-D & 11 & 23 & & 23 & 43 & \\
\hline SDM-MPBX1 (21.0-21.2)-D & 7 & 25 & 4 & 16 & 47 & \\
\hline SDM-MPBX1 (21.0-21.2)-D & 8 & 24 & 6 & 18 & 45 & \\
\hline
\end{tabular}




\begin{tabular}{|c|c|c|c|c|c|c|}
\hline $\begin{array}{l}\text { Sample \#* } \\
\text { (depth in ft) }\end{array}$ & Quartz & Cristobalite & Tridymite & Albite & Sanidine & Zeolite $^{2}$ \\
\hline \multicolumn{7}{|l|}{ (duplicate sample) } \\
\hline SDM-MPBX1 (31.9-32.1)-D & 3 & 31 & & 21 & 45 & \\
\hline SDM-MPBX1 (40.4-40.6)-D & 17 & 17 & 8 & 17 & 41 & \\
\hline SDM-MPBX1 (62.0)-D & 9 & 25 & & 22 & 44 & \\
\hline SDM-MPBX1 (80.7-80.9)-D & 10 & 24 & & 20 & 46 & \\
\hline SDM-MPBX2 (29.0-29.2)-D & 3 & 28 & & 23 & 45 & \\
\hline $\begin{array}{l}\text { SDM-MPBX2 (29.0-29.2)-D } \\
\text { (duplicate sample) }\end{array}$ & 3 & 29 & & 27 & 42 & \\
\hline SDM-MPBX2 (48.6)-D & 15 & 19 & & 21 & 45 & \\
\hline SDM-MPBX2 (72.0)-D & 5 & 29 & & 22 & 44 & \\
\hline SDM-MPBX2 (85.0)-D & 6 & 27 & & 24 & 43 & \\
\hline SDM-MPBX3 (17.5-17.7)-D & 7 & 26 & & 24 & 43 & \\
\hline SDM-MPBX3 (38.5-38.7)-D & 4 & 30 & & 21 & 45 & \\
\hline SDM-MPBX3 (85.6)-D & 9 & 23 & & 18 & 47 & 3 (st) \\
\hline AOD-HDFR\#1 (9.0)-D & 12 & 21 & & 20 & 46 & $1(\mathrm{cl})$ \\
\hline $\begin{array}{l}\text { AOD-HDFR\#1 (9.0)-D } \\
\text { (duplicate sample) }\end{array}$ & 13 & 21 & & 22 & 43 & $\operatorname{tr}^{3}(\mathrm{cl})$ \\
\hline AOD-HDFR\#1 (48.5)-D & 9 & 24 & & 21 & 46 & \\
\hline AOD-HDFR\#1 (68.6)-D & 11 & 24 & & 21 & 44 & \\
\hline AOD-HDFR\#1 (98.0)-D & 36 & 3 & & 23 & 39 & \\
\hline
\end{tabular}

Complete borehole designation:

SDM-MPBX1 = ESF-SDM-MPBX-1 (\#42) SDM-MPBX3 = ESF-SDM-MPBX-3 (\#44)

SDM-MPBX2 = ESF-SDM-MPBX-2 (\#43) AOD-HDFR\#1 = ESF-HDFR\#1 (193)

$1 \quad$ Normalized on corundum-free basis (totals may not sum to 100 because of round-off error). Average corundum abundance 22.0 \pm 0.8 . Average normalized abundances: total $\mathrm{SiO}_{2}$ polymorphs $-34.5 \pm 2.8$; total

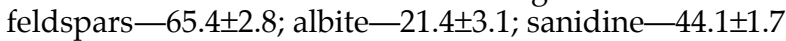

$(\mathrm{cl})=$ clinoptilolite; $(\mathrm{st})=$ stellerite

3 tr-The phase was identified in the XRD pattern, but Siroquant Rietveld analysis refined the abundance to zero.

\subsubsection{X-Ray Diffraction and Analytical Protocol}

\subsubsection{XRD Instrument and Parameter Settings}

X-ray scans were collected using a Scintag PAD-V generator equipped with a $\mathrm{Cu}$ x-ray tube operated at $45 \mathrm{kV}$ and $35 \mathrm{~mA}$ and using a Sieffert goniometer with a solid-state detector. Diffraction patterns were collected in step-scan mode at 2 sec per $0.02^{\circ} 2 \theta$. Collimation was provided by a $1^{\circ}$ divergence and $2^{\circ}$ scatter slit on the x-ray tube and a $0.3-\mathrm{mm}$ scatter and $0.2-\mathrm{mm}$ registration slit on the detector. Samples were scanned from $2-52^{\circ} 2 \theta, 2-72^{\circ} 2 \theta$, or $2-82^{\circ} 2 \theta$. 


\section{Calibration Correction}

Prior to mineral-phase identification and analysis, the observed diffraction pattern was corrected for instrumental error by means of a calibration curve determined from standard phases. The calibration correction used to correct data for this report was derived by scanning two standards: a fluorophlogopite mica for the low-angle peaks (National Institute of Standards [NIST] traceable) and a mixture of silicon (NIST traceable), tungsten, and silver metals (SiWAg) for the high-angle peaks. Both standards were scanned with the same instrumental parameters listed in the previous section: the mica from $2{ }_{-} 72^{\circ} 2 \theta$ and the SiWAg from $20-110^{\circ} 2 \theta$. The two scans were merged into one, and a calibration curve was built on observed versus the NIST and Joint Committee on Powder Diffraction Standards Powder Diffraction File (JCPDS-PDF) $2 \theta$ angles.

\section{Quantitative Analysis}

Previous x-ray diffraction analyses of samples from the ESF (Roberts and Viani 1997b; 1996, pp. 1-20) used the matrix-flushing method of Chung (1974, pp. 519-525) and an internal intensity standard (corundum) to quantify the abundance of individual phases present. Although the method is adequate for obtaining relative abundances, its accuracy and precision are limited by the inherent differences between the external standards used to compute the reference intensity ratio and the mineral phases in the sample. In a subsequent report (Roberts and Viani 1997a), mineral abundances were obtained using the Rietveld method of whole x-ray pattern fitting (Snyder and Bish 1989, pp. 101-144; Young 1993, pp. 1-38). The Rietveld technique has the potential to be more accurate and more precise for estimating mineral abundances (Snyder and Bish 1989, pp. 101-144.

\section{Methodology}

The Rietveld method is based on fitting a calculated XRD pattern to the observed pattern over the entire angular range over which data is collected. The calculated pattern is refined by adjusting the quantity of the phases included in the calculation (scale factor) and adjusting their crystallographic properties. The Rietveld method of quantification avoids the use of external standards. The method requires identification of all the phases in the sample, as the refined abundances are normalized to $100 \%$. To assess the overall accuracy of the method, a known quantity of corundum was added to each sample.

Mineral quantification using the Rietveld method involved two steps. First, the phases present in each sample were identified using an XRD pattern-processing software program (Jade, version 3.0, Materials Data, Inc., Livermore, CA), which uses data from the JCPDSPDF. After the mineral phases were identified, the Rietveld method of quantification was employed. A least-squares refinement was carried out until the best fit was obtained between the observed powder-diffraction pattern and the calculated pattern based on the crystal structures and lattice parameters of phases determined to be present. The Rietveld analyses were performed using a quantitative XRD software program (Siroquant, version 2.0, Sietronics, Australia). 


\section{Identification of Mineral Phases Present}

The Jade pattern-processing program was used to identify major and minor mineral phases present in each sample. The Jade program searches located peaks only and compares them with the strongest lines of a potential phase in the PDF database. The selected peaks were checked visually to confirm realistic phase identification.

\section{Rietveld Quantitative Analysis Parameters}

To calculate (or refine) an XRD pattern, Siroquant uses crystallographic information from its database and refines these default values to achieve a good fit to the observed data. The program refines the most important parameters first and then progresses to secondary parameters. This produces an optimum fit and the most accurate quantification of the abundances. For this study, all XRD patterns were analyzed using the same refinement parameters. These parameters, obtained after trying a variety of refinement procedures, produced the best estimate for the abundance of the corundum internal standard ( $20 \%$ by weight).

The x-ray analyses from previous reports (Roberts and Viani 1996, pp. 1-20; 1997a; 1997b) and new data not previously reported have been analyzed according to the following procedure. Background is removed from the observed XRD diffraction pattern, and a task is produced that specifies which mineral phases are to be included in the model. The calculated $\mathrm{XRD}$ pattern is then refined by varying the following parameters in order:

1. Scale (i.e., abundance of each identified phase)

2. Instrument zero

3. Peak width factor $(\mathrm{W})$

4. Unit cell dimensions $(a, b, c)$ (dependent on phase)

Each set of refinement parameters was refined for 10 cycles with a damping factor of 0.2 to reduce parameter oscillations. Additional refinement cycles were performed if chi-squared (error associated with refinement parameters) for any phase did not indicate a good fit. Refinement was terminated when chi-squared had reached its lowest level for all phases. The output from Siroquant consisted of the abundances of the identified phases (including the corundum internal standard) normalized to $100 \%$. For the three data sets tabulated, the average value of the corundum abundance varied between 20.6 and $22.0 \%$. The mineral abundances reported in Tables 4-2 through 4-4 have been renormalized on a corundum-free basis.

\section{Application to ESF Samples}

The mineral abundances originally determined using the matrix-flushing method (Roberts and Viani 1996, pp. 1-20; 1997b) were redetermined using the Rietveld method on the original x-ray scan and are reported in Tables 4-2 and 4-3. This redetermination led to an optimized set of Rietveld parameters. Consequently, mineral abundances previously determined using the Rietveld method (Roberts and Viani 1997a) were also re-analyzed with the optimized set; these are reported in Table 4-4. Finally, x-ray diffraction data for ESF drillcore samples not reported in earlier reports were also analyzed using the Rietveld method and are presented in Table 4-3. The data presented in these three tables represent the best estimates of mineral abundances for the listed samples. (These data supersede the mineral abundances previously reported in Roberts and Viani (1996, pp. 1-20; 1997a; 1997b). 
In addition to the samples analyzed for abundance, a suite of accompanying fracture and cavity-fill minerals was also analyzed to identify the phases present. The results of these analyses are shown in Table 4-5.

Table 4-5. Composition of cavity and fracture-fill samples from ESF drill-core samples (DTN LL970206704244.029)

\begin{tabular}{|c|c|c|}
\hline $\begin{array}{c}\text { Borehole \# } \\
\text { Depth Interval (ft) }\end{array}$ & Sample Type & Composition \\
\hline CHE-1; 53.4-54.2 & Lithophysae cavity filling & Quartz \\
\hline CHE-1; 66.6-67.3 & Large lithophysae filling & Quartz, minor feldspars ${ }^{1}$ \\
\hline CHE-1; 108.2-109.0 & Single black crystal & Hematite \\
\hline CHE-1; 108.2-109.0 & Conglomerate matrix & $\begin{array}{l}\text { Cristobalite, quartz, feldspars }{ }^{1} \text {, trace of } \\
\text { smectite }\end{array}$ \\
\hline CHE-1;122.6-123.2 & Coarse-grained cavity filling & Calcite + quartz \\
\hline CHE-2; 50.3-51.0 & Breccia fracture fill & Calcite \\
\hline CHE-2; 89.0-89.7 & Fracture fill crystals & Calcite \\
\hline CHE-5; 99.0-99.6 & Fracture fill crystals & Quartz, minor tridymite \\
\hline CHE-6; 63.9-64.6 & Fracture fill crystals & Quartz, minor tridymite \\
\hline CHE-7; 80.0-80.7 & Purple matrix & $\begin{array}{l}\text { Cristobalite, feldspars }{ }^{1} \text {, trace of } \\
\text { smectite }\end{array}$ \\
\hline CHE-10; 27.3-28.0 & Black crystals & Manganese oxide \\
\hline CHE-10; 27.3-28.0 & Fracture fill crystals & Quartz \\
\hline CHE-10; 85.0-85.7 & $\begin{array}{l}\text { Shallow rim around } \\
\text { lithophysae }\end{array}$ & $\begin{array}{l}\text { Quartz, cristobalite, feldspars }{ }^{1} \text {, trace of } \\
\text { smectite }\end{array}$ \\
\hline CHE-10; $124.0-124.7$ & Large, white vug crystal & Calcite \\
\hline
\end{tabular}

See Table 4-3 for complete borehole designations.

Primarily albite and sanidine of varying composition

\section{Comparison of Most Recent Analysis with Previously Reported Results}

From the information presented in the tables in this section, it is evident that the Topopah Springs tuff is predominantly silica and feldspar minerals with other minor phases. The tuff is also characterized by the presence of multiple silica polymorphs. For a comparison of the quantitative analytical methods, the determined weight percentages for two of these - quartz and cristobalite - are shown plotted in Figure 4-6, with the re-analyzed Rietveld results on the $x$ axis and the result from the previously employed method (either matrix flushing or Rietveld) on the $y$ axis. The two sets of uppermost plots represent the data obtained by Chung's matrix flushing, which was normalized to $100 \%$. The bottom set compares the differences between the two Rietveld analyses. One can see that the quantities determined from both methods and for both of these silica polymorphs are reasonably similar; the plotted line is a 1:1 correspondence; in most cases, the data cluster near the line. 
Figure 4-6. Comparison of normalized abundances of quartz and cristobalite (DTN LL980811004244.069)

Top and middle graphs: abundances determined using the matrixflushing method (August 1996 and February 1997 reports [Roberts and Viani 1996, pp. 1-20; 1997b]) with normalized abundances reanalyzed using the Rietveld method (solid line represents 1:1 correspondence)

\section{Lower graphs: abundances determined using initial and optimized Rietveld method parameters (May 1997 report [Roberts and Viani 1997a]) (solid line represents 1:1 correspondence)}

In contrast, the weight percentages for the feldspar components are significantly different, as estimated by the different analytical techniques. Although not plotted, the abundances of total feldspars are in reasonable agreement, but individual feldspar phases differ significantly. The discrepancy most likely stems from the wide chemical variability of this group of minerals and from the difficulty in establishing a reasonable "referenceintensity ratio" (or set of these), as required for analysis by the matrix-flushing method (Vaniman et al. 1997).

The greatest difference between the two methods, however, is in the estimate of the abundance of smectite. The Rietveld method consistently returned abundance values near zero for samples in which smectite was identified and for which the matrix-flushing method produced values between 1 and 5\%. The smectite abundances estimated using the matrixflushing method are similar to smectite values reported in Vaniman et al. (1997) for Topopah Spring tuff samples. However, aside from the discrepancies in the smectite abundances, mineral abundances estimated using the Rietveld approach are not only more easily obtained, but are more accurate and precise.

Re-analysis of the DST drill-core data from Roberts and Viani (1997b) resulted in the identification (in one sample) of stellerite that had not been identified previously. An additional sample containing stellerite was noted in a sample analyzed subsequent to the report of Roberts and Viani (1997b).

\subsubsection{Results and Discussion}

Except for one sample containing $12 \%$ zeolite (stellerite), $\mathrm{SiO}_{2}$ polymorphs and feldspars make up $\geq 95 \%$ by weight of the samples analyzed (Tables $4-2$ through $4-4$ ). Small amounts of mica, smectite, clinoptilolite, and stellerite were identified in approximately one-quarter of the samples. The total abundance of $\mathrm{SiO}_{2}$ polymorphs and feldspars was quite uniform, averaging between 30.5 and $34.5 \%$, and 65.4 and $67.1 \%$, respectively, for the three data sets. As might be expected, the data for the homogenized samples (Tables 4-2 and 4-4) show less variability than do the data for samples collected from the other ESF drill core on the basis of color (Table 4-3). The observed uniformity in total $\mathrm{SiO}_{2}$ polymorphs and total feldspar abundances are consistent with the highly uniform chemical composition of these rocks (Schuraytz et al. 1986, pp. 1-59; Vaniman et al. 1997).

The uniformity of total $\mathrm{SiO}_{2}$ polymorphs and total feldspar abundances was also noted by Vaniman et al. (1997) for the Topopah Spring tuff. However, the average abundances reported here differ from the abundances reported by Vaniman et al. (1997) for a relatively densely spaced set of core samples (UE-25 UZ\#16) taken from the upper lithophysal to lower lithophysal units of the Topopah Spring tuff (approximately 139 to $329 \mathrm{~m}$ ). Vaniman et al. 
report higher abundances of $\mathrm{SiO}_{2}$ polymorphs (approximately 40 vs. approximately 33\%), lower total feldspar (approximately 55 vs. approximately 66\%), and higher secondary minerals (approximately 6 vs. approximately 1\%). The relatively large zeolite (stellerite) abundances reported by Vaniman et al. (especially in the lower lithophysal unit) were thought to be unique to the repository horizon intersected by UE-25 UZ\#16. The identification of stellerite in three samples from the ESF area was consistent with the findings of Vaniman et al. (1997) and suggests that stellerite in the Topopah Spring tuff may be more widely distributed than previously thought. Other data (although not as densely sampled) for the Topopah Spring tuff reported in Vaniman et al. are more similar to the data reported here (e.g., UE-25a\#1- $\mathrm{SiO}_{2}$ polymorphs $34 \%$, total feldspar $63 \%$; UE-25p\#1- $\mathrm{SiO}_{2}$ polymorphs $34 \%$, total feldspar $64 \%$; USW G-1- $\mathrm{SiO}_{2}$ polymorphs $33 \%$, total feldspar $63 \%$ ).

The average abundances for the internal corundum standard (Tables 4-2 through 4-4) are consistently larger than $20 \%$, implying that one may not be identifying a phase that makes up 3-9\% of the sample by weight. However, a systematic error arising from a missed phase would tend to overestimate the abundances of all remaining phases, and this alone cannot explain the differences between Vaniman et al. (1997) and the data reported here. At least some of the differences between the data reported by Vaniman et al. and that reported here is probably due to differences between quantification by the Rietveld method and the matrix-flushing method. As mentioned in earlier reports (Roberts and Viani 1996, pp. 1-20; 1997a; 1997b) and as discussed by Vaniman et al. (1997), there can be significant errors and difficulties associated with the matrix-flushing method, especially for feldspars that display solid-solution behavior and for samples, such as the samples in question, with many overlapping peaks.

\subsubsection{1 $\mathrm{SiO}_{2}$ Polymorphs}

An important finding that has not been noted before is the correlation between matrix color and $\mathrm{SiO}_{2}$ mineralogy and the negative correlation observed between cristobalite abundance and the sum of quartz plus tridymite (see Figure 4-7 and Figure 4-8). The negative correlation simply reflects the near uniformity in the abundance of total $\mathrm{SiO}_{2}$ polymorph in these samples. Although the relationship is not quite inverse (the absolute values of the slopes of the best fit lines are less than unity), the negative correlation, and the correlation to matrix color discussed subsequently, suggests that differing degrees of alteration of cristobalite (and possibly tridymite) to the more thermodynamically stable quartz has occurred in a more or less closed system.

Figure 4-7. Variation in cristobalite abundance vs. quartz plus tridymite abundance for SHT and ESF thermal test samples (solid line is the best fit regression to the data) (DTN LL980811004244.069)

Figure 4-8. Variation in cristobalite abundance vs. quartz plus tridymite abundance for ESF core samples of different matrix color collected from the same core (solid line is the best fit regression to the data) (DTN LL980811004244.069)

As shown in Figure 4-8, the gray matrix zones adjacent to lithophysae and fractures have greater abundances of quartz and tridymite than do samples of the purple or brown matrix. In almost all cases, gray matrix samples have higher quartz plus tridymite weight percentages than do highly colored samples collected from the same drill core (Table 4-3). 
Tridymite abundance has been related to vapor-phase precipitation on fracture and lithophysae surfaces (Vaniman et al. 1997); hence, its greater abundance in the gray zones adjacent to fractures and lithophysal cavities is reasonable. However, tridymite was also identified in the more highly colored matrix zones that are apparently not adjacent to macroscopic fractures or lithophysae. As noted by Vaniman et al. (1997), microscopic fractures may be the source of tridymite in zones not adjacent to readily observable fractures or lithophysae.

These data suggest that alteration of cristobalite to quartz may have been favored in the zones adjacent to fluid pathways (i.e., interconnecting fractures and lithophysae) and may support the hypothesis that liquid water is necessary for the conversion of cristobalite to more stable phases (see, e.g., Ernst and Calvert 1969, pp. 114-133). Whether the increased tridymite abundances in the gray matrix zones reflect vapor phase deposition at the time of devitrification or subsequent aqueous phase alteration of cristobalite to a more stable phase cannot be ascertained without supporting textural evidence.

Color differences of the matrix have been explained as differences in the distribution of hematite: more highly colored zones (brown and purple) are characterized by small quantities of finely disseminated hematite; gray zones are characterized by hematite that is more localized (e.g., as fracture-lining minerals) or are zones from which hematite has been depleted. The relationship, if any, between hematite distribution and $\mathrm{SiO}_{2}$ mineralogy cannot be assessed from the data in this report. However, if hematite redistribution in the matrix is a result of post-devitrification fluid-flow regimes, perhaps hematite redistribution and alteration of cristobalite to quartz occurred in response to the same flow events.

\subsubsection{Fracture Minerals}

The cavity and fracture-fill samples were hand-picked from the core sections to obtain specific phases for $x$-ray analysis. The representative phases comprise lithophysae cavity-fill crystals, breccia-fill crystals, black lathelike crystals, and two matrix material samples. Two matrix types were also analyzed qualitatively: a purple matrix sample and a conglomerate matrix sample exhibiting all three color variations. The results of these analyses are shown in Table 4-5. The diffraction patterns yielded relatively pure quartz for the lithophysae cavity fillings from boreholes CHE-1, CHE-5, CHE-6, and CHE-10 and yielded quartz with minor tridymite in the samples from boreholes CHE-5 and CHE-6. (These sample designations are defined in the footnotes of the reporting table.) One lithophysae fracture-fill sample (CHE-1; 66.6-67.3) yielded quartz with minor feldspars because of inclusion of some of the surrounding matrix in the sample. Sample CHE-1; 122.6-123.2 yielded coexisting calcite and quartz. Breccia-fill samples from boreholes CHE-2 and CHE-10 yielded large (approximately 0.5 -cm-square) crystals determined to be calcite. A relatively large, single crystal of hematite was identified in CHE-1. A manganese-oxide phase (pyrolusite) was tentatively identified in CHE-10; the mass of material isolated was very small, and the diffraction pattern obtained yielded poor peak intensities. The conglomerate matrix sample was composed of cristobalite, quartz, feldspars, and a minor amount of smectite. The purple matrix sample contained cristobalite as the silica phase, with feldspars and a minor amount of smectite.

\subsubsection{Conclusions}

X-ray analysis of samples of Topopah Spring tuff has shown, in agreement with previous work, the uniformity of the total $\mathrm{SiO}_{2}$ polymorph and feldspar abundances in the repository horizon. Within the repository horizon and adjacent zones of the Topopah Spring member, 
the relative abundance of quartz plus tridymite is positively correlated with gray, altered zones adjacent to lithophysae and fractures. The relative abundance of cristobalite relative to quartz plus tridymite could potentially be used to assess the density of paleo fluid pathways. A strong negative correlation between cristobalite and quartz plus tridymite abundances may reflect post-devitrification alteration by aqueous fluids.

\subsection{References}

Arthur, R.C., and Murphy, W.M. 1989. “An analysis of gas-water-rock interactions during boiling in partially saturated tuff." Sci. Geol. Bull. 42(4):313-327.

Chung, F.H. 1974. “Quantitative interpretation of X-ray diffraction patterns of mixtures. I. Matrix-flushing method for quantitative multicomponent analysis." J. Appl. Crystallogr. 7:519-525. NNA.19890405.0179.

Criscenti, L.J., and Arthur, R.C. 1991. "The calculated effects of isothermal boiling on tuff-water interactions." Radiochim. Acta 52/53:513-517. HQX.19891005.0043.

Ernst, W.G., and Calvert, S.E. 1969. "An experimental study of the recrystallization of porcelanite and its bearing on the origin of some bedded cherts." Am. J. Sci. 267A:114-133.

Glassley, W.E. 1997. Third Quarter Report: Chemical Analyses of Waters Collected from the Single Heater Test. Milestone report for the CRWMS Management and Operating Contractor, U.S. Department of Energy. SP9281M4. Livermore, California: Lawrence Livermore National Laboratory. MOL.19980105.0625.

Glassley, W.E., and Boyd, S. 1995. Preliminary Description of Small Block Mineralogical Features. Milestone report for the CRWMS Management and Operating Contractor, U.S. Department of Energy. MOL062. Livermore, California: Lawrence Livermore National Laboratory. MOL.19950721.0246. (Also UCRL-ID-129847)

Harrar, J., Carley, J.F., Isherwood, W.F., and Raber, E. 1990. Report of the Committee to Review the Use of J-13 Well Water in Nevada Nuclear Waste Storage Investigations. UCRL-ID-21867. Livermore, California: Lawrence Livermore National Laboratory. NNA.910131.0274.

Johnson, J.W., Knauss, K.G., Glassley, W.E., and DeLoach, L.D. 1998. “Reactive transport modeling of plug-flow-reactor experiments: significance, initial results, and future applications." Journal of Hydrology (in press)

Roberts, S., and Viani, B. 1997a. Mineral Abundances for Samples from Instrumentation Boreholes in the Access Drift Scale Test (DST) Area of the ESF. Milestone report for the CRWMS Management and Operating Contractor, U.S. Department of Energy. SP9511M4. Livermore, California: Lawrence Livermore National Laboratory. MOL.19970507.0186.

Roberts, S., and Viani, B. 1997b. Mineral Abundances for Samples from Six Chemistry (SEAMIST) Boreholes in the Drift Scale Test (DST) Area of the ESF. Milestone report for the CRWMS Management and Operating Contractor, U.S. Department of Energy. SP9510M4. Livermore, California: Lawrence Livermore National Laboratory. MOL.19980105.0238. 
Roberts, S.K., and Viani, B.E. 1996. Determination of Mineral Abundances in Core Samples from the Exploratory Studies Facility Using X-ray Diffraction. Milestone report for the CRWMS Management and Operating Contractor, U.S. Department of Energy. SPY195M4. Livermore, California: Lawrence Livermore National Laboratory. DTN LL960810604244.016. MOL.19961022.0030. (Also UCRL-ID-129748, 1998)

Rousseau, J.P., Kwicklis, E.M., and Gillies, D.C. 1998. Hydrogeology of the Unsaturated Zone, North Ramp Area of the Exploratory Studies Facility, Yucca Mountain, Nevada. In press. Water-Resources Investigations Report 98-4050. U.S. Geological Survey. MOL.19980220.0164.

Schuraytz, B.C., Vogel, T.A., and Younker, L.W. 1986. Geochemical Gradients in the Topopah Spring Member of the Paintbrush Tuff: Evidence for Eruption Across a Magmatic Interface. UCRL-53698. Livermore, California: Lawrence Livermore National Laboratory. HQS.19880517.1439.

Snyder, R.L., and Bish, D.L. 1989. “Quantitative Analysis.” Bish, D.L., and Post, J.E., eds. Modern Powder Diffraction. Reviews in mineralogy 20. pp. 101-144. Washington, District of Columbia: Mineralogical Society of America.

Steefel, C.I., and Yabusaki, S.B. 1995. OS3D/GIMRT: Software for Modeling MulticomponentMultidimensional Reactive Transport. Richland, Washington: Pacific Northwest National Laboratory, Battelle Memorial Institute.

Vaniman, D.T., Bish, D.L., Chipera, S.J., Carlos, B.A., and Guthrie, G.D., Jr. 1997. Summary and Synthesis Report on Mineralogy and Petrology Studies for the Yucca Mountain Site Characterization Project, Volume I: Chemistry and Mineralogy of the Transport Environment at Yucca Mountain. Yucca Mountain Project milestone 3665. Los Alamos, New Mexico: Los Alamos National Laboratory. MOL.19961230.0037.

Wolery, T.J. 1992a. EQ3/6, A Software Package for Geochemical Modeling of Aqueous Systems: Package Overview and Installation Guide. UCRL-MA-110662. Livermore, California: Lawrence Livermore National Laboratory. NNA.19921023.0028. (Part 1)

Wolery, T.J. 1992b. EQ3NR, A Computer Program For Geochemical Aqueous Speciation-Solubility Calculations: Theoretical Manual, User's Guide, and Related Documentation. UCRL-MA-110662. Livermore, California: Lawrence Livermore National Laboratory. NNA.19921218.0010. (Version 7.0)

Yang, I.C., Rattray, G.W., and Yu, P. 1996. Interpretations of Chemical and Isotopic Data from Boreholes in the Unsaturated Zone at Yucca Mountain, Nevada. Water Resources Investigations Report. WRIR 96-4058. Location not given: U.S. Geological Survey. MOL.19970715.0401.

Yang, I.C., Turner, A.K., Sayre, T.M., and Montazar, P. 1988. Triaxial-Compression Extraction of Pore Water from Unsaturated Tuff, Yucca Mountain, Nevada. Water Resources Investigations Report. 88-4189. Location not given: U.S. Geological Survey. NNA.19890309.0161.

Young, R.A. 1993. "Introduction to the Rietveld Method." Young, R.A., ed. The Rietveld Method. IUCr Monographs on Crystallography 5. pp. 1-38. New York, New York: Oxford University Press. 
Chapter 4 Figures 



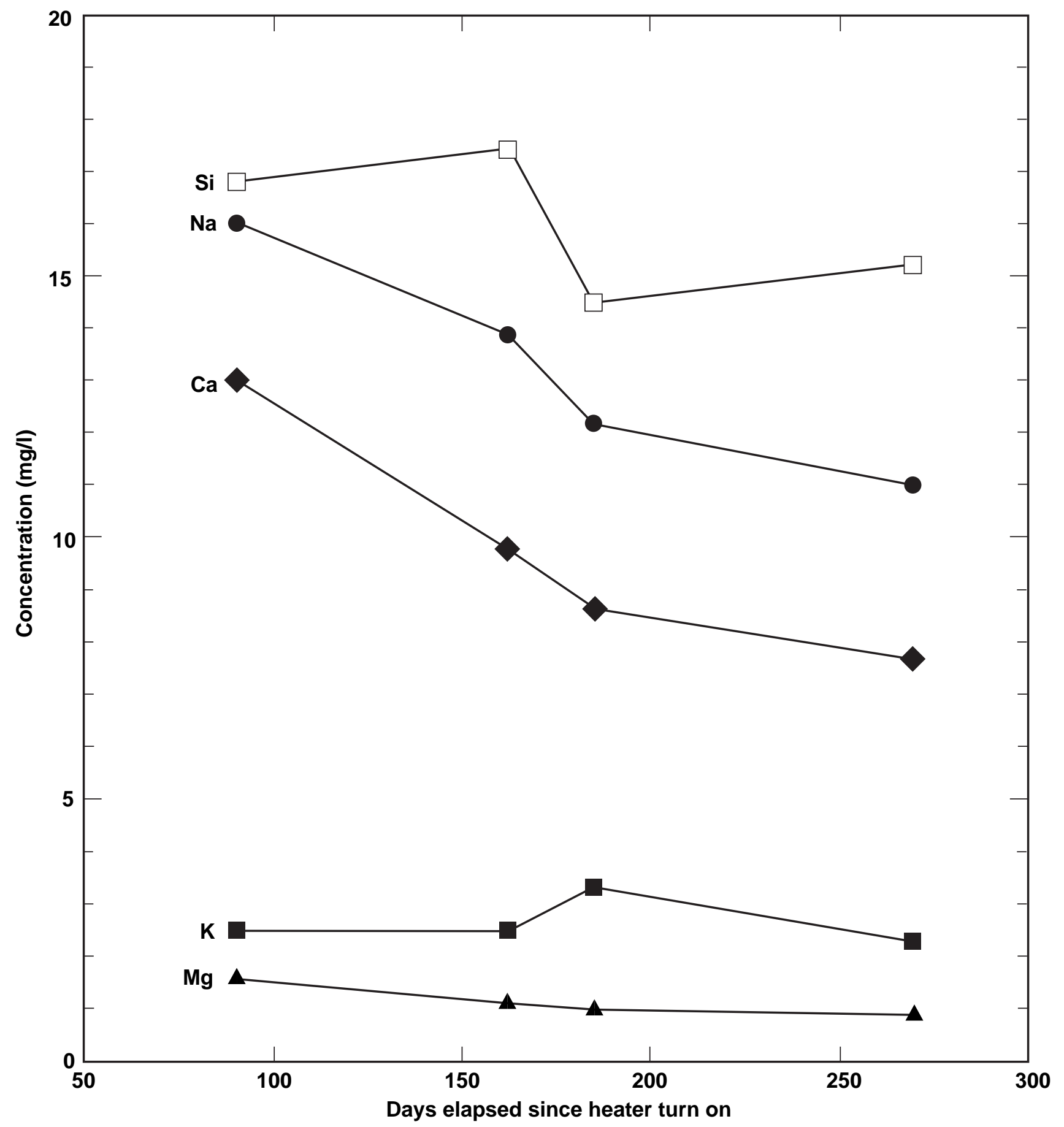

Figure 4-1. SHT Borehole 16-4 water composition as a function of time 


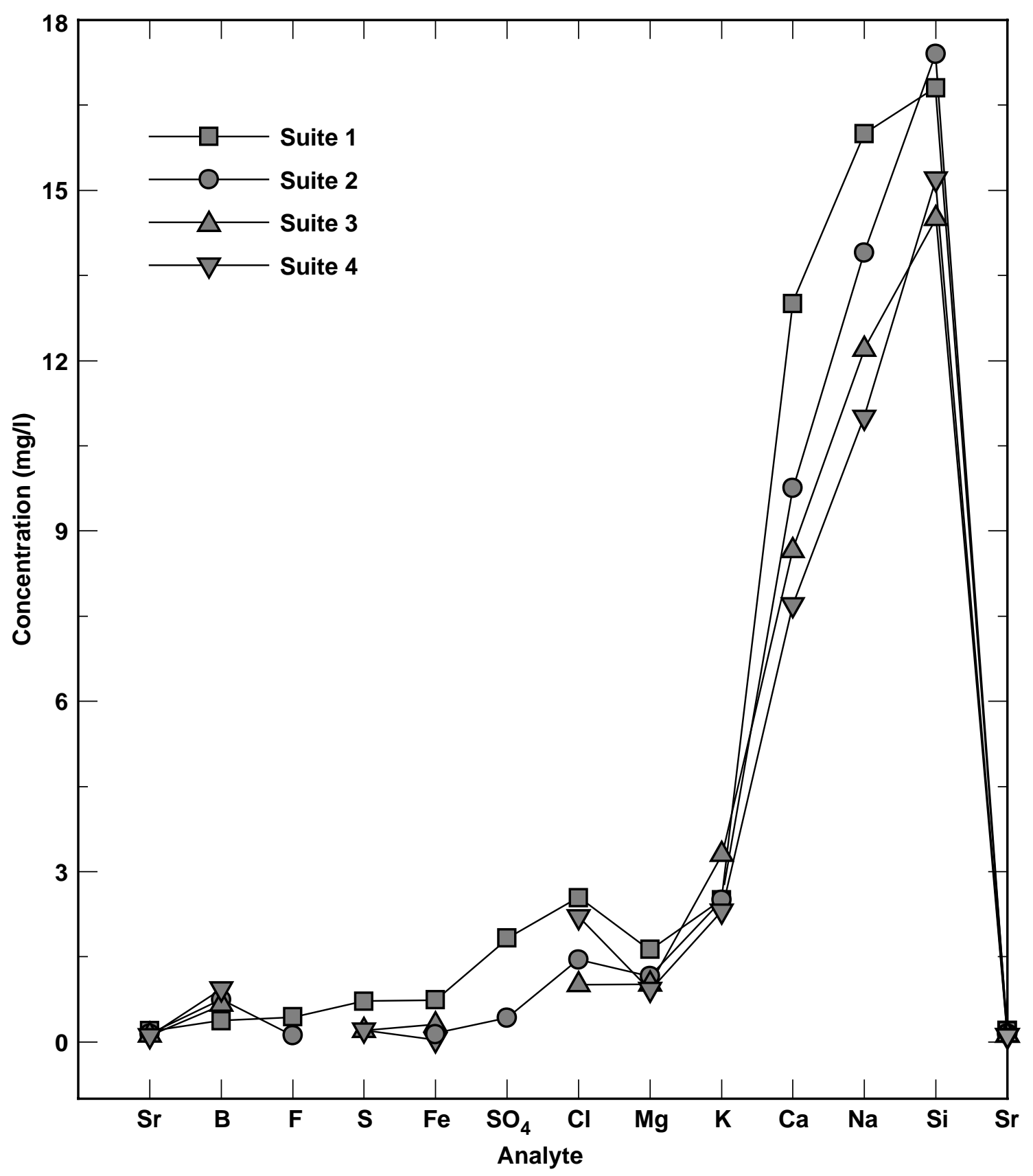

Figure 4-2. Composition of SHT waters compared for Suites 1-4 


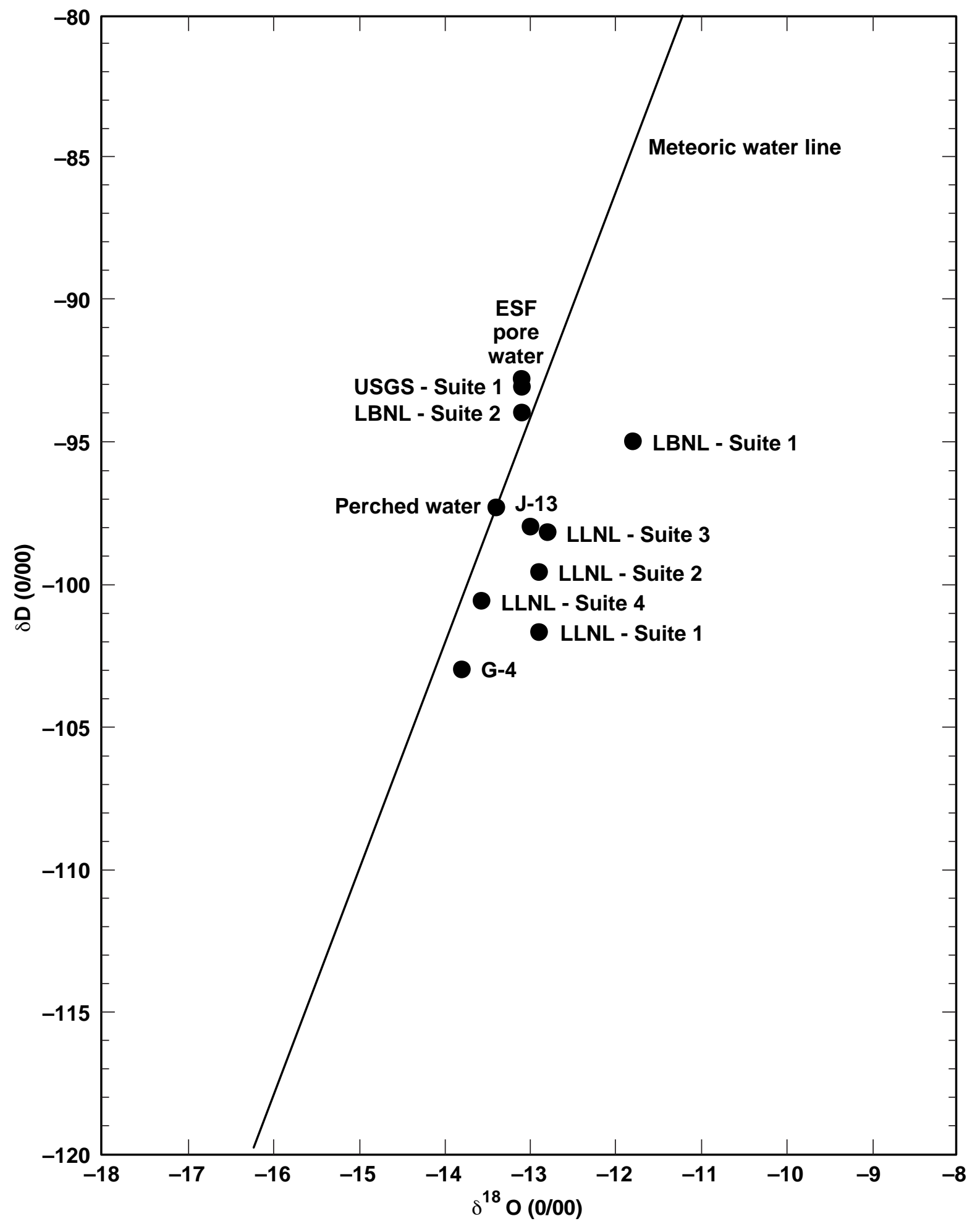

Figure 4-3. Stable isotope data for SHT waters (Suite 1-4), saturated-zone waters G-4 and J-13, UZ-14 perched water, and ESF pore water 


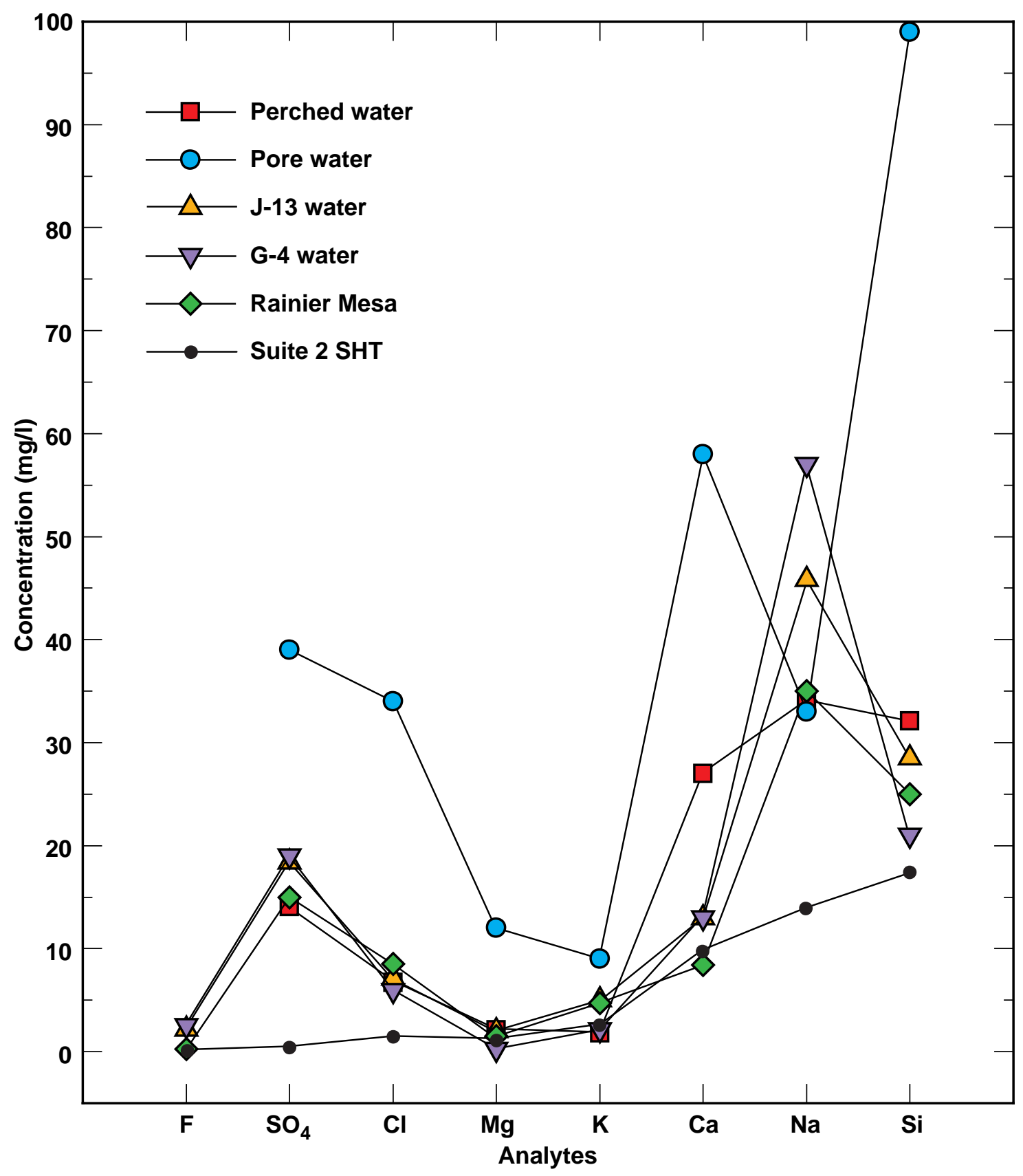

Figure 4-4. Comparison of SHT water, pore water, perched water, saturated-zone water, and fracture water (Rainier Mesa) 


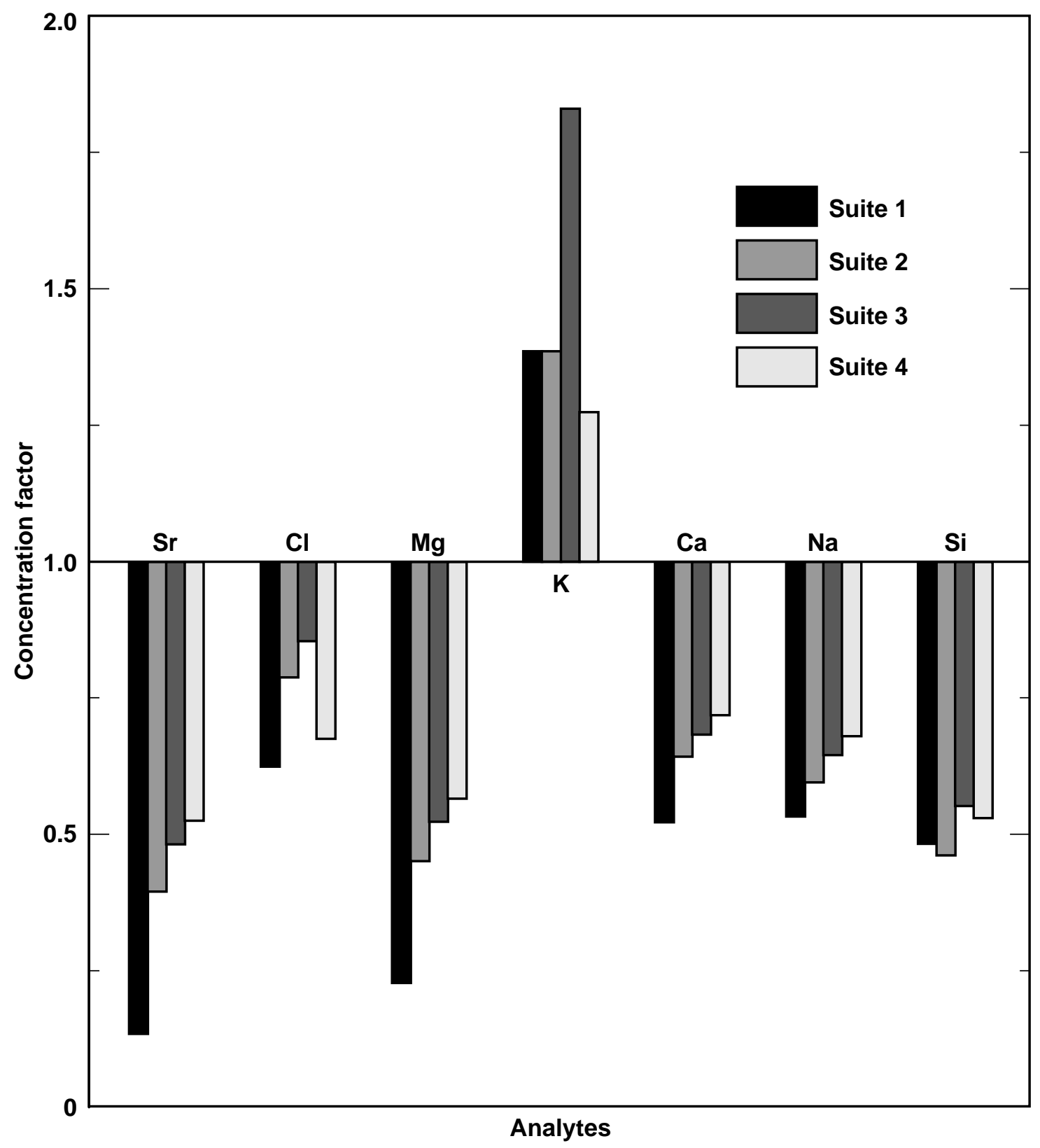

Figure 4-5. Concentration ratios of SHT water to perched water (perched water concentrations plot on the $y=1$ line; above this line, SHT water is enriched in the represented ions; below the line, SHT waters are depleted in the represented ions) 

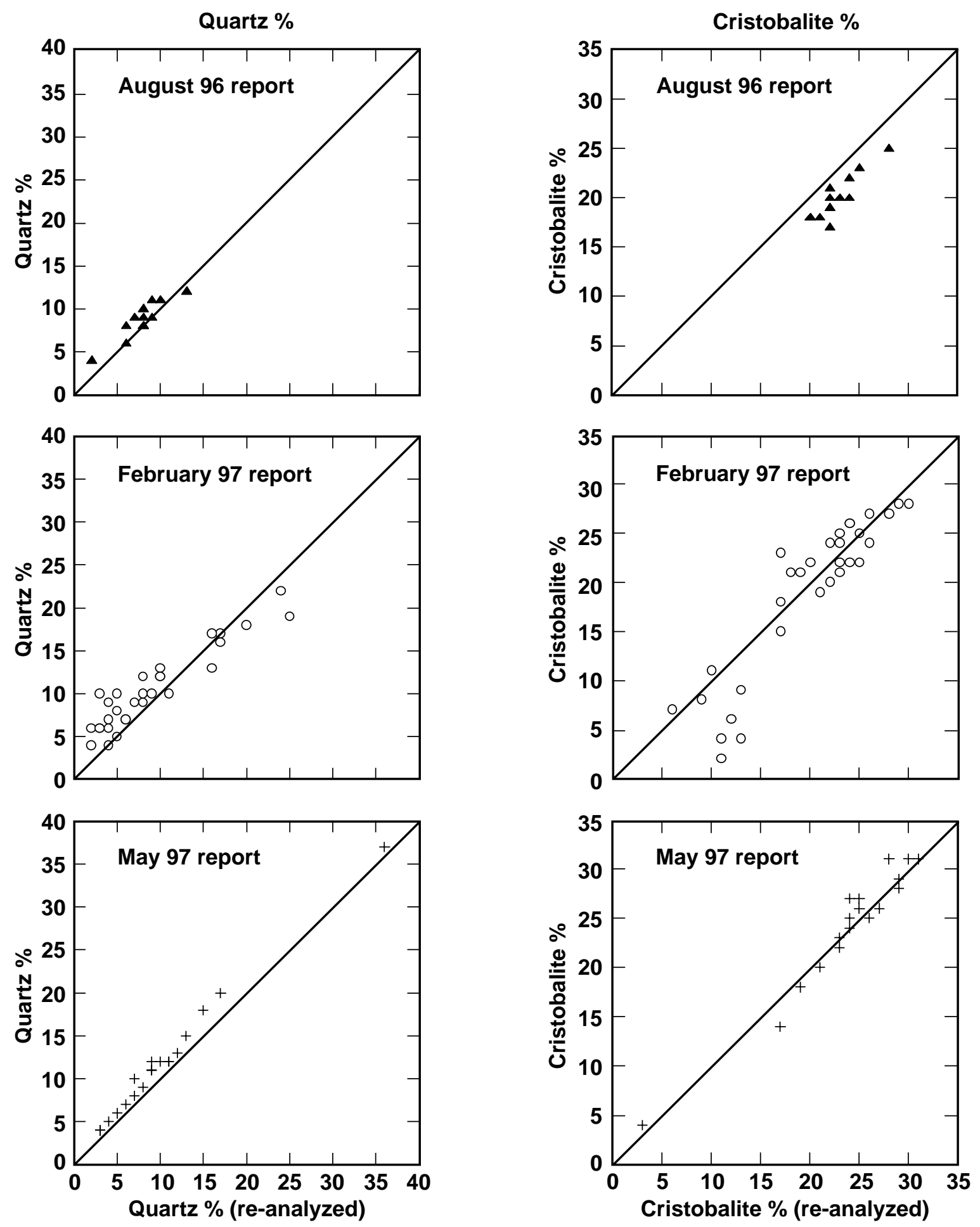

Figure 4-6. Comparison of normalized abundances of quartz and cristobalite (in top and middle graphs, abundances were determined using the matrix-flushing method with normalized abundances re-analyzed using the Rietveld method; in lower graphs, abundances were determined using initial and optimized Rietveld method parameters; solid line represents 1:1 correspondence) 

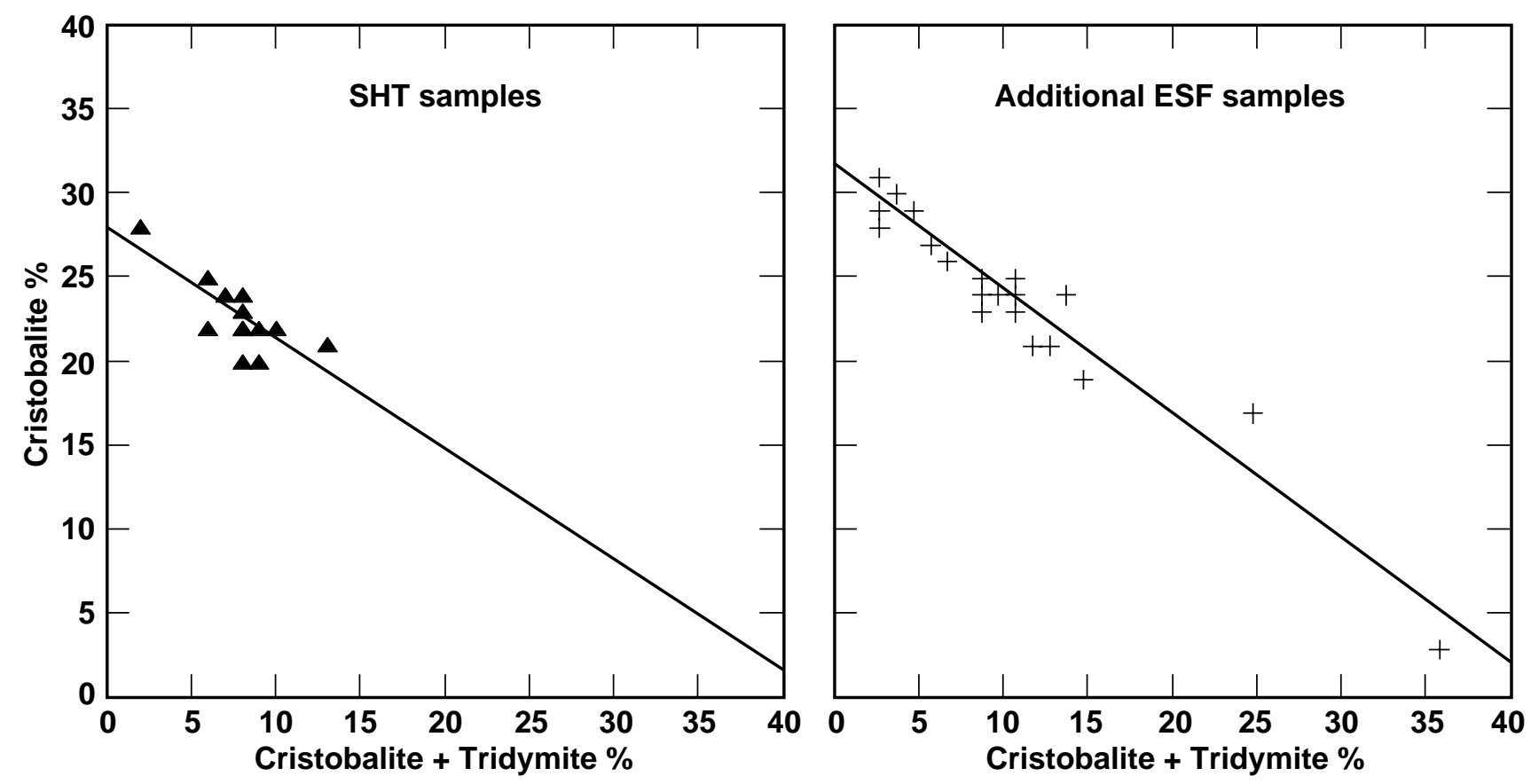

Figure 4-7. Variation in cristobalite abundance vs. quartz plus tridymite abundance for SHT and ESF thermal test samples (solid line is the best fit regression to the data) 


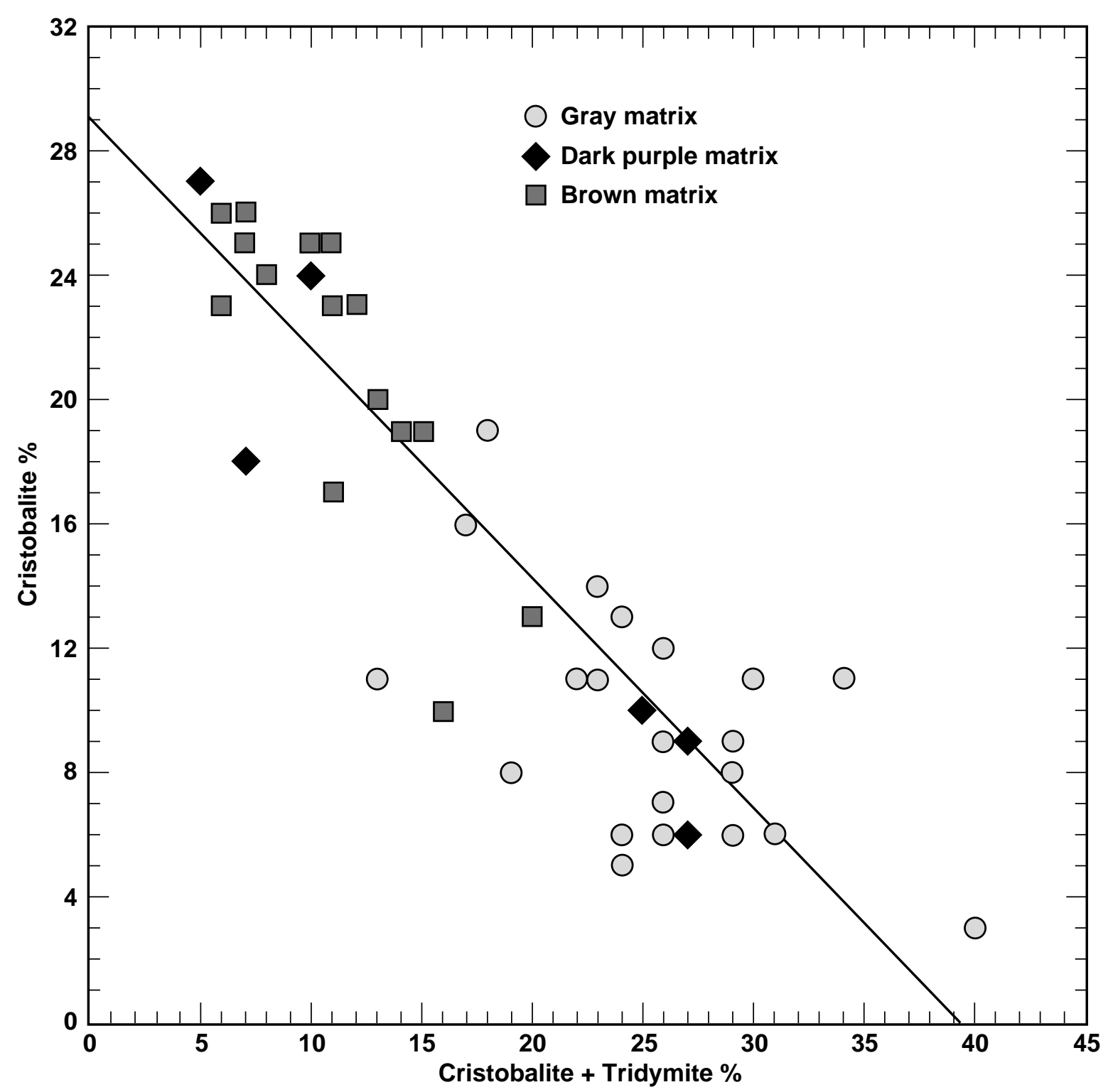

Figure 4-8. Variation in cristobalite abundance vs. quartz plus tridymite abundance for ESF core samples of different matrix color collected from the same core (solid line is the best fit regression to the data) 


\section{Results of O-MPBX Studies}

\section{by Stephen C. Blair}

An extensometer has been developed for measurement of distance and displacements in a geologic repository for high-level nuclear waste. This is an optical extensometer that measures distance using a modulated laser beam. In this design, reflecting targets are placed at desired measurement locations, and distances between each target and an optical head are measured repeatedly using the modulated laser beam. All electronic and moving parts are located outside of the hostile or difficult environment; because the optical head is connected to the laser, switching and signal analysis hardware use optical fibers. A reference beam is used to provide direct correction of system behavior. The system also uses movable reflective anchors that can be repositioned. The system was installed in the Single-Heater Test (SHT) conducted in Alcove 5 of the Exploratory Studies Facility (ESF) at Yucca Mountain.

\subsection{Introduction and Motivation}

Measurement of deformation in boreholes encountered in geotechnical or civil engineering applications is often accomplished using rod, wire, or tape extensometers. These are commonly referred to as multipoint borehole extensometers (MPBX). In these units, anchors are placed at selected points, and long rods, wires, or tapes, which are connected to the anchors, extend to an extensometer-head assembly located at the borehole collar. The movement of the anchors is assumed to be the same as the movement of the rod ends. In these units, displacement transducers are located in the extensometer-head assembly. These extensometers exhibit a variety of measurement problems and their recalibration may not be possible if they are located in a high-temperature or otherwise inaccessible or hostile environment. In recent tests at elevated temperatures appropriate to a geologic repository for high-level radioactive waste, failure rates of $50 \%$ for the transducers have been observed (Martino and Read 1996).

While conventional displacement transducers can be made rugged for use in hightemperature or otherwise hostile environments, the more rugged versions are often quite expensive. In addition, conventional MPBX applications often require that the rods, wires, or tapes be put under tension so that the anchors are permanently affixed at the measurement point. Consequently, interpretation of the data requires several assumptions. In particular, the rods, wires, or tapes under tension are assumed to have small thermal response, and tension is assumed to remain uniform during the duration of the measurement. Range is another limitation of conventional designs. Selection of the transducer used must be based on the anticipated amount of movement and the precision required for the analysis. Finally, the rods used in these extensometers often experience corrosion when used in high-temperature rock-engineering environments

The development of inexpensive lasers and optical-fiber technology offers the potential to eliminate many of these problems. A review of available technologies has been conducted to assess their suitability for application to a geologic repository for high-level nuclear waste. Results of this review are presented in Table 5-1. 
Table 5-1. Summary of available technologies for underground deformation measurements

\begin{tabular}{|l|l|l|}
\hline \multicolumn{1}{|c|}{ Technology } & \multicolumn{1}{|c|}{ Pro } & \multicolumn{1}{c|}{ Con } \\
\hline \hline MPBX-Mechanical & $\begin{array}{l}\text { Off-the-shelf } \\
\text { Good precision }\end{array}$ & $\begin{array}{l}\text { \$\$ for high temp. } \\
\text { Temp. correction is tedious } \\
\text { Limited range }\end{array}$ \\
\hline MPBX-Acoustic & Off-the-shelf & Unsuitable for high temp. \\
\hline Optical-Theodolite & $\begin{array}{l}\text { Off-the-shelf } \\
\text { Flexible } \\
\text { Best for large distances }\end{array}$ & $\begin{array}{l}\text { \$\$ } \$ \\
\text { Manual technique }\end{array}$ \\
\hline Interferometer & $\begin{array}{l}\text { High precision } \\
\text { No moving parts }\end{array}$ & $\begin{array}{l}\text { \$\$\$ } \$ \\
\text { Limited range } \\
\text { Uninterrupted power } \\
\text { Needs development }\end{array}$ \\
\hline Phase Modulated Laser & $\begin{array}{l}\text { Flexible } \\
\text { Wide range } \\
\text { No moving parts }\end{array}$ & $\begin{array}{l}\text { Requires clean optical path } \\
\text { alignment over time } \\
\text { Needs development }\end{array}$ \\
\hline
\end{tabular}

Based on this review, an optical extensometer was developed for use in the hightemperature environment expected in a geologic repository for high-level nuclear waste. This instrument uses a phase-modulated laser and optical-fiber technology. Some of the advantages of this instrument are the following:

- Because optical technology is used, no moving parts are located in high-temperature or otherwise-inaccessible regions, such as those expected in a high-level nuclear waste repository.

- Because the signal is transmitted over optical cables, electrical noise and resistance are eliminated.

- Recalibration is simplified by incorporating a system correction into the design.

- All electronic and switching components are located outside the high-temperature or otherwise-hostile environment.

- Measurements can be made over a wide range of lengths, from a few $\mathrm{cm}$ to $60 \mathrm{~m}$.

- Anchors are attached to the rock at discrete, isolated locations, thus eliminating putting rods, tapes, and wires under tension.

\subsection{Description}

This is an optical extensometer that measures distance using an amplitude-modulated laser beam. The principle of the laser-ranging instrument is illustrated in Figure 5-1.

Figure 5-1. Illustration of how a modulated signal can be used to measure distance 
In this design, reflecting targets are placed at desired measurement locations (e.g., along the length of a borehole), and distances between each target and an optical head located at the collar of the borehole are measured repeatedly using the modulated laser beam. That is, the laser is aimed at a target, and a portion of the reflected beam is collected by a photodiode located in the instrument, as shown in Figure 5-2.

\section{Figure 5-2. Schematic of distance measuring module}

This instrument has been named the reflective optical extensometer (ROX); a schematic view of the system is shown in Figure 5-3. The ROX system consists of the following components:

- An electro-optics module that contains a laser distance-measuring device and optical switching apparatus-The distance measurement is done using the Refleks instrument from Phase Laser, Inc., Phoenix, Arizona (Woodbury et al. 1996, pp. 16-26). This instrument makes discrete distance measurements using frequency modulation of the laser amplitude. It has a measurement range of $2 \mathrm{~cm}$ to $60 \mathrm{~m}$, with theoretical precision of approximately $50 \mu \mathrm{m}$. The Phase Laser unit used in the distance-measuring module has been modified to include fiberized laser diodes and photo diodes. The electro-optics module is controlled by a computer and allows the user to determine laser intensity, to switch between different optical fibers, to record data on disk, and to perform other data-acquisition and -control functions.

- An optical head and associated retro-reflectors-The laser beam is transmitted from the electro-optics module to the optical head using optical fibers. The optical head collimates the laser beam and transmits it to a retro-reflector located at a desired measurement point. The return beam is collected by a lens, located in the optical head, that focuses the beam onto an optical fiber, which transmits the beam back to the electro-optics module. The design of the optical head and associated downhole reflectors is shown in Figure 5-4.

The system has been implemented into a borehole extensometer, as shown in Figure 5-4, to measure axial deformation of a borehole. The prototype is a four-channel system; the optical head is set up with four sets of collimating lenses located concentrically at $0,90,180$, and $270^{\circ}$ about the axis of the head. One of the beams is used as a reference and returns distance from the electronic module to the borehole head. The other three are used for measurements. Three borehole anchors containing retro-reflectors are placed at different depths in the borehole, and each is oriented to one of the prescribed rotations.

\section{Figure 5-3. Schematic of ROX borehole extensometer system}

\section{Figure 5-4. Schematic of optical head and downhole reflectors used for ROX system}

The instrument measures the distance to each retro-reflector and the reference in sequence, repeating the measurement at prescribed intervals and averaging and recording as directed.

In addition, a system was developed for emplacing, positioning, and retrieving retroreflectors (and other anchors) in wells and boreholes. The system allows the rotational orientation of the anchors by locating a mercury switch on the installation tool. Once the anchor is at the desired location in the hole, it is rotated until the switch indicates it is 
properly oriented. Then a screw driven wedge is used to secure the anchor in place. The installation tool can also be used to retrieve the anchors. The installation tool and one reflective anchor are shown in Figure 5-5.

Figure 5-5. Borehole anchor and installation tool prior to installation in the SHT

\subsection{Results for the Single-Heater Test}

This system was used to monitor deformation in the SHT conducted in the ESF at Yucca Mountain, Nye County, Nevada. The purpose of the SHT was to monitor the thermalhydrologic-chemical-mechanical (THCM) behavior of Topopah Spring tuff. In this test, a line heat source approximately $5 \mathrm{~m}$ long and oriented in the horizontal plane was emplaced in a pillar of Topopah Spring tuff in Alcove 5 of the ESF. The ROX system was used to monitor the positions of reflective anchors placed in Boreholes 6 and 7 of the SHT (see Figure 1-1). These holes are in the horizontal plane and in directions parallel and perpendicular to the heater. Depths of the anchors from the borehole collar are given in Table 5-2.

Table 5-2. Locations of anchors in Boreholes 6 and 7 of the SHT (DTN LL980109904243.015)

\begin{tabular}{|c|l|l|l|l|}
\hline Date & Borehole & \multicolumn{1}{|c|}{ Anchor } & \multicolumn{1}{c|}{ Depth } & \multicolumn{1}{c|}{ Comment } \\
\hline \hline $8 / 20 / 96$ & 6 & 8 & $5.75 \mathrm{~m}\left(18^{\prime}, 109 / 16^{\prime \prime}\right)$ & Fracture at 1.6 m (8'), between anchorage 2 and 1 \\
& & 2 & $3.02 \mathrm{~m}\left(9^{\prime}, 111 / 16^{\prime \prime}\right)$ & \\
& & 1 & $1.52 \mathrm{~m}\left(5^{\prime} 0 "\right)$ & \\
\hline $8 / 22 / 96$ & 7 & 2 & $3.92 \mathrm{~m}\left(12^{\prime}, 109 / 16^{\prime \prime}\right)$ & \\
& & 1 & $2.09 \mathrm{~m}\left(6^{\prime}, 109 / 16^{\prime \prime}\right)$ & \\
\hline
\end{tabular}

ROX measurements started in late August 1996 and continued through December 1997. The system operated nearly continuously over several months in a location that was near continuous mining operations, including drill and blast, and mechanical excavation activities. The optical switches and Phase Laser module did not experience significant or long-term effects from the dust, shaking, and frequent electrical outages associated with the mining operations. Thus, the system is rugged enough to hold up over extended periods in the underground environment.

\subsubsection{General Results}

The ROX system operated successfully from August 1996 through December 1997. However, the quality of the data was not adequate for the purpose of geomechanical monitoring. Data for November 1996 through January 1997 show extension over the measured interval, which is consistent with analytical predictions of the test and with data observed using conventional MPBX systems in boreholes parallel with the ROX borehole. Although data from the ROX system were within an order of magnitude of the values observed by the conventional system, a higher precision result was expected. This result is disappointing because, as mentioned previously, the Phase Laser instrument is capable of precision in the range of $50 \mu \mathrm{m}$. Additional development is required to improve the precision of the system. 
During the installation, the ability to make a measurement over a length of approximately $3 \mathrm{~m}$ with one anchor in the hole was demonstrated. However, when multiple anchors were placed in the borehole, it was found that the shallower anchors blocked some of the return beam from the deep anchors and, while detectable beams were returned from the deepest anchors, the signal level for them was below that required by the Phase Laser instrument. The laser power was increased, and the beam collimation was improved, but only limited success was achieved in monitoring multiple anchors simultaneously.

Both of the boreholes used for the ROX system were unlined, and it was found that nearby drill and blast mining activities impacted the system. In particular, the blasting introduced a muddy mist into the boreholes, which fogged the reflectors. Because the anchors were retrievable, they were pulled out, the reflectors were cleaned, and the anchors were reset in the boreholes.

\subsubsection{Results for Borehole 6}

Borehole 6 was a horizontal borehole drilled parallel to the heater and approximately $1.5 \mathrm{~m}$ to the side and slightly above the heater. After approximately 1 month of heating, a substantial amount of condensation occurred in the outer $2 \mathrm{~m}$ of the hole. This condensation fogged the lens on the optical head; a small air stream was introduced onto the head to keep the lens clear. Inspections showed that this moisture was entering the hole via a major fracture zone subparallel to the drift face and approximately $0.15 \mathrm{~m}$ from the drift wall. During the second month of heating, the rock forming the outer $0.15 \mathrm{~m}$ of the drift wall displaced down and to the left approximately $6 \mathrm{~mm}$ in each direction. This precluded alignment of the laser head with the anchors, and measurements in this hole were terminated.

\subsubsection{Results for Borehole 7}

The ROX instrumentation for Borehole 7 operated consistently from August 1996 through December 1997. It is important to note that the data-acquisition and -control computer 's hard disk failed in January 1997. Consequently, the ROX system was not operational from January to June 1997. Several upgrades were made to the system during this time, including an upgrade to the laser-ranging unit incorporated in the system, streamlining of the optical path, and revision of the software.

The system was brought back online in early June 1997. However, during the period February through May 1997, significant amounts of moisture, probably associated with the heating, started moving into Borehole 7 . This moisture caused condensation on the optical head and a loss of signal from the unit. To overcome this, the system was used in a manual mode to obtain a measurement on June 7,1997 , and then a defogging system was installed to reduce the condensation on the optical head. The system recorded data continuously during the period November 11-18 and December 11-31, 1997. Data values were recorded every $30 \mathrm{~min}$. These values were then averaged over 24 -hr periods (midnight to midnight); the averaged values are listed in Table 5-3.

Figure 5-6 shows data over the entire period. The variation in values is much greater than is physically reasonable for the rock in this environment; this is interpreted as indication of inconsistency in instrument performance between the August-September 1996, the June 1997, and the November-December 1997 data sets. This is can be attributed to modifications made to the computational and optical instrumentation. 
Table 5-3. Summary data for separation of anchors 2 and 3 in Borehole 7 of the SHT (DTN LL980109904243.015)

\begin{tabular}{|c|c|}
\hline Date & Separation $(\mathrm{mm})$ \\
\hline 8/22/1996 & 1828.8 \\
\hline 9/18/1996 & 1831.6 \\
\hline $6 / 5 / 1997$ & 1815.1 \\
\hline $11 / 11 / 1997$ & 1839.4 \\
\hline $11 / 12 / 1997$ & 1837.7 \\
\hline $11 / 13 / 1997$ & 1836.9 \\
\hline $11 / 14 / 1997$ & 1837.6 \\
\hline 11/15/1997 & 1838.2 \\
\hline $11 / 16 / 1997$ & 1837.3 \\
\hline $11 / 17 / 1997$ & 1836.9 \\
\hline 11/18/1997 & 1837.2 \\
\hline $12 / 11 / 1997$ & 1842.5 \\
\hline $12 / 12 / 1997$ & 1837.2 \\
\hline $12 / 13 / 1997$ & 1833.3 \\
\hline $12 / 14 / 1997$ & 1834.0 \\
\hline $12 / 15 / 1997$ & 1834.2 \\
\hline 12/16/1997 & 1834.0 \\
\hline $12 / 17 / 1997$ & 1833.0 \\
\hline $12 / 18 / 1997$ & 1833.2 \\
\hline $12 / 20 / 1997$ & 1833.6 \\
\hline 12/21/1997 & 1833.7 \\
\hline 12/22/1997 & 1834.0 \\
\hline $12 / 23 / 1997$ & 1833.5 \\
\hline $12 / 24 / 1997$ & 1832.7 \\
\hline $12 / 25 / 1997$ & 1833.9 \\
\hline $12 / 26 / 1997$ & 1831.9 \\
\hline $12 / 27 / 1997$ & 1832.2 \\
\hline $12 / 28 / 1997$ & 1831.8 \\
\hline $12 / 29 / 1997$ & 1832.1 \\
\hline $12 / 30 / 1997$ & 1832.0 \\
\hline 12/31/1997 & 1831.3 \\
\hline
\end{tabular}

Figure 5-6. Deformation data from SHT, Borehole 7 over period July 1996 through December 1997 (DTN LL980109904243.015) 
Data from November through December 1997 for Borehole 7 are plotted in Figure 5-7. These data are self-consistent and indicate that anchors 3 and 4 have converged over the 2 -month period. The amount of convergence is approximately $7 \mathrm{~mm}$. This indicates a strain of approximately 0.004 over this length. It is also important to note that the deformation is linear over time, with the exception of data taken on December 11 and 12. The high values noted for these dates may be due to instabilities in the system associated with restarting the unit after a few weeks of shut-down. The linear trend is consistent with the cooling regime that was occurring over this time interval. While the trend of the data is sensible, a deformation this large is not to be expected and indicates that more development is needed before the ROX system is suitable for monitoring thermal-mechanical behavior of rock.

Figure 5-7. Deformation data from SHT, Borehole 7 over period November 11, 1997, to December 31, 1997 (DTN LL980109904243.015)

Circles represent values averaged over 24 -hr periods.

\subsection{Summary}

An optical extensometer was developed for use in the high-temperature environment that is expected in a geologic repository for nuclear waste. This instrument is flexible and rugged and can be used in a variety of other geotechnical and civil engineering applications. The system has many advantages over conventional rod extensometers because there are no moving parts in the borehole, and a system correction is incorporated in the design. This system was installed in the SHT, and some problems were encountered-including loss of alignment, poor signal due to absorption, scattering of the laser, and instability of the detection algorithm-because of a combination of optical and electronic effects. However, the system is still under development, and it is hoped that the system performance and data quality will be improved in future realizations of this instrument.

\subsection{References}

Martino, J., and Read, R. 1996. “AECL's heated failure tests: An overview.” Int. Soc. Rock Mech. News J. 4:1.

Woodbury, N., Brubacher, M., and Woodbury, J. 1996. “The frequency-modulated laser tank gauge: Designing a practical system." Sensors 13:9. 

Chapter 5 Figures 


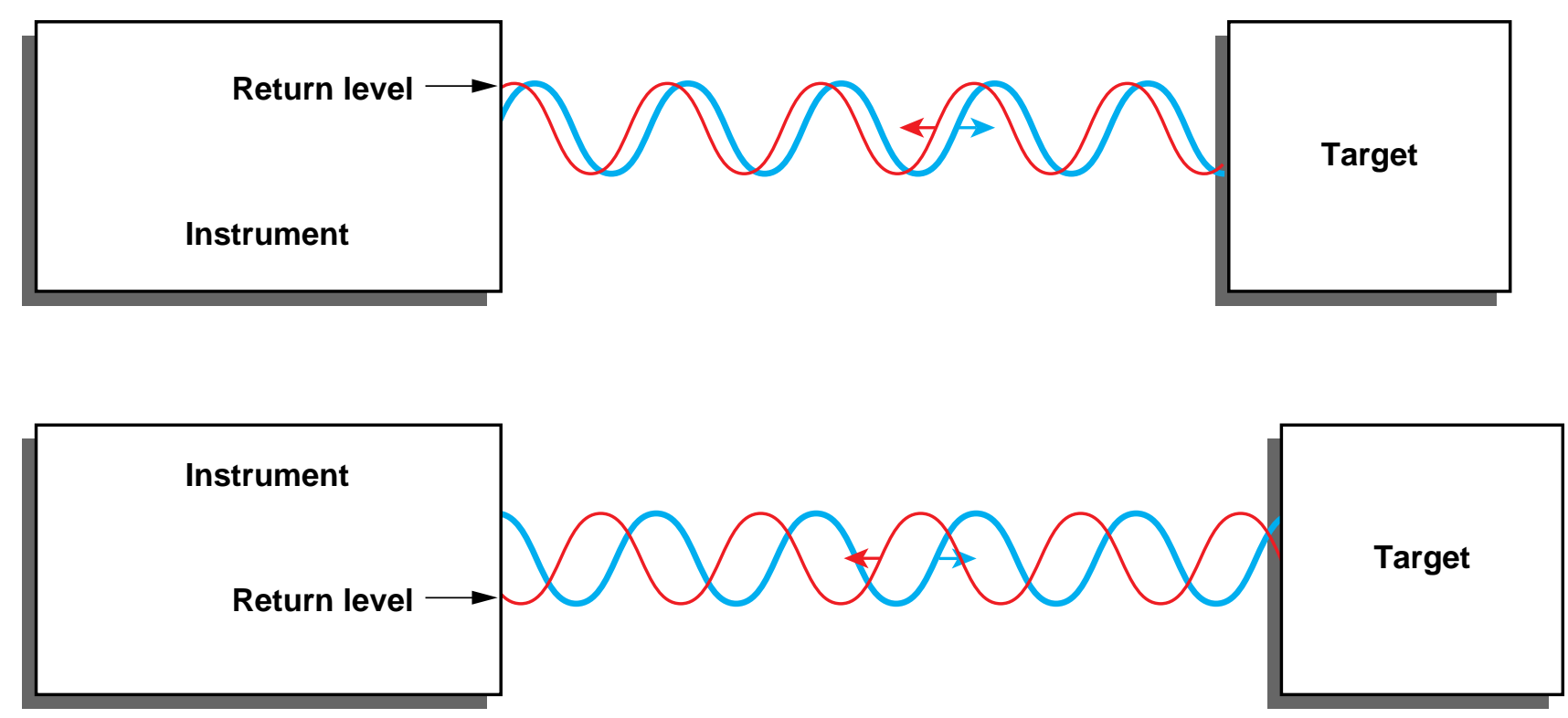

- Wavelength and relative phase determine measurement accuracy.

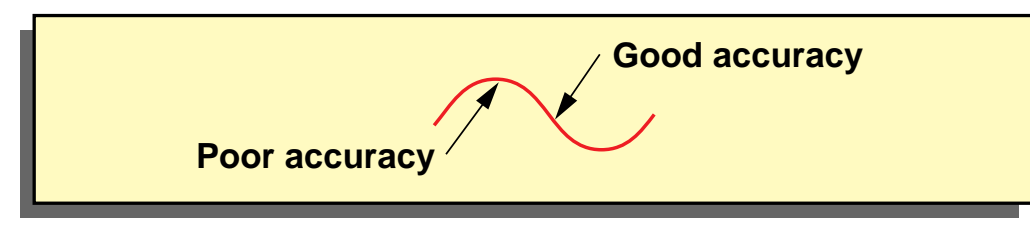

- Phase shift repeats after one wavelength.

- Absolute distance must be determined.

- Two-frequency modulation

Figure 5-1. Illustration of how a modulated signal can be used to measure distance 


\section{Figures}

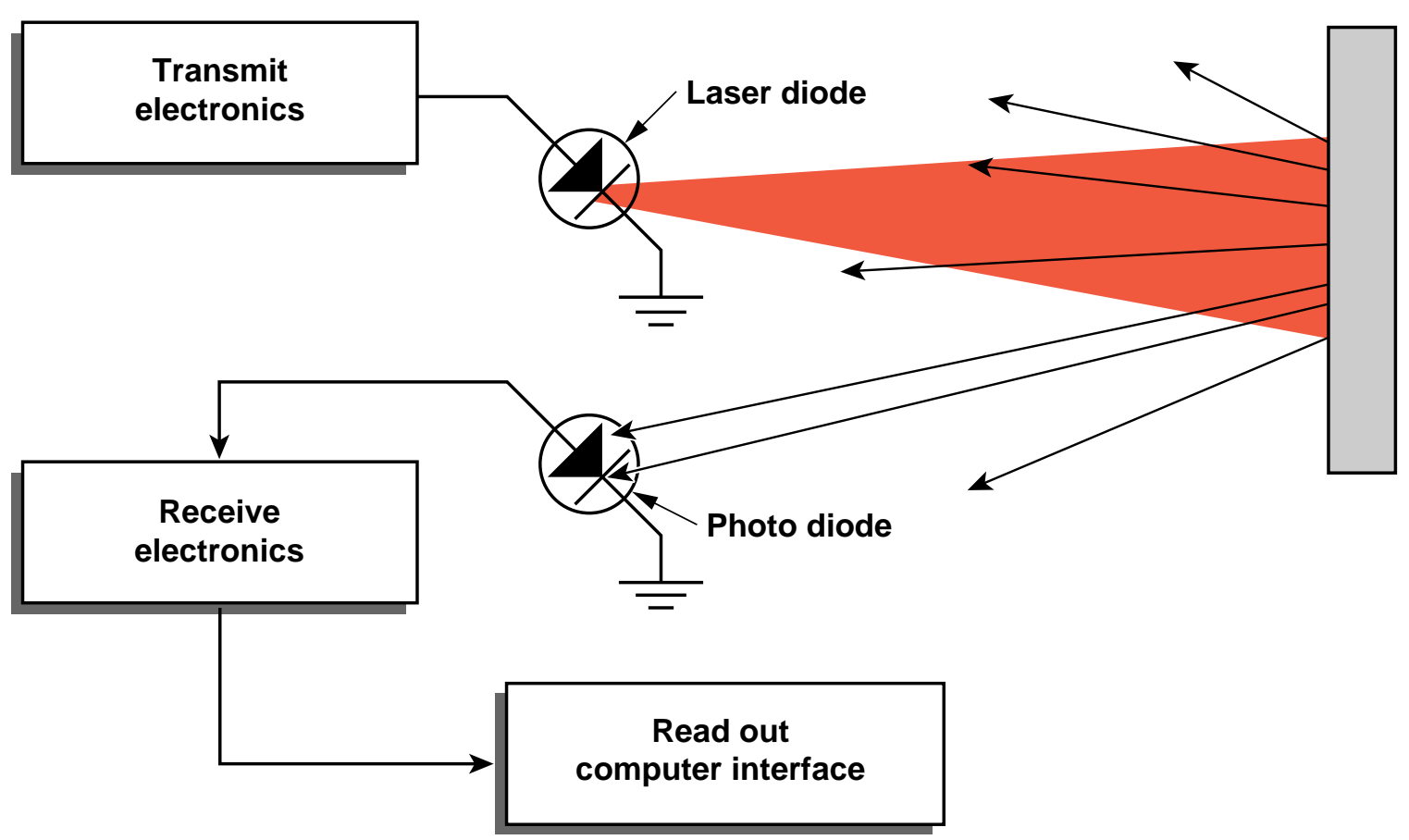

Figure 5-2. Schematic of distance measuring module

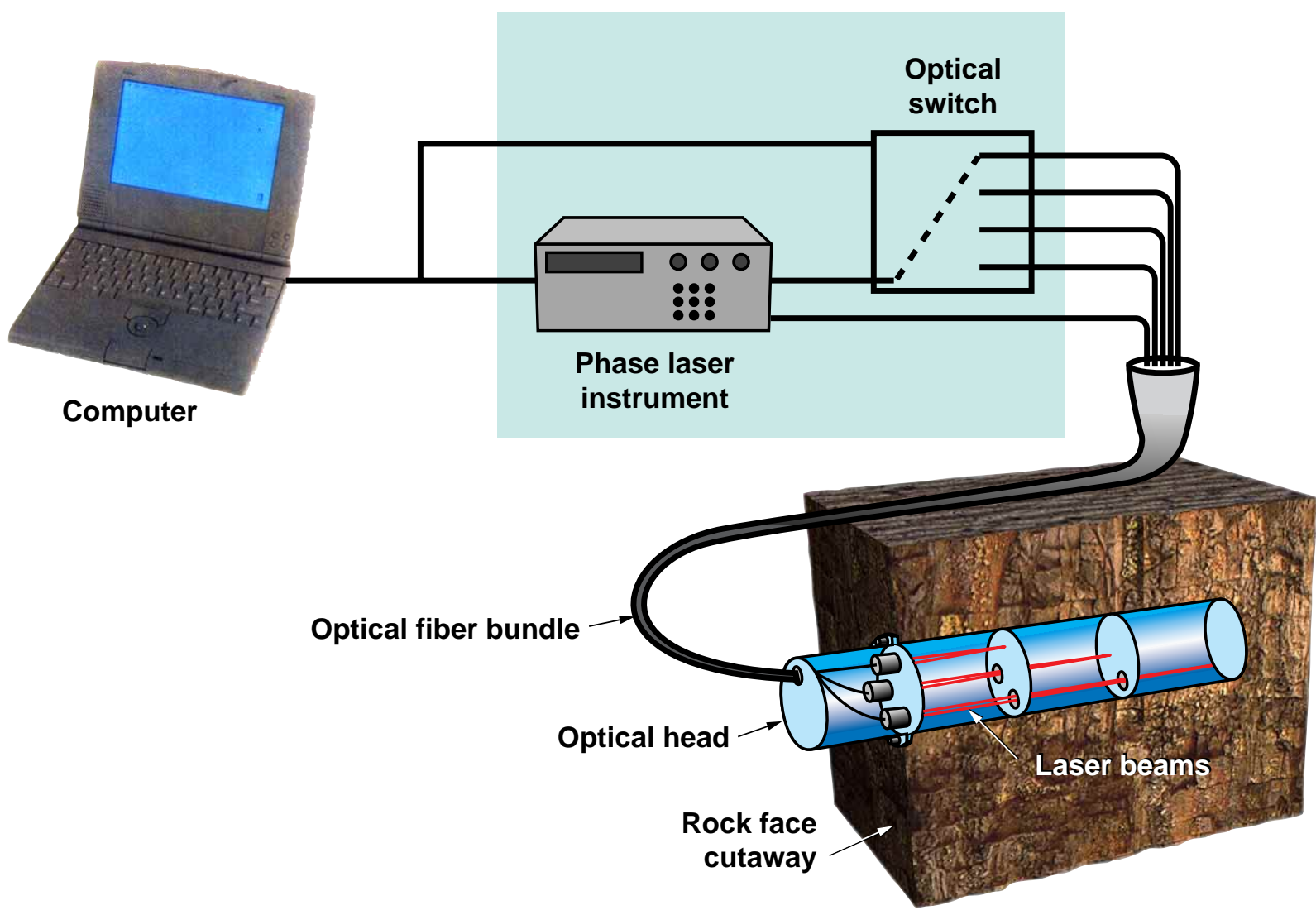

Figure 5-3. Schematic of ROX borehole extensometer system 


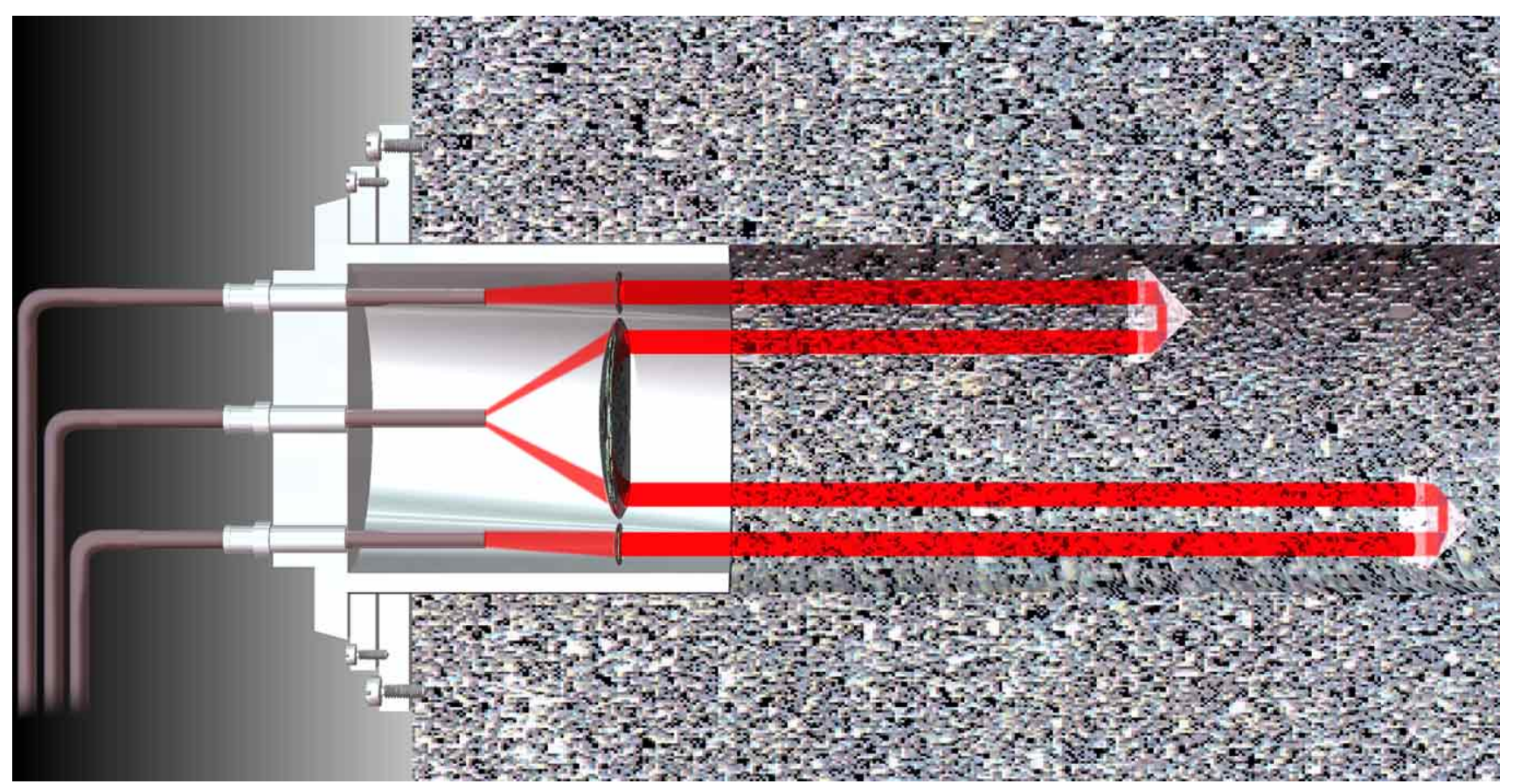

Figure 5-4. Schematic of optical head and downhole reflectors used for ROX system

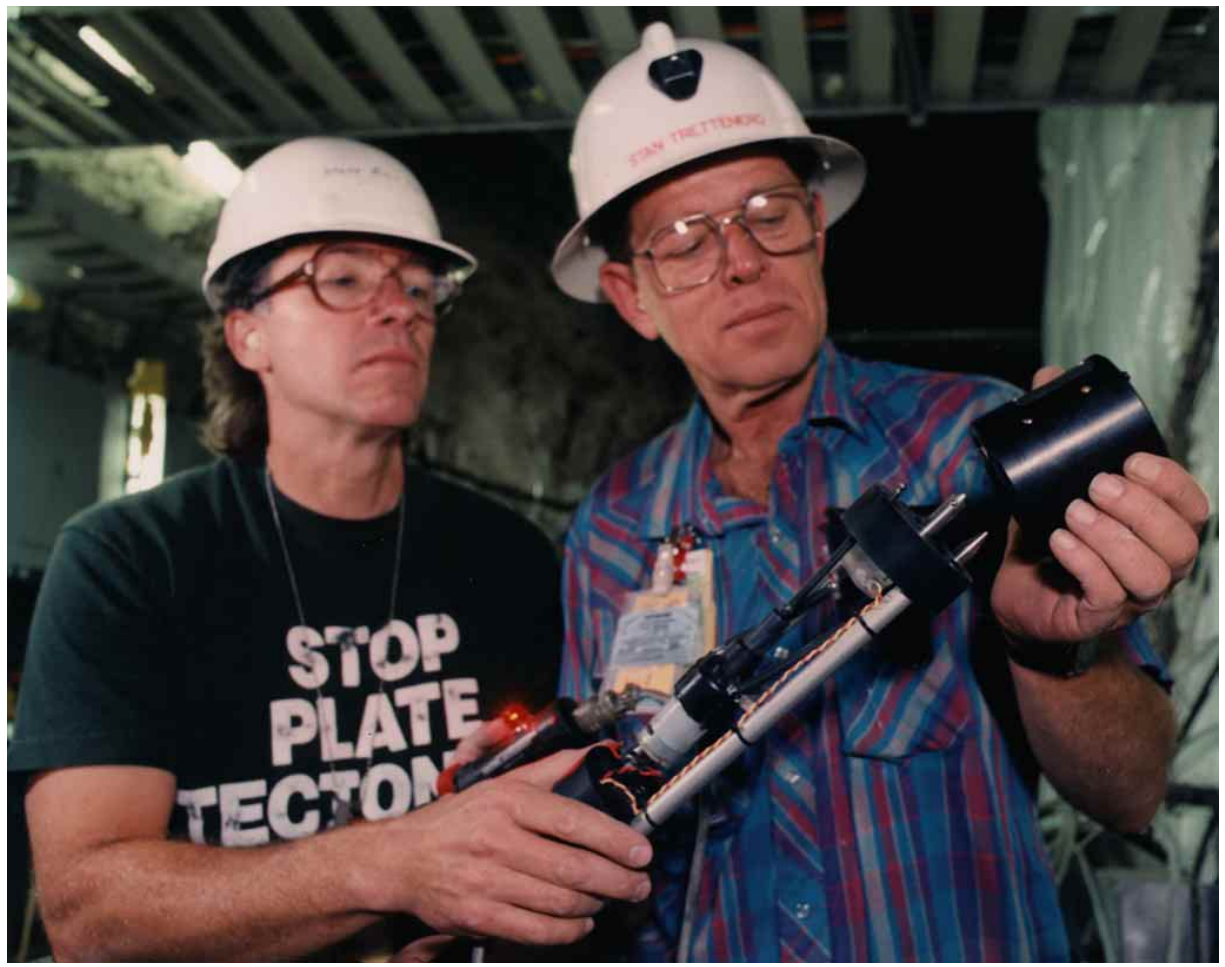

Figure 5-5. Borehole anchor and installation tool prior to installation in the SHT 


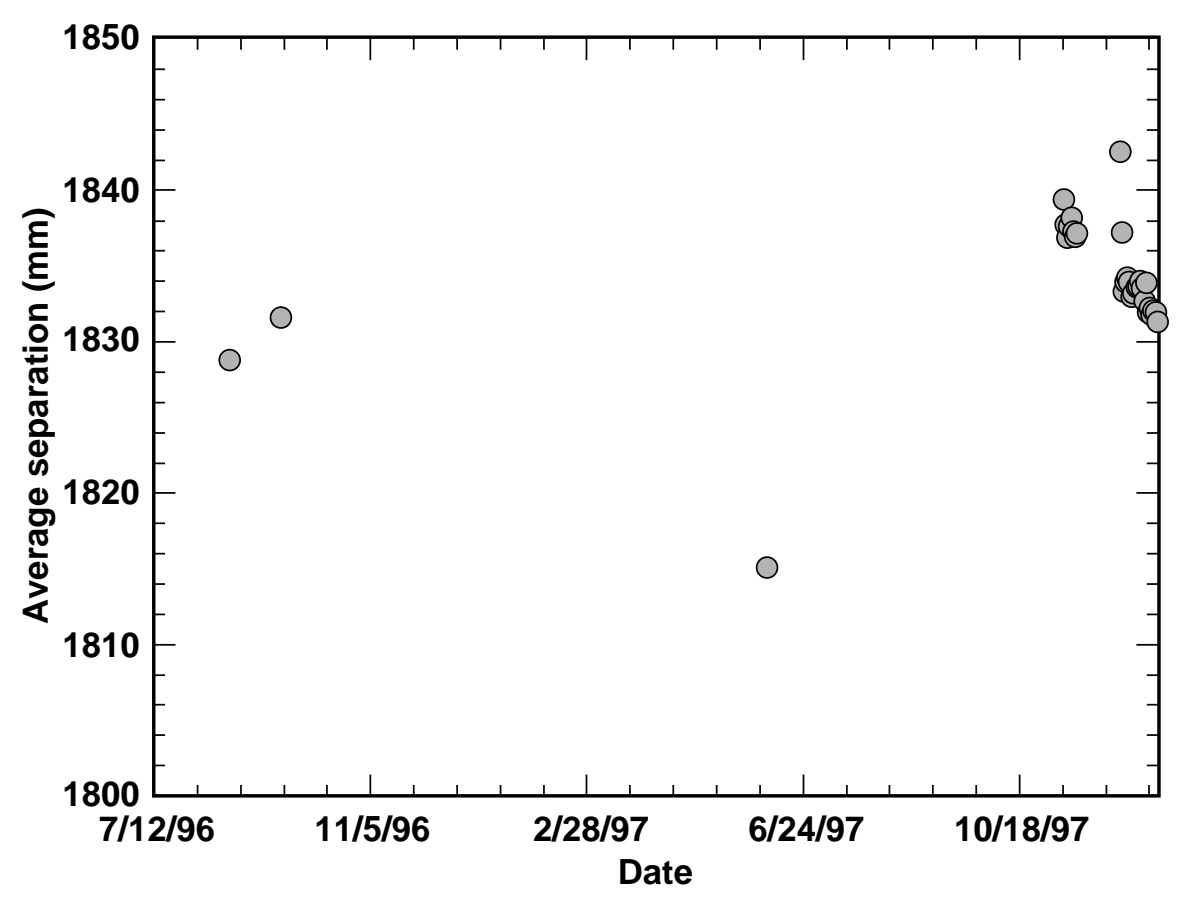

Figure 5-6. Deformation data from SHT Borehole 7 over period July 1996 through December 1997

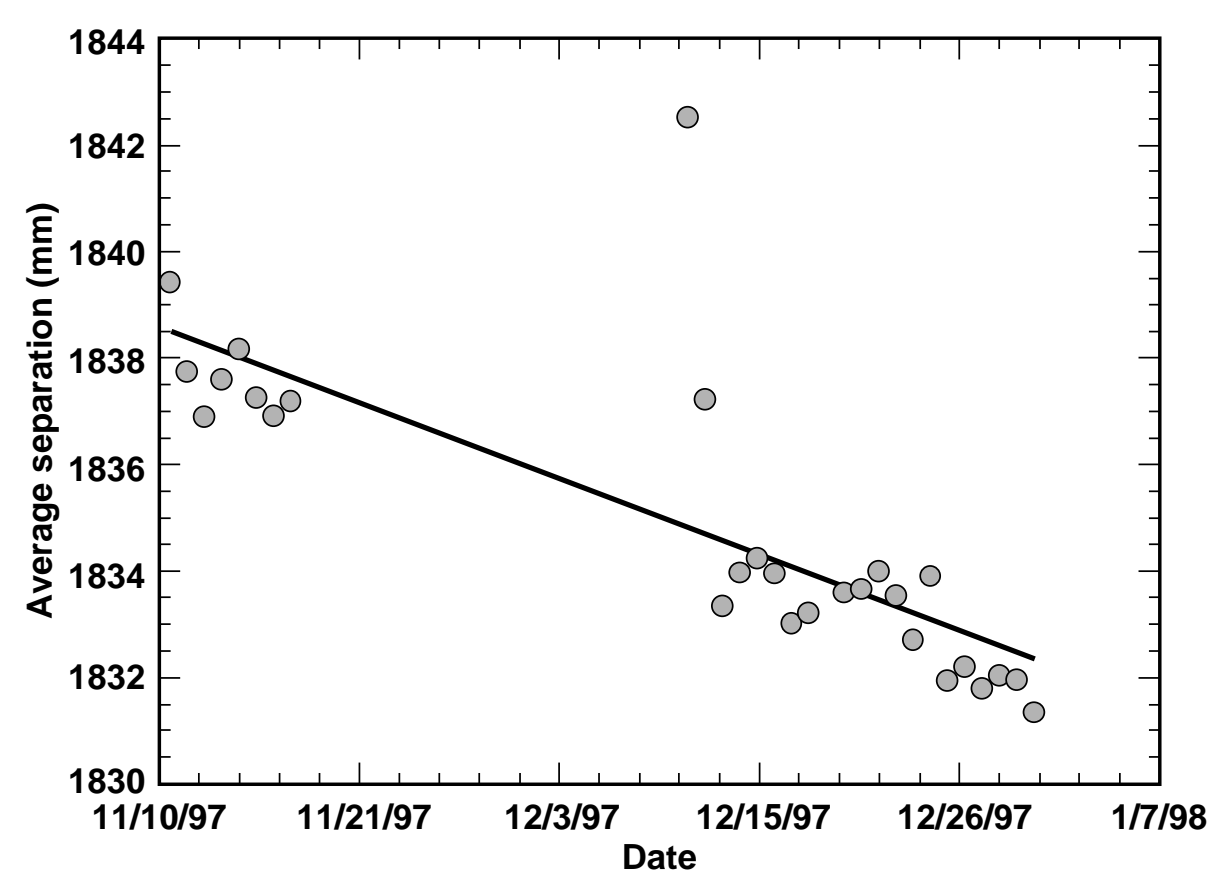

Figure 5-7. Deformation data from SHT Borehole 7 over period November 11, 1997, to December 31, 1997 (circles represent values averaged over $24-\mathrm{hr}$ periods) 


\title{
6. Thermohydrologic Modeling
}

\author{
by Thomas A. Buscheck, Kenrick H. Lee, and Truc H. De Lorenzo
}

\subsection{Introduction}

Thermohydrologic (TH) model calculations have been conducted with the Nonisothermal Unsaturated-Saturated Flow and Transport (NUFT) code for the Single-Heater Test (SHT). The SHT was conducted in the Tptpmn unit, which is one of the three major host-rock units for the potential repository at Yucca Mountain, Nevada. A primary purpose of the TH-model calculations described in this chapter is to compare the simulated temperatures with the temperatures measured in the field during the heat-up and cool-down periods of the SHT. The TH-model calculations assume the December 1997 base-case hydrologic parameter set used in the Total System Performance Assessment-Viability Assessment (TSPA-VA); thus, this comparison between simulated and measured temperatures is a useful way of assessing the applicability of that property set to predicting TH behavior in one of the three major hostrock units. In the process of comparing the simulated and measured temperatures, it is necessary to analyze the relationship between temperature change and (gas- and liquidphase) moisture movement in the SHT. Another purpose of the TH-model calculations is to investigate differences in predicted $\mathrm{TH}$ behavior between two different approaches to representing fracture-matrix interaction: the equivalent-continuum method (ECM) and the dual-permeability method (DKM).

The TH models of the SHT described in this chapter are similar to the three-dimensional (3-D) TH models used in previous studies (Buscheck et al. 1997b). Several significant improvements and changes have been incorporated in the current TH models of the SHT, including the following:

- The model assumes the TSPA-VA (December 1997) base-case hydrologic parameter set for $I \times 1 \alpha_{f, \text { mean }}$ where I stands for the nominal infiltration-flux map and $\alpha_{\mathrm{f}}$ is the van Genuchten alpha parameter. In the TSPA-VA analysis, this set is assumed to be the most likely hydrologic parameter set. Previous TH-model calculations (Buscheck et al. 1997b) considered the TSPA-VA (July 1997) preliminary base-case hydrologic parameter set.

- The model includes the influence of vapor and heat flow along the axis of the heater borehole. The previous TH-model neglected this effect.

- The model domain is extended (westward) to include the entire thermomechanical (TM) alcove as well as $33 \mathrm{~m}$ of rock to the west of the TM alcove. The western boundary of the previous TH model domain was at the eastern face of the TM alcove.

- Fracture-matrix interaction is represented with DKM. Two alternatives for representing the degree of fracture-matrix disequilibrium are considered: (1) using a static fracture-matrix interaction (FMX) term and (2) using a dynamic fracture-matrix coupling term that is a function of the liquid-phase relative permeability in the fractures.

The first two features are included in all TH-model calculations. The third feature is included in all but one of the TH-model calculations. The fourth feature (DKM) is included in two of the TH-model calculations; the other calculations use ECM to represent fracture-matrix interaction. 


\subsection{Numerical Models and Assumptions}

\subsubsection{NUFT Numerical Simulation Code}

All of the TH-model calculations in this study used the NUFT code (Nitao 1998a; Nitao 1998b). NUFT uses the integrated-finite-difference method and simulates the transport of air, water, energy, and other species such as radionuclides. NUFT determines the spatial and temporal distribution of gas- and liquid-phase pressure, gas- and liquid-phase saturation, airmass fraction in gas and liquid phases, water-mass fraction in gas and liquid phases, and temperature. NUFT can treat the mechanical dispersion of components. NUFT was successfully benchmarked against the VTOUGH code (Nitao 1988, pp. 1-24), which has been qualified for quality-affecting work, and was recently qualified for quality-affecting work, according to the individual software plan for NUFT.

\subsubsection{Representing Fracture-Matrix Interaction}

There are three principal classes of the mathematical treatment of fracture-matrix interaction that are used in TH models: the ECM, the DKM, and the discrete-fracture method (DFM) (chapter 3 of Hardin et al., 1998). Because of the computational demands of the DKM and the DFM, past TH-model calculations have used the ECM. Both the ECM and the DKM are used in the TH-models described in this chapter. Cases 1 and 2 use ECM; Cases 3 and 4 use the DKM (Table 6-1).

Table 6-1. Summary of the four cases considered in this study

\begin{tabular}{|l|c|c|c|c|}
\hline & Case 1 & Case 2 & Case 3 & Case 4 \\
\hline \hline $\begin{array}{l}\text { Hydrologic } \\
\text { parameter set }\end{array}$ & $\begin{array}{c}12 / 97 \text { TSPA-VA } \\
\text { base case }\end{array}$ & $\begin{array}{c}12 / 97 \text { TSPA-VA } \\
\text { base case* }\end{array}$ & $\begin{array}{c}12 / 97 \text { TSPA-VA } \\
\text { base case }\end{array}$ & $\begin{array}{c}\text { 12/97 TSPA-VA } \\
\text { base case* }^{*}\end{array}$ \\
\hline $\begin{array}{l}\text { Conceptual model } \\
\text { for fracture-matrix } \\
\text { interaction }\end{array}$ & ECM & ECM & DKM & DKM \\
\hline $\begin{array}{l}\text { Fracture-matrix } \\
\text { connectivity factor } \\
\text { (FMX) }\end{array}$ & NA & NA & Fixed FMX & Dynamic FMX \\
\hline Model domain & $\begin{array}{c}\text { Western boundary } \\
33 \text { m to the west } \\
\text { of the TM alcove }\end{array}$ & $\begin{array}{c}\text { Western boundary } \\
\text { at the eastern wall } \\
\text { of the TM alcove }\end{array}$ & $\begin{array}{c}\text { Western boundary } \\
33 \text { m to the west } \\
\text { of the TM alcove }\end{array}$ & $\begin{array}{c}\text { Western boundary } \\
\text { 33 m to the west } \\
\text { of the TM alcove }\end{array}$ \\
\hline
\end{tabular}

${ }^{*}$ All hydrologic parameters except for the bulk permeability, fracture-continuum permeability, and fracture porosity values were taken from this set.

\subsubsection{Equivalent-Continuum Method}

The ECM assumes that the local matric potential (water potential plus osmotic potential) is equal in the fractures and the adjacent matrix. Local thermodynamic equilibrium is assumed between the fractures and matrix. Composite functions are derived to describe the equivalent behavior of a single continuum and to define the relations between unsaturated hydraulic conductivity and liquid-phase saturation and between matric potential and liquidphase saturation (Klavetter and Peters 1986, pp. 1-55). The ECM does not treat fractures as 
discrete features; instead, fracture-flow effects are averaged over the whole spatial domain. The ECM involves less computational effort than do the DKM and the DFM because it uses a single continuum to represent the fractures and matrix.

The assumption of local equilibrium between fractures and matrix is appropriate if the liquid-phase flux in the fractures is sufficiently small (Buscheck et al. 1991; Nitao et al. 1993, pp. 1-26). Thus, the ECM is appropriate for modeling condensate drainage during periods of quasi-steady moisture movement in thermally driven models, but may be less well suited for modeling the early stages of repository heating, when the rate of thermally driven moisture reflux will be near its peak and when condensate shedding between emplacement drifts is greatest. Because of the large liquid-phase fluxes that were expected to occur during the heatup period of the SHT, the ECM is probably not well suited for representing the influence of condensate shedding around the dry-out zone in the SHT.

\subsubsection{Dual-Permeability Method}

The DKM treats the matrix and the fractures as two distinct porous continua, with transfer terms to represent the mass and heat flux between them. Because the DKM does not assume capillary-pressure equilibrium between fracture and matrix continua, it can handle much larger liquid-phase fluxes than can the ECM without producing conditions near 100\% liquid saturation in the matrix. The DKM also allows thermodynamic disequilibrium between matrix blocks and the adjoining fractures because of its capability to represent heat flow between these two continua.

The DKM approach has been applied in drift-scale TH models supporting TSPA-VA, with direct bearing on prediction of conditions in the near field and altered zone (NF/AZ). The DKM is applied to all the line-averaged-heat-source drift-scale thermohydrologic (LDTH) model calculations used in the multiscale TH modeling approach to predict near-field environment (NFE) conditions for performance assessment (CRWMS M\&O 1998, Chapter 3, Volume 2). In this family of models, the fracture-to-matrix liquid flow is strongly influenced by the FMX parameter, which is specified as a model input for each hydrostratigraphic unit. This parameter varies between 0 and 1 and quantifies the fraction of the fracture surfaces that is wetted by the liquid phase. This fraction, together with a specified value for the fracture spacing, quantifies the interfacial flow area per unit volume of the rock matrix available for fracture-to-matrix liquid-phase mass transfer.

The FMX parameter for liquid-phase interaction accounts for channeling of flow as the liquid phase "fingers" through the fracture network. However, this factor probably underrepresents the wetted surface area of fractures that occurs during condensate drainage in TH models. Other approaches (Ho 1997) attempt to account dynamically for changes in the influence of condensate drainage on the FMX parameter. In such approaches, the parameter that is analogous to FMX increases with the magnitude of liquid flux in the fracture continuum. Because repository decay heat will generally produce greater liquid flux than that which occurs at ambient conditions, and because condensate flow may be more ubiquitous than ambient percolation in fractures, this dynamic approach results in a larger value of the interaction factor where there is development of condensate flow. As the repository heat output declines, thermally driven reflux decreases asymptotically toward the ambient percolation, and the interaction factor decreases to its previous value. The drift-scale TH calculations supporting TSPA-VA assume a constant value for FMX rather than taking the dynamic-FMX approach. In this study, the constant-FMX approach is compared with the dynamic-FMX approach. 
The dynamic-FMX approach used in this study assumes that FMX is equal to the square of the liquid-phase relative permeability $k_{\mathrm{r}, \mathrm{liq}, \mathrm{f}}$ in the fractures. The basis for this dynamic-FMX approach is that the fraction of the fracture surfaces that are wetted by the liquid phase increases strongly with increasing $q_{\text {liq. }}$. The value of the dynamic FMX was chosen to be the square of $k_{\mathrm{r}, \mathrm{liq}, \mathrm{f}}$ because this relationship was judged to be much stronger than a simple linear relationship. Because $k_{\mathrm{r}, \mathrm{liq}, \mathrm{f}}$ increases with liquid-phase flux $q_{\mathrm{liq}}$ FMX increases with $q_{\mathrm{liq}}$. For the relatively small $q_{\mathrm{liq}}$ that occur under ambient percolation conditions, FMX is small. For the much larger $q_{\text {liq }}$ that occur as a result of radioactive decay heat, FMX is much largerrepresenting how condensate flux is more ubiquitously distributed over the fracture surfaces. During the heat-up period of the SHT, the TH-model-predicted $q_{\mathrm{liq}}$ is relatively large, resulting in a much larger value of FMX than occurred prior to heating.

\subsubsection{Model Geometry, Boundary Conditions, and Numerical Mesh}

A conceptual plan and overview of the SHT is described by Wagner (CRWMS M\&O, 1996a; 1996b). The test layout is shown in Figure 6-1. An electrical-resistance heater placed in a small-diameter horizontal borehole was used to heat the rock. The thermal-hydrologicchemical-mechanical (THCM) response of the rock was monitored by instrumentation placed in boreholes at various locations within the rock. The heated block was $12.86 \mathrm{~m}$ wide, bounded to the north by the access / observation drift, to the south by the TM alcove extension, and to the west by the TM alcove. The horizontal heater borehole was $9.6 \mathrm{~cm}$ in diameter, collared $6.59 \mathrm{~m}$ from the access/observation drift and $1.52 \mathrm{~m}$ above the floor of the TM alcove, and drilled parallel to the access/observation drift. The heater was $5.0 \mathrm{~m}$ long, installed with its front (i.e., closest) end $1.99 \mathrm{~m}$ from the borehole collar. The walls of the access / observation drift and alcoves that faced the block were covered by a 15-cm-thick layer of fiberglass insulation with a thermal conductivity of $0.044 \mathrm{~W} / \mathrm{m}-\mathrm{K}$. The nominal electrical power supplied to the heater was $3.86 \mathrm{~kW}$. The actual deviations of power from $3.86 \mathrm{~kW}$, because of fluctuations and outages, is accounted for in all the model calculations.

Figure 6-1. SHT layout, including dimensions and SHT-model coordinate system, in plan view and vertical Section A-A'

The 3-D SHT model takes into account the geometric details of the SHT area, including the heater hole, the access / observational drift, the TM alcove, and the TM alcove extension . The model uses a Cartesian $(x, y, z$ or $i, j, k)$ coordinate system. The $x$ direction is transverse to the heater borehole, with $x$ or $i$ increasing to the right (i.e., south). The $y$ direction is parallel to the heater borehole, with $y$ or $j$ increasing with distance from the borehole collar into the rock mass. The $z$ direction is vertical, with $z$ or $k$ increasing with distance above the heater borehole axis. The overall grid-block dimensions of the model are $i=54, j=32$, and $k=44$. For the ECM models there are 2484 null blocks in the model, which results in a total of 73,548 active grid blocks. For the DKM models there are 147,096 active grid blocks and 4968 inactive blocks.

The lateral model boundaries are adiabatic/no-mass flow boundaries. The northern and southern boundaries are $52.5 \mathrm{~m}$ from the heater axis, while the eastern boundary is $62.7 \mathrm{~m}$ to the east of the eastern end of the heater (Figure 6-1). The ground surface is far enough above the SHT horizon $(250 \mathrm{~m})$ that fluctuations in surface conditions are do not influence TH conditions at the SHT horizon. Thus, the ground surface can be accurately represented as a constant-temperature, constant-pressure, and constant-relative-humidity boundary. The water table, which is $572.3 \mathrm{~m}$ below the ground surface, is a constant-temperature, constant- 
pressure, and constant-liquid-saturation boundary. The models are initialized to account for the geothermal temperature gradient and static air-pressure gradient in the SHT area. The initial temperature at the heater horizon is $24.4^{\circ} \mathrm{C}$.

In previous TH calculations (Hardin et al. 1998, Chapter 3), the western boundary was the inside surface of the insulation on the eastern wall of the TM alcove (at $y=0$ in Figure 6-1); one of the ECM TH calculations in this study (Case 2) uses the same western boundary. For all of the other TH calculations reported here (Cases 1, 3, and 4), the western boundary is 33 $\mathrm{m}$ to the west of the western side of the TM alcove, which places this boundary $40.64 \mathrm{~m}$ to the west of the western end of the heater. For the model, the access/observation drift and the TM alcove extension are maintained at a constant temperature $\left(24.4^{\circ} \mathrm{C}\right), \mathrm{RH}(82.5 \%)$ and a constant gas-phase pressure $\left(8.91 \times 10^{4} \mathrm{~Pa}\right)$. These values were chosen to account approximately for the influence of ventilation in the SHT area.

\subsubsection{Thermal/Hydrologic Properties and Percolation-Flux Assumptions}

The thermal properties used in the TH models are similar to those used in previous SHTmodel studies (Buscheck et al. 1997b, Table 2-1). The only difference in thermal properties is that the wet value of thermal conductivity $K_{\text {th,wet }}$ used in this study $\left(K_{\text {th,wet }}=2.1 \mathrm{~W} / \mathrm{m}-\mathrm{K}\right)$ is slightly higher than that used in previous studies $\left(K_{\text {th,wet }}=2.0 \mathrm{~W} / \mathrm{m}-\mathrm{K}\right)$. The measured in situ value of $K_{\mathrm{th}}$ is $2.0 \mathrm{~W} / \mathrm{m}-\mathrm{K}$ (CRWMS M\&O 1996a; CRWMS M\&O 1997, Table 9-1). The in situ liquid-phase saturation $S_{\text {liq }}$ is 0.92 ; thus, ambient saturation conditions are less than fully saturated. Extrapolating to full saturation (i.e., wet) conditions results in $K_{\text {th,wet }}=2.1 \mathrm{~W} / \mathrm{m}-\mathrm{K}$.

With the exception of the values of bulk permeability $k_{\mathrm{b}}$, fracture-continuum permeability $k_{\mathrm{f}}$, and fracture porosity $\phi_{\mathrm{f}}$, the hydrologic properties used in this study are taken from the December 1997 TSPA-VA base-case hydrologic parameter set (Table 6-2). The value of $k_{\mathrm{b}}(122$ millidarcy) used in this study is the log center mean of the values measured in the SHT area (CRWMS M\&O 1996a; CRWMS M\&O 1997, Table 9-1) and is the same as that used in a previous study (Case 2 in Section 3.4 of Hardin et al. 1998z). Because $k_{\mathrm{b}}$ is equal to $k_{\mathrm{f}} \phi_{\mathrm{f}}+k_{\mathrm{m}}(1-$ $\left.\phi_{\mathrm{f}}\right)$, where $k_{\mathrm{m}}$ is equal to the matrix permeability, and $k_{\mathrm{b}}>>k_{\mathrm{m}}, k_{\mathrm{b}}$ is essentially equal to $k_{\mathrm{f}} \phi_{\mathrm{f}}$ (where $k_{\mathrm{b}}, k_{\mathrm{f}}$ and $k_{\mathrm{m}}$ are expressed in $\mathrm{m}^{2}$ ). Note that the ECM- and DKM-model calculations use the same matrix and fracture properties.

Table 6-2. Thermal and hydrologic properties summarized for the host rock for the SHT area (tsw34 unit) (DTN LL980810804242.050)

With the exception of the bulk permeability and fracture-continuum permeability, these property values are the same as in the December 1997 TSPA-VA base-case hydrologic property set.

\begin{tabular}{|l|c|c|c|}
\hline \multicolumn{1}{|c|}{ TH Property } & Cases 1 \& 2 & Case 3 & Case 4 \\
\hline \hline Percolation flux $q_{\text {perc }}(\mathrm{mm} / \mathrm{yr})$ & 0.23 & 0.22 & 11.52 \\
\hline Bulk permeability $k_{\mathrm{b}}($ millidarcy $)$ & 122 & 122 & 122 \\
\hline Bulk permeability $k_{\mathrm{b}}\left(\mathrm{m}^{2}\right)$ & $1.22 \times 10^{-13}$ & $1.22 \times 10^{-13}$ & $1.22 \times 10^{-13}$ \\
\hline Matrix permeability $\left(\mathrm{m}^{2}\right)$ & $4.07 \times 10^{-18}$ & $4.07 \times 10^{-18}$ & $4.07 \times 10^{-18}$ \\
\hline Fracture-continuum permeability $\left(\mathrm{m}^{2}\right)$ & $9.84 \times 10^{-10}$ & $9.84 \times 10^{-10}$ & $9.84 \times 10^{-10}$ \\
\hline Matrix porosity & 0.089 & 0.089 & 0.089 \\
\hline Fracture porosity & $1.46 \times 10^{-4}$ & $1.46 \times 10^{-4}$ & $1.46 \times 10^{-4}$ \\
\hline
\end{tabular}




\begin{tabular}{|l|c|c|c|}
\hline \multicolumn{1}{|c|}{ TH Property } & Cases 1 \& 2 & Case 3 & Case 4 \\
\hline \hline Matrix van Genuchten $\alpha_{\mathrm{m}}(1 / \mathrm{Pa})$ & $1.02 \times 10^{-6}$ & $1.02 \times 10^{-6}$ & $1.02 \times 10^{-6}$ \\
\hline Matrix van Genuchten $\mathrm{m}$ & 0.322 & 0.322 & 0.322 \\
\hline Matrix residual saturation & 0.18 & 0.18 & 0.18 \\
\hline Fracture van Genuchten $\alpha_{\mathrm{f}}(1 / \mathrm{Pa})$ & $8.36 \times 10^{-4}$ & $8.3 \times 10^{-4}$ & $8.36 \times 10^{-4}$ \\
\hline Fracture van Genuchten $\mathrm{m}$ & 0.492 & 0.492 & 0.492 \\
\hline Fracture residual saturation & $1.00 \times 10^{-2}$ & $1.00 \times 10^{-2}$ & $1.00 \times 10^{-2}$ \\
\hline Initial liquid saturation & 0.92 & 0.92 & 0.92 \\
\hline Dry thermal conductivity $(\mathrm{W} / \mathrm{m}-\mathrm{K})$ & 1.67 & 1.67 & 1.67 \\
\hline Wet thermal conductivity $(\mathrm{W} / \mathrm{m}-\mathrm{K})$ & 2.10 & 2.10 & 2.10 \\
\hline Specific heat $(\mathrm{J} / \mathrm{kg}-\mathrm{K})$ & 865 & 865 & 865 \\
\hline Grain density $\left(\mathrm{kg} / \mathrm{m}^{3}\right)$ & 2560 & 2560 & 2560 \\
\hline $\begin{array}{l}\text { Notes: conceptual model for fracture- } \\
\text { matrix interaction }\end{array}$ & ECM & DKM with fixed & $\begin{array}{c}\text { DKM with } \\
\text { dynamic FMX }\end{array}$ \\
\hline
\end{tabular}

The percolation flux $q_{\text {perc }}$ values in Table 6-2 are those required to obtain a liquid-phase saturation $S_{\text {liq }}=0.92$ in the rock at the heater horizon. The ECM cases and the DKM case with a fixed FMX of unity (Case 3) require nearly the same value of $q_{\text {perc }}$ to obtain $S_{\text {liq }}=0.92$. The dynamic-FMX case assumes that FMX is equal to the square of the relative liquid-phase permeability $k_{\mathrm{r}, \mathrm{liq}, \mathrm{f}}$ in the fracture. Because $k_{\mathrm{r}, \mathrm{liq}, \mathrm{f}}$ is almost always less than one (and usually much less than one), FMX is usually much smaller than one. Thus, under ambient conditions, Case 4 has an FMX that greatly restricts fracture-to-matrix flow, which effectively allows much of the percolation flux to bypass the rock matrix. Therefore, $q_{\text {perc }}$ must be much larger in Case 4 (than it is in the cases that do not restrict fracture-to-matrix flow) to achieve a given level of liquid-phase saturation (such as $S_{\mathrm{liq}}=0.92$ ). In other words, when fracture-to-matrix flow is restricted (as it is in Case 4) a larger value of $q_{\text {perc }}$ is required to wet the rock matrix to $S_{\text {liq }}=0.92$. Note that the value of $q_{\text {perc }}(11.52 \mathrm{~mm} / \mathrm{yr})$ for Case 4 is closer to the repository-areaaverage value of $q_{\text {perc }}(7.8 \mathrm{~mm} / \mathrm{yr})$ than are Cases 1-3 (Section 3.2 of (Hardin et al. 1998). However, as will be discussed later in this chapter, predicted TH behavior in the SHT is insensitive to the value of $q_{\text {perc }}$.

\subsection{Modeling Results}

\subsubsection{Simulated Temperature and Liquid-Phase Saturation}

\subsubsection{Equivalent-Continuum-Method Calculations}

The simulated temperature $T$ and liquid-phase saturation $S_{\text {liq }}$ distributions at the end of the heating phase (275 days) of the SHT are given in Figure 6-2 and Figure 6-3 for Case 1 (see Table 6-1). The simulated $T$ and $S_{\text {liq }}$ distributions for Case 2 are essentially identical to those of Case 1 at the end of heating-thus, Figure 6-2 and Figure 6-3 are also representative of Case 2. 
Figure 6-2. (a) Temperature $T$ distribution and (b) liquid-phase saturation $S_{\text {liq }}$ distribution at the end of the SHT heating phase ( $t=275$ days) plotted in a vertical $(x-z)$ plane transverse to the midpoint of the heater for Case 1, which uses the ECM (DTN LL980810804242.050)

Figure 6-3. (a) Temperature $T$ distribution and (b) liquid-phase saturation $S_{\text {liq }}$ distribution at the end of the SHT heating phase ( $t=275$ days) plotted in a vertical $(y-z)$ plane along the axis of the heater for Case 1 , which uses the ECM (DTN LL980810804242.050)

\section{Zero axial distance corresponds to the collar of the heater borehole.}

Because the 5-m-long heater effectively functions as a point heat source, the temperature $T$ and liquid-phase saturation $S_{\text {liq }}$ distributions attain nearly steady-state profiles within 9 mos. Because of the relatively short distance between the western end of the heater and the TM alcove $(1.99 \mathrm{~m})$, the temperature field is influenced by heat loss to the TM alcove, which is clearly indicated by the flattening of the $40^{\circ} \mathrm{C}$ contour (Figure 6-3a). The model assumes the drifts and alcoves bounding three sides of the SHT area are maintained at a constant temperature $\left(24.4^{\circ} \mathrm{C}\right)$ to represent the influence of ventilation. Figure 6-3a shows that there is no flattening of the $40^{\circ} \mathrm{C}$ contour in the vicinity of the drifts bounding the northern and southern sides of the SHT area, which indicates that the access / observation drift and TM alcove extension exert little influence on the temperature distribution around the heater, including the boiling and superheated zones. Because the heater axis is $6.59 \mathrm{~m}$ from the access / observation drift and $6.26 \mathrm{~m}$ from the TM alcove extension-distances which are relatively large compared to the radius of the boiling zone-these rooms are too far from the heater to exert a noticeable influence on the temperature distribution.

The liquid-phase saturation $S_{\text {liq }}$ distribution (Figure 6-2b and Figure 6-3b) has the same overall shape as does the temperature distribution; both distributions are essentially symmetric with respect to the heater axis. Dry-out is seen to occur for temperatures in excess of $96^{\circ} \mathrm{C}$. The $96^{\circ} \mathrm{C}$ contour almost exactly coincides with the $S_{\text {liq }}=0.9$ contour, which is close to the initial (ambient) value $S_{\text {liq }}=0.92$ in the SHT area. Notice that the $150^{\circ} \mathrm{C}$ isotherm approximately coincides with the $S_{\text {liq }}=0.2$ contour; therefore, it is necessary to drive temperatures well above the nominal boiling point to significantly dry out the rock.

Figure $6-2 \mathrm{~b}$ and Figure $6-3 \mathrm{~b}$ indicate the formation of a pronounced condensation zone, which is the area where $S_{\text {liq }}>0.92$. This zone is nearly symmetric about the heater axis. The ECM-model calculations indicate that the condensate zone is pronounced (and, therefore, should be readily observable) and is vertically symmetrical about the heater axis. The ECMmodel calculations also imply that the effects of gravity-driven condensate drainage are negligible for the SHT. However, the field measurements of electrical-resistance tomography (ERT), which are described in Chapter 2 of this report, show that the condensation zone primarily forms below the heater, indicating the importance of gravity-driven condensate drainage for the SHT. Therefore, the ECM model does not adequately capture the influence of gravity on condensate drainage. As will be discussed in Section 6.3.2, the ECM model also predicts temperatures that are lower than the measured temperatures in the superheated/dry-out zone.

The potential importance of gravity on condensate drainage has been demonstrated in previous calculations of field-scale thermal tests. When a model is used that represents fracture-matrix disequilibrium (e.g., the DKM model or the DFM model), the influence of 
gravity-driven drainage is readily apparent. Calculations of the G-Tunnel (single-heater) test (Nitao and Buscheck, 1995, Figures 3 and 4, p. 751), which used the DFM model and hydrologic properties that did not result in strongly capillary-driven liquid-phase flow, predicted significant gravity-driven drainage around the dry-out zone. The DKM-model calculations conducted for this report (see Section 6.3.1.2) also clearly show the importance of gravity-driven condensate drainage.

In previous TH-model studies of the SHT (Buscheck et al. 1997a; Hardin et al. 1998, Section 3.4), the heater borehole was assumed to be impermeable; thus, the influence of vapor and heat flow along the heater borehole were neglected. In this study, the entire length of the heater borehole, including unheated interval, is assumed to be permeable, which allows vapor and heat flow along the borehole axis. Figure 6-3b shows the influence of vapor flow and condensation effects along the axis of the heater borehole, which results in a highly efficient mass- and heat-transport mechanism called the "cold-trap" effect. Vapor is driven from the heated interval to the cold end of the borehole adjacent to the borehole collar on the TM alcove wall; there the vapor condenses and imbibes into the rock, resulting in a local increase in $S_{\text {liq }}$. The cold-trap effect efficiently transports heat toward the borehole collar, which is manifested by the elongated $T$ contours (Figure 6-3a). It is important to note that, as discussed in Section 5.3.2, considerable moisture was observed near the wall of the TM alcove. This moisture can be explained by the cold-trap effect. This effect is a potentially important mechanism influencing TH behavior in replacement drifts (Buscheck et al. 1996, p. 1029).

\subsubsection{Dual-Permeability-Method Calculations}

The simulated temperature $T$ and liquid-phase saturation $S_{\text {liq }}$ distributions at the end of the heating phase (275 days) of the SHT are given in Figure 6-4 through Figure 6-7 for Case 3 (see Table 6-1). Because the DKM readily distinguishes between TH conditions in the matrix and fracture continua, the simulated $T$ and $S_{\text {liq }}$ distributions are given for the matrix continuum (Figure 6-4 and Figure 6-6) as well as for the fracture continuum (Figure 6-5 and Figure 6-7). As indicated by Figure 6-8, the simulated $T$ distribution for Case 4 is essentially identical to that of Case 3 at the end of heating; thus, Figure 6-4a, Figure 6-5a, Figure 6-6a and Figure 6-7a are also representative of Case 4 . Because the simulated matrix $S_{\text {liq }}$ distribution for Case 3 is similar to that of Case 4 at the end of heating, Figure 6-4b and Figure 6-6b are also representative of Case 4. Qualitatively, the fracture $S_{\text {liq }}$ distribution for Case 3 is similar to that of Case 4; thus, Figure 6-5b and Figure 6-7b are qualitatively representative of Case 4.

Figure 6-4. (a) Temperature $T$ distribution and (b) liquid-phase saturation $S_{\text {liq }}$ distribution in the matrix continuum at the end of the SHT heating phase $(t$ $=275$ days) plotted in a vertical $(x-z)$ plane transverse to the midpoint of the heater for Case 3, which uses the DKM (DTN LL980810804242.050)

Figure 6-5. (a) Temperature $T$ distribution and (b) liquid-phase saturation $S_{\text {liq }}$ distribution in the fracture continuum at the end of the SHT heating phase ( $t=275$ days) plotted in a vertical $(x-z)$ plane transverse to the midpoint of the heater for Case 3 , which uses the DKM (DTN LL980810804242.050)

Note that the color scale for $S_{\text {liq }}$ is different than the one used in Figure 6-4. 
Figure 6-6. (a) Temperature $T$ distribution and (b) liquid-phase saturation $S_{\text {liq }}$ distribution in the matrix continuum at the end of the SHT heating phase $(t$ $=275$ days) plotted in a vertical $(y-z)$ plane along the axis of the heater for Case 3, which uses the DKM (DTN LL980810804242.050)

Zero axial distance corresponds to the collar of the heater borehole.

Figure 6-7. (a) Temperature $T$ distribution and (b) liquid-phase saturation $S_{\text {liq }}$ distribution in the fracture continuum at the end of the SHT heating phase ( $t=275$ days) plotted in a vertical $(y-z)$ plane along the axis of the heater for Case 3, which uses the DKM (DTN LL980810804242.050)

Zero axial distance corresponds to the collar of the heater borehole. Note that the color scale for $S_{\text {liq }}$ is different than the one used in Figure 6-6.

Figure 6-8. (a) Simulated and measured temperature histories compared at thermocouple TMA-TC-1A-9, located at $x=-0.221, y=2.978$, and $z=0.331$; simulated and measured temperature distributions compared along borehole TMA-TC-5 at (b) the end of the SHT heating period ( $t=275$ days) and (c) 213 days after the end of heading ( $t=487$ days)

(DTN LL980810804242.050)

The negligible differences in simulated $T$ between Cases 3 and 4 indicate that the SHT cannot distinguish between alternative conceptual models of the FMX factor. The much higher ambient percolation flux in Case $4\left(q_{\text {perc }}=11.52 \mathrm{~mm} / \mathrm{yr}\right)$ than in Case $3\left(q_{\text {perc }}=0.22\right.$ $\mathrm{mm} / \mathrm{yr}$ ), along with the negligible difference in simulated $T$ for these two cases, indicates that TH behavior in the SHT is insensitive to the magnitude of $q_{\text {perc }}$. The lack of sensitivity of the SHT to $q_{\text {perc }}$ arises from the heat-driven condensate fluxes being much greater than any of the values of $q_{\text {perc }}$ that were considered. Therefore, the SHT is not a useful test for diagnosing the magnitude of percolation flux. In general, any in situ thermal test that is relevant to TH behavior in the repository, such as the DST, generates heat-driven condensate fluxes that are much greater than $q_{\text {perc }}$ during the heating phase. However, during the cool-down phase, the condensate fluxes will quickly decline to the point that they are less than $q_{\text {perc }}$. If percolation flux (rather than imbibition flux in the matrix) is found to be the rate-limiting process controlling rewetting of the dry-out zone in the DST, the DST may turn out to be a very useful test for diagnosing the magnitude of the local percolation flux.

The $T$ distributions in the matrix and fractures are quite similar; $T$ in the fractures is slightly cooler than $T$ in the matrix (compare Figure 6-4a and Figure 6-5a). The $T$ distributions in both the matrix and fractures are symmetrical about the heater axis. The $S_{\text {liq }}$ distribution in the matrix has a similar shape to that of the $T$ distribution; thus, the $S_{\text {liq }}$ distribution in the matrix is symmetrical about the heater axis. The $S_{\text {liq }}$ distribution in the fracture is horizontally symmetrical about the heater axis; however, there is strong vertical asymmetry in the $S_{\text {liq }}$ distribution in the fractures. The vertical asymmetry results from gravity-driven condensate drainage. Because the DKM represents nonequilibrium fracture-matrix interaction, condensate is able to readily shed around the dry-out zone. The increase in $S_{\text {liq }}$ in the fractures is much greater below the heater than above the heater. This agrees qualitatively with the field ERT measurements of $S_{\text {liq }}$ change (Chapter 2 of this report) that indicate that the condensation zone primarily forms below the heater; this indicates the importance of gravitydriven condensate drainage for the SHT. 
The DKM-model calculations indicate that the cold-trap effect strongly influences the distribution of condensate flux and the formation of the condensate zone. The greatest increase in $S_{\text {liq }}$ occurs adjacent to the borehole collar (Figure 6-6b and Figure 6-7b). The increase in $S_{\text {liq }}$ in the fractures is nearly twice as great next to the borehole collar than it is in the condensate-shedding zone lying immediately below the heater (Figure 6-7b); the greater $S_{\text {liq }}$ increase next to the borehole collar indicates that condensate drainage flux is heavily concentrated in that area. In the matrix, a discernible increase in $S_{\text {liq }}$ is seen only in the area adjacent to the borehole collar. The cold-trap effect is also manifested by the strongly elongated $T$ contours between the heater and the borehole collar. These DKM calculations indicate that the cold-trap effect is an important mechanism because it may result in strongly focusing decay-heat-driven seepage flux into cooler intervals of the emplacement drifts and thereby cause condensate to drip onto cooler waste packages.

The DKM model predicts less intensive matrix dry-out (for the region where $S_{\text {liq }}<0.8$ ) than does the ECM model (compare Figure 6-4b with Figure 6-2b, and compare Figure 6-6b with Figure 6-3b). Because the ECM assumes equilibrium between the fractures and matrix blocks, there is essentially no resistance to the flow of vapor out of the matrix blocks; thus, there is no gas-phase pressure $P_{\text {gas }}$ buildup in the matrix blocks (relative to the fractures) that can lead to any throttling of dry-out. Because the DKM represents the disequilibrium between the fractures and matrix blocks, there is $P_{\text {gas }}$ buildup in the matrix blocks that tends to throttle dry-out in the matrix blocks. For rock dry-out around emplacement drifts, this throttling behavior is only likely to be significant during the heat-up period, which lasts approximately $30 \mathrm{yr}$ (Buscheck 1996, Section 1.8).

For $S_{\text {liq }}>0.8$, the DKM model predicts a larger spatial extent of rock dry-out than does the ECM model. Thus, the dry-out front extends farther away from the heater in the DKM-model calculations. For DKM-model calculation, the $S_{\text {liq }}=0.9$ contour occurs at a radial distance of $1.45 \mathrm{~m}$ from the heater axis (Figure 6- $4 \mathrm{~b}$ ); for the ECM-model calculation, the $S_{\text {liq }}=0.9$ contour occurs at a radial distance of only $1.1 \mathrm{~m}$ (Figure 6-2b). The radial extent of dry-out predicted by the DKM model agrees qualitatively with the neutron-probe measurements of $S_{\text {liq }}$ change (see Chapter 3 of this report). The greater spatial extent of rock dry-out (for $S_{\text {liq }}>0.8$ ) results from the DKM model predicting more effective condensate shedding than that predicted by the ECM model. More effective condensate shedding causes less $S_{\text {liq }}$ increase in the matrix, which reduces the rate of rewetting resulting from matrix imbibition. Greater condensate shedding also causes less $S_{\text {liq }}$ increase in the fractures, which reduces the rate of rewetting resulting from capillary wicking in the fractures.

\subsubsection{Comparison of Simulated and Measured Temperatures}

The temporal and spatial evolution of temperatures in the SHT area is a useful indicator of TH behavior during the test. Of particular importance is the ability to use the temperature distribution as an indicator of the extent of rock dry-out. Figure 6-8 compares the predicted temperatures for the four cases with temperatures observed in the field. During the heating stage, the two ECM cases (Cases 1 and 2) predict nearly identical temperatures. During both the heating and cooling stages, the two DKM cases (Cases 3 and 4) predict nearly identical temperatures.

During heating, there are differences in the predicted temperatures between the ECM and DKM cases. In spite of the fact that the ECM model predicts more intense matrix dry-out for the lower liquid-phase saturation $S_{\text {liq }}$ range $\left(S_{\text {liq }}<0.8\right)$ than does the DKM model, the ECM model predicts lower temperatures (compared to the DKM model) in the superheated/dryout zone. The differences in predicted temperatures arise from two causes. First, the spatial 
extent of matrix dry-out for the higher liquid-phase saturation $S_{\text {liq }}$ range $\left(S_{\text {liq }}>0.8\right)$ is greater for the DKM-model cases, causing superheated/dry-out conditions to extend over a slightly larger region than in the ECM-model cases. The second (and probably more significant) cause is the manner in which fracture-matrix interaction is represented in the respective models. Because the DKM model allows $P_{\text {gas }}$ in the matrix to increase well above ambient conditions, the saturation temperature $T_{\text {sat }}$ (which is the boiling temperature at the local pressure) can increase well above the nominal boiling point $\left(96^{\circ} \mathrm{C}\right)$. Thus, the larger temperature increase predicted by the DKM model is primarily facilitated by the elevated $P_{\text {gas }}$ in the matrix (whereas the ECM predicts no increase in $P_{\text {gas }}$ in the matrix) and is partly facilitated by the greater extent of dry-out in the matrix (for $S_{\text {liq }}>0.8$ ) predicted by the DKM model.

At thermocouple TMA-TC-1A-9 (Figure 6-8a), the ECM model underpredicts temperatures by as much as $5-10^{\circ} \mathrm{C}$ during the heating stage, while the DKM model predicts temperatures that are only as much as $1-4^{\circ} \mathrm{C}$ higher than the observed temperatures. At the end of the heating stage (275 days), the DKM-model-simulated temperatures are within less than $1^{\circ} \mathrm{C}$ of most of the measured temperatures along borehole TMA-TC-5 (Figure 6-8b), while the ECM-model-predicted temperatures are as much as $10^{\circ} \mathrm{C}$ lower than the observed temperatures.

During the cool-down period (Figure 6-8c), the three cases with the extended western boundary (Cases 1,3, and 4) predict similar temperatures-all of which are in slightly better agreement with the measured temperatures than are those predicted in Case 2 (which has the western boundary located at the eastern wall of the TM alcove). As discussed in a previous SHT-model study (Hardin et al. 1998, Section 3.4), placing the western boundary (which is adiabatic above and below the TM alcove) too close to the heated interval tends to underpredict the heat loss to the TM alcove. Because fracture-matrix disequilibrium processes are less important during the cool-down period, the ECM model is nearly as good as the DKM model in predicting temperatures during the cool-down period.

Although Cases 1, 3, and 4 are in somewhat better agreement, than is Case 2, with the observed temperatures during the cool-down period, all of the cases overpredict temperatures in the vicinity of the TM alcove; this overprediction increases as the distance to the TM alcove decreases. The likely cause for this overprediction is the manner in which heat flow is treated in the TM alcove. The contribution of thermal radiation is neglected in the TM alcove. Because thermal-radiative heat transfer is proportional to the difference in $T^{4}$ it is a highly efficient mechanism for transferring heat from warmer to cooler surfaces. Had thermal radiation from the warmer to cooler wall surfaces in the TM alcove been accounted for in the SHT models, it is likely that the cooling rate on the eastern TM alcove wall would have been substantially greater. The enhanced cooling rate would lower the temperatures in the rock mass close to the TM alcove. Explicitly incorporating thermal radiation into the TH models would substantially add to the computational requirements of these models, probably making it impossible for them to run on the SUN ULTRA2 workstations that were used in this study. Future TH calculations of the SHT will be conducted that approximate the influence of thermal radiation in the TM alcove with the use of an effective thermal conductivity that has been calibrated to represent the influence of thermal radiation.

\subsection{Conclusions}

The heating and cooling stages of the SHT were modeled with the NUFT code, using the December 1997 TSPA-VA base-case hydrologic parameter set, which was modified to include the field measurements of bulk permeability in the SHT area. Two different conceptual 
models for fracture-matrix interaction were considered: the ECM, which assumes equilibrium between the fracture and matrix continua, and the DKM that accounts for disequilibrium processes between the fracture and matrix continua. For the DKM-model calculations, two different approaches for representing the FMX were considered: a fixed-FMX approach and a dynamic-FMX approach. For the ECM-model calculations, two different western boundaries were considered: one that placed the western boundary at the eastern wall of the TM alcove and one that placed the western boundary $33 \mathrm{~m}$ to the west of the western wall of the TM boundary. Unlike earlier TH models of the SHT, all of the models in this study included the influence of vapor and heat flow along the heater borehole. This modeling study resulted in the following observations and conclusions:

- The DKM predicts higher temperatures in the superheated/dry-out zone than does the ECM model, primarily because the DKM model predicts a substantial gas-phase pressure $P_{\text {gas }}$ increase in the matrix blocks, whereas the ECM model assumes $P_{\text {gas }}$ equilibrium between the matrix and adjoining fractures. The $P_{\text {gas }}$ increase predicted by the DKM model causes the saturated temperature $T_{\text {sat }}$ (which is the boiling temperature at the local pressure) to increase well above the nominal boiling point $\left(96^{\circ} \mathrm{C}\right)$.

- The DKM model predicts temperatures that are in outstanding agreement with the observed temperatures throughout the heating stage of the SHT.

- The ECM model predicts temperatures that are in good agreement with the observed temperatures in the sub-boiling region of the SHT during the heating stage. In the superheated/dry-out zone, the ECM model predicts temperatures that are lower than the observed temperatures during the heating stage.

- For the DKM model, the predicted radial extent of the dry-out zone is in good, qualitative agreement with the neutron-probe measurements of liquid-phase saturation change. For the ECM model, the radial extent of the dry-out zone is less than that predicted by the DKM model (and is somewhat less than that indicated by the neutron-probe measurements).

- The DKM model predicts a condensate-shedding zone that is to the sides and below the dry-out zone, which is qualitatively consistent with the measurements of liquidphase saturation change made with electrical-resistance tomography (ERT).

- The ECM model predicts a pronounced condensation zone that is vertically symmetrical about the heater axis; this is inconsistent with the measurements of liquid-phase saturation change made with ERT.

- For the lower liquid-phase saturation $S_{\text {liq }}$ range $\left(S_{\text {liq }}<0.8\right)$, the DKM model predicts less dry-out in the matrix than is predicted by the ECM model. The DKM model accounts for flow resistance in the matrix blocks (as vapor is driven out of the matrix into the adjoining fractures), thereby throttling dry-out in the matrix. The ECM model neglects this flow resistance; thus, the ECM model does not throttle matrix dry-out.

- For the higher $S_{\text {liq }}$ range $\left(S_{\text {liq }}>0.8\right)$, the DKM model predicts greater dry-out in the matrix than is predicted by the ECM model. The DKM model accounts for how nonequilibrium, fracture-matrix interaction facilitates more effective condensate shedding around the dry-out zone than does the ECM model. More effective condensate shedding causes less $S_{\text {liq }}$ increase in the matrix, which reduces the rate of rewetting arising from matrix imbibition, and less $S_{\text {liq }}$ increase in the fractures, which reduces the rate of rewetting arising from capillary wicking in the fractures. 
- The SHT is not a useful test for diagnosing the magnitude of percolation flux $q_{\text {perc }}$. The lack of sensitivity of the SHT to $q_{\text {perc }}$ arises from the heat-driven condensate fluxes being much greater than any of the values of $q_{\text {perc }}$ that were considered.

- The SHT cannot distinguish between alternative conceptual models of the FMX factor. Both approaches result in the same outstanding agreement with observed temperatures, and both approaches predict the same distribution of $S_{\text {liq }}$ in the matrix continua.

- Both the ECM and DKM models predict a pronounced cold-trap effect in the heater borehole. Vapor and latent-heat flow from the heated interval of the heater borehole to the cool end of the heater borehole adjacent to its collar, where the vapor condenses, resulting in focused condensate drainage and a local increase in $S_{\text {liq }}$ in the matrix. The cold-trap effect efficiently transfers heat along the heater borehole toward the TM alcove. The cold-trap effect is a potentially important mechanism influencing $\mathrm{TH}$ behavior in emplacement drifts.

- The models with an extended western boundary predict temperatures that are in better agreement with the observed temperatures than are those predicted by the model with the western boundary located at the eastern wall of the TM alcove.

- All of the models underrepresent the heat loss to the TM alcove, resulting in predicted temperatures being greater than the observed temperatures in the vicinity of the TM alcove; this overprediction increases as the distance to the TM alcove decreases. The cause for this overprediction is the manner in which heat flow in the TM alcove is treated. Had thermal radiation from the warmer to cooler wall surfaces in the TM alcove been accounted for in the SHT models, the cooling rate on the eastern TM alcove wall would have been much greater, resulting in lower predicted temperatures in the vicinity of the TM alcove.

\subsection{References}

Buscheck, T.A. 1996. "Hydrothermal Modeling (Section 1.0)." Wilder, D.G., ed. Near-Field and Altered-Zone Environment Report (Volume II). UCRL-JC-124998. Livermore, California: Lawrence Livermore National Laboratory. MOL.19961212.0122.

Buscheck, T.A., Nitao, J.J., and Chesnut, D.A. 1991. "The impact of episodic nonequilibrium fracture-matrix flow on geological repository performance." In proceedings from ANS Conference on Nuclear Waste Packaging, FOCUS '91. Las Vegas, Nevada: September 29-October 2, 1991. NNA.911231.0023. 2032525. (Also UCRL-JC-106759-SUM, Lawrence Livermore National Laboratory, Livermore, California)

Buscheck, T.A., Nitao, J.J., and Ramspott, L.D. 1996. “Near-Field Thermal-Hydrological Behavior for Alternative Repository Designs at Yucca Mountain." Gray, W.J., and Triay, I.R., eds. Scientific Basis for Nuclear Waste Management XX. Materials Research Society Symposium Proceedings 465. Warrendale, Pennsylvania: Materials Research Society. MOL.19961014.0031. (Also UCRL-JC-124629, Lawrence Livermore National Laboratory, Livermore, California)

Buscheck, T.A., Shaffer, R.J., Lee, K.H., and Nitao, J.J. 1997a. Analysis of Thermal-Hydrological Behavior During the Heating Phase of the Single-Heater Test at Yucca Mountain. Milestone report for the CRWMS Management and Operating Contractor, U.S. Department of Energy. SP9266M4. Livermore, California: Lawrence Livermore National Laboratory. MOL.19980109.0241. 
Buscheck, T.A., Shaffer, R.J., and Nitao, J.J. 1997b. Pretest Thermal-Hydrological Analysis of the Drift-Scale Thermal Test at Yucca Mountain. SP9318M4. Livermore, California: Lawrence Livermore National Laboratory. MOL.19980507.0359.

CRWMS M\&O 1996a. Characterization of the ESF Thermal Test Area. B00000000-01717-570500047 REV 1. Las Vegas, Nevada: Civilian Radioactive Waste Management System Management and Operating Contractor: TRW Environmental Safety Systems, Inc. MOL.19970116.0187.

CRWMS M\&O 1996b. Test Design, Plans, and Layout for the First ESF Thermal Test. BAB000000-01717-4600-00025 REV 1. Las Vegas, Nevada: Civilian Radioactive Waste Management System Management and Operating Contractor: TRW Environmental Safety Systems, Inc. MOL.19970114.0166.

CRWMS M\&O 1997. Single Heater Test Interim Report. Yucca Mountain Site Characterization Project Milestone Report. BABEAF000-01717-69000001 REV 00. Las Vegas, Nevada: Civilian Radioactive Waste Management System, Management and Operating Contractor: TRW Environmental Safety Systems, Inc.

CRWMS M\&O 1998. Total System Performance Assessment-Viability Assessment Technical Basis Document: Chapter 3, Volume 2. B00000000-01717-4301-00003 REV 0. Las Vegas, Nevada: prepared by the Civilian Radioactive Waste Management System, Management and Operating Contractor, TRW Environmental Safety Systems, Inc.

Hardin, E.L., Blair, S.C., Buscheck, T.A., Chesnut, D.A., DeLoach, L.D., Glassley, W.E., Johnson, J.W., Knapp, R.B., Lee, K., Meike, A., Myers, K., Nitao, J.J., Palmer, C.E., Rogers, L.L., Rosenberg, N.D., Viani, B.E., Wang, H.F., Wittwer, C., and Wolery, T.J. 1998. Near-Field/Altered-Zone Models Report. Milestone report for the CRWMS Management and Operating Contractor, U.S. Department of Energy. SP3100M3. Livermore, California: Lawrence Livermore National Laboratory. MOL.19980630.0560. MOL.19980715.0247. (Also UCRL-ID-129179)

Ho, C.K. 1997. "Models of fracture-matrix interactions during multiphase heat and mass flow in unsaturated fractured porous media." In proceedings from 1997 ASME International Mechanical Engineering Congress and Exposition. Dallas, Texas: ASME Fluids Engineering Division. MOL.19971125.0236.

Klavetter, E.A., and Peters, R.R. 1986. Estimation of Hydrologic Properties of an Unsaturated, Fractured Rock Mass. SAND-84-2642. Albuquerque, New Mexico: Sandia National Laboratories. NNA.870317.0738. 202727.

Nitao, J.J. 1988. VTOUGH-An Enhanced Version of the TOUGH Code for Thermal and Hydrologic Simulation of Large-Scale Problems in Nuclear Waste Isolation. UCID-21954. Livermore, California: Lawrence Livermore National Laboratory. NNA.19900508.0040.

Nitao, J.J. 1998a. Reference Manual for the NUFT Flow and Transport Code, Version 2.0. UCRL-MA-130651. Livermore, California: Lawrence Livermore National Laboratory.

Nitao, J.J. 1998b. User's Manual for the USNT Module of the NUFT Code, Version 2.0 (NP-Phase, NC-Component, Thermal). UCRL-MA-130653. Livermore, California: Lawrence Livermore National Laboratory. 
Nitao, J.J., and Buscheck, T.A. 1995. “Discrete-Fracture Modeling of Thermal-Hydrological Processes at Yucca Mountain and the LLNL G-Tunnel Field Test." Murphy, W.M., and Knecht, D.A., eds. Scientific Basis for Nuclear Waste Management XIX. Materials Research Society Symposium Proceedings 412. Warrendale, Pennsylvania: Materials Research Society. MOL.19970825.0089. (Also UCRLJC-121231, Lawrence Livermore National Laboratory, Livermore, California)

Nitao, J.J., Buscheck, T.A., and Chesnut, D.A. 1993. "Implications of episodic nonequilibrium fracture-matrix flow on repository performance." Nucl. Technol. 104(3):385-402. NNA.19930727.0005. 208836. (Also UCRL-JC-109216, Lawrence Livermore National Laboratory, Livermore, California) 

Chapter 6 Figures 


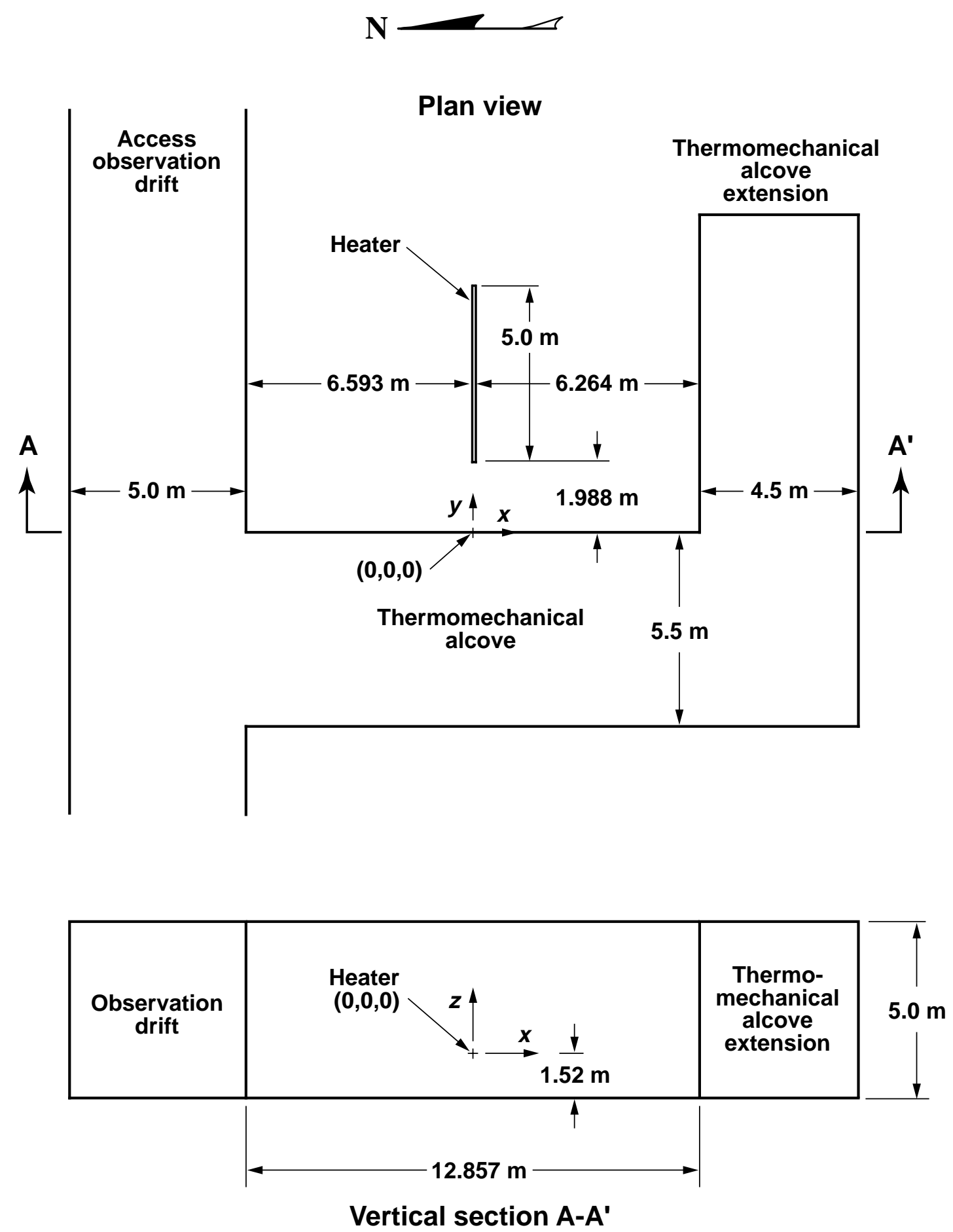

Figure 6-1. SHT layout, including dimensions and SHT-model coordinate system, in plan view and vertical Section A-A' 


\section{Figures}

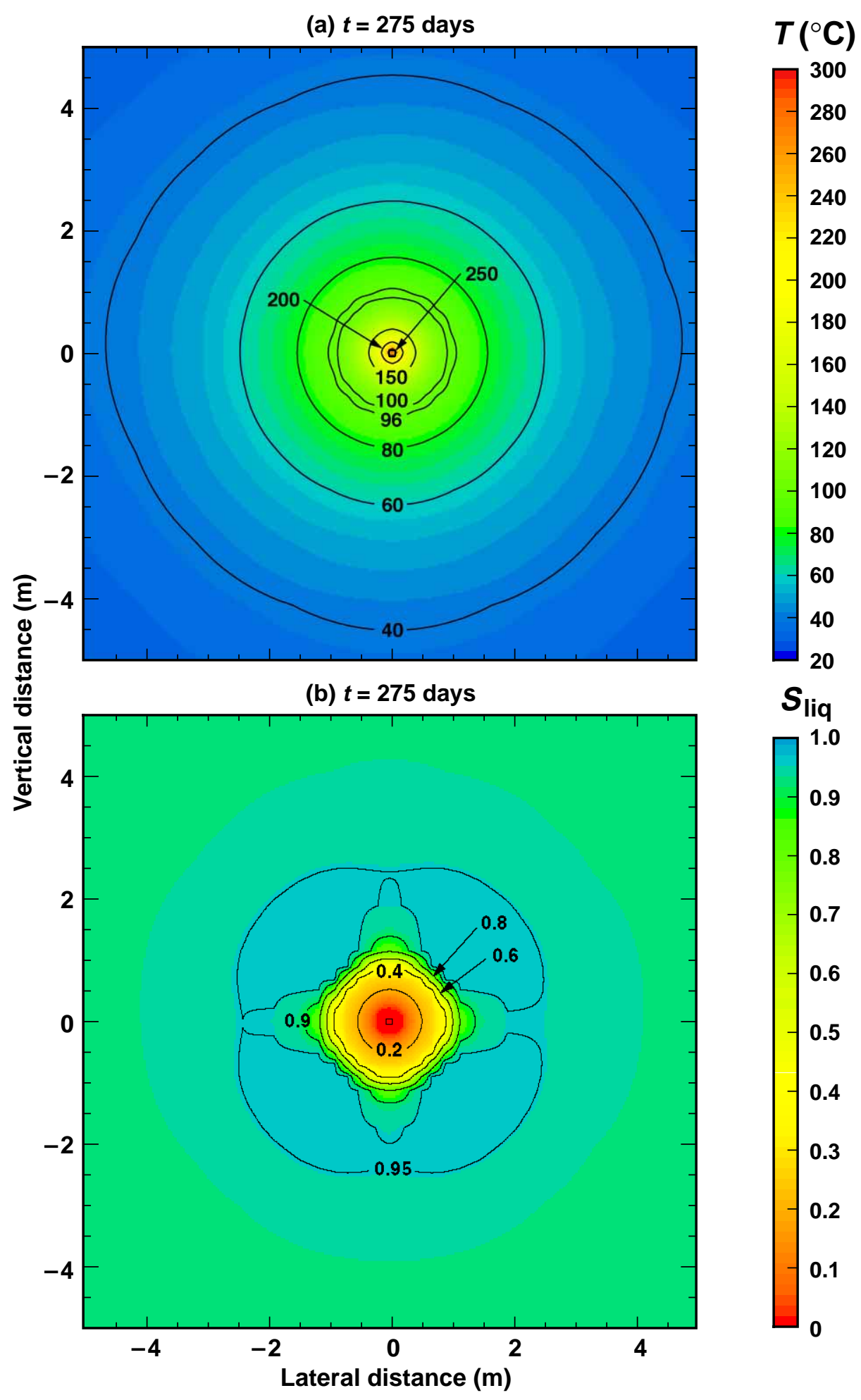

Figure 6-2. (a) Temperature $T$ distribution and (b) liquid-phase saturation $S_{\text {liq }}$ distribution at the end of the SHT heating phase ( $t=275$ days) plotted in a vertical $(x-z)$ plane transverse to the midpoint of the heater for Case 1, which uses the ECM 


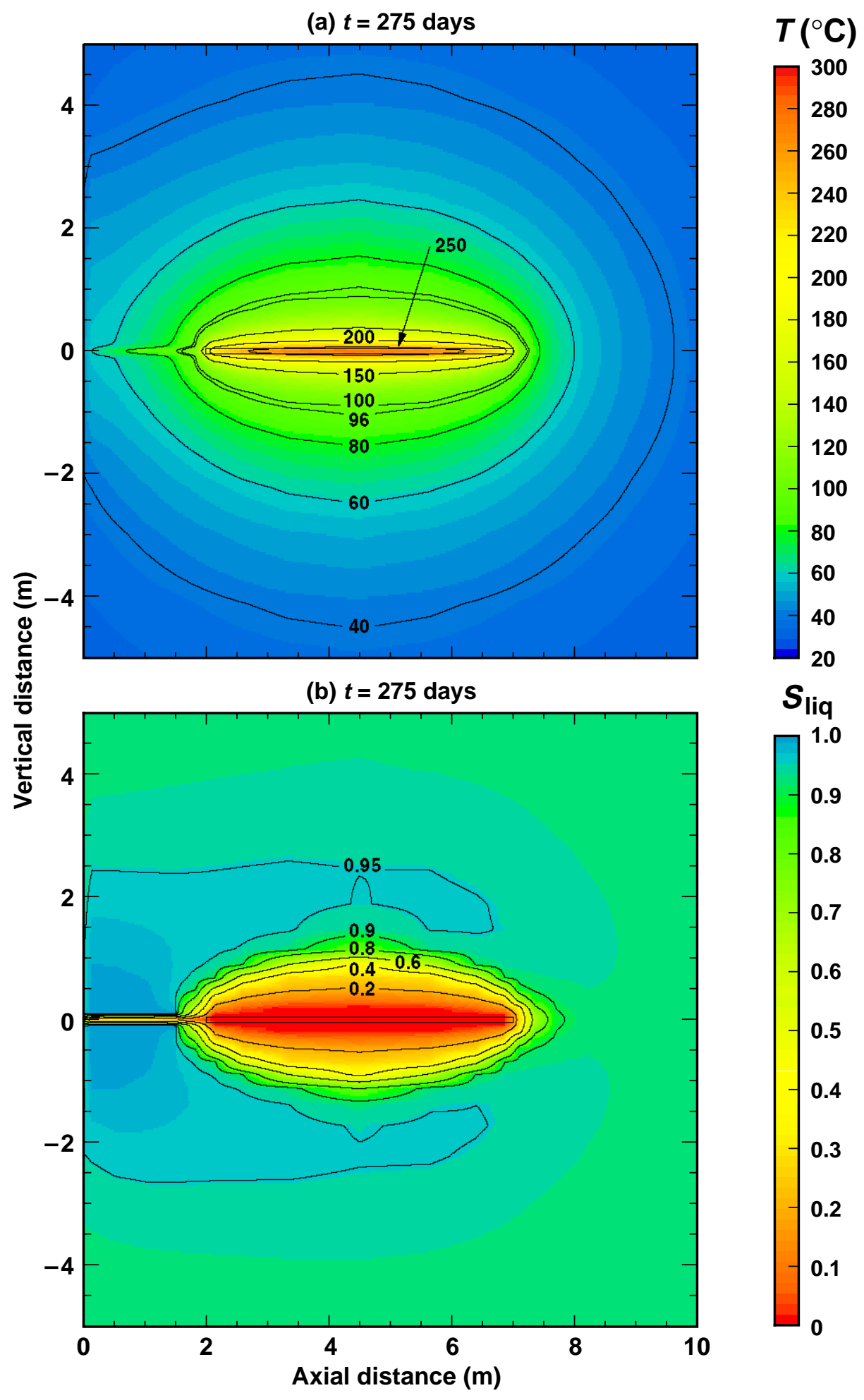

Figure 6-3. (a) Temperature $T$ distribution and (b) liquid-phase saturation $S_{\text {liq }}$ distribution at the end of the SHT heating phase $(t=275$ days) plotted in a vertical $(y-z)$ plane along the axis of the heater for Case 1 , which uses the ECM (zero axial distance corresponds to the collar of the heater borehole) 


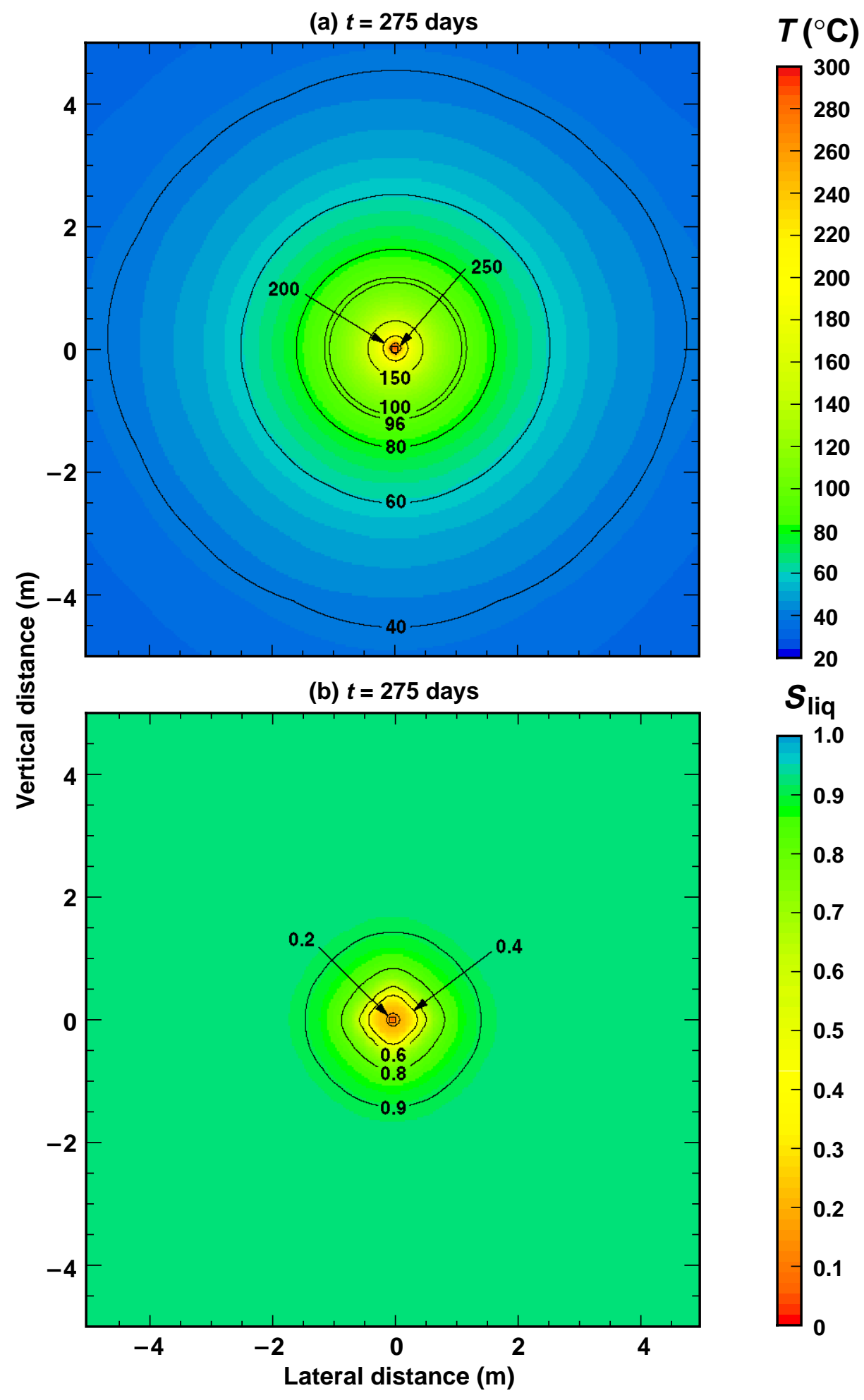

Figure 6-4. (a) Temperature $T$ distribution and (b) liquid-phase saturation $S_{\text {liq }}$ distribution in the matrix continuum at the end of the SHT heating phase $(t=275$ days) plotted in a vertical $(x-z)$ plane transverse to the midpoint of the heater for Case 3, which uses the DKM 


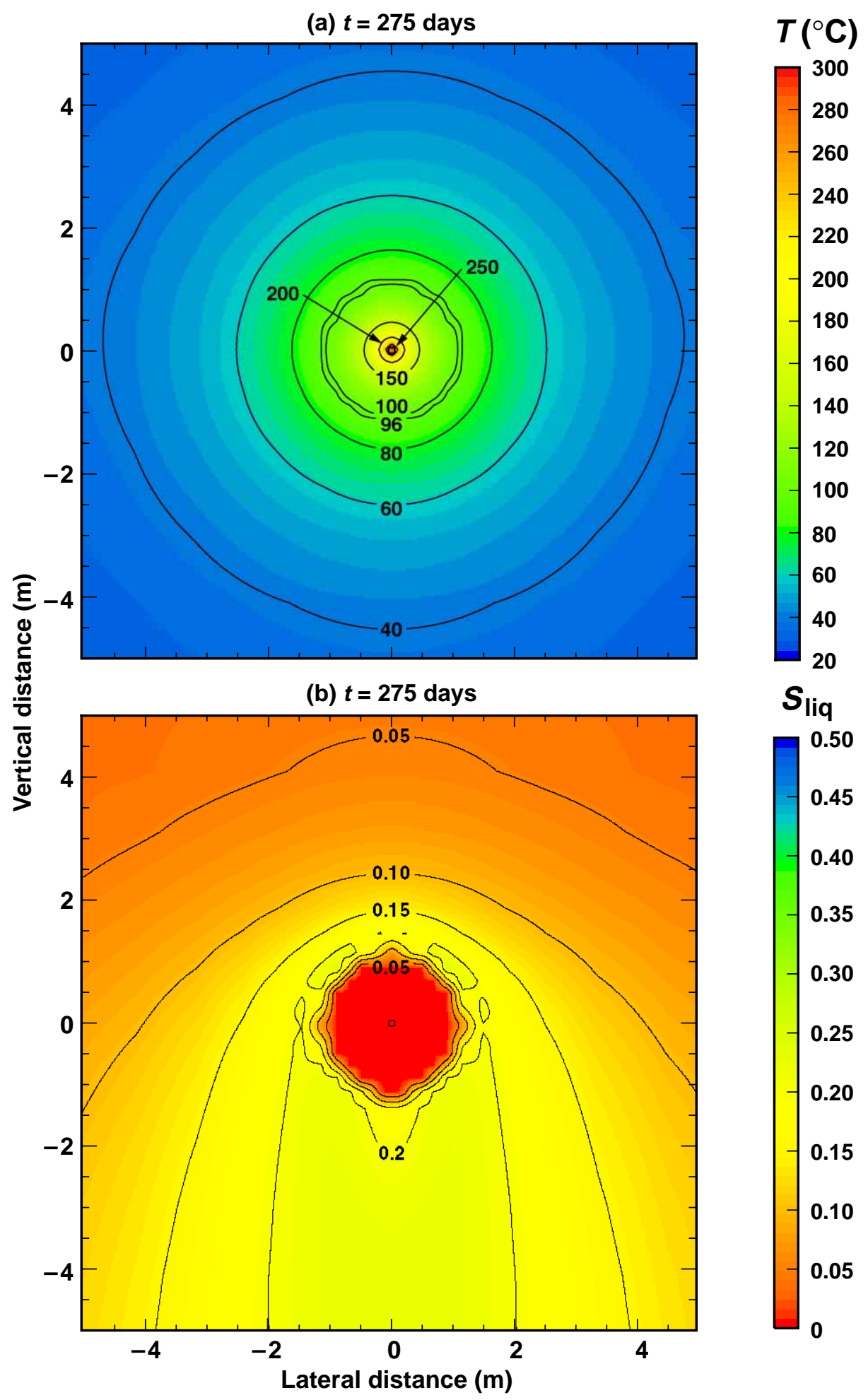

Figure 6-5. (a) Temperature $T$ distribution and (b) liquid-phase saturation $S_{\text {liq }}$ distribution in the fracture continuum at the end of the SHT heating phase $(t=275$ days) plotted in a vertical $(x-z)$ plane transverse to the midpoint of the heater for Case 3, which uses the DKM (note that the color scale for $S_{\text {liq }}$ is different than the one used in Figure 6-4) 


\section{Figures}

(a) $t=275$ days

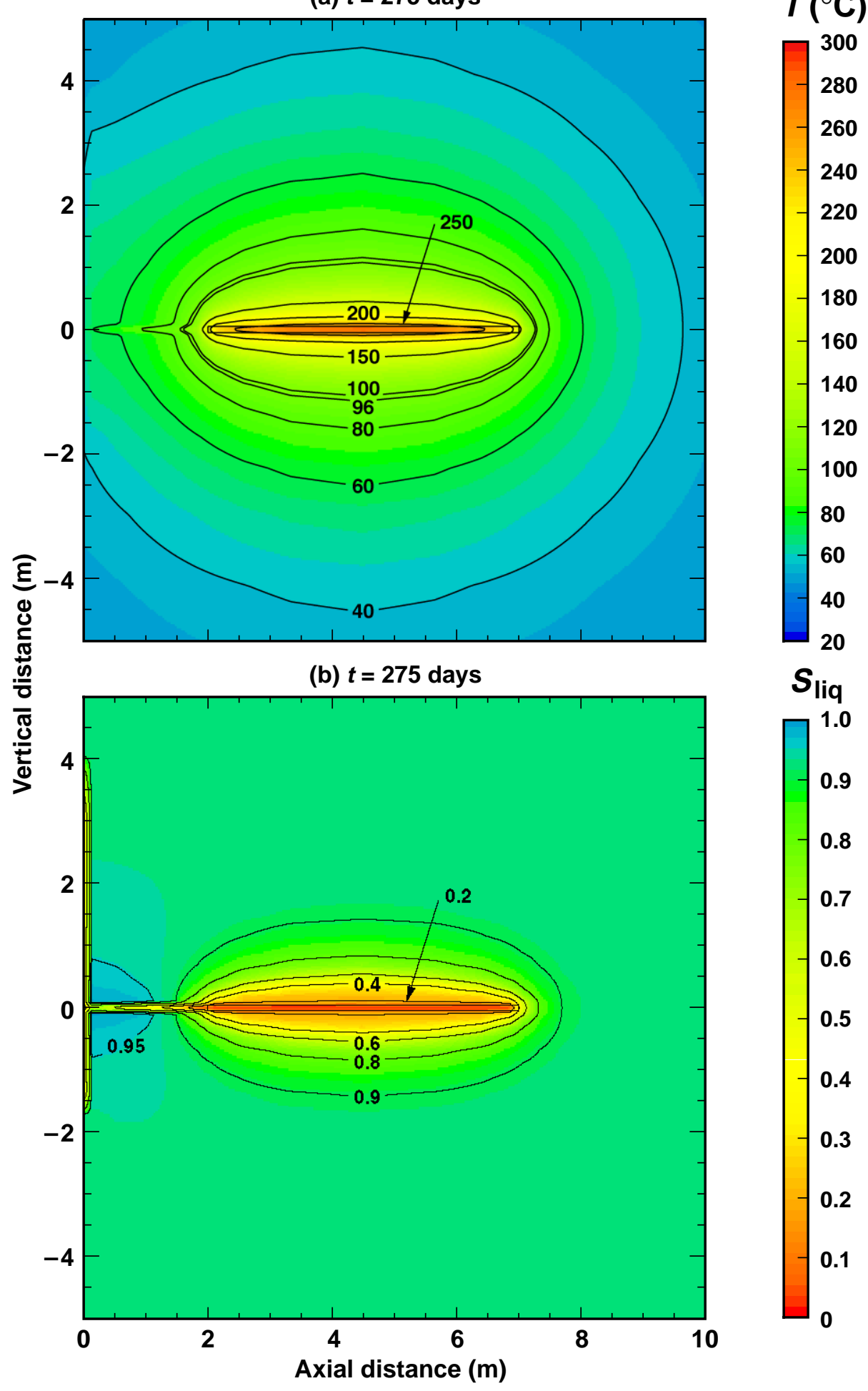

Figure 6-6. (a) Temperature $T$ distribution and (b) liquid-phase saturation $S_{\text {liq }}$ distribution in the matrix continuum at the end of the SHT heating phase $(t=275$ days) plotted in a vertical $(y-z)$ plane along the axis of the heater for Case 3, which uses the DKM (zero axial distance corresponds to the collar of the heater borehole) 


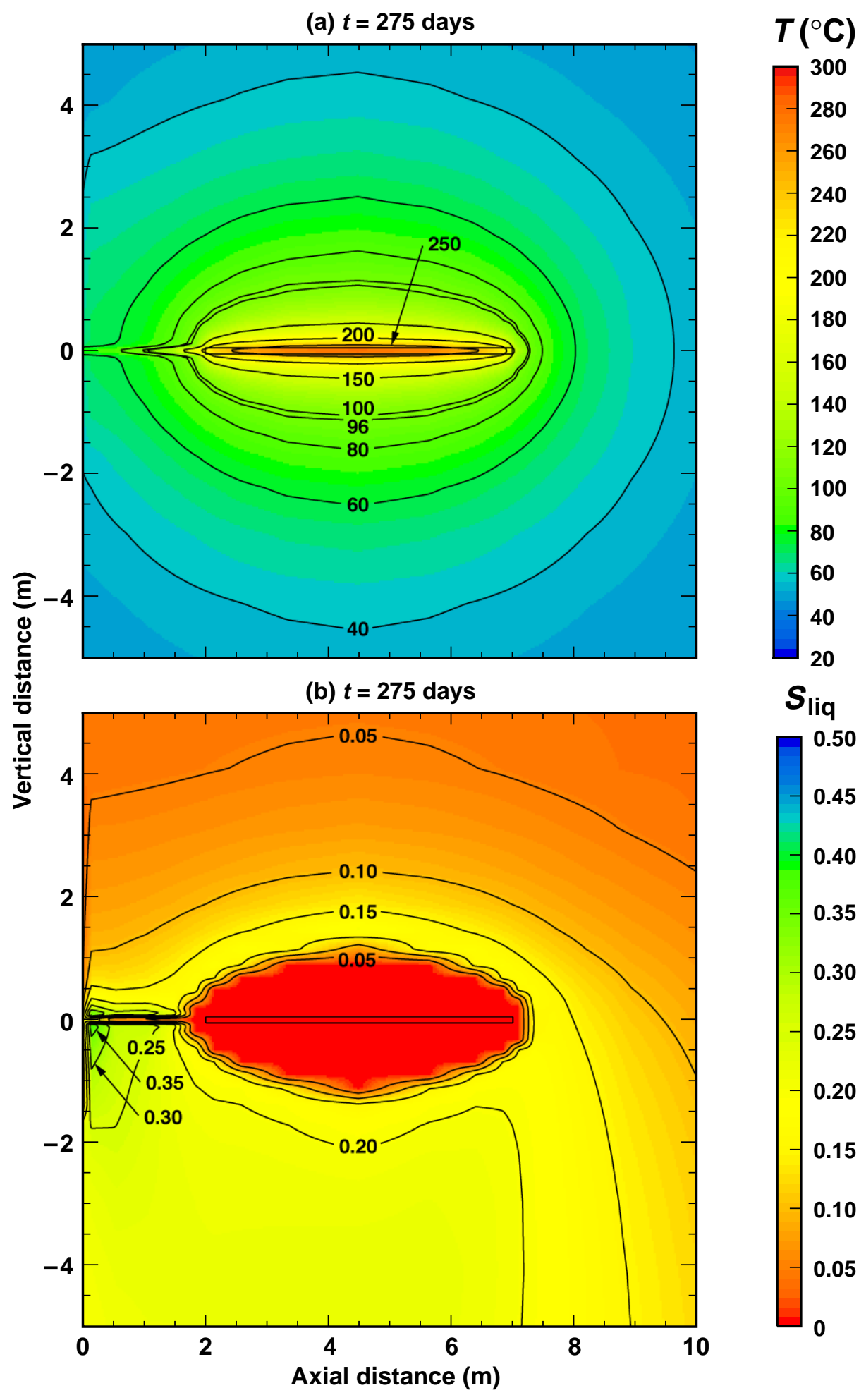

Figure 6-7. (a) Temperature $T$ distribution and (b) liquid-phase saturation $S_{\text {liq }}$ distribution in the fracture continuum at the end of the SHT heating phase $(t=275$ days) plotted in a vertical $(y-z)$ plane along the axis of the heater for Case 3, which uses the DKM (zero axial distance corresponds to the collar of the heater borehole; note that the color scale for $S_{\text {liq }}$ is different than the one used in Figure 6-6) 
(a) thermocouple TMA-TC-1A-9

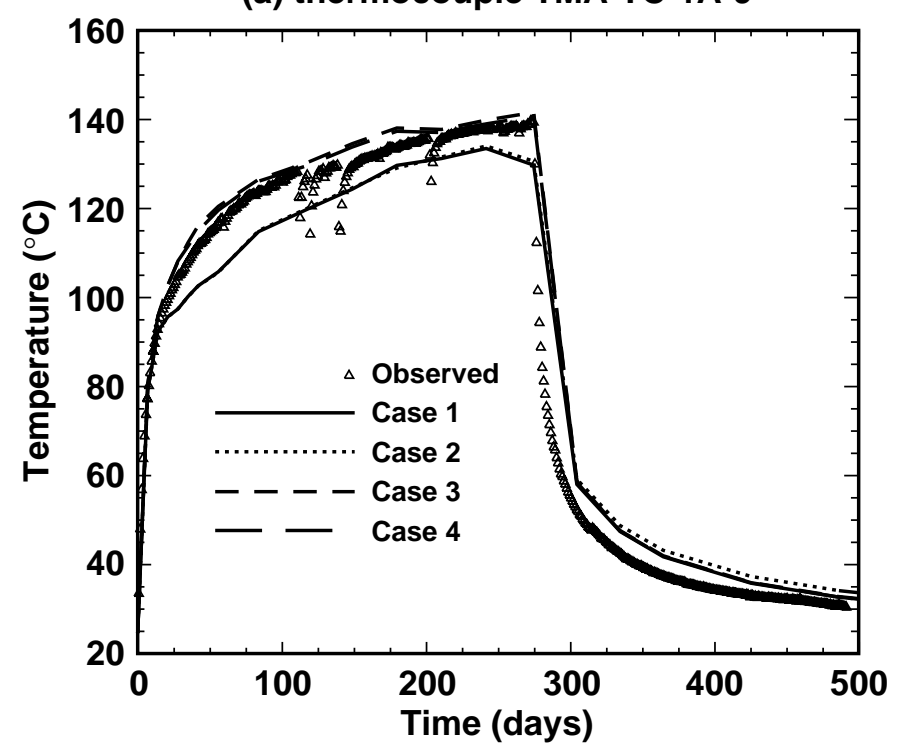

(b) borehole TMA-TC-5

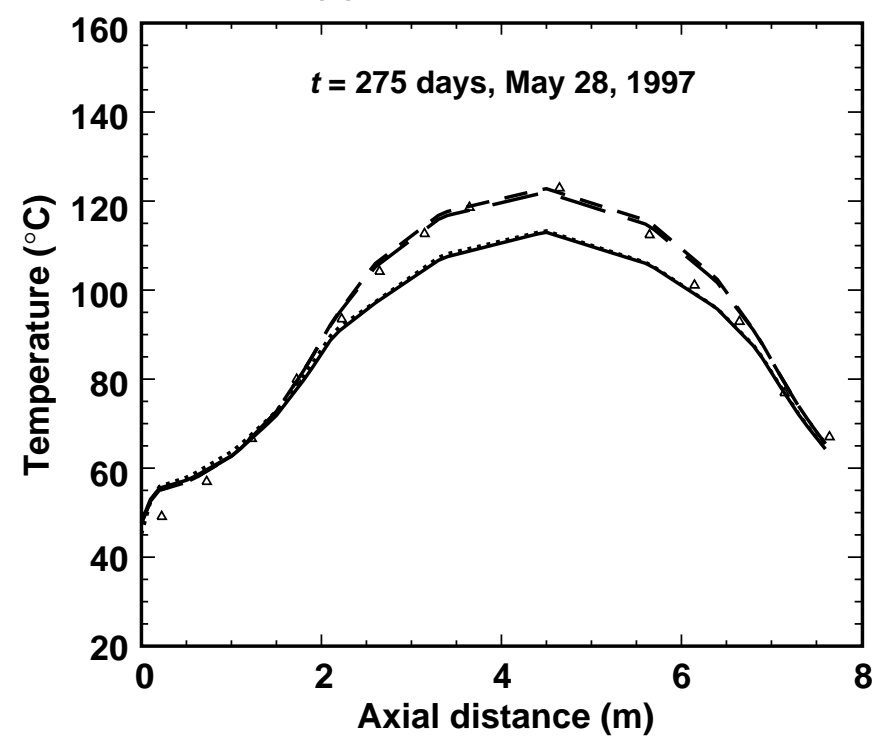

(c) borehole TMA-TC-5

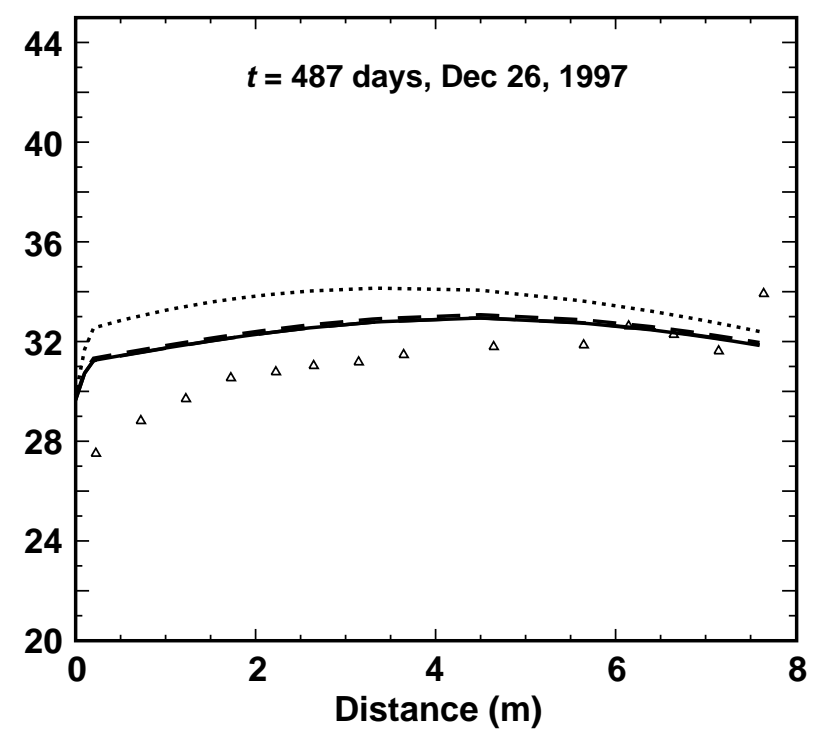

Figure 6-8. (a) Simulated and measured temperature histories compared at thermocouple TMA-TC-1A-9, located at $x=-0.221, y=2.978$, and $z=0.331$; simulated and measured temperature distributions compared along borehole TMA-TC- 5 at (b) the end of the SHT heating period ( $t=275$ days) and (c) 213 days after the end of heading ( $t=487$ days) 


\title{
7. Thermomechanical Analysis and Estimates of Permeability Changes
}

\author{
by Stephen C. Blair, Patricia A. Berge, and Herbert F. Wang
}

\subsection{Introduction}

This chapter presents results of a simple thermomechanical (TM) analysis of the SingleHeater Test (SHT) (Figure 7-1 and Figure 1-1). This analysis was designed to assess the potential for TM stresses developed in the SHT to cause shear slip on fracture sets occurring in the rock mass heated during the SHT.

Figure 7-1. Layout of Single-Heater Test in plan and cross section (SNL 1997, p. 5)

An earlier TM analysis (Blair et al. 1998) concluded that thermal stresses in the Drift-Scale Test (DST) would be likely to induce shear slip and enhance permeability on pre-existing fracture sets in the test. In this earlier analysis, stresses were calculated using a twodimensional (2-D) TM (Fast Lagrangian Analysis of Continua [FLAC] by Itasca Consulting Group) in conjunction with the Mohr-Coulomb criterion. This chapter presents results obtained by applying this same methodology to the SHT. Estimates of regions of shear-slip and implications for permeability changes are presented.

Geomechanical data collected in the SHT included MPBX measurements, drift convergence measurements, Goodman Jack measurements described in Chapter 5 of the Single-Heater Test Interim Report (CRWMS M\&O 1997), and the O-MPBX measurements described in Chapter 5 of this report. None of these measurements was designed to monitor the shear stress or displacement in the regions below and to the heater sides of the drifts; thus, these measurements could not be compared with results reported here.

\subsection{2-D FLAC Model of the Single-Heater Test}

The TM analysis is based on the 2-D version of the geomechanical FLAC code (Itasca Consulting Group Inc. 1996). FLAC is an uncoupled, TM model. The stress field depends on the temperature field, but the temperature field is independent of the stress field. Therefore, the thermal conduction problem can be solved independently of the mechanical equilibrium problem.

A cross section through the SHT was simulated. The model grid for this simulation consisted of 35 zones in the horizontal $x$-direction and 40 zones in the vertical $y$-direction (Figure 7-2). The smallest zones for the heater cross section were about $0.1 \mathrm{~m} \times 0.1 \mathrm{~m}$, and the largest zones at the far corners of the model were $20 \mathrm{~m} \times 6 \mathrm{~m}$. This model was also symmetrical, with the heater cross section placed at the edge of the FLAC model and the 5-mwide tunnel cross section placed $5 \mathrm{~m}$ away, closer to the center of the model. The edge of the FLAC model that represented the axis of symmetry was fixed in the direction perpendicular to that edge, while the other far edges of the model were fixed in both directions. The tunnels were assumed to have rounded corners because large stress concentrations otherwise occur near the corners. 
Figure 7-2. FLAC grid (DTN LL980810904244.068)

Heater is at the center of the left edge of the model. The alcove observation tunnel and observation drift are located symmetrically about $x=0$.

The heater was represented by an interior source at the origin with a power density of $7000 \mathrm{~W} / \mathrm{m}^{3}$. <question $>$ This source strength was chosen to be equivalent to the heater in the hydrology model of Buscheck and Nitao (1995, pp. 32-34). The heater was modeled as a constant-watt source, producing heat for a period of 200 days. Because FLAC requires that the heater power be specified in watts per square meter per meter in the third dimension, the heater in this model was a slice through an infinite rod. In this model, the smallest grid zone dimension was somewhat larger than the actual heater hole diameter in the SHT; this contributed to the difficulty in converting FLAC heater values to actual heater wattages. For the purposes of the FLAC modeling, heat sources in the grid zones used to represent the heater were set to values that would allow nearby zones to reach temperatures of approximately $200^{\circ} \mathrm{C}$ in 200 days of heating. This may be approximately equivalent to a 10 -m-long heater producing about 500 watts, but three-dimensional (3-D) modeling would be required to calibrate the modeled heater.

Table 7-1 FLAC properties and sources

\begin{tabular}{|l|l|l|}
\hline \multicolumn{1}{|c|}{ Property } & \multicolumn{1}{|c|}{ Value } & \multicolumn{1}{c|}{ Source } \\
\hline \hline Bulk modulus & $13 \mathrm{GPa}$ & $\begin{array}{l}\text { Computed from Young's modulus and Poisson's ratio; } \\
\text { values of uncertainty of approximately } \pm 3 \text { to 4 GPa }\end{array}$ \\
\hline Young's modulus & $31 \mathrm{GPa}$ & $\begin{array}{l}\text { (Bodvarsson and Bandurraga 1996, pp. 1-607; } \\
\text { Bodvarsson et al. 1997, pp. 1-738) }\end{array}$ \\
\hline Shear modulus & $14 \mathrm{GPa}$ & $\begin{array}{l}\text { Computed from Young's modulus and Poisson's ratio; } \\
\text { values of uncertainty of approximately } \pm \text { 3 to 4 GPa }\end{array}$ \\
\hline Bulk density & $2300 \mathrm{~kg} / \mathrm{m}^{3}$ & $\begin{array}{l}\text { (Bodvarsson and Bandurraga 1996, pp. 1-607; } \\
\text { Bodvarsson et al. 1997, pp. 1-738) }\end{array}$ \\
\hline Thermal conductivity & $2.1 \mathrm{w} /(\mathrm{m}-\mathrm{K})$ & Large-Block Test modeling (Lee 1995, pp. 1-22) \\
\hline Specific heat & $840 \mathrm{~J} /(\mathrm{kg}-\mathrm{K})$ & Large-Block Test modeling (Lee 1995, pp. 1-22) \\
\hline $\begin{array}{l}\text { Thermal expansion } \\
\text { coefficient }\end{array}$ & $9.1 \times 10^{-6} \mathrm{~K}^{-1}$ & $\begin{array}{l}\text { (Bodvarsson and Bandurraga 1996, pp. 1-607; } \\
\text { Bodvarsson et al. 1997, pp. 1-738) }\end{array}$ \\
\hline
\end{tabular}

The mechanical boundary conditions were chosen to be $\sigma_{x x}$ (horizontal) $=-5.0 \mathrm{MPa}$ and $\sigma_{\mathrm{yy}}$ (vertical) $=-10.0 \mathrm{MPa}$ (where compression is negative). The center of the heater and the far edges of model were taken to be symmetry (zero displacement) boundaries. The TM simulation was performed in several stages:

1. The mechanical model containing the heated drift and access drift excavations was run until force equilibrium was achieved.

2. The observation and tunnel alcove extensions were excavated, and the mechanical model was again run to achieve force equilibrium.

3. FLAC's mechanical mode was switched off, and the thermal option was switched on. The initial temperature was set to $20^{\circ} \mathrm{C}$ throughout the models. The tunnel walls and the edges of the models were assumed to be adiabatic boundaries. In the thermal 
modeling, the FLAC-explicit solution used a thermal time step of approximately 1 step per $3100 \mathrm{~s}$. Therefore, 200 days of heating required approximately 5500 thermal time steps. The thermal conduction solution was saved at 100 days and at 200 days . The temperature fields for these two times are shown in Figure 7-3 and Figure 7-4. The temperatures are in general agreement with those in the thermohydrologic $(\mathrm{TH})$ model of Buscheck and Nitao. Figure 7-4 shows that, after 200 days of heating, the highest temperature attained was approximately $200^{\circ} \mathrm{C}$. The temperature in the zone closest to the heater reached maximum values of about $130^{\circ} \mathrm{C}$ after 10 days of heating, about $190^{\circ} \mathrm{C}$ after 100 days, and about $210^{\circ} \mathrm{C}$ after 200 days of heating. After 200 days of heating, temperatures remain within a few degrees of the initial $20^{\circ} \mathrm{C}$ value for all the model regions that lay more than about $10 \mathrm{~m}$ away from the heater.

4. Finally, the thermal option was switched off, and the mechanical mode was switched on to calculate the thermally coupled stress field at each of the five times at which the temperature field was saved. The TM solution was then saved at 100 days and at 200 days. The stress fields for before heating and for these two times after heating are shown in Figure 7-5, Figure 7-6, and Figure 7-7. The thermal stresses cause the maximum principal stress to turn in toward the heater in the direction of the thermal gradient.

Figure 7-3. Temperature field near the single heater at 100 days (DTN LL980810904244.068)

Figure 7-4. Temperature field near the single heater at 200 days (DTN LL980810904244.068)

Figure 7-5. Principal stresses near the single heater before heating (DTN LL980810904244.068)

Figure 7-6. Principal stresses near the single heater at 100 days (DTN LL980810904244.068)

Figure 7-7. Principal stresses near the single heater at 200 days (DTN LL980810904244.068)

After 200 days of heating, the horizontal stress in the cross-sectional model exceeded $30 \mathrm{MPa}$ in compression in the region within a few $\mathrm{cm}$ of the heater. The horizontal stress was compressional everywhere in the model and remained near the original $5 \mathrm{MPa}$ value everywhere except the area between the heater and the tunnel wall. There the stress varied from about $5 \mathrm{MPa}$ right by the tunnel wall to more than $30 \mathrm{MPa}$ of compression as it neared the heater. The top and bottom walls of the tunnel also showed stress concentrations of as much as 15 to $20 \mathrm{MPa}$ of compression, probably because the grid was too coarse to smoothly model the tunnel walls. After 200 days of heating, the vertical stress in the cross-sectional model reached a maximum value of approximately $40 \mathrm{MPa}$ of compression within a few $\mathrm{cm}$ of the heater. Vertical stress was compressional everywhere in the cross-sectional model. The vertical stress near the tunnel wall $5 \mathrm{~m}$ from the heater reached values of approximately 15 to $20 \mathrm{MPa}$ of compression after 200 days of heating. These values were also found in the regions about 3 to $5 \mathrm{~m}$ above and below the heater. The tunnel walls showed some small areas of stress concentrations because of the grid coarseness. Vertical stresses remained near the 
original $10 \mathrm{MPa}$ value elsewhere in the model. After 200 days of heating, shear stresses of as much as approximately $8 \mathrm{MPa}$ developed in the cross-sectional model in the region between the heater and the tunnel wall $5 \mathrm{~m}$ away.

This model shows high values for the horizontal stress near the heater, 20 to $30 \mathrm{MPa}$ of compression, and a large gradient for the horizontal stress between the heater and the tunnel wall $5 \mathrm{~m}$ away. Stress concentrations of approximately 10 to $20 \mathrm{MPa}$ were also shown where the grid was too coarse to model smooth tunnel corners. After 200 days of heating, shear stress values of as much as about $8 \mathrm{MPa}$ are shown in the region between the heater and the tunnel wall $5 \mathrm{~m}$ away.

\subsection{Shear Slip Model}

Barton et al. (1997) presented convincing evidence that hydraulically conductive fractures in the Dixie Valley geothermal field are critically stressed, potentially active, normal faults based on the Mohr-Coulomb frictional slip criterion. This criterion was applied to the stress field calculated from the TM model to determine if permeability changes due to heating were likely to occur.

In broad terms, three fracture sets have been identified in the Exploratory Study Facility (ESF) (Albin et al., 1997, p. 1):

1. A steeply dipping set striking east-west

2. A steeply dipping set striking north-south

3. A subhorizontal set striking east-west

The axis of the single heater is oriented east-west; hence, set \#1 and set \#3 have their strike perpendicular to the plane of the FLAC model. The planes are defined by the angle $\theta$ of their normals to the $x$-axis. Therefore, an angle of zero degrees corresponds to a vertical plane (set \#1) and an angle of $90^{\circ}$ corresponds to a horizontal plane (set \#3). The Mohr-Coulomb criterion is

$$
|\tau| \geq c+f S_{n},
$$

where $c$ is the cohesion, $f$ is the coefficient of friction, $\tau$ is the shear stress, and $S_{\mathrm{n}}$ is the compressive normal stress. The maximum potential for frictional slip occurs for a cohesion value of zero (i.e., shear offset occurs when the ratio $\left.|\tau| /\left(f S_{n}\right) \geq 1\right)$. This ratio is contoured for the two pre-existing fracture sets after 100 and 200 days of heating for the vertical fracture set (Figure 7-8 and Figure 7-9, respectively) and similarly for the horizontal fracture set (Figure 7-10 and Figure 7-11, respectively). (The vertical fracture results are the FLAC variable EX_1, and the horizontal fracture results are the variable EX_4.)

Figure 7-8. Ratio of shear stress to frictional resistance for vertical planes at 100 days (DTN LL980810904244.068)

Shear slip is expected in the gray regions where the ratio exceeds one.

Figure 7-9. Ratio of shear stress to frictional resistance for vertical planes at 200 days (DTN LL980810904244.068)

Shear slip is expected in the gray regions where the ratio exceeds one. 
Figure 7-10. Ratio of shear stress to frictional resistance for horizontal planes at 100 days (DTN LL980810904244.068)

Shear slip is expected in the gray regions where the ratio exceeds one.

Figure 7-11. Ratio of shear stress to frictional resistance for horizontal planes at 200 days (DTN LL980810904244.068)

Shear slip is expected in the gray regions where the ratio exceeds one.

The regions of frictional slip for planes of different orientation correlated with the principal stresses plotted in Figure 7-5, Figure 7-6, and Figure 7-7. For example, vertical fractures were expected to be favorably oriented for slip when they are approximately $30^{\circ}$ to the maximum principal stress direction. The effect of heating is to create thermal gradients that are approximately radial toward the heat source. These gradients are equivalent to body forces and superpose with the isothermal stress field. The thermal gradients for the SHT were not as large as those predicted for several years of heating in the larger-scale DST. Thus, the region in which the thermal stresses are large enough to induce shear slip on pre-existing fracture planes is small. Additionally, the ratio of shear-to-normal stresses was not as large. The region of induced shear slip decreased between 100 and 200 days of heating. The exact shape was also affected by the approximation of the tunnel drift by a circle and the treatment of the tunnel boundary as an adiabatic boundary.

It is important to note that the thermal gradients generated in the SHT are much smaller than those expected, after many years of heating, in the potential repository. Thus, although the region of slip induced here was small, this effect must also be considered specifically in relation to the potential respository.

\subsection{Discussion}

A critical link in the methodology linking the TM analysis to permeability is the concept that permeability is enhanced results from shear offset due to Mohr-Coulomb slip on preexisting fracture sets. Previous use of the Brown (1995, pp. 5941-5952) and Brown and Bruhn (1997, pp. 1-36) model suggested that slip might lead to increasing permeability by a factor of two. The largest zone of enhanced permeability occurred at approximately 100 days for the vertical east-west fracture set. Using electrical resistivity tomography, Ramirez and Daily (see Chapter 2 of this report) observed water collected in a U-shaped region between the heater and the two tunnel drifts (Figure 7-12). This saturation pattern might be related to enhanced vertical permeability in the region shown in Figure 7-8 conducting water into the region of unenhanced permeability where it collects.

Figure 7-12. Electrical resistance tomography showing drying and wetting regions in a cross section through the single heater as a function of time (DTN LL980810904244.068)

The December 4, 1996, tomograph is approximately 100 days after the heater was turned on, and the April 22, 1996, tomograph is approximately 200 days after the heater was turned on. The drying zone is approximately circular and centered around the axis of the heater. The wetting zone extends between the heater and drifts in a U-shaped pattern. 


\subsection{References}

Albin, A.L., Singleton, W.L., Moyer, T.C., Lee, A.C., Lung, R.C., Eatman, G.L.W., and Barr, D.L. 1997. Geology of the Main Drift-Station 28+00 to 55+00, Exploratory Studies Facility. Yucca Mountain Project, Yucca Mountain, Nevada. Denver, Colorado: Bureau of Reclamation and U.S. Geological Survey. MOL.19970625.0096.

Barton, C.A., Hickman, S., Morin, R., Zoback, M.D., Finkbeiner, T., Sass, J., and Benoit, D. 1997. "Fracture permeability and its relationship to in-situ stress in the Dixie Valley, Nevada, Geothermal Reservoir." In proceedings from Twenty-Second Workshop on Geothermal Reservoir Engineering. Stanford University, Stanford, California: January 27-29, 1997. MOL.19980710.0823.

Blair, S.C., Wang, H.F., and Berge, P.A. 1998. "Estimating Changes in Rock Permeability due to Thermal-Mechanical Effects." Proceedings of the Eighth International Conference on High-Level Radioactive Waste Management Conference. La Grange Park, Illinois: American Nuclear Society. (Also UCRL-JC-128799-EXT-ABS, Lawrence Livermore National Laboratory, Livermore, California)

Bodvarsson, G.S., and Bandurraga, T.M. 1996. Development and Calibration of the ThreeDimensional Site-Scale Unsaturated Zone Model of Yucca Mountain, Nevada. LBNL-39315. Berkeley, California: Lawrence Berkeley National Laboratory, Earth Sciences Division. MOL.19970211.0176.

Bodvarsson, G.S., Bandurraga, T.M., and Wu, Y.S. 1997. The Site-Scale Unsaturated Zone Model of Yucca Mountain, Nevada, for the Viability Assessment. June, 1997. LBNL-40376, UC-814. Berkeley, California: Lawrence Berkeley National Laboratory, in collaboration with the U.S. Geological Survey. MOL.19971014.0232.

Brown, S.R. 1995. "Simple mathematical model of a rough fracture." J. Geophys. Res. 100:5941-5952. 222415.

Brown, S.R., and Bruhn, R.L. 1997. Fluid Permeability of Deformable Fracture Networks. SAND97-0159. Albuquerque, New Mexico: Sandia National Laboratories. MOL.19980514.0045.

Buscheck, T.A., and Nitao, J.J. 1995. Thermal-Hydrological Analysis of Large-Scale Thermal Tests in the Exploratory Studies Facility at Yucca Mountain. UCRL-ID-121791.

Livermore, California: Lawrence Livermore National Laboratory. MOL.19960501.0392. 223657.

CRWMS M\&O 1997. Single Heater Test Interim Report. Yucca Mountain Site Characterization Project Milestone Report. BABEAF000-01717-69000001 REV 00. Las Vegas, Nevada: Civilian Radioactive Waste Management System, Management and Operating Contractor: TRW Environmental Safety Systems, Inc.

Itasca Consulting Group Inc. 1996. FLAC, Fast Lagrangian Analysis of Continua, Version 3.3, Vol. I-IV, User's Manuals. Minneapolis, Minnesota: Itasca Consulting Group, Inc.

Lee, K.H. 1995. Progress Report on Pre-Test Calculations for the Large Block Test. UCRL-ID118699. Livermore, California: Lawrence Livermore National Laboratory. MOL.19950314.0178. 214965. 
SNL 1997. Evaluation of Single Heater Test Thermal and Thermomechanical Data: Second Quarter Results (8/26/96 through 2/28/97). April 18, 1997. Milestone report for the CRWMS Management and Operating Contractor, U.S. Department of Energy. SP9238M4 and SP9239M4. Albuquerque, New Mexico: Sandia National Laboratories. 

Chapter 7 Figures 


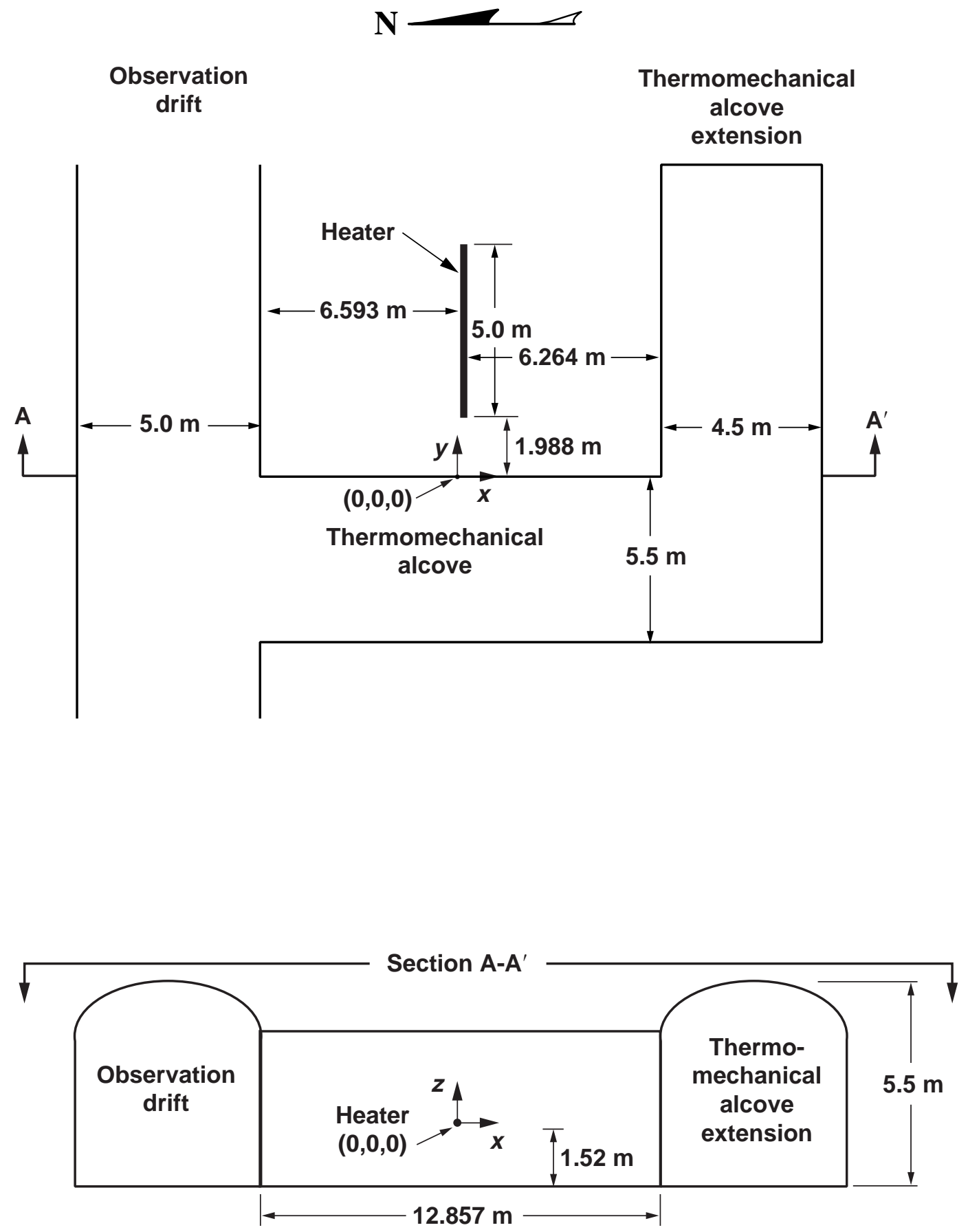

Figure 7-1. Layout of Single-Heater Test in plan and cross section (SNL 1997) 


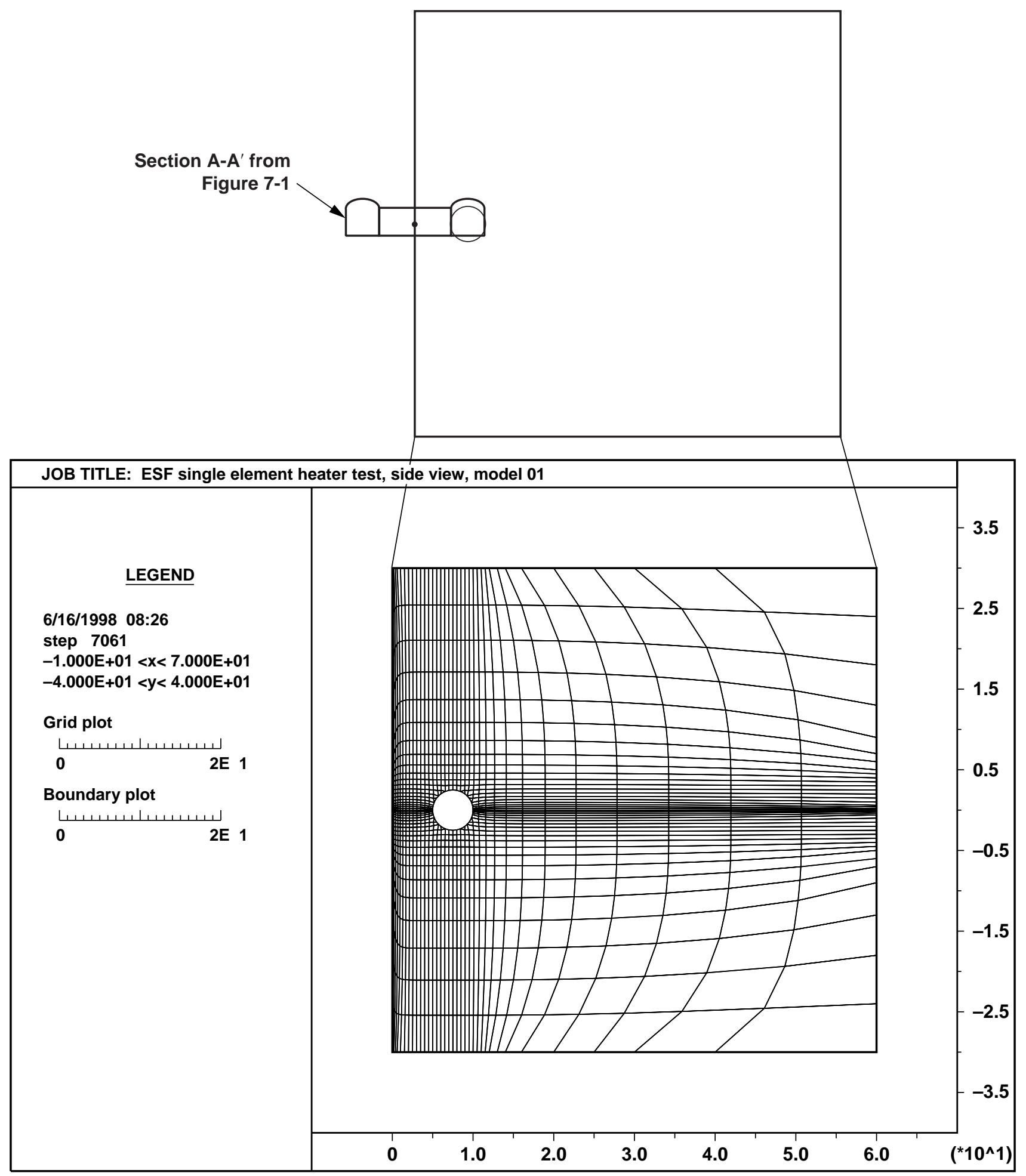

Figure 7-2. FLAC grid (Heater is at the center of the left edge of the model. The alcove observation tunnel and observation drift are located symmetrically about $x=0$.) 


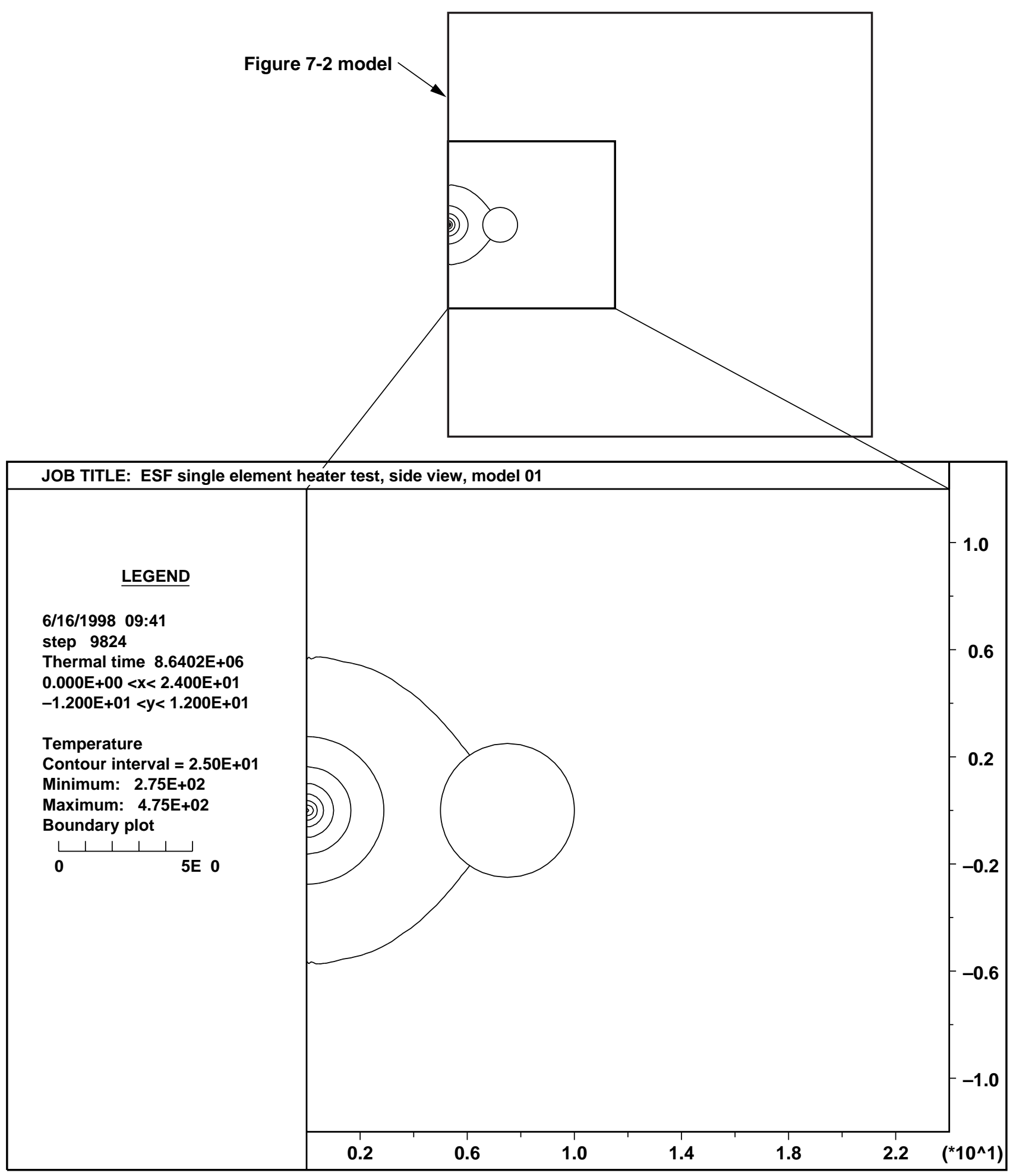

Figure 7-3. Temperature field near the single heater at 100 days 


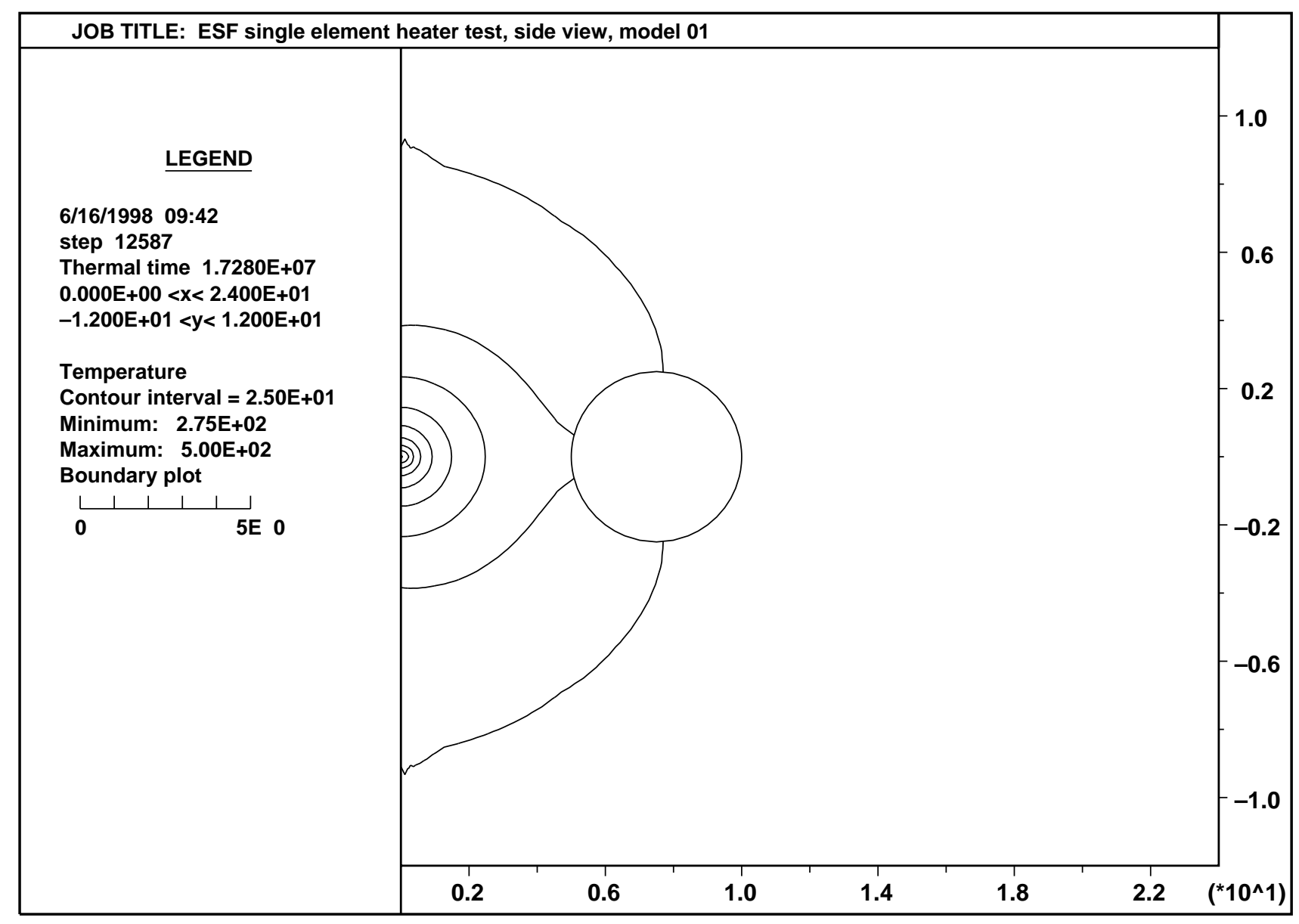

Figure 7-4. Temperature field near the single heater at 200 days 


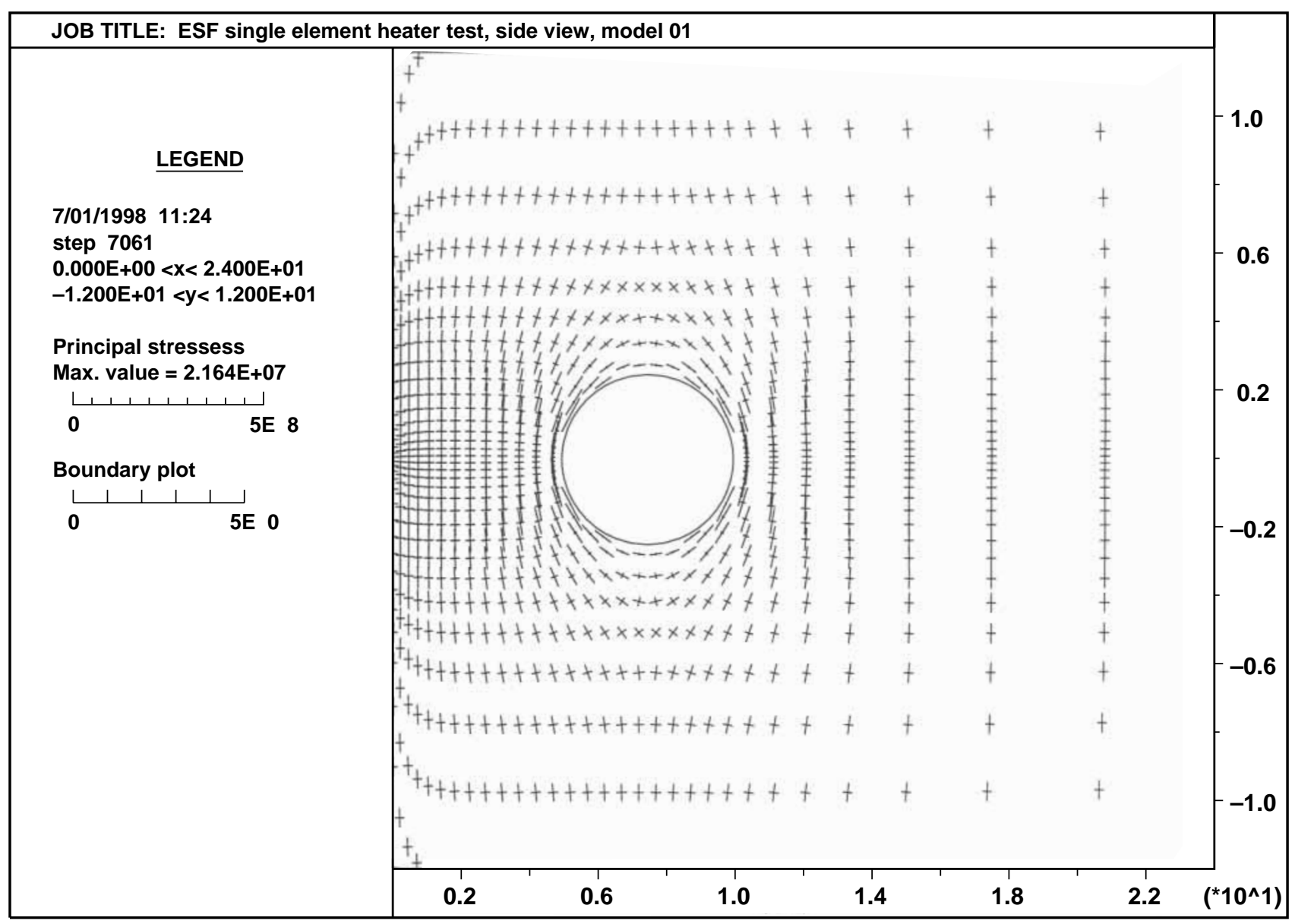

Figure 7-5. Principal stresses near the single heater before heating 
JOB TITLE: ESF single element heater test, side view, model 01

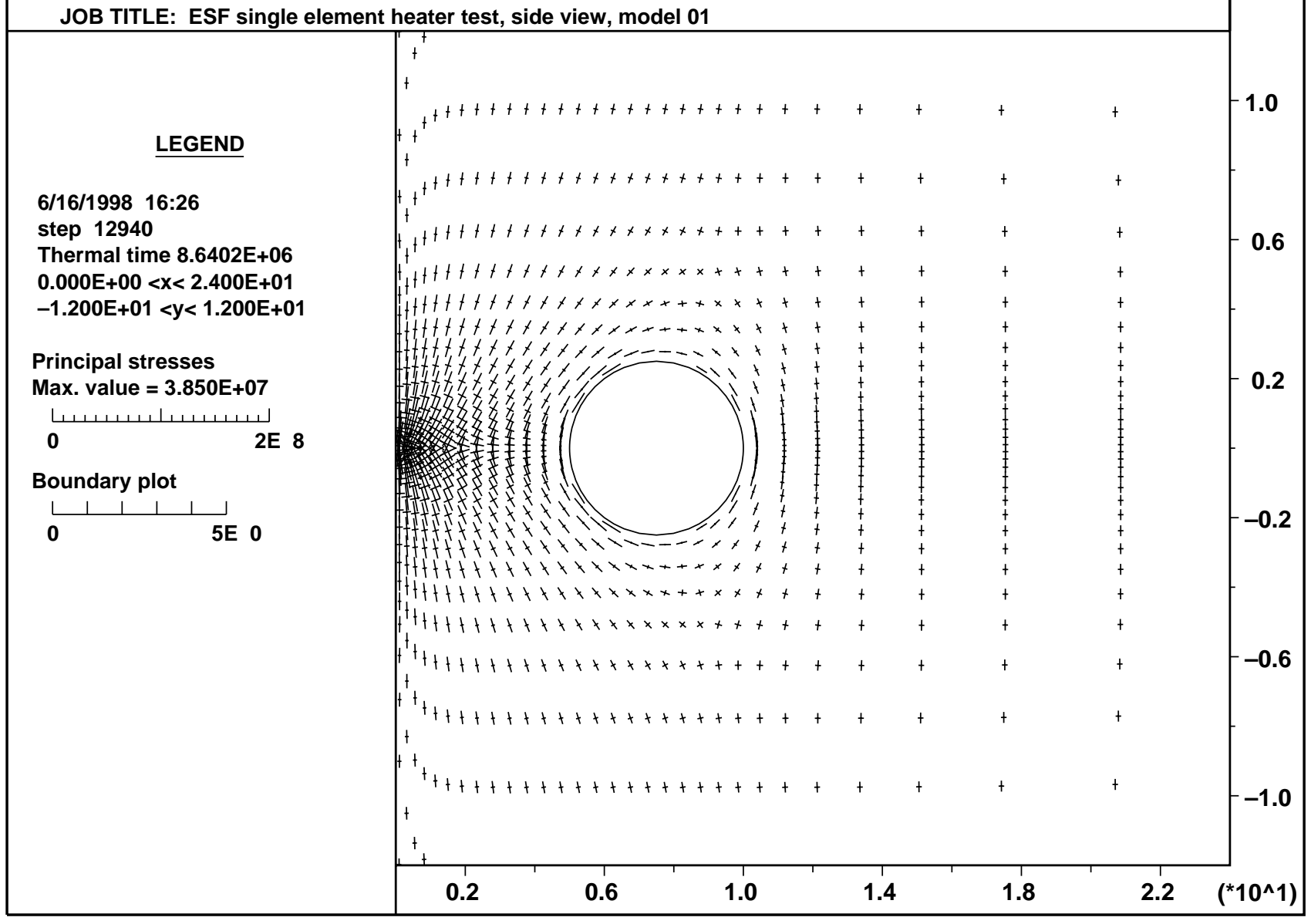

Figure 7-6. Principal stresses near the single heater at 100 days 


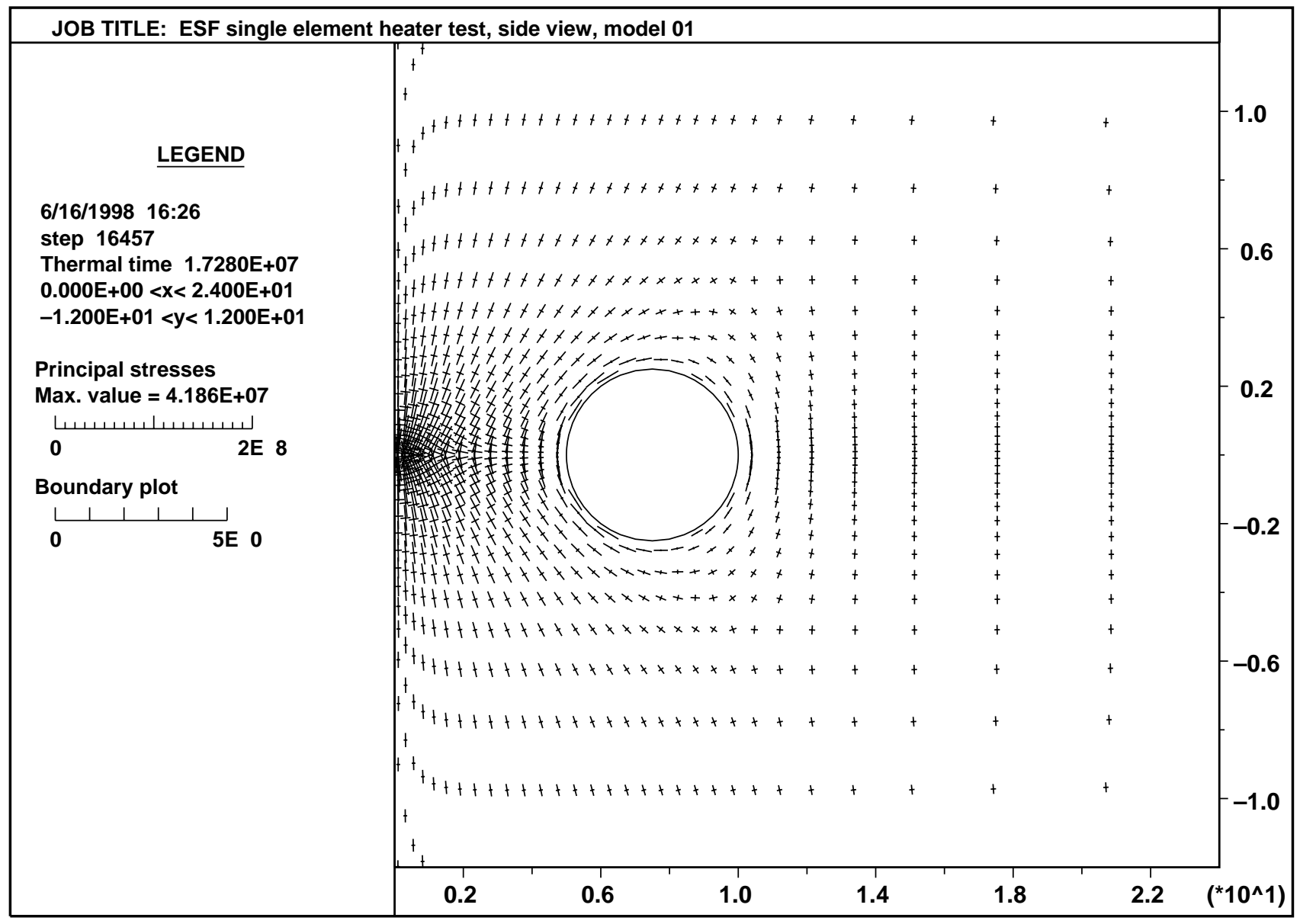

Figure 7-7. Principal stresses near the single heater at 200 days 


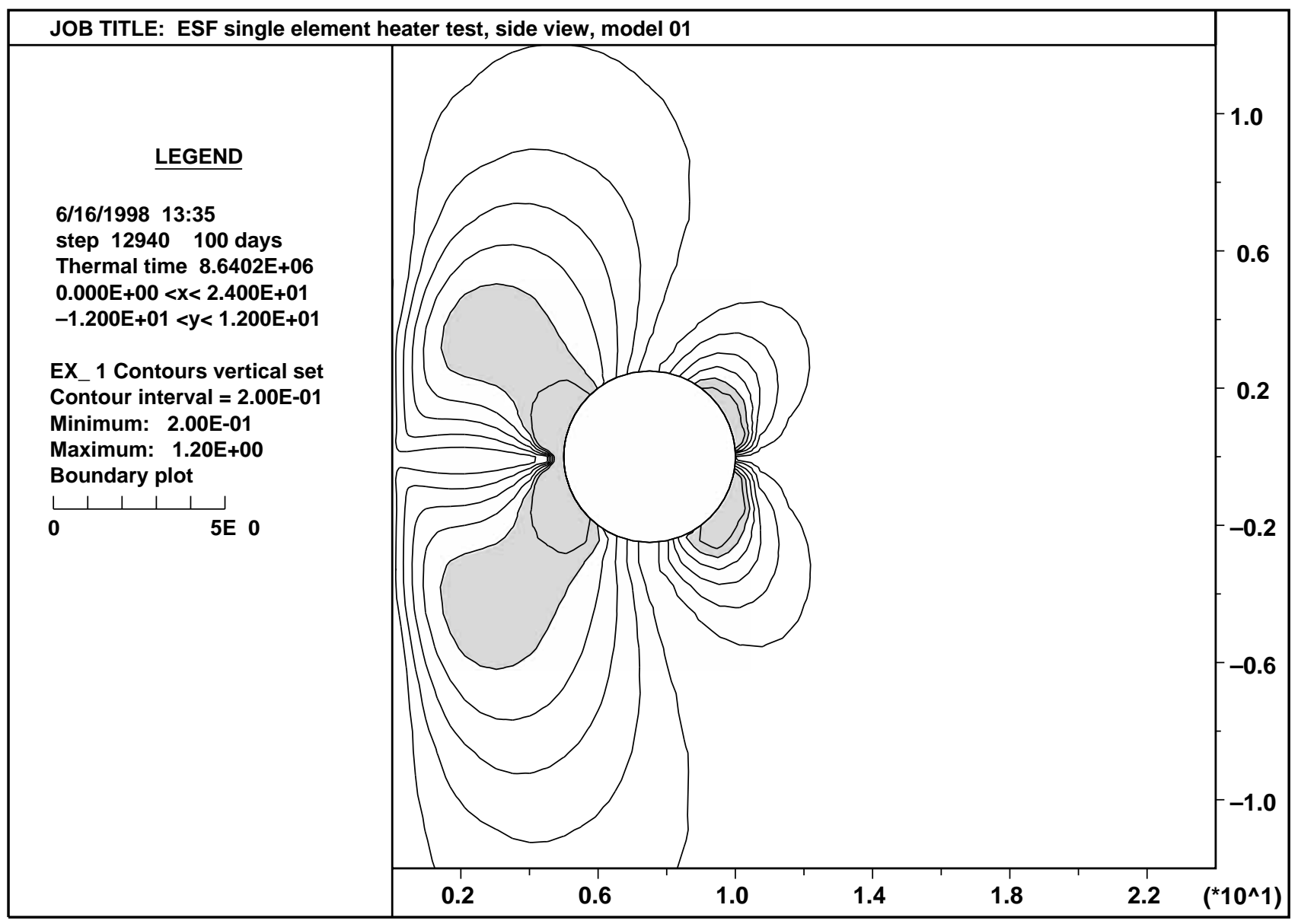

Figure 7-8. Ratio of shear stress to frictional resistance for vertical planes at 100 days (Shear slip is expected in gray regions where the ratio exceeds one.) 


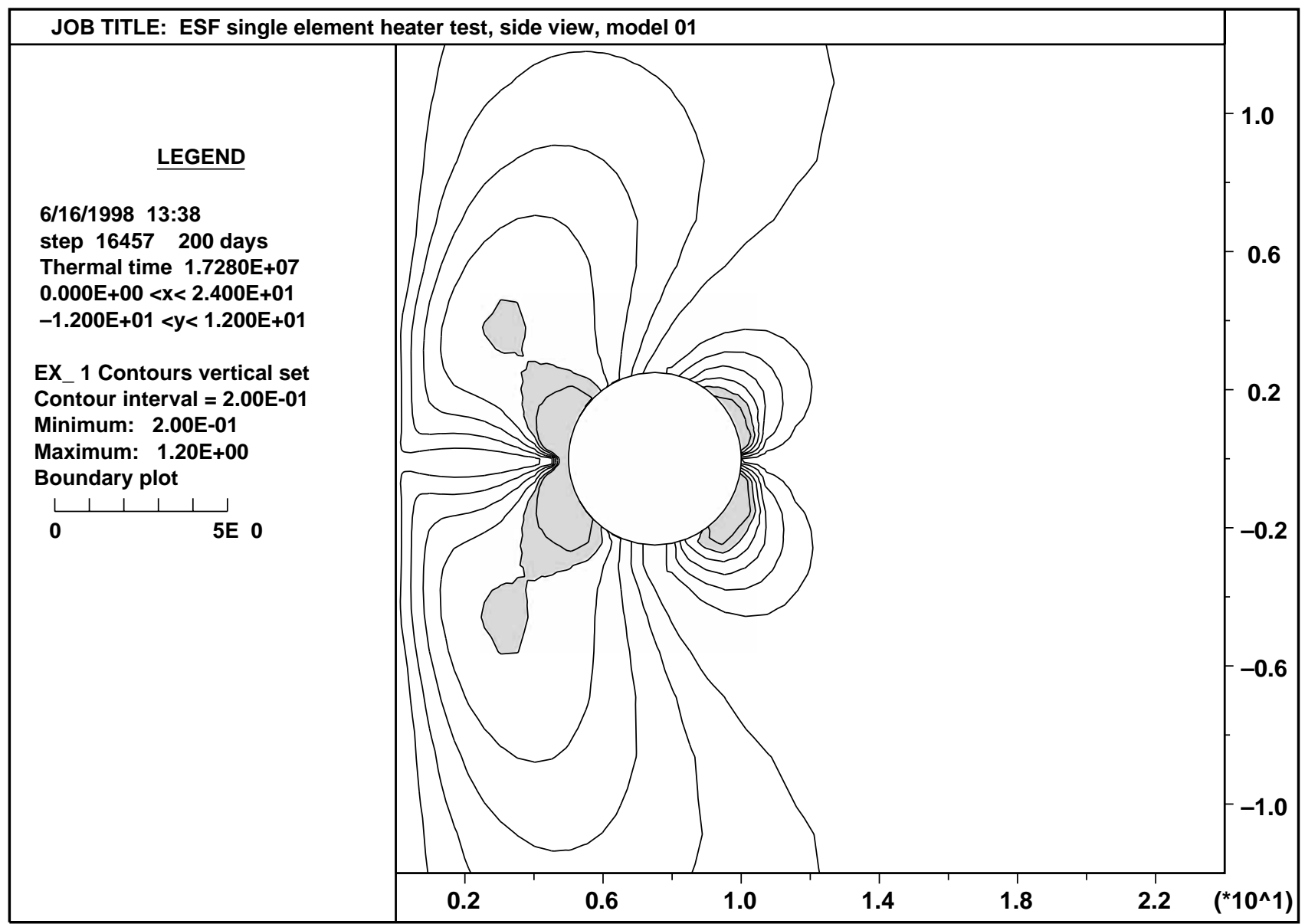

Figure 7-9. Ratio of shear stress to frictional resistance for vertical planes at 200 days (Shear slip is expected in gray regions where the ratio exceeds one.) 


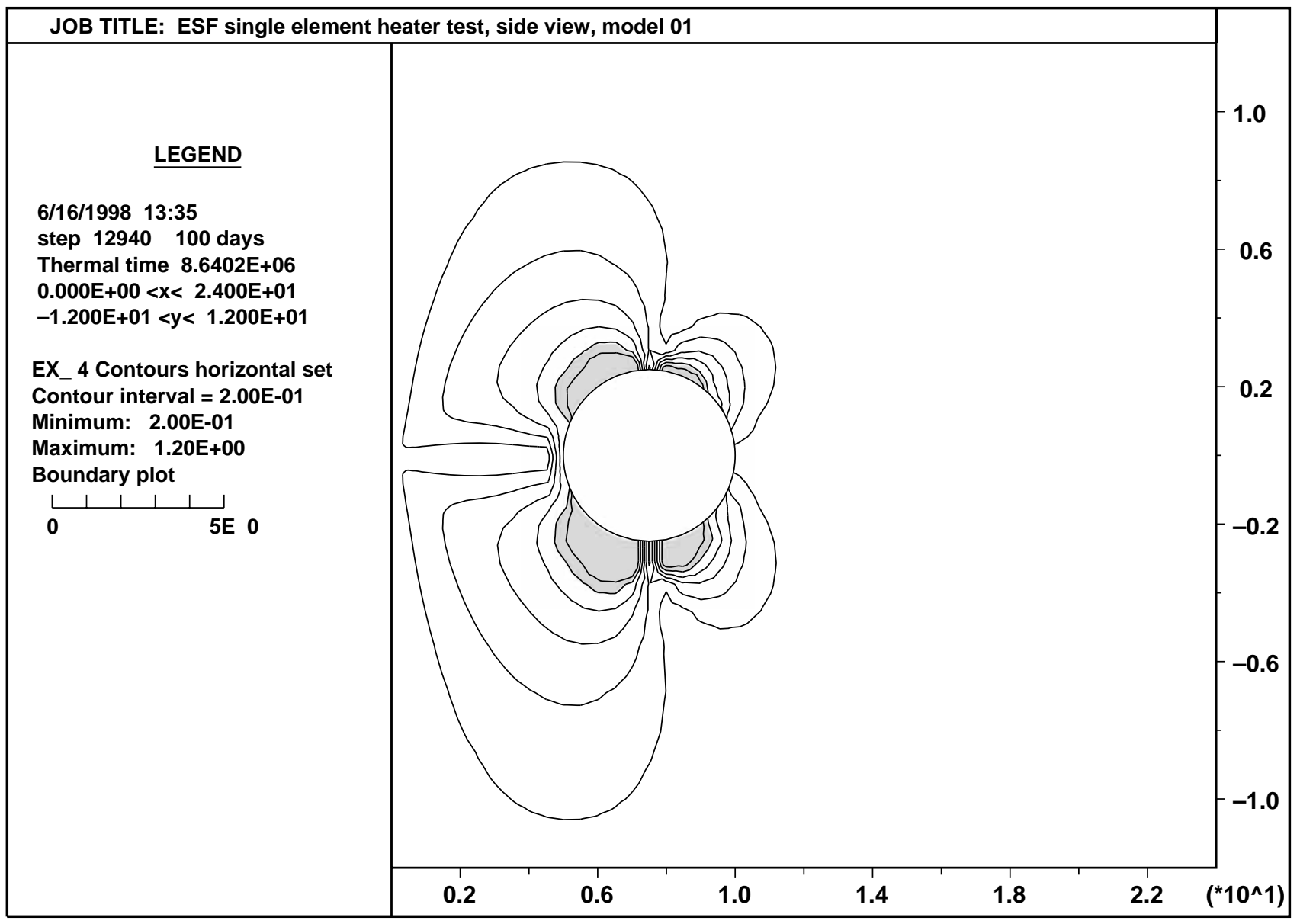

Figure 7-10. Ratio of shear stress to frictional resistance for horizontal planes at 100 days (Shear slip is expected in gray regions where the ratio exceeds one.) 


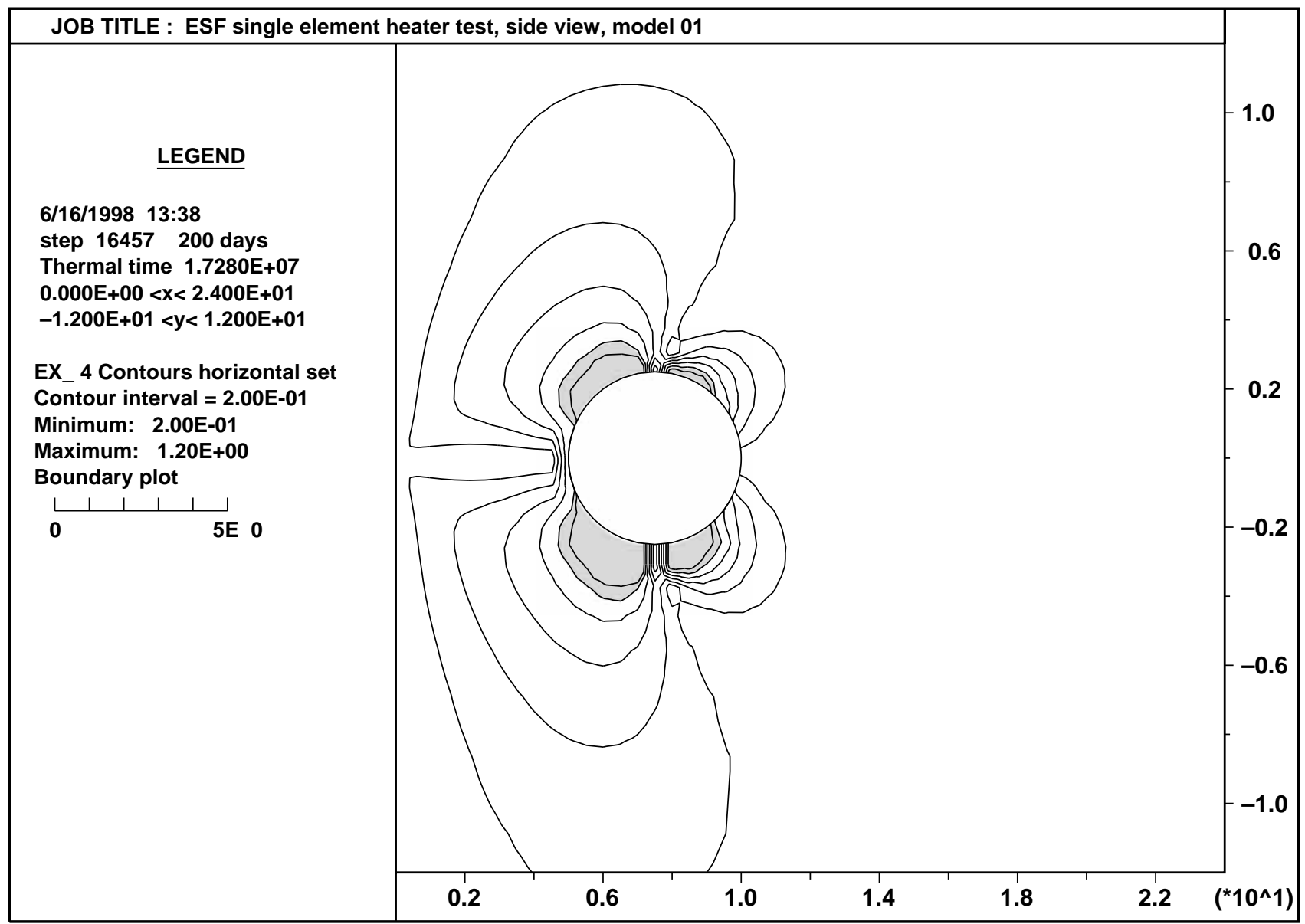

Figure 7-11. Ratio of shear stress to frictional resistance for horizontal planes at 200 days (Shear slip is expected in gray regions where the ratio exceeds one.) 

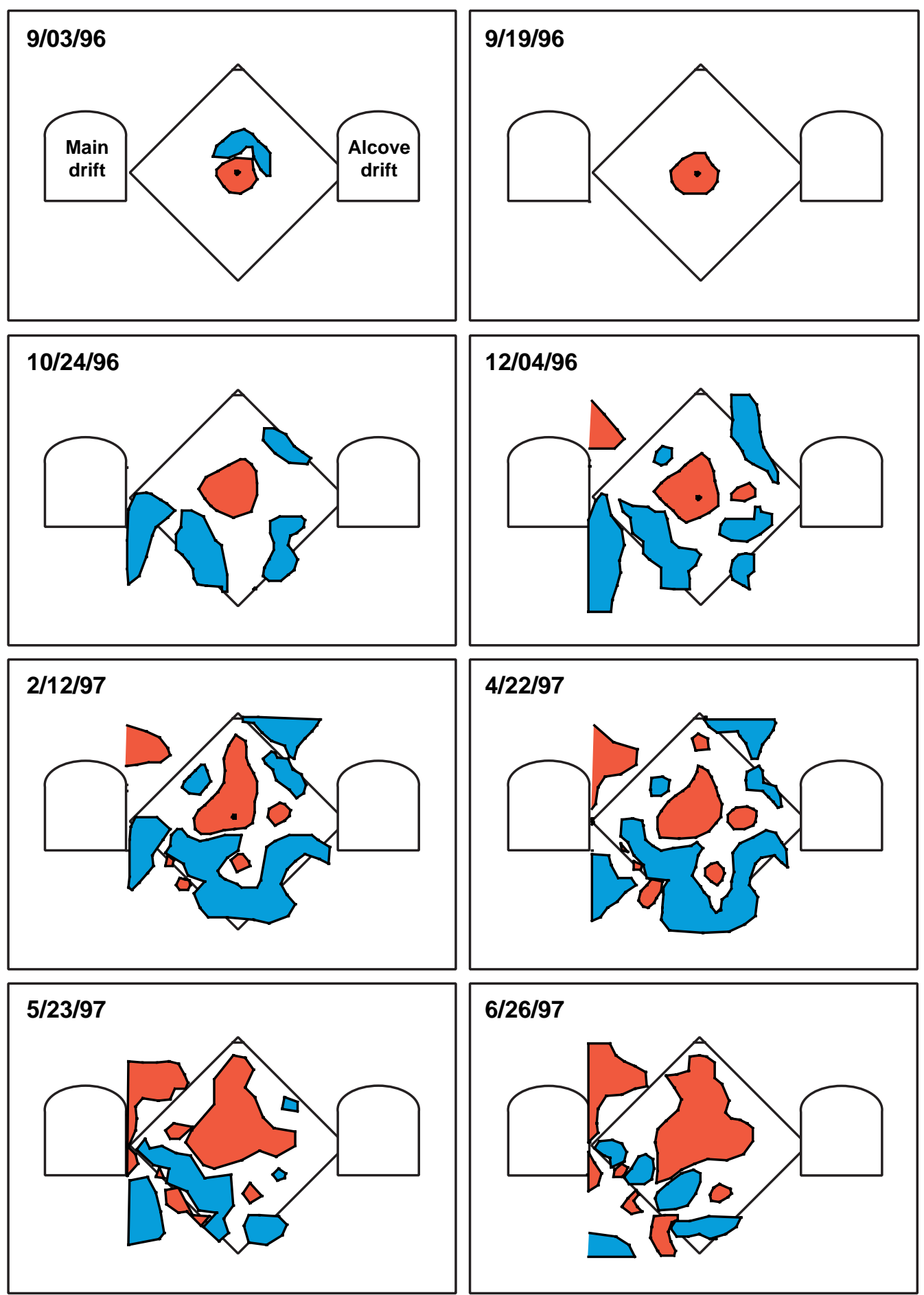

Wetting regions

Drying regions

Figure 7-12. Electrical resistance tomography showing drying and wetting regions in a cross section through the single heater as a function of time (The December 4, 1996, tomograph is approximately 100 days after the heater was turned on, and the April 22, 1996, tomograph is approximately 200 days after the heater was turned on. The drying zone is approximately circular and centered around the axis of the heater. The wetting zone extends between the heater and drifts in a U-shaped pattern.) 


\section{Synthesis and Discussion}

This report presents results of several sets of measurements and analyses conducted by Lawrence Livermore National Laboratory for the Single-Heater Test (SHT) at Yucca Mountain, Nevada. The primary foci of the studies discussed in this report was to map moisture using electrical-resistivity tomography (ERT) and neutron-logging, to monitor geochemical changes, to simulate temperature and hydrologic environments, and to estimate shear slip on fractures. Data and analysis presented in this report provide information on the thermal-hydrologic-chemical-mechanical (THMC) behavior of the SHT.

\subsection{Synthesis of Collected Data}

Comparison of data sets presented in this report yield the following observations:

- The ERT imaging and the neutron logs indicated that heating of the rock generally caused drying (decreased liquid saturation) near and above the heater and wetting (increased liquid saturation) in rock below and to the north of the heater. Figure 8-1 presents a compilation of the ERT and neutron measurements made near the end of the heating phase (day 270). This figure shows very good agreement between the two data sets. The transition from drying to wetting regions observed from neutron logs in Boreholes 22 and 23 especially well matches the drying/wetting transition derived from ERT measurements.

- As discussed in Section 2.2.2, the most extensive drying is observed in regions at the heater elevation and above. However, the dry zone detected by ERT is not centered on the heater and is not symmetric about the heater; rather, it has lobes that extend upward from and to either side of the heater (Figure 8-1). The ERT measurements do indicate that the driest region was right around the heater and that it had a saturation of approximately $10 \%$ (see Figure 2-2). In addition, temperature measurements in the neutron holes indicated that drying occurred at temperatures in the range of 60 to $90^{\circ} \mathrm{C}$. Figure 8-2 presents the ERT tomograph for 270 days overlaid with temperatures calculated for 275 days. This figure shows that, for the region below the level of the heater, measurable drying is indicated for rock at temperatures greater than $60^{\circ} \mathrm{C}$.

- A significant amount of water was collected in one packed-off interval of Borehole 16 (see Figure 8-1). Analysis of the water composition indicated that the water may be condensate that traveled as far as $2 \mathrm{~m}$ in fractures. The condensate was collected in a region associated with drying behavior.

Figure 8-1. Synthesis of ERT and neutron measurements for SHT near the end of the heating phase

Also shown is sampling interval for water samples.

Figure 8-2. Synthesis of ERT measurements and predicted temperatures near the end of the heating phase (concentric circles indicate predicted temperatures in ${ }^{\circ} \mathrm{C}$ )

Note that drying is indicated for areas with temperatures greater than $60^{\circ} \mathrm{C}$. 


\subsection{Implications for Coupled Processes}

Observations made from collected data suggest the following implications:

- During the heating phase of the SHT, moisture was driven out of a region around the heater having a minimum diameter of approximately $5 \mathrm{~m}$. Regions of reduced saturation also extended above the heater and to the sides, forming anisotropic lobes extending out from the heater. The regions of drying/wetting are attributed to movement of moisture cause by heating. Temperature measurements and thermohydrologic (TH) modeling results (Chapter 6) indicate that rock within $1.25 \mathrm{~m}$ of the heater reached temperatures greater than $96^{\circ} \mathrm{C}$ (boiling, at this location). In this region, water was converted to steam and moved away from the heater. The steam condensed into water when it reached the cooler region. Some of this condensate slowly imbibed into the cooler surrounding rock and caused an increase in saturation. The remainder of the condensate may have shed and drained along fractures into lower-elevation regions and thus might have been captured in open fractures or cavities. Results shown in Chapter 2 and Chapter 3 indicate that condensate drains quickly. Zones below the heater received condensate generated locally as well as condensate that had drained from above; this made possible the imbibition of larger amounts of water below the heater.

- ERT and neutron logging data also indicated drying in regions of rock that were well below the boiling temperature. Moisture movement in these regions was probably by means of evaporation rather than boiling.

- Comparison of SHT Borehole 16-4 waters over time showed them to be slowly evolving while maintaining certain consistent compositional characteristics. These characteristics are that $\mathrm{Na}$ and $\mathrm{Si}$ were the dominant cations in solution, followed by $\mathrm{Ca}, \mathrm{K}$, and $\mathrm{Mg}$. Values of $\mathrm{pH}$ at about 6.5 all reflect slightly acidic waters. The low $\mathrm{pH}$ is indicative of higher $\mathrm{CO}_{2}$ partial pressures. Increased $\mathrm{CO}_{2}$ partial pressures of approximately two orders of magnitude, relative to ambient atmospheric values, would account for the conditions seen.

The characteristics of these waters are similar to those of perched water obtained from UZ-14 but are distinct from pore waters, saturated-zone waters, and fracture waters previously documented. However, no simple mechanism exists for generation of Borehole 16-4 waters by condensate dilution of pre-existing waters. This suggests a model in which both perched waters and Borehole 16-4 waters evolve from condensate (or rain water, in the case of the perched water) through interaction of fracture-lining minerals during fracture flow. However, the specific histories were uniquely determined by the time and mineralogical interaction in their respective settings.

\subsection{Simulation and Analysis}

Simulations of the SHT were conducted using TH, thermomechanical (TM), and thermochemical (TC) codes. Comparison of the predicted and observed results aids in the interpretation of the behavior and in evaluation of models and data.

\subsubsection{Temperature}

TH models (Chapter 6) were used to predict temperature and moisture distribution. Comparison of observed and calculated temperatures indicates that the TH models (especially the dual-permeability [DKM] approach) predicted the thermal behavior of the 
SHT very well. The TH models predicted a pronounced cold-trap effect in the heater borehole. Vapor and latent heat flowed from the heated interval of the heater borehole to the cool end of the heater borehole adjacent to its collar, where the vapor condensed; This resulted in focused condensate drainage and a local increase in $S_{\text {liq }}$ in the matrix. The coldtrap effect efficiently transferred heat along the heater borehole toward the TM alcove. The cold-trap effect is a potentially important mechanism influencing TH behavior in emplacement drifts.

The TH models under-represented the heat loss to the TM alcove, resulting in predicted temperatures being greater than the observed temperatures in the vicinity of the TM alcove; this overprediction increased as the distance to the TM alcove decreased. The cause for this overprediction is the manner in which heat flow in the TM alcove was treated. Had thermal radiation from the warmer to cooler wall surfaces in the TM alcove been accounted for in the SHT models, the cooling rate on the eastern TM alcove wall would have been much greater, resulting in lower predicted temperatures in the vicinity of the TM alcove.

\subsubsection{Hydrologic Processes}

TH simulations showed that the SHT could not distinguish between alternative conceptual models of the fracture-matrix interaction (FMX) factor. Both approaches resulted in the same outstanding agreement with observed temperatures, and both approaches predicted the same distribution of $S_{\text {liq }}$ in the matrix continua. Moreover, the SHT was not a useful test for diagnosing the magnitude of percolation flux $q_{\text {perc }}$. The SHT's lack of sensitivity to $q_{\text {perc }}$ arose from the heat-driven condensate fluxes being much greater than any of the values of $q_{\text {perc }}$ that were considered.

The prediction of the radial extent of the dry-out zone provided by the DKM approach was in qualitative agreement with the ERT and neutron observations. Although the DKM predicted the overall extent of dry-out, it did not reflect the geometry of the dry-out lobes observed. The ECM model, on the other hand, did reflect these lobes, but predicted four symmetric lobes rather than as two irregular features that were observed. The asymmetric drying/wetting distribution observed using ERT and neutron also contrasts with the symmetry of the temperature field.

\subsubsection{Wetting/Drying Asymmetry}

The cause of the asymmetry in the distribution of wetting/drying zones measured during the SHT is unclear. The occurrence of the wetting zone on only one side of the heater may be associated with natural heterogeneity in the number and spacing of fractures in the rock mass. The TM analysis of the SHT presented in Chapter 7 indicated that shear-slip could be expected in the region below and to the heater side of the TM alcove extension. This shearslip was predicted to occur on vertical fractures oriented parallel to the heater throughout much of the heating phase. While the TM calculation only considered one-half of the SHT cross-section geometry, the layout of the TM alcove extension and the access/observation drift (AOD)is approximately symmetric about a vertical plane through the heater axis (see Figure 1-1). This symmetry was used to extend the TM model to the entire test region.

Figure 8-3 shows the shear-stress field for vertical fractures after 200 days of heating, with the results reflected about a vertical plane through the heater. Comparison of Figure 8-3 and Figure 8-1 shows that the large wetting region below and to the south of the AOD is spatially correlated with the large wetting region observed using ERT. Analysis of ERT shown in Figure 2-5 indicates that wetting was detectable in this region after only 59 days of heating, 
and the calculation presented in Chapter 7 shows this slip region to be well formed at 100 days of heating. A similar region of shear-slip is predicted below to the heater side of the TM alcove extension; however, only a small region of wetting develops on the side with the zone of predicted slip. This correlation of wetting with zones of predicted slip on vertical fractures suggests that there may be some TM influence on TH behavior.

Figure 8-3. Regions of shear slip predicted for vertical fractures, oriented perpendicular to the page

\section{Note the correlation of predicted shear slip with wetting shown below Boreholes 21 and 23 in Figure 8-1.}

It is also important to note that the anisotropic distribution of wet regions may be an artifact produced by injection of cool air into Boreholes 20 and 21. These boreholes are located coplanar with the ERT and neutron holes on the AOD side of the test. They were instrumented with the inflatable SEAMIST ${ }^{\mathrm{TM}}$ liner system, and the liners were found to leak. To keep the liners inflated, air from the AOD was continuously injected into the holes. This may have caused development of cold-finger effect similar to that suspected at the heater. The potential for this to affect the test could be evaluated.

\subsubsection{Water Chemistry}

Analysis of the chemistry of the water collected from zone 4 in Borehole 16 of the SHT, as a function of time, indicate that the composition is slowly evolving. This evolution is consistent with a simple model in which condensate interacts only with fracture-lining minerals. As dissolution and evolution of secondary minerals proceed, the effective surface areas of reactant phases decrease, and those of equilibrium secondary minerals increase. Thus, condensate is closer to equilibrium with the evolved fracture surfaces, and this results in less dissolution per unit time and distance of flow leading to a lower dissolved load by the time the solution reaches Borehole 16-4.

Preliminary modeling suggests that the flow distance was 3 to $6 \mathrm{~m}$ from the heater and also that the concentration of Ca followed precisely that expected if calcium concentration reflects the interaction of calcite and a water in which $\mathrm{pH}$ is externally controlled, that the solution concentration remains saturated with respect to quartz, and that the concentrations of $\mathrm{K}$ are consistent with K-feldspar dissolution.

These conclusions are also consistent with the primary characteristics of the solution chemistry developing within a few meters of the heater, at temperatures and flow conditions expected in the actively convecting portion of the heated region, and later entering the Borehole 16-4 cavity. 
Chapter 8 Figures 



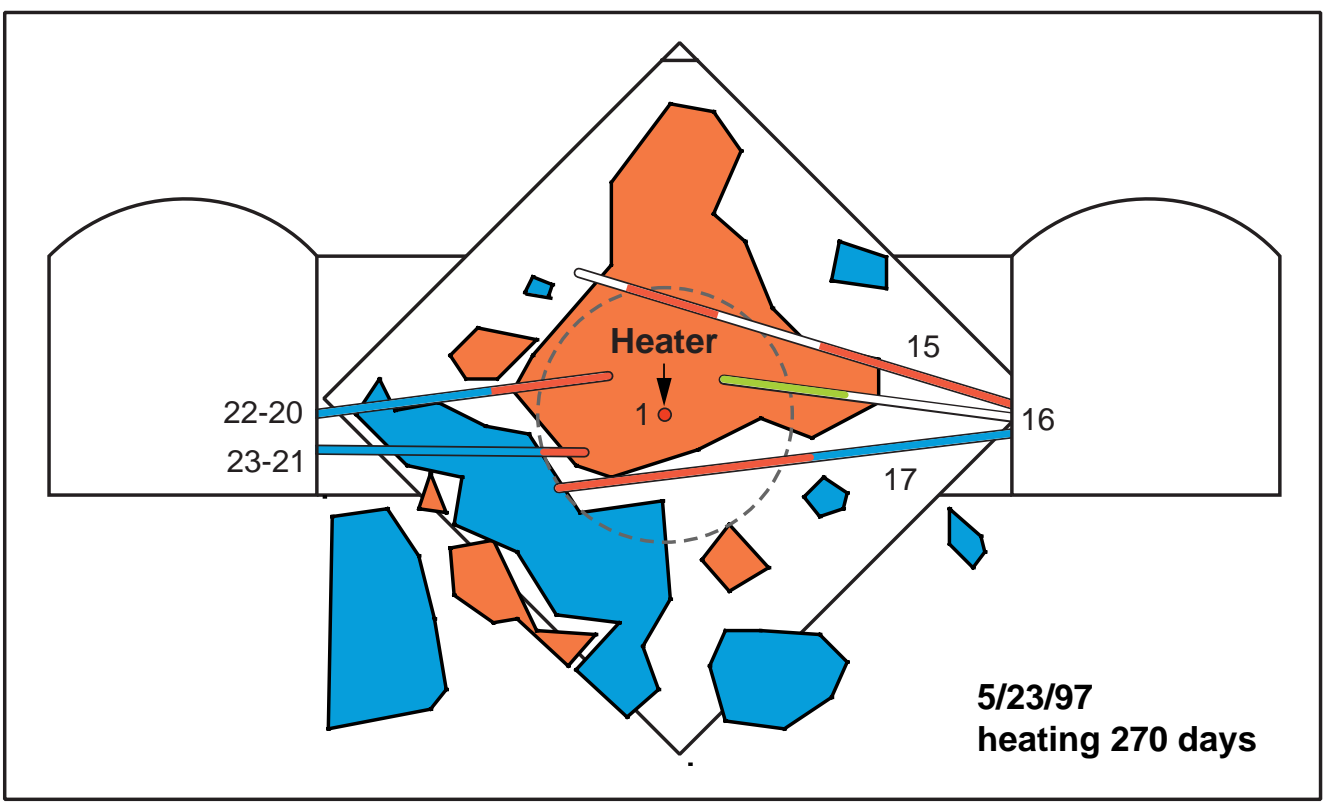

Wetting regions $\square$ Drying regions $\square$ Interval for water collection

Figure 8-1. Synthesis of ERT and neutron measurements for SHT near the end of the heating phase (also shown is sampling interval for water samples)

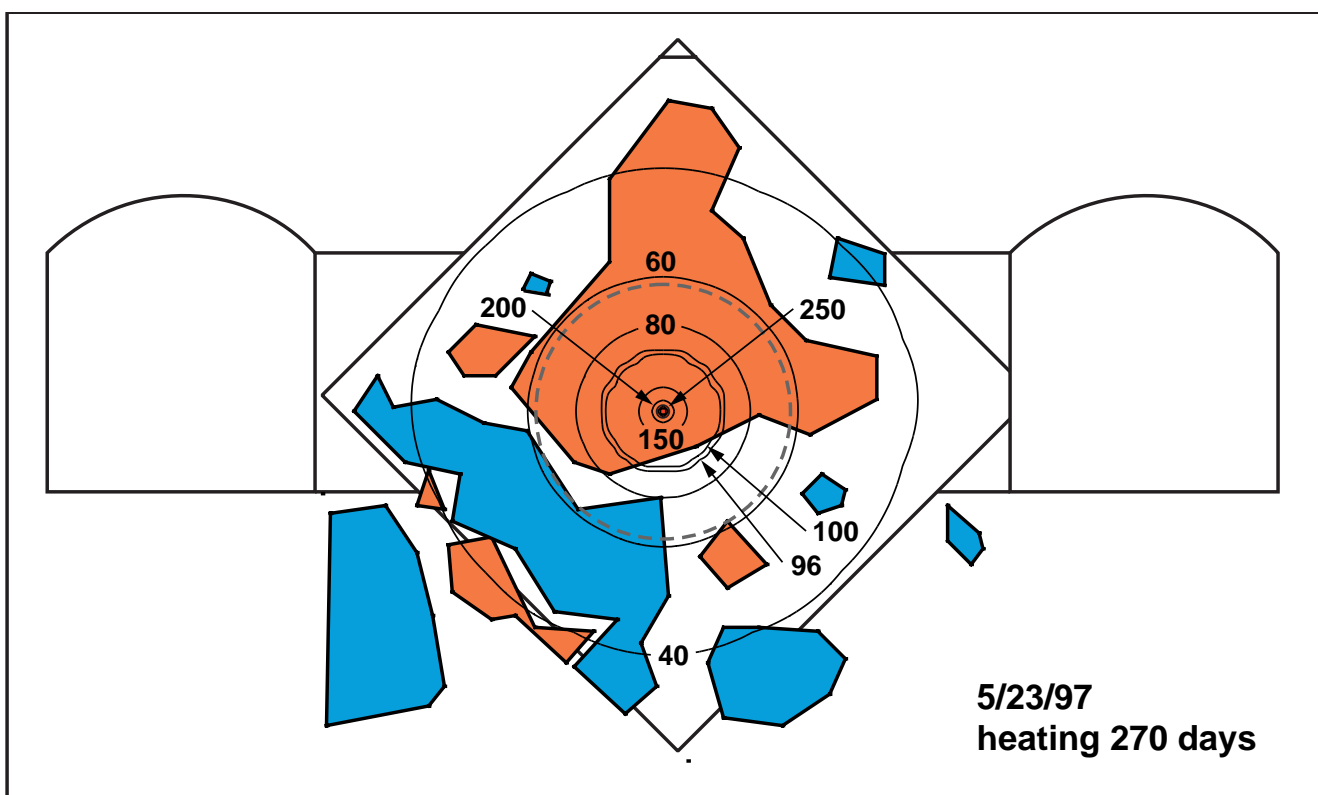

Wetting regions

Drying regions

Figure 8-2. Synthesis of ERT measurements and predicted temperatures near the end of the heating phase (concentric circles indicate predicted temperatures in ${ }^{\circ} \mathrm{C}$; note that drying is indicated for areas with temperatures greater than $60^{\circ} \mathrm{C}$ ) 


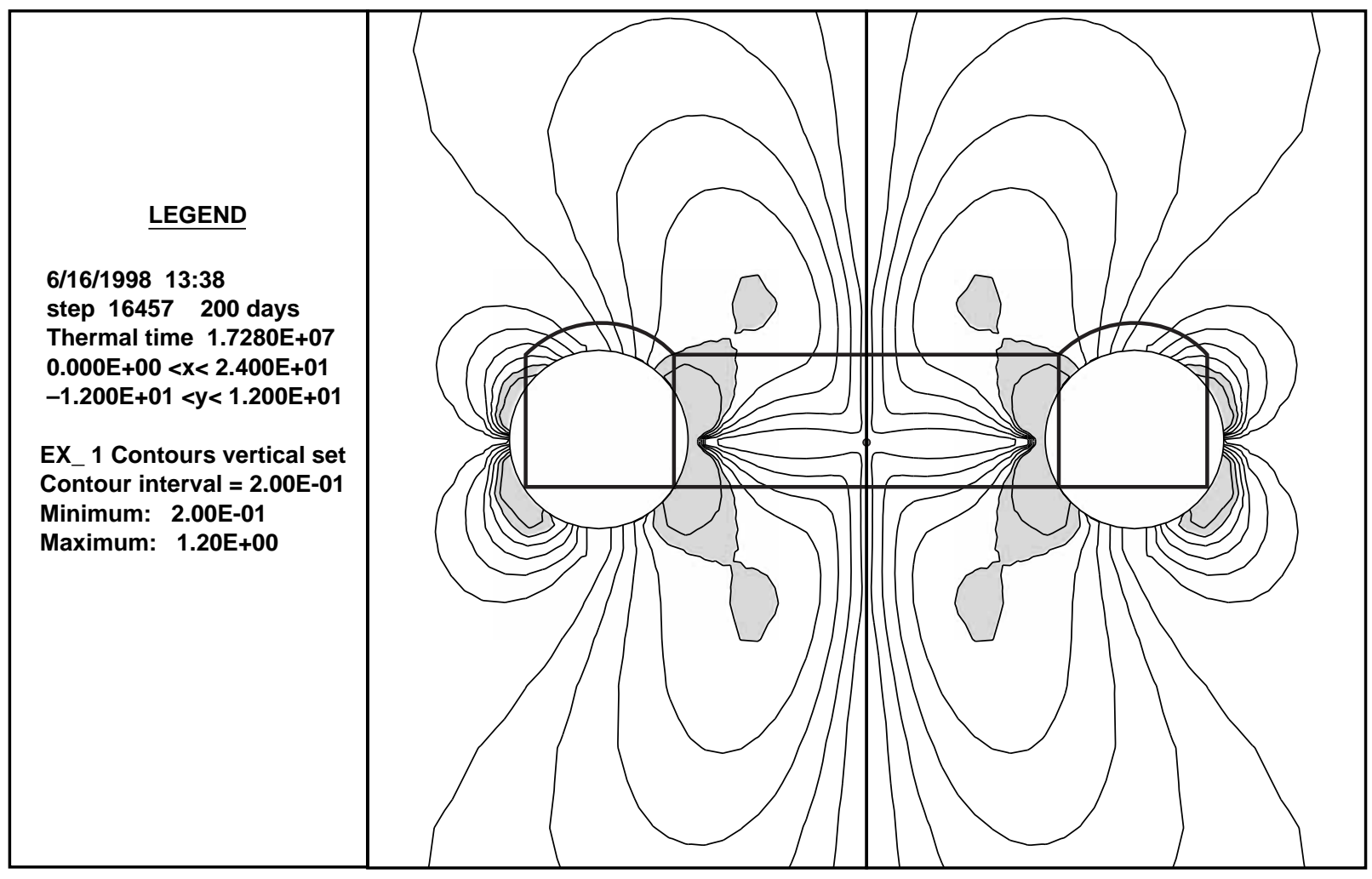

Figure 8-3. Regions of shear slip predicted for vertical fractures, oriented perpendicular to the page (note the correlation of predicted shear slip with wetting shown below Boreholes 21 and 23 in Figure 8-1) 